\title{
A THEORETICAL APPROACH TO GAS-PHASE ION CHEMISTRY
}

by

Brian Francis Yates, B.Sc. (Hons.)

A thesis submitted for the degree of

Doctor of Philosophy

of The Australian National University.

Research School of Chemistry, The Australian National University 
DECLARATION

The work reported in this thesis is my own, unless otherwise stated, and has not been submitted for any other degree. Close cooperation has been maintained throughout with my supervisor, Dr Leo Radom. In addition, collaboration occurred with Dr Willem J. Bouma during the early stages of the work described in Chapters Three to Seven.

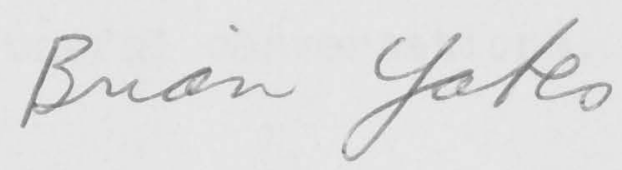

Brian Francis Yates 


\section{ACKNOWLEDGEMENTS}

I am very grateful to my supervisor, Dr Leo Radom, for his patience, guidance and encouragement throughout the course of this work and for stimulating my initial interest in ab initio molecular orbital theory. I would also like to thank Dr Willem Bouma for his cheerful help and enthusiastic discussions.

My sincere thanks are extended to Prof Arvi Rauk, Prof Noel Riggs, Dr Dieter Poppinger, Dr Jon Baker, Dr Ross Nobes, Dr Wai-Kee Li, Dr Minh Tho Nguyen, Mr Peter Gill and Mr Ming Wah Wong for their assistance and for many interesting and useful conversations.

I wish to record my thanks to all other members of the Research School of Chemistry who have helped me, especially Mrs Janet Thompson, Mrs Carolyn Jacob and Mr Byam Wight, and to members of the staff of the Computer Services Centre for their co-operation and advice during the course of my Ph.D. I am also grateful to Dr Anne Nobes for her assistance with typing this thesis and to my colleagues for their thoughtful comments on the manuscript.

The award of a Commonwealth Postgraduate Research Scholarship is gratefully acknowledged.

Finally, I would like to express my deep gratitude to my friends-in-song, Mike, Leonie and my special friend, Kathy, for their companionship and moral support throughout my time in Canberra. 


\section{SUMMARY}

Ab initio molecular orbital calculations with split-valence plus polarization basis sets and incorporating electron correlation and zero-point energy corrections have been used to examine potential energy surfaces for a number of neutral and ionic species. Equilibrium structures have been identified and pathways for their various rearrangement and dissociation processes investigated.

An outline of the theoretical methods employed in this work to study molecules which might exist in the gas phase is presented in Chapter one. Chapter Two contains a brief discussion of some of the corresponding experimental procedures which are commonly used to characterize such gas-phase species and which are referred to in later chapters.

The structures and stabilities of prototype ylides $\mathrm{CH}_{2} \mathrm{XH}$ and ylidions $\dot{\mathrm{CH}}_{2} \stackrel{+}{\mathrm{X}} \mathrm{H}\left(\mathrm{X}=\mathrm{NH}_{2}, \mathrm{OH}, \mathrm{F}, \mathrm{PH}_{2}, \mathrm{SH}\right.$ and $\left.\mathrm{Cl}\right)$ are examined in Chapters Three and Four, respectively. Comparisons are made across the periodic table, between first-and second-row compounds, and between the ylides and ylidions. The ylidions are confirmed to be much more stable with respect to unimolecular rearrangement or decomposition than their neutral counterparts. For both ylides and ylidions, this stability decreases across a row of the periodic table. For the ylides, the first-row species tend to be less stable energetically than the second-row species, while the reverse is true for the ylidions. The effects of high-level calculations have been 
examined for the ylides, ylidions and their conventional isomers and the results are compared with recent experimental data.

In Chapter Five, a study of the ylide dications $\mathrm{CH}_{2} \mathrm{XH}^{2+}(\mathrm{X}=$ $\mathrm{NH}_{2}, \mathrm{OH}, \mathrm{F}, \mathrm{PH}_{2}$, $\mathrm{SH}$ and $\mathrm{Cl}$ ) is described and the results compared with those of Chapters Three and Four. Although highly exothermic fragmentation processes exist for the ylide dications, the barriers for such dissociations are calculated to be substantial. The ylide dications lie in relatively deep potential wells and are predicted to be observable species. In contrast, the more conventional $\mathrm{CH}_{3} \mathrm{x}^{2+}$ dications are found to have little or no barrier to dissociation and/or rearrangement. Calculated ionization energies are compared with $Q_{\text {min }}$ values recently reported from charge-stripping experiments.

In principle, the relatively stable ylidions could provide a means for observing the unstable neutral ylides. This possibility is explored in Chapter Six, where a theoretical prediction of the detectability of the prototype ylides via neutralization-reionization mass spectrometry is presented. According to the calculations, there are only a few cases where these reactive neutral molecules will be stable under the conditions of the experiment.

\section{In Chapter Seven, a systematic study of distonic radical}

cations is reported. Initial calculations on the distonic ions $\dot{\mathrm{C}} \mathrm{H}_{2}\left(\mathrm{CH}_{2}\right) \stackrel{+}{\mathrm{N}} \mathrm{H}_{3}$ and their conventional isomers $\mathrm{CH}_{3}\left(\mathrm{CH}_{2}\right)_{\underline{n}} \mathrm{NH}_{2}^{+\cdot}(\underline{\mathrm{n}}=0,1,2$ and 3) indicate a preference in each case for the distonic isomer. The energy difference appears to converge with increasing $\underline{n}$ towards a limit which is close to the energy difference between the component systems $\mathrm{CH}_{3} \dot{\mathrm{C}} \mathrm{H}_{2}+\mathrm{CH}_{3} \stackrel{+}{\mathrm{N}_{3}}$ (representing the distonic isomer) and $\mathrm{CH}_{3} \mathrm{CH}_{3}$ 
$+\mathrm{CH}_{3} \mathrm{NH}_{2}^{+\cdot}$ (representing the conventional isomer). The generality of this result is assessed by using results for the component systems $\mathrm{CH}_{3} \dot{\mathrm{Y}}+\mathrm{CH}_{3} \stackrel{+}{\mathrm{X}} \mathrm{H}$ and $\mathrm{CH}_{3} \mathrm{YH}+\mathrm{CH}_{3} \mathrm{X}^{+\cdot}$ (or $\mathrm{CH}_{3} \mathrm{YH}^{+\cdot}+\mathrm{CH}_{3} \mathrm{X}$ ) to predict the relative energies of the distonic ions $\dot{\mathrm{Y}}\left(\mathrm{CH}_{2}\right) \stackrel{+}{\mathrm{X}} \mathrm{H}$ and their conventional isomers $\mathrm{HY}\left(\mathrm{CH}_{2}\right){ }_{n} \mathrm{X}^{+\cdot}\left(\mathrm{X}=\mathrm{NH}_{2}, \mathrm{OH}, \mathrm{F}, \mathrm{PH}_{2}, \mathrm{SH}, \mathrm{Cl} ; \quad \mathrm{Y}=\mathrm{CH}_{2}\right.$, $\mathrm{NH}, \mathrm{O})$ and testing the predictions through explicit calculations for systems with $\underline{\mathrm{n}}=0,1$ and 2 . Although the predictions based on component systems are often close to the results of direct calculations, there are substantial discrepancies in a number of cases; the reasons for such discrepancies are discussed. For the systems examined in the present study, the conventional radical cation is predicted in most cases to lie lower in energy than its distonic isomer. It is found that the more important factors contributing to a preference for distonic over conventional radical cations are the presence in the system of a group (X) with high proton affinity and the absence of a group (X,Y or perturbed C-C) with low ionization energy

A number of possible equilibrium structures on the $\left[\mathrm{C}_{2} \mathrm{H}_{7} \mathrm{~N}\right]^{+\cdot}$ surface are examined in Chapter Eight. In addition to the radical cations of ethylamine and dimethylamine, three other isomers comparable in energy but having no stable neutral counterparts are found. These are the distonic radical cations $\dot{\mathrm{C}} \mathrm{H}_{2} \mathrm{CH}_{2} \stackrel{+}{\mathrm{N}} \mathrm{H}_{3}, \mathrm{CH}_{3} \dot{\mathrm{C}} \mathrm{H}^{+} \mathrm{H}_{3}$ and $\mathrm{CH}_{3} \stackrel{+}{\mathrm{N}} \mathrm{H}_{2} \stackrel{\dot{\mathrm{C}}}{\mathrm{H}_{2}}$. It is found that there are substantial barriers for rearrangements between the various isomers and significant binding energies with respect to possible fragmentation products. The predictions for $\dot{\mathrm{C}}_{2} \mathrm{CH}_{2} \stackrel{+}{\mathrm{N}_{3}} \mathrm{H}_{3}$ and $\mathrm{CH}_{3} \stackrel{\bullet}{\mathrm{C}} \stackrel{+}{\mathrm{N}} \mathrm{H}_{3}$ are consistent with their recent observation in the gas phase. The remaining isomer, $\mathrm{CH}_{3} \stackrel{+}{\mathrm{N}} \mathrm{H}_{2} \stackrel{\text { C }}{\mathrm{H}_{2}}$, is predicted also to be experimentally observable. 
In Chapter Nine, the barriers to 1, $\underline{n}$-hydrogen migration for simple ionized amines, including the radical cations of methylamine, ethylamine, $\underline{n}$-propylamine and $\underline{n}$-butylamine, are investigated. The barrier heights decrease monotonically on progressing from the 1,2- to the 1,5-hydrogen shift. This smooth trend may be correlated in part with a decrease in ring strain and an increase in linearity of the calculated $\mathrm{C}---\mathrm{H}_{---\mathrm{N}}$ angle in the corresponding transition structures. The calculated barriers and rate constants for hydrogen migration are consistent with facile rearrangements taking place in the gas phase in long-chain amine radical cations.

The research reported in this thesis demonstrates the benefits of applying theory to the study of reactive gas-phase species. Through its determination of structures, relative energies and reaction pathways, theory provides an important counterpart to the experimental approach. 


\section{LIST OF PUBLICATIONS}

Parts of the work described in this thesis have been published:

"On the Structures and Relative Energies of $\mathrm{CH}_{3} \mathrm{~F}^{+}$. Isomers"

Bouma, W.J.; Yates, B.F.; Radom, L. Chem. Phys. Lett. 1982, 92, 620.

"Detection of the Prototype Phosphonium $\left(\mathrm{CH}_{2} \mathrm{PH}_{3}\right)$, Sulphonium $\left(\mathrm{CH}_{2} \mathrm{SH}_{2}\right)$, and Chlor onium $\left(\mathrm{CH}_{2} \mathrm{ClH}\right)$ Ylides by Neutralization-Reionization Mass Spectrometry: A Theoretical Prediction"

Yates, B.F. ; Bouma, W.J.; Radom, L. J. Am. Chem. Soc. 1984, 106, 5805.

"A Theoretical Approach to Gas-Phase Ion Chemistry"

Radom, L. ; Bouma, W.J.; Nobes, R.H. ; Yates, B.F. Pure Appl. Chem. $1984,56,1831$.

"The Methyleneammonium Radical Cation $\left(\mathrm{CH}_{2} \mathrm{NH}_{3}{ }^{+} \cdot\right.$ )"

Yates, B.F.; Nobes, R.H. ; Radom, L. Chem. ${ }^{2}$ Phys. Lett. 1985, 116, 474.

"Distonic Radical Cations: Guidelines for the Assessment of their Stability"

Yates, B.F.; Bouma, W.J.; Radom, L. Tetrahedron, in press.

"Ylide Dications: An Examination of First- and Second-Row Systems"

Yates, B.F.; Bouma, W.J.; Radom, L. J. Am. Chem. Soc., in press.

"Ylides and Ylidions: A Comparative Study of Unusual Gas-Phase Structures"

Yates, B.F.; Bouma, W.J.; Radom, L., submitted.

"Spontaneous Intramolecular Hydrogen Migration in Ionized Ethane-1,2diol"

Yates, B.F. ; Bouma, W.J. ; MacLeod, J.K.; Radom, L., submitted.

"Intramolecular Hydrogen Migration in Ionized Amines: A Theoretical Study of the Gas-Phase Analogues of the Hofmann-Löffler and Related Rearrangements"

Yates, B.F.; Radom, L., submitted.

"Structures and Relative Energies of Gas-Phase $\left[\mathrm{C}_{2} \mathrm{H}_{7} \mathrm{~N}\right]^{+\cdot}$ Radical Cations"

Yates, B.F.; Radom, L., submitted.

"Substituted Methylene Dications $\left(\mathrm{HCX}^{2+}\right)$ : Some Remarkably Short Bonds to Carbon"

Wong, M.W.; Yates, B.F.; Nobes, R.H.; Radom, L., submitted. 


\section{TABLE OF CONTENTS}

ACKNOWLEDGEMENTS

SUMMARY

LIST OF PUBLICATIONS

TABLE OF CONTENTS

INTRODUCTION

CHAPTER ONE THEORETICAL METHODS .................... 3

1.1 Introduction $\ldots \ldots \ldots \ldots \ldots \ldots \ldots \ldots \ldots \ldots \ldots \ldots \ldots \ldots \ldots \ldots \ldots \ldots$

1.2 Ab Initio Molecular Orbital Theory ................... 4

1.2.1 The Schrödinger Equation $\ldots \ldots \ldots \ldots \ldots \ldots \ldots \ldots \ldots$

1.2.2 The Born-Oppenheimer Approximation ............. 5

1.2.3 The Orbital Approximation .......................... 6

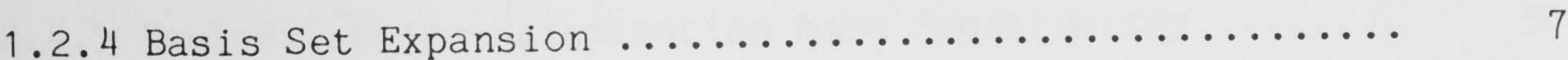

1.2.5 The Variational Principle and Hartree-Fock Theory .... 8

1.2.6 Restricted and Unrestricted Hartree-Fock Methods ..... 9

1.2.7 Improving the Single-Determinant Wavefunction ....... 9

1.3 Implementation of the Theory $\ldots \ldots \ldots \ldots \ldots \ldots \ldots \ldots \ldots \ldots \ldots$

1.3.1 Standard Basis Sets .............................. 11

1.3.1.1 Split-Valence Basis Sets ................. 12

1.3.1.2 Polarization Basis Sets ................. 12

1.3.2 Electron Correlation Methods ................ 13

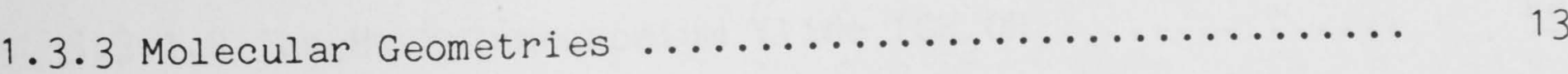


1.3.4 Vibrational Frequencies and Thermodynamic Properties .

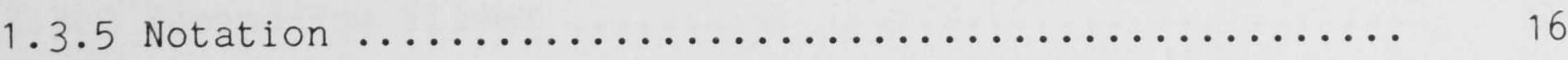

1.4 Reliability of the Theoretical Model $\ldots \ldots \ldots \ldots \ldots \ldots \ldots$

1.4.1 Molecular Geometries, Relative Energies and

Vibrational Frequencies $\ldots \ldots \ldots \ldots \ldots \ldots \ldots \ldots \ldots \ldots$

1.4.2 The Unrestricted Hartree-Fock (UHF) Model ......... 19

1.4.3 The Additivity Approximation $\ldots \ldots \ldots \ldots \ldots \ldots \ldots . . \ldots \ldots$

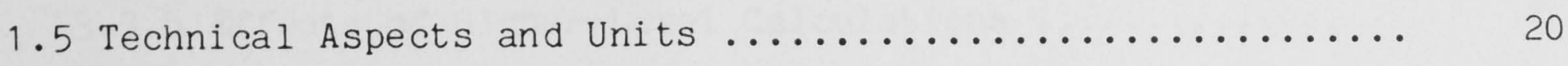

CHAPTER TWO EXPERIMENTAL BACKGROUND $\ldots \ldots \ldots \ldots \ldots \ldots \ldots \ldots \ldots$

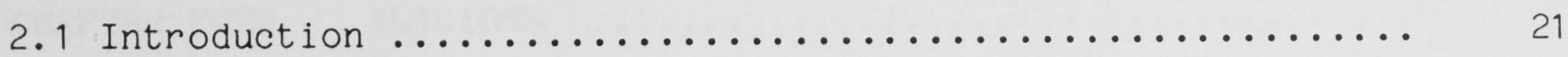

2.2 The Double-Focusing Mass Spectrometer $\ldots \ldots \ldots \ldots \ldots \ldots \ldots . \ldots \ldots$

2.3 Ion Thermochemistry $\ldots \ldots \ldots \ldots \ldots \ldots \ldots \ldots \ldots \ldots \ldots \ldots \ldots \ldots \ldots \ldots$

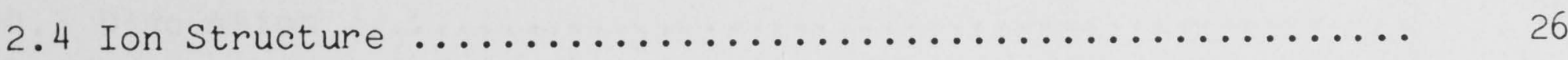

2.4.1 Metastable Peak Observation ................. 27

2.4.2 Collisional-Activation Mass Spectrometry ......... 28

2.4.3 Charge-Stripping Mass Spectrometry ............. 29

2.4.4 Collision-Induced Dissociative-Ionization Mass

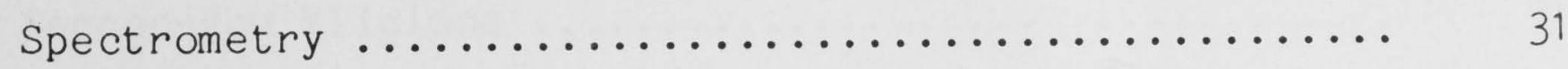

2.4.5 Neutralization-Reionization Mass Spectrometry ...... 32

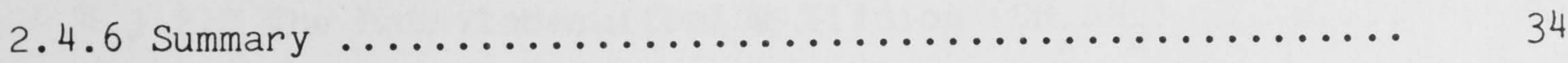

CHAPTER THREE $\quad$ YLIDES $\ldots \ldots \ldots \ldots \ldots \ldots \ldots \ldots \ldots \ldots \ldots \ldots \ldots \ldots \ldots \ldots \ldots \ldots \ldots$

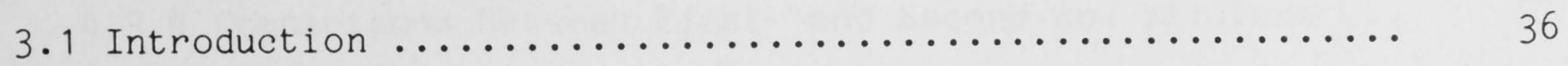

3.2 Method and Results .............................. 37

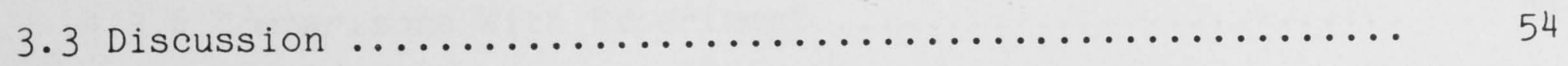

3.3 .1 First-Row Ylides $\ldots \ldots \ldots \ldots \ldots \ldots \ldots \ldots \ldots \ldots \ldots \ldots \ldots \ldots \ldots \ldots \ldots \ldots \ldots \ldots$

3.3.1.1 The Methyleneammonium Ylide $\left(\mathrm{CH}_{2} \mathrm{NH}_{3}\right) \ldots \ldots \ldots \ldots .54$

3.3.1.2 The Methyleneoxonium Ylide $\left(\mathrm{CH}_{2} \mathrm{OH}_{2}\right) \ldots \ldots \ldots \ldots$ 
3.3.1.3 The Methylenefluoronium Ylide $\left(\mathrm{CH}_{2} \mathrm{FH}\right) \ldots \ldots$

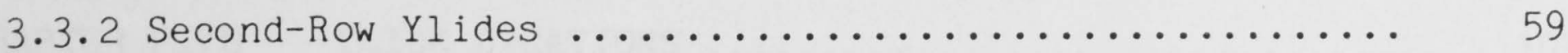

3.3.2.1 The Methylenephosphonium Ylide $\left(\mathrm{CH}_{2} \mathrm{PH}_{3}\right) \ldots \ldots 9$

3.3.2.2 The Methylenesulfonium Ylide $\left(\mathrm{CH}_{2} \mathrm{SH}_{2}\right) \ldots \ldots$

3.3.2.3 The Methylenechloronium Ylide $\left(\mathrm{CH}_{2} \mathrm{ClH}\right) \ldots \ldots \ldots$

3.3.3 Comparisons Across the Periodic Table ............. 63

3.3.4 Comparisons Between First- and Second-Row Ylides ..... 64

3.3.5 Effects of Higher-Level Calculations ............. 65

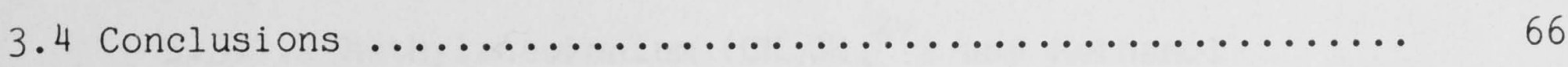

CHAPTER FOUR YLIDIONS $\ldots \ldots \ldots \ldots \ldots \ldots \ldots \ldots \ldots \ldots \ldots \ldots \ldots \ldots$

4.1 Introduction $\ldots \ldots \ldots \ldots \ldots \ldots \ldots \ldots \ldots \ldots \ldots \ldots \ldots \ldots \ldots \ldots$

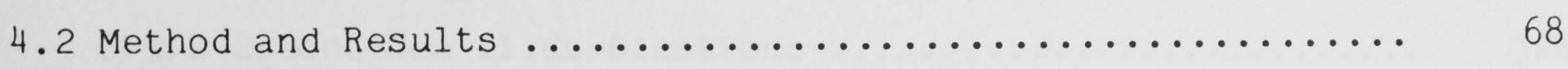

4.3 Discussion $\ldots \ldots \ldots \ldots \ldots \ldots \ldots \ldots \ldots \ldots \ldots \ldots \ldots \ldots \ldots \ldots \ldots \ldots \ldots \ldots$

4.3 .1 First-Row Ylidions $\ldots \ldots \ldots \ldots \ldots \ldots \ldots \ldots \ldots \ldots \ldots \ldots$

4.3.1.1 The Methyleneammonium Ylidion $\left(\dot{\mathrm{C}}_{2} \stackrel{+}{\mathrm{N}} \mathrm{H}_{3}\right) \ldots \ldots 84$

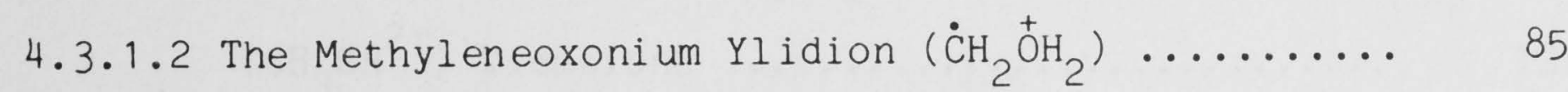

4.3.1.3 The Methylenefluoroni um Ylidion $\left(\dot{\mathrm{C}}_{2} \stackrel{+}{\mathrm{F}} \mathrm{H}\right) \ldots \ldots 6$

4.3 .2 Second-Row Ylidions $\ldots \ldots \ldots \ldots \ldots \ldots \ldots \ldots \ldots \ldots \ldots \ldots \ldots$

4.3.2.1 The Methylenephosphonium Ylidion $\left(\dot{\mathrm{C}}_{2} \stackrel{+}{\mathrm{P}}_{3}\right) \ldots 91$

4.3.2.2 The Methylenesulfonium Ylidion $\left(\stackrel{\dot{\mathrm{C}}}{\mathrm{H}_{2}} \stackrel{+}{\mathrm{S}} \mathrm{H}_{2}\right) \ldots . . . .92$

4.3.2.3 The Methylenechlor oni um Ylidion $\left(\stackrel{\mathrm{C}_{\mathrm{C}}}{2} \stackrel{+}{\mathrm{C}} \mathrm{H} \mathrm{H}\right) \ldots \ldots$

4.3.3 Comparisons Across the Periodic Table ............. 96

4.3.4 Comparisons Between First-and Second-Row Ylidions ... 97

4.3.5 Effects of Higher-Level Calculations ............. 98

4.3 .6 Comparisons with Experiment $\ldots \ldots \ldots \ldots \ldots \ldots \ldots \ldots$

4.4 Comparisons Between the Ylides and the Ylidions .......... 100

4.5 Concluding Remarks ............................ 102 
5.1 Introduction

5.2 Method and Results

5.3 Discussion

5.3.1.1 Methyleneammonium $\left(\mathrm{CH}_{2} \mathrm{NH}_{3}{ }^{2+}\right)$ and Methylamine

$$
\left(\mathrm{CH}_{3} \mathrm{NH}_{2}{ }^{2+}\right) \text { Dications } \ldots \ldots \ldots \ldots \ldots \ldots \ldots \ldots \ldots \ldots \ldots \ldots \ldots \ldots \ldots
$$

5.3.1.2 Methyleneoxonium $\left(\mathrm{CH}_{2} \mathrm{OH}_{2}{ }^{2+}\right)$ and Methanol

$$
\left(\mathrm{CH}_{3} \mathrm{OH}^{2+}\right) \text { Dications } \ldots \ldots \ldots \ldots \ldots \ldots \ldots \ldots \ldots \ldots \ldots \ldots \ldots \ldots \ldots \ldots \ldots
$$

5.3.1.3 Methylenefluor onium $\left(\mathrm{CH}_{2} \mathrm{FH}^{2+}\right)$ and Fluoromethane

$$
\left(\mathrm{CH}_{3} \mathrm{~F}^{2+}\right) \text { Dications } \ldots \ldots \ldots \ldots \ldots \ldots \ldots \ldots \ldots \ldots \ldots \ldots \ldots \ldots \ldots \ldots
$$

5.3.2 Second-Row Ylide Dications

5.3.2.1 Methylenephosphonium $\left(\mathrm{CH}_{2} \mathrm{PH}_{3}{ }^{2+}\right)$ and Methylphosphine $\left(\mathrm{CH}_{3} \mathrm{PH}_{2}{ }^{2+}\right)$ Dications $\ldots \ldots \ldots \ldots \ldots \ldots \ldots \ldots \ldots \ldots \ldots \ldots \ldots \ldots \ldots \ldots \ldots$

5.3.2.2 Methylenesulfonium $\left(\mathrm{CH}_{2} \mathrm{SH}_{2}{ }^{2+}\right)$ and Methanethiol

$$
\left(\mathrm{CH}_{3} \mathrm{SH}^{2+}\right) \text { Dications } \ldots \ldots \ldots \ldots \ldots \ldots \ldots \ldots \ldots \ldots \ldots \ldots \ldots \ldots \ldots \ldots \ldots
$$

5.3.2.3 Methylenechloronium $\left(\mathrm{CH}_{2} \mathrm{ClH}^{2+}\right)$ and Chloromethane

$$
\left(\mathrm{CH}_{3} \mathrm{Cl}^{2+}\right) \text { Dications } \ldots \ldots \ldots \ldots \ldots \ldots \ldots \ldots \ldots \ldots \ldots \ldots \ldots \ldots \ldots \ldots \ldots \ldots
$$

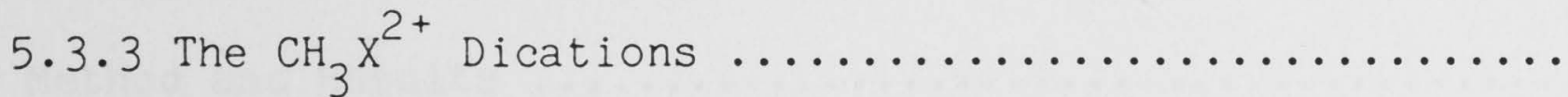

5.3. 4 Comparisons Across the Periodic Table ............ 136

5.3.5 Comparisons Between First- and Second-Row

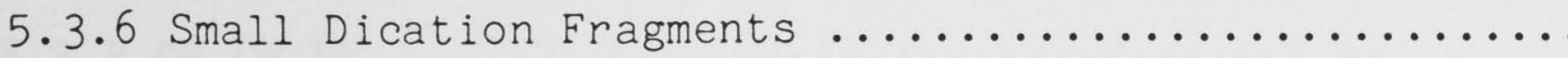

5.3.7 Comparative Data for Possible Fragmentation Products

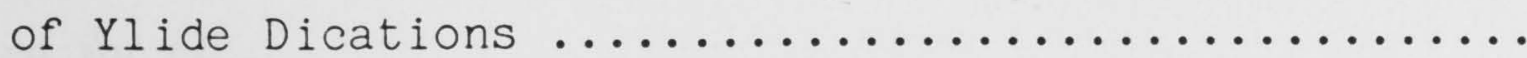

5.3.8 Calculated Ionization Energies and Relationship With Charge-Stripping Mass Spectrometry Experiments ...... 140

5.3.9 Comparisons With the Ylides and Ylidions ......... 145 5.4 Concluding Remarks ......................... 146 
CHAPTER SIX POSSIBLE DETECTION OF PROTOTYPE YLIDES BY NEUTRALIZATION-REIONIZATION MASS SPECTROMETRY:

A THEORETICAL PREDICTION $\ldots \ldots \ldots \ldots \ldots \ldots \ldots \ldots \ldots \ldots$

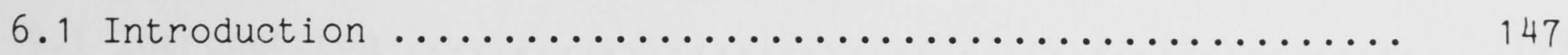

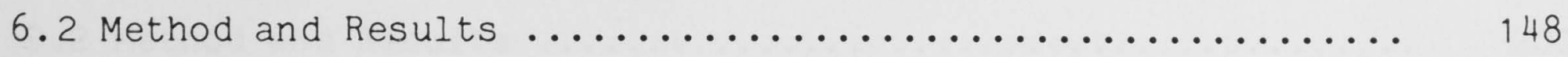

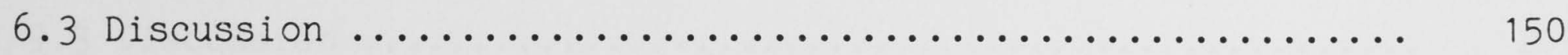

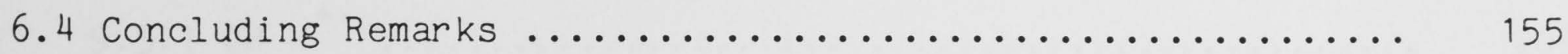

CHAPTER SEVEN DISTONIC RADICAL CATIONS: GUIDELINES FOR THE ASSESSMENT OF THEIR STABILITY $\ldots \ldots \ldots \ldots \ldots \ldots$

7.1 Introduction $\ldots \ldots \ldots \ldots \ldots \ldots \ldots \ldots \ldots \ldots \ldots \ldots \ldots \ldots \ldots \ldots \ldots \ldots \ldots$

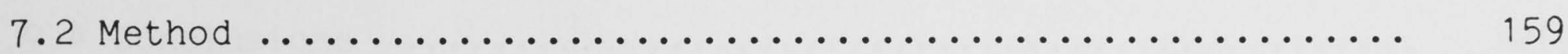

7.3 Results and Discussion ........................... 160

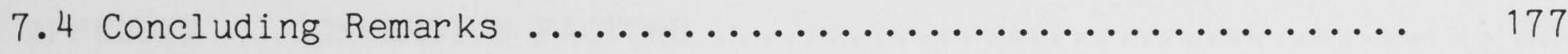

CHAPTER EIGHT STRUCTURES AND RELATIVE ENERGIES OF GAS-PHASE

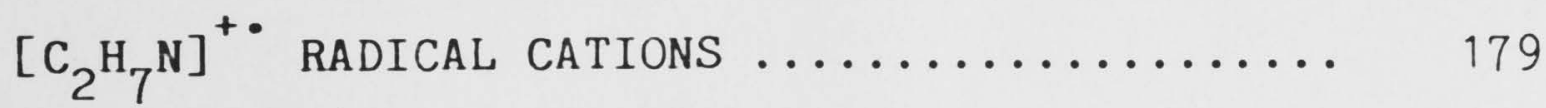

8.1 Introduction $\ldots \ldots \ldots \ldots \ldots \ldots \ldots \ldots \ldots \ldots \ldots \ldots \ldots \ldots \ldots \ldots$

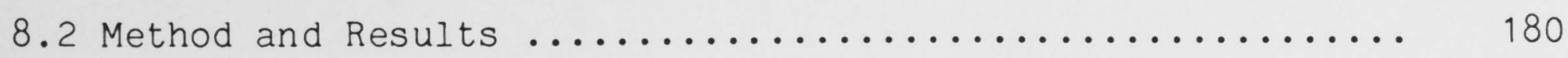

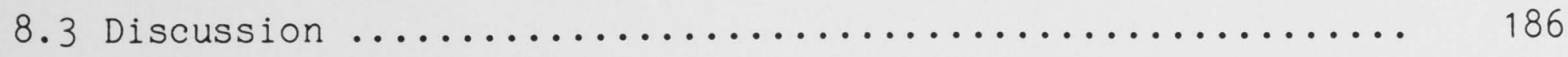

$8.3 .1 \stackrel{\mathrm{CH}_{2}}{\mathrm{CH}_{2} \stackrel{+}{\mathrm{N}} \mathrm{H}_{3} \ldots \ldots \ldots \ldots \ldots \ldots \ldots \ldots \ldots \ldots \ldots \ldots \ldots \ldots \ldots \ldots \ldots \ldots \ldots \ldots \ldots} 186$

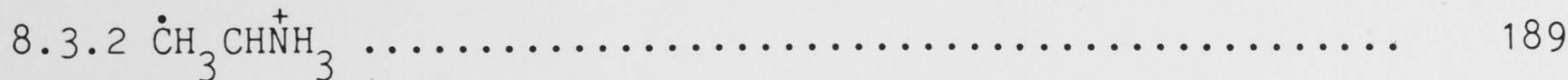

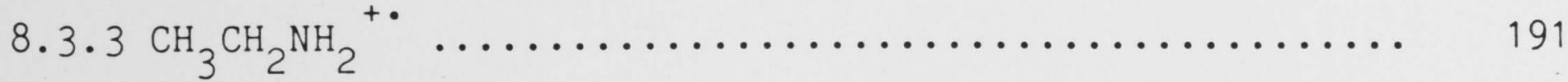

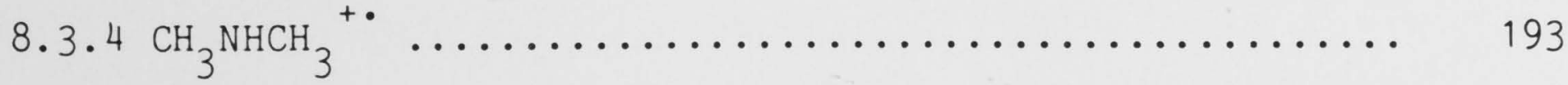

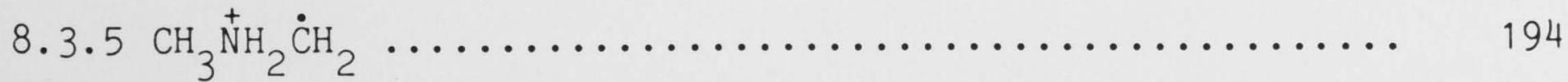

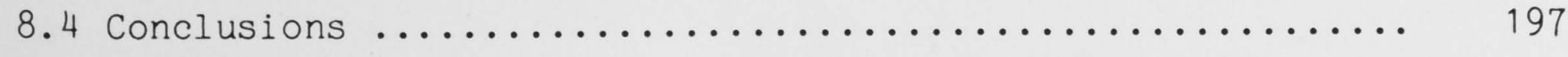


CHAPTER NINE INTRAMOLECULAR HYDROGEN MIGRATION IN IONIZED AMINES: A THEORETICAL STUDY OF THE GAS-PHASE ANALOGUES OF THE HOFMANN-LÖFFLER AND RELATED REARRANGEMENTS .... 199

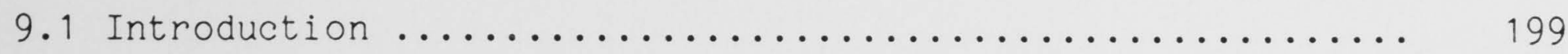

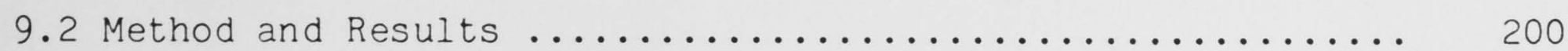

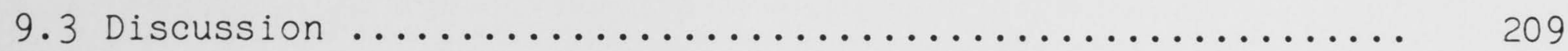

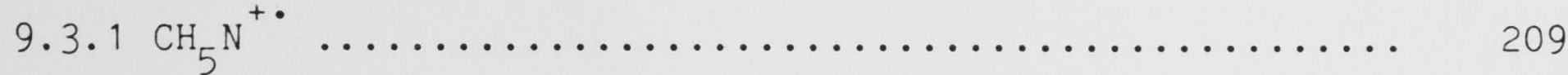

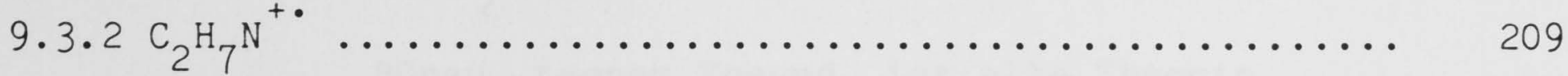

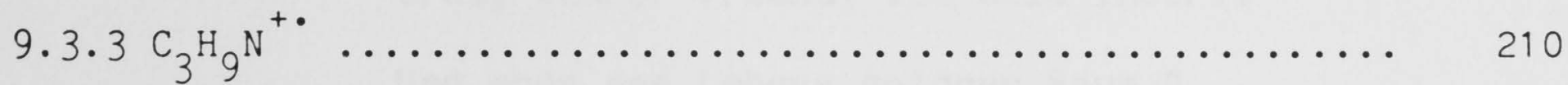

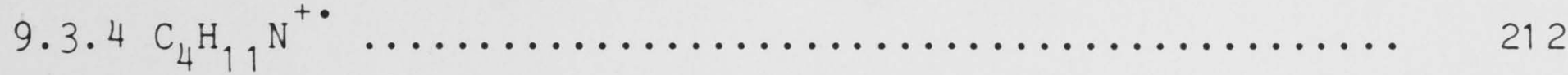

9.3.5 Barriers and Rates for Hydrogen Migration ......... 215

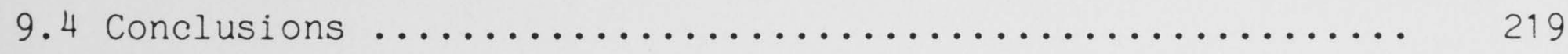

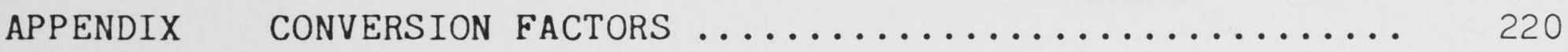

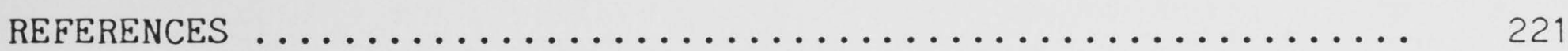


"Grau, teurer Freund, ist alle Theorie

Und grün des Lebens goldner Baum."

Johann W.v. Goethe,

Faust 


\section{INTRODUCTION}

Fundamental studies of gas-phase ion chemistry have attracted the attention of scientists for many years. The benefits of such studies have included a better understanding of the structures and reactions of gas-phase species, as well as some important industrial spin-offs in the area of analytical chemistry. Why might one want to use theory to study gas-phase ions? Because these species are highly reactive or hard to produce in sufficient quantities, they are often difficult to investigate experimentally. In addition, the methods used to detect them may lead to ambiguous results. On the other hand, theoretical methods may be used to study both stable and unstable species with equal ease in an unambiguous manner. An important feature of most calculations is that they apply to isolated molecules, so they are particularly suited to investigating the chemistry that would take place in low-pressure environments, such as inside a mass spectrometer or in interstellar clouds.

For these reasons, theoretical calculations of molecular properties of gas-phase ions are increasingly being used to complement available experimental methods. The results from such calculations can be used to confirm or interpret experimental data or, as the reliability of the theoretical method increases, to predict new experimental results. Using quantum mechanical principles, one can obtain molecular structures, energies, dipole moments, charge distributions and so on. It is also possible to calculate a 
potential energy surface for a system that describes the relative stabilities and possible rearrangement and fragmentation pathways for the molecules considered.

The combination of theoretical and experimental techniques has become so profitable, that in a recent review of mass spectrometric research, it was stated that "the most significant recent developments in ion-structure studies have come from the marriage of theory and experiment, the major theoretical contribution coming from Radom's group in Canberra". ${ }^{1}$ Some of these exciting applications of theory to the study of gas-phase ion chemistry are discussed in the work presented here. 


\section{CHAPTER ONE}

\subsection{Introduction}

Although in principle quantum theory can be exactly applied to any system, in practice this has only been achieved for a small number of one-electron molecules. Application of the theory to other systems requires a number of approximations to be made, giving rise to three broad classes of theoretical methods. The most severe approximations lead to 'model' theories, such as Hückel theory ${ }^{2}$ or extended Huckel theory, ${ }^{3}$ which are useful in some qualitative applications. The second class of methods comprises semi-empirical procedures, ${ }^{4}$ in which some of the intermediate quantities in the calculations are either calibrated from experiment or simply neglected; an example is the recently developed 'third-generation' AM1 method. ${ }^{5}$ The third class is that of ab initio molecular orbital methods in which, in order to facilitate computation, only the form of the wavefunction (see below) is restricted. ${ }^{6}$ In these methods, various properties are calculated from first principles, using only the values of a small number of physical constants.

Because ab initio calculations are performed from first principles, they have the advantage over semi-empirical methods that they can be applied to systems where no experimental parametrization is available. Systems that fall into this category include reactive species with short lifetimes, such as gas-phase radical cations and the transition structures for most chemical reactions. The 


$$
4 .
$$

application of ab initio molecular orbital theory to study such species is the subject of this thesis.

\subsection{Ab Initio Molecular Orbital Theory}

The summary presented here will necessarily be brief. For a comprehensive account of the theory and applications of ab initio molecular orbital theory, see ref 6 .

\subsubsection{The Schrödinger Equation}

In 1925 Erwin Schrödinger and Werner Heisenberg independently formulated a general quantum theory. ${ }^{7}$ Although the two formulations are mathematically equivalent, Schrödinger presented his theory in terms of partial differential equations ${ }^{8}$ and, within this framework, the energy of an isolated molecule can be obtained by solution of the Schrödinger wave equation. In its time-independent form, this can be written as

$$
\hat{H} \Psi=E \Psi,
$$

where $\hat{H}$ is the Hamiltonian operator, $\Psi$ is the wavefunction, and $E$ is the energy of the system relative to the state in which the nuclei and electrons are infinitely separated and at rest. The Hamiltonian operator $\hat{H}$ is the sum of kinetic and potential energy parts,

$$
\hat{H}=\hat{T}+\hat{V} \text {. }
$$

The kinetic energy operator $\hat{T}$ is simply the sum of the kinetic energy operators of all the particles in the system: 


$$
\hat{T}=\frac{-h^{2}}{8} \bar{\pi}^{2} \sum_{i} \frac{1}{m_{i}}-\left(-\frac{\partial^{2}}{\partial x_{i}}-\overline{2}+\frac{\partial^{2}}{\partial y_{i}-\overline{2}}+\frac{\partial^{2}}{\partial z-\bar{z}}\right)
$$

while the potential energy operator $\hat{V}$ is the sum of the various coulomb interactions (electron-electron, electron-nucleus and nucleusnucleus).

\subsubsection{The Born-Oppenheimer Approximation}

The masses of the nuclei are much larger and their velocities much smaller than those of the electrons, and it is possible to simplify the solution of equation (1.1) by separating it into parts, one describing the motions of the electrons in a field of fixed nuclei and the other describing the motions of the nuclei. This is known as the adiabatic or Born-Oppenheimer approximation. 9

\section{Molecular orbital theory is concerned with finding} approximate solutions to the first part, that is, the electronic Schrödinger equation

$$
\hat{\mathrm{H}}^{\mathrm{el}} \Psi^{\mathrm{el}}=\mathrm{E}^{\mathrm{el}} \Psi^{\mathrm{el}} \text {, }
$$

where each quantity is implicitly a function of the nuclear coordinates, R. (The superscripts in (1.4) will be omitted for conciseness from now on.) Solution of this equation gives rise to wavefunctions $\Psi_{i}$, which, if they satisfy appropriate boundary conditions, are eigenfunctions of the operator $\hat{\mathrm{H}}$, and to electronic energies $E_{i}$, which are the eigenvalues. Since $E$ is a function of the 
nuclear coordinates, it is termed the potential energy surface for the molecule in the particular electronic state being considered.

\subsubsection{The Orbital Approximation}

In molecular orbital theory, equation (1.4) is further simplified by assuming that each electron is associated with a separate one-electron wavefunction or spin orbital, $x$. This is known as the orbital approximation. The spin orbitals are a product of a spatial function, $\psi(x, y, z)$, and a spin function, $\alpha$ or $\beta$.

It was proposed by Hartree ${ }^{10}$ that the wavefunction in $(1.4)$ could be expressed simply as a product of spin orbitals, one for each electron:

$$
\Psi=x_{1}(1) x_{2}(2) \cdots x_{n}(n) .
$$

According to the Pauli Principle, however, the wavefunction must change sign when any pair of electrons is exchanged, i.e. the wavefunction must be 'antisymmetric'. This is not the case with (1.5). To ensure antisymmetry, the wavefunction $\Psi$ may be expressed as a determinant of spin orbitals:

$$
\Psi=(n !)^{-1 / 2}\left|\begin{array}{cccc}
x_{1}(1) & x_{2}(1) & \cdots & x_{n}(1) \\
x_{1}(2) & x_{2}(2) & \cdots & x_{n}(2) \\
\vdots & & & \\
x_{1}(n) & x_{2}(n) & \cdots & x_{n}(n)
\end{array}\right| .
$$

This determinant is of ten referred to as a Slater determinant. ${ }^{11}$ 


\subsubsection{Basis Set Expansion}

For practical reasons, the spatial molecular orbitals, $\psi_{i}$, are usually expressed as linear combinations of a finite set of known one-electron functions, $\phi_{\mu}$, called basis functions:

$$
\psi_{i}=\sum_{\mu=1}^{N} c_{\mu i} \phi_{\mu} .
$$

As the number of basis functions in the finite set is increased, the description of each molecular orbital, $\psi_{i}$, is improved. When the basis functions take the form of the atomic orbitals of the constituent atoms, expression ( 1.7$)$ is sometimes called a linear combination of atomic orbitals (LCAO).

Basis functions usually employed are either Slater-type atomic orbitals (STOs, asymptotic radial dependence $\left.e^{-\zeta r}\right)^{12}$ or Gaussian-type atomic functions (asymptotic radial dependence $e^{-\alpha r^{2}}$ ). ${ }^{13}$ Although STOs provide a better representation of atomic orbitals, Gaussian-type functions are more commonly used because the subsequent evaluation of the two-electron integrals is much simpler. The Gaussian-type basis function $\phi_{\mu}$ may, in addition, be expressed as a linear combination of Gaussian functions, $g_{k}$ :

$$
\phi_{\mu}=\sum_{k} d_{\mu k} g_{k}
$$

where the coefficients $d_{\mu k}$ are fixed and the $g_{k}$ are all of the same type $(\underline{s}, \underline{p}, \ldots)$. Such basis functions are known as contracted Gaussians and the individual $g_{k}$ are called primitives. 


\subsubsection{The Variational Principle and Hartree-Fock Theory}

The next task is to determine the coefficients $c_{\mu i}$ in

expression (1.7). The variational principle states that for a trial wavefunction $\Phi$ the corresponding energy expectation value $E^{\prime}$ represents an upper bound to the exact value E. Minimizing $E^{\prime}$ with respect to $c_{\mu i}$ will yield the best (i.e. lowest) energy within the limits of the basis set used. The corresponding wavefunction $\phi$ will then be the closest approximation possible to the exact wavefunction $\Psi$.

The variational principle leads to the Roothaan-Hall

equations ${ }^{14,15}$ for determining the molecular orbital coefficients, $c_{\mu i}:$

$$
\sum_{\nu=1}^{N}\left(F_{\mu \nu}-\varepsilon_{i} S_{\mu \nu}\right) c_{\nu i}=0 \quad \mu=1,2, \ldots, N,
$$

where $F_{\mu \nu}$ are elements of the Fock matrix (containing terms representing the energy of a single electron in a field of the 'bare' nuclei and the average field of the other electrons), $\varepsilon_{i}$ is the oneelectron energy of molecular orbital $\psi_{i}$, and $S_{\mu \nu}$ are elements of the overlap matrix (representing the overlap between pairs of basis functions). The Fock matrix itself depends on $c_{\mu i}$ and therefore it is necessary to use an iterative procedure when solving (1.9) for the coefficients. This iterative approach was first outlined by Hartree ${ }^{10}$ and Fock ${ }^{16}$ and is known as Hartree-Fock (HF) or selfconsistent-field (SCF) theory. 


\subsubsection{Restricted and Unrestricted Hartree-Fock Methods}

For closed-shell systems, electrons are assigned to the molecular orbitals in pairs. This is not possible, however, for open-shell systems, which (by definition) contain one or more unpaired electrons. If, during the SCF procedure, a single set of spatial orbitals is used (some of which will be singly occupied), then the result is a spin-restricted Hartree-Fock (RHF) wavefunction. 17,18 If, on the other hand, different spatial orbitals are assigned to $\alpha$ and $B$ electrons, the result is a spin-unrestricted Hartree-Fock (UHF) wavefunction. 19 Although the UHF wavefunction results in an energy equal to or below the RHF value, it has the disadvantage that it is not an exact eigenfunction of the total spin operator, $\hat{S}^{2}$, and may be contaminated by states of higher spin multiplicity. The UHF method for open-shell sytems is, however, mathematically more straightforward.

\subsubsection{Improving the Single-Determinant Wavefunction}

Within the framework of Hartree-Fock theory, the description of a wavefunction $\Psi$ may be improved by using larger and larger basis sets. Ultimately, however, the accuracy of the description is limited by the choice of a single-determinant wavefunction in (1.6). The major deficiency of using such a wavefunction is that it neglects part of the correlation between motions of electrons. This is particularly significant when attempting to describe the homolytic breaking of a bond in a molecule. To overcome this deficiency, the molecular wavefunction $\Psi$ may be written as a linear combination of Slater determinants: 


$$
\Psi=a_{0} \Psi_{0}+a_{1} \Psi_{1}+a_{2} \Psi_{2}+\ldots
$$

where $\Psi_{0}$ is the Hartree-Fock wavefunction and $\Psi_{1}, \Psi_{2}, \ldots$ represent other electron configurations. Various methods have been used to approximate the effects of electron correlation in molecular orbital calculations (for recent discussions, see refs 20 and 21 ). These methods include limited configuration interaction (CI), ${ }^{22}$ coupledelectron-pair approximations (CEPA), ${ }^{23}$ coupled-cluster methods, ${ }^{24-27}$ and multi-configuration self-consistent field (MCSCF) procedures. ${ }^{28,29}$

An alternative approach is to use perturbation theory, in which the generalized electronic Hamiltonian operator, $\hat{H}_{\lambda}$, is written as a Hartree-Fock part, $\hat{\mathrm{H}}_{0}$, plus a perturbation:

$$
\hat{\mathrm{H}}_{\lambda}=\hat{\mathrm{H}}_{0}+\lambda\left(\hat{\mathrm{H}}-\hat{\mathrm{H}}_{0}\right) \text {. }
$$

The perturbation expansions for the wavefunction and energy are then

$$
\Psi=\Psi^{(0)}+\lambda \Psi^{(1)}+\lambda^{2} \Psi^{(2)}+\ldots
$$

and

$$
E_{\lambda}=E^{(0)}+\lambda E^{(1)}+\lambda^{2} E^{(2)}+\cdots \cdot
$$

This approach is known as the Moller-Plesset method ${ }^{30}$ and termination of the series in (1.13) at second order, third order and so on is referred to as MP2, MP3, etc. 
It may be shown ${ }^{6}$ that the first-order Moller-Plesset energy corresponds simply to the Hartree-Fock energy. At the MP2 ${ }^{31}$ and $\mathrm{MP}^{31}$ levels of theory various doubly-excited configurations, in which two occupied spin orbitals in the Hartree-Fock wavefunction are replaced by two unoccupied orbitals, are included in (1.10). At the MP4 level of theory 32,33 single, double, triple and quadruple substitutions all contribute to the Moller-Plesset energy.

Finally, it is important to note that, compared with some other correlation procedures, the MP2, MP3 and MP4 methods have the advantage of being well-defined (they avoid specific formulations or choices of configurations) and size-consistent (the resulting energies are additive for an assembly of isolated molecules). The energies, however, are no longer variational and, in addition, the perturbation series may be poorly convergent in cases where the Hartree-Fock wavefunction provides a particularly poor starting point.

\subsection{Implementation of the Theory}

The ab initio molecular orbital calculations reported in this thesis have been carried out with modified versions ${ }^{34,35}$ of the Gaussian $80^{36}$ and Gaussian $82^{37}$ programs. Some specific features used in these programs are outlined in the following sections.

\section{3 .1 Standard Basis Sets}

A number of built-in basis sets have been used in the work reported here in order to facilitate uniform comparisons among a 
variety of species. These basis sets may be classified into two groups:

\subsubsection{Split-Valence Basis Sets These have one basis}

function per core orbital and two or more basis functions per valence orbital of the constituent atoms. They permit the radial size of the valence atomic orbital to be adjusted and thus make allowance for variable atom size and anisotropy. Examples of split-valence basis sets are $3-21 G^{38,39}$ and $6-31 G .^{40,41}$ The expression '3-21G' denotes the use of a contracted set of three primitive Gaussians for the core orbitals and sets of two and one primitive Gaussians for the inner and outer parts, respectively, of the valence orbitals.

1.3.1.2 Polarization Basis Sets These sets are derived from the split-valence basis sets by the addition of functions of higher orbital angular-momentum quantum number (for example, $\underline{d}-$ and $\underline{f}$-type functions on carbon, $\underline{p}$ - and $\underline{d}$-type functions on hydrogen). This allows for small displacements of the electronic charge away from the atomic nuclei. Some polarization basis sets used for results reported in this thesis are:

(a) $3-21 G^{(*)}, 42$ formed from $3-21 G$ by adding a set of $\underline{d}$-type functions to second-row atoms;

(b) $6-31 G^{*}$ (also written as $6-31 G(\underline{d})$ ), ${ }^{41,43}$ formed from 6-31G by addition of a set of d-type functions to all non-hydrogen atoms;

(c) $6-31 G^{* *}$ (also written as $6-31 G(\underline{d}, \underline{p})$ ), ${ }^{41,43}$ formed from $6-31 G^{*}$ by addition of a set of $\underline{p}$-type functions to hydrogen atoms; and 
(d) $6-31 G(\underline{d f}, \underline{p d}),{ }^{44}$ formed from $6-31 G$ by addition of sets of d- and f-type functions to non-hydrogen atoms and sets of $\underline{p}-$ and $\underline{d}$-type functions to $\mathrm{H}$.

\subsubsection{Electron Correlation Methods}

All calculations incorporating electron correlation reported in this thesis are based on the Moller-Plesset approach of Section 1.2.7 terminated at second (MP2), third (MP3) or fourth (MP4) order. In this thesis, MP4 is used to denote the full (i.e. SDTQ) fourthorder treatment. All single-point Møller-Plesset calculations were carried out within the 'frozen-core' approximation in which excitations from the core orbitals are excluded.

\subsubsection{Molecular Geometries}

As stated in Section 1.2.2, the energy E evaluated by molecular orbital calculations is a function of the nuclear coordinates $\mathbf{R}$ and forms a potential surface for the system under consideration. Positions of special significance on this surface are stationary points, where the gradient of the energy with respect to $3 \mathrm{~N}-6$ internal coordinates (for an $\mathrm{N}$-atom system) is zero:

$$
\frac{\partial E_{-}}{\partial r_{i}}=0, \quad i=1,2, \ldots, 3 N-6
$$

The two most important types of stationary points are local minima (corresponding to equilibrium structures) and first-order saddle points (corresponding to transition structures for rearrangement or fragmentation processes). 


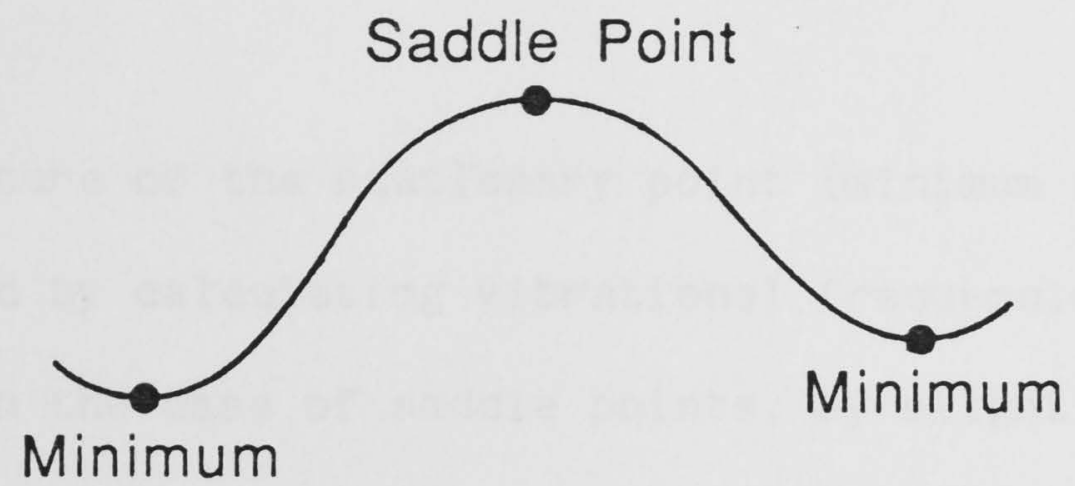

Figure 1.1 Schematic potential energy profile showing two local minima connected by a first-order saddle point.

Minima and saddle points may be distinguished by evaluating the second derivative matrix

$$
\frac{\partial^{2}}{\partial r_{i}-\frac{E}{\partial r}-} \quad \quad i, j=1,2, \ldots, 3 N-6
$$

For a minimum, all the eigenvalues of (1.15) will be positive. For a first-order saddle point there will be one and only one negative eigenvalue, whose eigenvector corresponds to the direction of the reaction coordinate.

The geometries of all the molecules studied in this thesis have been optimized by gradient techniques, using efficient algorithms for locating minima $36,37,45$ and saddle points. ${ }^{45,46}$ For such uses, the Gaussian 82 program has built in to it analytical first derivatives of the energy for wavefunctions up to MP2 47 and has analytical second derivatives for HF wavefunctions. (For recent developments in the calculation of analytical derivatives, see refs 48 and 49.) For some of the systems studied, optimizations were carried 
out using algorithms in which the energy derivatives were evaluated numerically. 46,50

The nature of the stationary point (minimum or saddle point) was investigated by calculating vibrational frequencies (see next section) and, in the case of saddle points, by slightly distorting the system along the reaction coordinate and following the surface 'downhill' (see Figure 1.1).

\subsubsection{Vibrational Frequencies and Thermodynamic Properties}

Evaluation of the second derivative matrix (1.15) by analytical or numerical techniques enables the harmonic frequencies of a structure to be calculated using standard methods. ${ }^{51}$ stationary points corresponding to equilibrium structures are characterized by all real frequencies, those corresponding to transition structures by exactly one imaginary frequency.

To facilitate comparisons with experiment, the following thermodynamic properties may be calculated from the vibrational frequencies using standard formulae: ${ }^{6,52}$

(a) zero-point vibrational energy ( $\mathrm{PPVE}$ ), used throughout this thesis to obtain relative energies at $0 \mathrm{~K}$;

(b) enthalpy corrections $\left(\mathrm{H}_{\mathrm{T}}-\mathrm{H}_{0}\right)$, used to correct experimental heats of formation to $0 \mathrm{~K}^{53,54}$ (or, more rarely, to correct theoretical relative energies to a temperature T);

(c) absolute entropies $\left(\mathrm{S}_{\mathrm{T}}\right)$, used in combination with $\mathrm{H}_{\mathrm{T}}-\mathrm{H}_{\mathrm{O}}$ to obtain the free energy $G_{T}$; and 
(d) partition functions $\left(Q_{T}\right)$, used in evaluating rate constants via classical transition state theory (Chapter Nine).

When correcting the heats of formation of ions to a certain

temperature, the 'stationary electron' convention ${ }^{55}$ has been used (i.e. the heat capacity of an electron is assumed to be zero). This is the convention employed in Rosenstock's widely-used tabulation of experimental heats of formation. ${ }^{56}$

\subsubsection{Notation}

The various theoretical models used for the calculations reported in this thesis are indicated by the standard notation ${ }^{6}$

\section{METHOD/BASIS SET.}

For example, a calculation using the $6-31 \mathrm{G}^{*}$ basis set and the unrestricted Hartree-Fock (UHF) procedure would be described as UHF $/ 6-31 \mathrm{G}^{*}$. A similar calculation using third-order Moller-Plesset theory would be described as UMP $3 / 6-31 G^{*}$. In this thesis, the use of just HF or MP implies RHF or RMP for closed-shell systems, and UHF or UMP for open-shell systems. Complete omission of a 'method' implies the use of the appropriate HF procedure. Finally, the geometry used for the calculation is specified using the $1 / 1$ ' symbol. MP3/6-31 $\mathrm{G}^{*} / / \mathrm{HF} / 6-31 \mathrm{G}^{*}$ describes an MP3 calculation with the $6-31 \mathrm{G}^{*}$ basis set using a geometry optimized at the Hartree-Fock level with the same basis set. 


\subsection{Reliability of the Theoretical Model}

The success of a particular theoretical model may be measured in terms of how well it reproduces experimental results such as geometries, relative energies and vibrational frequencies. Extensive assessments have been carried out by Pople and co-workers ${ }^{6}$ for the application of certain ab initio models to neutral molecules. However, the situation is less satisfactory for short-lived reactive intermediates (including many of the species reported in this thesis) where less experimental information is available (particularly with respect to geometries). Nevertheless, for these systems it is possible to determine the reliability of a model by examining the convergence of results as one uses increasingly more sophisticated theoretical treatments (see, for example, ref 57). This possibility represents a distinct advantage over semi-empirical methods.

\subsubsection{Molecular Geometries, Relative Energies and Vibrational}

\section{Frequencies}

Hartree-Fock theory with split-valence or polarization basis sets has been shown to provide, on the whole, a useful level of reliability for determining geometries of stable neutral molecules. 6 For many of the short-lived systems studied in this thesis, the changes between geometries optimized at $\mathrm{HF} / 3-21 \mathrm{G}^{(*)}, \mathrm{HF} / 6-31 \mathrm{G}^{*}$ and MP2 $/ 6-31 \mathrm{G}^{*}$ are only minor, which suggests that the HF/6-31G ${ }^{*}$ model might also be a reasonable approximation for these reactive species. For some systems, however, MP2 optimizations do lead to significant changes in geometry from the HF results, particularly for weaklybonded species or those containing electronegative elements. For a 
few of these molecules it has been shown that higher-level

optimizations using more complete treatments of electron correlation lead to only minor further structural changes. 50,58

Satisfactory evaluation of relative energies usually requires higher levels of theory than those needed to obtain the underlying geometries. This is particularly true in determining the relative energies of transition structures (that is, in determining the activation energies for various rearrangement or fragmentation processes). For this reason, the best relative energies reported in this thesis are the results of single-point calculations, in which the energy of each system is evaluated with a high level of theory using geometries optimized at a lower level. For the most part, relative energies obtained at MP2, MP3 and MP4 appear to converge to limiting values (see, however, ref 59).

Vibrational frequencies calculated at the $\mathrm{HF} / 3-21 \mathrm{G}^{(*)}$ level are known ${ }^{6}$ to be on average $-10 \%$ greater than the experimental values for a wide range of neutral molecules. In this work, all frequencies calculated at this level were scaled by 0.9 before evaluating the thermodynamic properties outlined in Section 1.3 .4 . In a few cases, frequencies calculated at $\mathrm{HF} / 6-31 \mathrm{G}^{*}$ or $\mathrm{MP} 2 / 6-31 \mathrm{G}^{*}$ were also used after scaling by $0.9^{6}$ and $0.93,60,61$ respectively. For these few systems, only small differences were observed between the three sets of scaled frequencies which suggests that the scale factors for neutral molecules might also be appropriate (or at least lead to systematic errors) for radical cations and other reactive intermediates. 


\subsubsection{The Unrestricted Hartree-Fock (UHF) Model}

For nearly all the open-shell equilibrium structures reported in this thesis, the expectation value of the $\hat{S}^{2}$ operator, $\left\langle\hat{S}^{2}\right\rangle$, is close to the true values of 0.75 for a doublet or 2.00 for a triplet (that is, the spin contamination is small). For these systems we might expect, therefore, that the UHF model will be an appropriate one to use. 6 However, in some of the transition structures (where electron pairs are being broken), the spin contamination becomes significant. Although the geometries may not be badly affected, it has been demonstrated ${ }^{59,62}$ that in such cases there is only slow convergence of the Møller-Plesset perturbation expansion. Singlepoint calculations incorporating electron correlation via truncated perturbation series lead to relative energies for these species which are probably too high.

\subsubsection{The Additivity Approximation}

Computational expense sometimes precludes the combination of large polarization basis sets with extensive treatments of electron correlation where such calculations would otherwise be desirable. In these circumstances, additivity approximations such as

$$
\begin{aligned}
\Delta E\left(M P 3 / 6-31 G^{* *}\right)=\Delta E\left(M P 3 / 6-31 G^{*}\right) & +\Delta E\left(H F / 6-31 G^{* *}\right) \\
& -\Delta E\left(H F / 6-31 G^{*}\right)
\end{aligned}
$$

have been used, where the terms on the right-hand side of (1.16) are evaluated exactly and it is assumed that the contributions to the relative energy from the basis set enhancement and the electron 
correlation treatment are additive. Such approximate schemes have been tested for a variety of systems (including the difficult calculation of singlet-triplet splittings) and have been found to hold well. 63,64

\subsection{Technical Aspects and Units}

The calculations reported in this thesis were carried out on Univac $1100 / 82$, Vax $11 / 780$ and Facom M360 computers at the Australian National University Computer Services Centre. For all structures, bond lengths are given in angstroms and angles in degrees. Total energies are expressed in hartrees and relative energies in kilojoules per mole $\left(\mathrm{kJ} \mathrm{mol}^{-1}\right)$. Conversion factors used in this work are listed in the Appendix. 


\section{CHAPTER TWO EXPERIMENTAL BACKGROUND}

\subsection{Introduction}

Although the results presented in this thesis are based solely on theoretical methods (as described in chapter one), frequent reference is made to corresponding information that has been derived from gas-phase experiments carried out using mass spectrometers. Since it is important to know something of the type and quality of information available from such gas-phase studies, a brief outline of some of the experimental methods referred to in later chapters is presented below. The discussion is by no means comprehensive and is intended, rather, for the non-specialist.

\subsection{The Double-Focusing Mass Spectrometer}

The schematic outline of a typical double-focusing mass spectrometer of reversed geometry is shown in Figure 2.1.65,66,67 The geometry is said to be reversed because the magnetic analyser is placed in front of the electrostatic analyser, in contrast to the arrangement that was used in the first double-focusing mass spectrometers to be built for organic analysis.

Ions may be produced in the ion source in a number of different ways. The traditional method is to bombard neutral molecules with a beam of electrons emitted from a filament. The energy of these ionizing electrons is tunable and for qualitative 


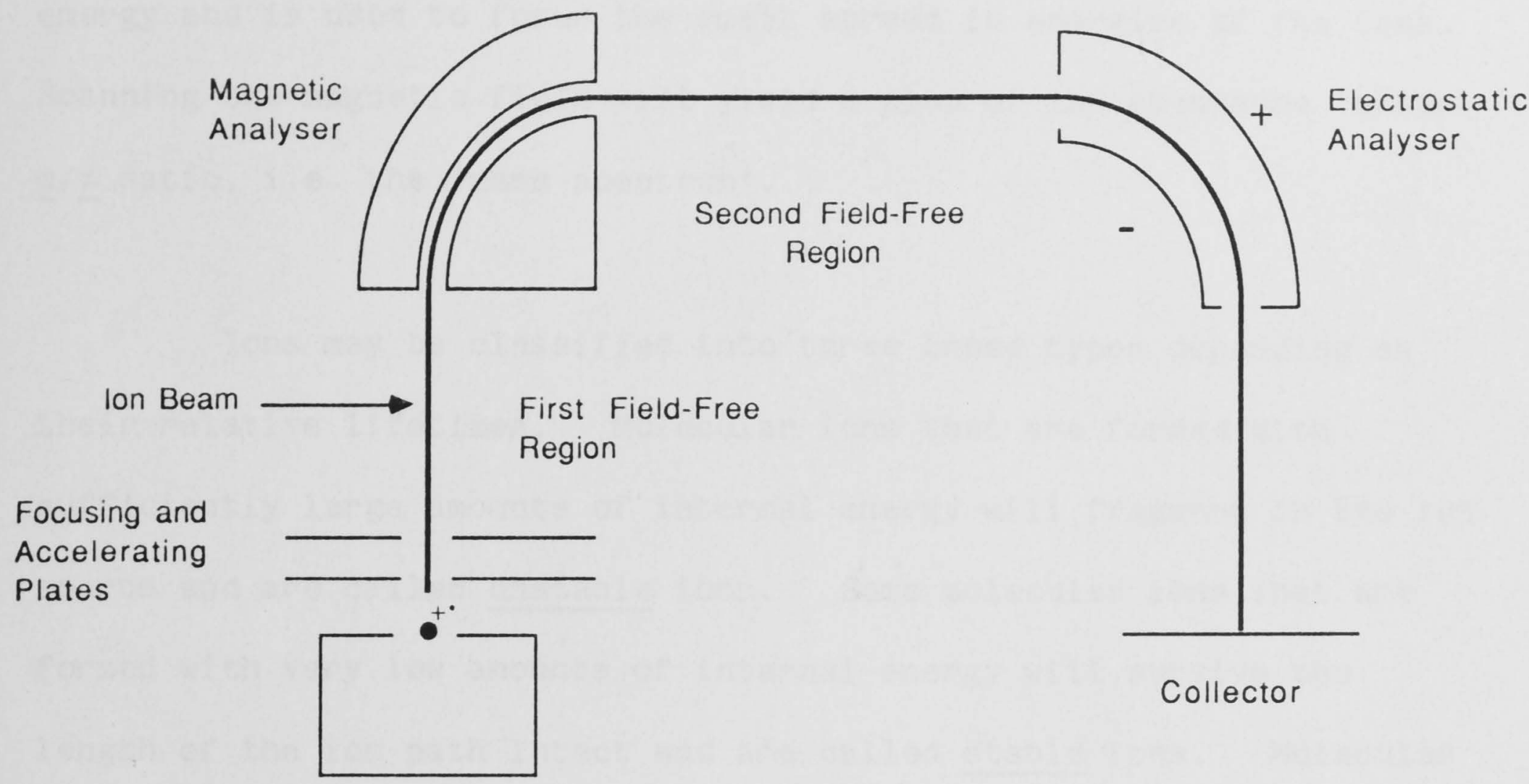

Ion Source

Figure 2.1 Schematic outline of a double-focusing mass spectrometer of reversed geometry.

organic analysis is usually set at $70 \mathrm{eV}$. The typical ionization energy of an organic compound is $10-12 \mathrm{eV}$ and so a molecular ion formed in a mass spectrometer will have a considerable spread of internal energies. Such ions will undergo unimolecular decomposition to give fragment ions in a manner which is usually characteristic of their structure (see, for example, refs 68 and 69). It is this feature which makes the mass spectrometer an important tool in analytical chemistry.

The molecular ions and their fragments are accelerated from the ion source and pass through a magnetic analyser where they are separated according to their mass-to-charge $(\underline{m} / \underline{z})$ ratio. The electrostatic analyser separates ions according to their kinetic 
energy and is used to focus the small spread in energies of the ions. Scanning the magnetic field will yield a plot of ion abundance versus $\underline{m} / \underline{z}$ ratio, i.e. the 'mass spectrum'.

Ions may be classified into three broad types depending on their relative lifetimes. Molecular ions that are formed with sufficiently large amounts of internal energy will fragment in the ion source and are called unstable ions. Some molecular ions that are formed with very low amounts of internal energy will survive the length of the ion path intact and are called stable ions. Molecular ions formed with intermediate amounts of internal energy and which fragment between the ion source and the collector are known as metastable ions.

\subsection{Ion Thermochemistry}

The first important piece of information that can be obtained from mass spectrometry experiments is the thermochemistry of the ions involved. $56,70,71,72,73$

The (first) ionization energy of a molecule is the least amount of energy required to remove an electron from the neutral species (Figure 2.2). The adiabatic ionization energy ( $\left.\mathrm{IE}_{\mathrm{a}}\right)$ corresponds to the transition from the ground state of the neutral to the ground state of the ion. In contrast, the vertical ionization energy $\left(I E_{v}\right)$ corresponds to that transition from the ground state of the neutral for which the Franck-Condon factor is largest. This usually leads to to a vibrationally excited state of the ion. Extensive tabulations of such ionization energies have been 


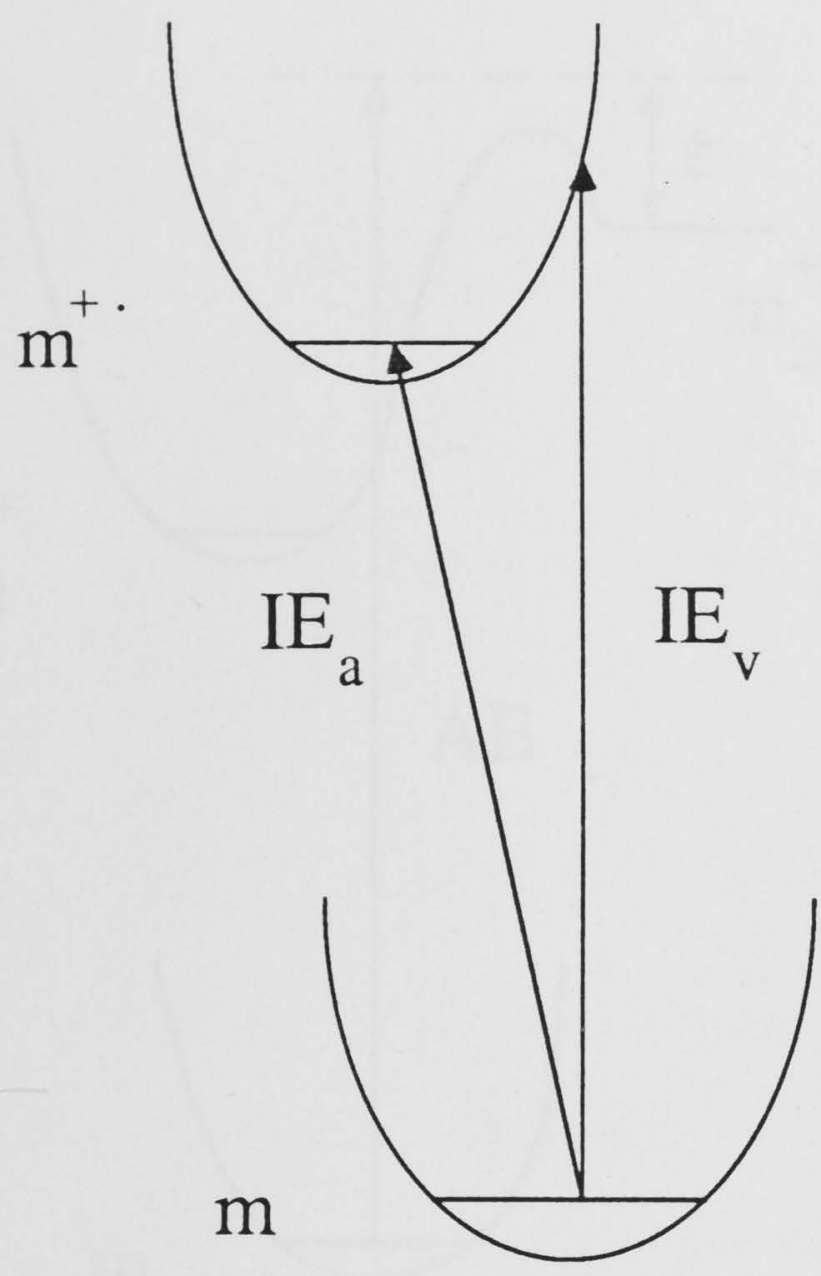

Figure 2.2 Schematic energy diagram of adiabatic ( $\mathrm{IE}_{a}$ ) and vertical $\left(\mathrm{IE}_{\mathrm{v}}\right)$ ionization processes.

published. 56,74 Provided one knows the heat of formation of the neutral species, then the heat of formation of the ion can be calculated from

$$
\Delta \mathrm{H}_{\mathrm{f}}\left(\mathrm{m}^{+\cdot}\right)=\Delta \mathrm{H}_{\mathrm{f}}(\mathrm{m})+\mathrm{IE} \mathrm{a}_{\mathrm{a}}(\mathrm{m})
$$

If the molecular ion fragments upon ionization according to

$$
\mathrm{m}_{1} \stackrel{\text { Ionization }}{\longrightarrow} \mathrm{m}_{2}^{+}+\mathrm{m}_{3}+\mathrm{e}^{-}
$$

and if the energy of ionization is varied using specialized equipment, ${ }^{75,76}$ then the lowest energy at which $\mathrm{m}_{2}{ }^{+}$appears may be determined and is called the appearance energy, $\mathrm{AE}$, of $\mathrm{m}_{2}^{+}$(Figure 2.3). 
25.

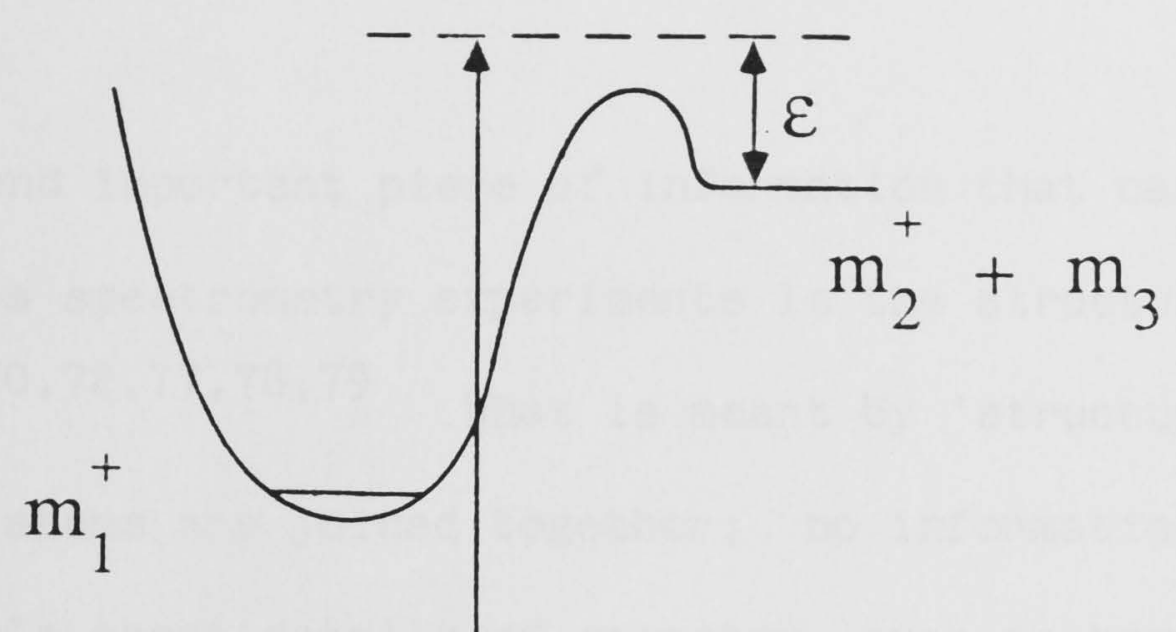

$\mathrm{AE}$

Figure 2.3 Schematic energy diagram of the appearance energy (AE) required to produce fragment species.

The heat of formation of the fragment ion $\mathrm{m}_{2}^{+}$may be derived from

$$
\Delta H_{f}\left(m_{2}^{+}\right)=\Delta H_{f}\left(m_{1}\right)+A E\left(m_{2}^{+}\right)-\Delta H_{f}\left(m_{3}\right)-\varepsilon,
$$

where the term $\varepsilon$ contains contributions from the kinetic shift (the energy in excess of the barrier height required to produce fragmentation of $\mathrm{m}_{1}^{+\cdot}$ ) and the reverse activation energy for the process. Some estimate of the magnitude of these two factors may be obtained from an analysis of the shape of the metastable ion-abundance peak in the mass spectrum. Methods for minimizing or taking into account $\varepsilon$ in equation (2.2) have been discussed by Holmes. ${ }^{72}$ 
26.

\subsection{Ion Structure}

The second important piece of information that can be obtained from mass spectrometry experiments is the structure of the ions involved. ',70,72,77,78,79 What is meant by 'structure' in this context is which atoms are joined together; no information is generally available about details of geometry, such as bond lengths and bond angles.

Two main sources of structural information are considered in this section. The first source is the heats of formation of the various ions. These may be used in some cases to distinguish isomeric species. However, the heat of formation of an ion is usually not enough on its own to characterize the structure and it is generally used (as circumstantial evidence) in combination with other techniques. 72

The second source of structural information comes from the unimolecular and collision-induced dissociation characteristics of the ion. Instead of the arrangement in Figure 2.1 being used as a double-focusing instrument, ions of a particular mass are selected by the magnetic analyser and after undergoing some reactions in the second field-free region the products are examined using the electrostatic analyser. In effect, one obtains a mass spectrum of the mass-selected ions. Such techniques have been referred to as 'MS/MS' (mass spectrometry/mass spectrometry). ${ }^{78}$ These methods are clearly very important for the investigation of structures of ions for 
which there are no (stable) neutral counterparts. In the following sections, five techniques which use MS/MS will be discussed. ${ }^{a}$

\subsubsection{Metastable Peak Observation}

Mass-selected ions which undergo unimolecular dissociation in the second field-free region of the mass spectrometer give rise to metastable peaks having characteristic shapes. ${ }^{82}$ For the fragmentation reaction

$$
\mathrm{m}_{1}^{+} \rightarrow \mathrm{m}_{2}^{+}+\mathrm{m}_{3}
$$

the $\underline{m} / \underline{z}$ value of the metastable peak is dependent on the masses of $m_{1}$ and $m_{2}$. The use of such metastable peaks to isolate specific reaction channels and identify ion structures has been reviewed by Holmes. ${ }^{72}$ As an example, two isomers may dissociate to give the same fragments as shown in Figure 2.4. The respective dissociation processes, however, can give rise to very different metastable peak shapes, which allows the isomeric ions to be distinguished. 83,84

a. The material presented here does not include a discussion of the possibility of determining the electronic structure of ions based on their absorption of electromagnetic radiation (see refs 80 and 81). Such spectroscopic methods will undoubtedly become more widespread than at present and will provide a useful means of characterizing gas-phase species. 


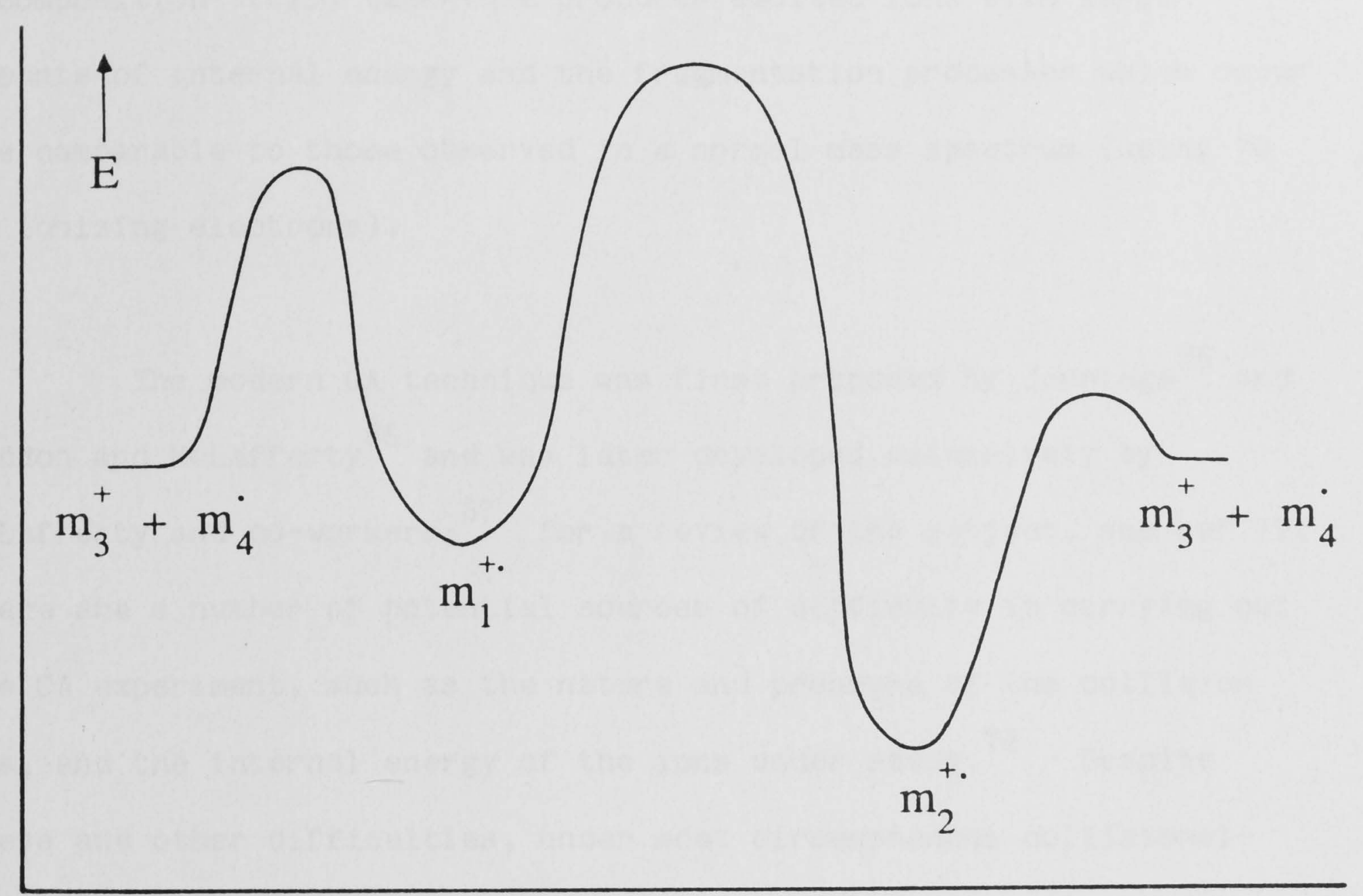

Figure 2.4 Schematic energy diagram showing metastable dissociation processes for two isomers, $\mathrm{m}_{1}^{+}$and $\mathrm{m}_{2}^{+\bullet}$.

\subsubsection{Collisional-Activation Mass Spectrometry}

Although some ions undergo unimolecular dissociation as described in the preceding section, the number of such dissociations can be increased by introducing a collision gas ( $N$ ) into the path of the ions in the second field-free region. The ions will then be 'activated' by the collisions (i.e., some of their kinetic energy will be converted into internal energy) and undergo fragmentation.

$$
\left.\mathrm{m}_{1}^{+} \longrightarrow \mathrm{N}_{1}^{+}\right)^{*} \longrightarrow \mathrm{m}_{2}^{+}+\mathrm{m}_{3}
$$

This 'collisional-activation' (CA) or 'collision-induced- 
decomposition' (CID) technique produces excited ions with large amounts of internal energy and the fragmentation processes which occur are comparable to those observed in a normal mass spectrum (using 70 eV ionizing electrons).

The modern CA technique was first proposed by Jennings ${ }^{85}$ and Haddon and McLafferty ${ }^{86}$ and was later developed extensively by McLafferty and co-workers; ${ }^{87}$ for a review of the subject, see ref 77 . There are a number of potential sources of difficulty in carrying out the CA experiment, such as the nature and pressure of the collision gas, and the internal energy of the ions under study. ${ }^{72}$ Despite these and other difficulties, under most circumstances collisionalactivation mass spectrometry provides a characteristic fingerprint of the structure of a particular ion.

\subsubsection{Charge-Stripping Mass Spectrometry}

If a positive ion undergoes a sufficiently high-energy collision during the collisional-activation process described above, it may lose a second electron:

$$
\mathrm{m}_{1}^{+} \stackrel{\mathrm{N}}{\longrightarrow} \mathrm{m}_{1}^{2+}+\mathrm{e}^{-}
$$

This 'charge-stripping' (CS) process was first investigated systematically by Cooks, Beynon and Ast ${ }^{89}$ and has been the subject of two reviews. 77,90

b. It may be noted that the 'activation' or excitation of an ion in the gas phase can also be carried out using low-energy lasers (ref 77). For a recent discussion of the technique and its use in differentiating isomeric ion structures, see ref 88 . 
The dications formed in a charge-stripping experiment give rise to sharp spikes in the normal CA mass spectrum and are observed at half the $\underline{m} / \underline{z}$ values of the corresponding monocations. Various monocation isomers often give rise to very different charge-stripping spectra and this feature has been used extensively to distinguish such isomeric species. (For reviews of recent work, see refs 72,91 and 92.) The relative abundances of the charge-stripping peaks from these isomers may also provide information about the relative stabilities of the dications themselves. ${ }^{\mathrm{C}}$

The main source of energy for the charge-stripping process is the translational energy of the monocation. The minimum translational energy loss measured $\left(Q_{\text {min }}\right)$ is given by ${ }^{77}$

$$
Q_{\min }=\operatorname{IE}\left(m^{+}\right)-E E\left(m^{+}\right)
$$

where $\mathrm{EE}$ is the electronic excitation energy of the ion $\mathrm{m}^{+}$. For most organic compounds it may be assumed ${ }^{77}$ that by the time the monocations reach the second field-free region they will be in their ground state and so $E E\left(\mathrm{~m}^{+}\right)=0$. Thus $Q_{\mathrm{min}}$ can give an estimate of the ionization energy of a monocation. The question of whether $Q_{\min }$ corresponds to a vertical or adiabatic ionization appears to be unresolved. It was originally proposed ${ }^{95}$ that the charge-stripping process corresponded to vertical ionization $\left(Q_{\mathrm{min}} \approx \operatorname{IE}_{\mathrm{v}}\left(\mathrm{m}^{+}\right)\right)$. More recently, however, it has been suggested ${ }^{96}$ that there are some cases where the process corresponds more closely to adiabatic ionization $\left(Q_{\min } \approx \operatorname{IE}_{a}\left(\mathrm{~m}^{+}\right)\right)$.

c. Peaks due to doubly-charged ions are in fact observed in conventional electron-ionization mass spectrometry (refs 85 and 93). Although such peaks are usually neglected, it has been shown recently (ref 94) that they can provide a useful source of additional structural information in the conventional mass spectrometry experiment. 
One of the problems that may occur in a charge-stripping experiment is that the signal due to a doubly-charged species can be masked to some extent by that due to a singly-charged species. For example, the mass-selected ion $\mathrm{m}_{1}^{+}$can be charge-stripped to give $\mathrm{m}_{1}{ }^{2+}$ but could also fragment to give $\mathrm{m}_{2}{ }^{+}$with a mass half that of $\mathrm{m}_{1}$. Recently, a procedure has been suggested to resolve these peaks.91,97,98,99 Mass-selected ions are subjected to charge stripping in a primary collision cell in the normal way and the ions then undergo charge exchange in a second collision cell according to

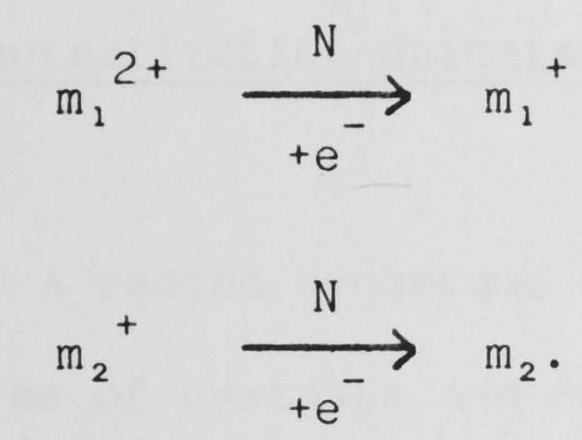

and

Using this method, only those ions corresponding to the dications are observed in the final mass spectrum. This procedure, called 'charge stripping/charge exchange' (CS/CE), 91 has been used to distinguish between a number of isomeric structures.

\subsubsection{Collision-Induced Dissociative-Ionization Mass Spectrometry}

As discussed in Section 2.4.1, mass-selected ions can undergo unimolecular dissociation in the second field-free region of a mass spectrometer:

$$
\mathrm{m}_{1}^{+} \rightarrow \mathrm{m}_{2}^{+}+\mathrm{m}_{3}
$$

If the ions $\mathrm{m}_{2}{ }^{+}$are deflected or retarded electrostatically then only the neutral fragments $m_{3}$ will enter the collision cell. It has been 
shown ${ }^{100,101,102}$ that these neutrals can be ionized by collision with a target gas and those product ions formed with sufficient internal energy will then undergo further fragmentation. This collisioninduced dissociative-ionization (CIDI) procedure therefore gives rise to a mass spectrum of the neutral fragment, $m_{3}$. It has been used successfully to distinguish between isomers of neutral molecules that are only stable within the timeframe of the mass spectrometry experiment. $101,103,104,105$

\subsubsection{Neutralization-Reionization Mass Spectrometry}

A second technique which has been developed to study the structures of unstable and reactive neutrals is that of neutralization-reionization mass spectrometry (NRMS). 106 In this technique the mass-selected ions first of all undergo neutralization in a primary collision cell in the second field-free region of the mass spectrometer:

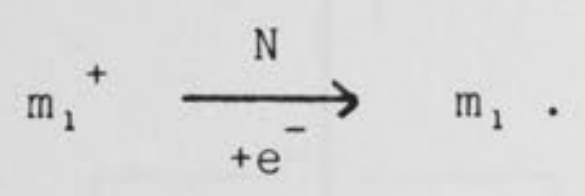

Any surviving ions are deflected from the main beam. The neutral species then undergo CIDI in a second collision cell (Figure 2.5) and the products are examined using the electrostatic sector. Since the neutral species are generated from stable parent ions, the technique has the potential for investigating the stability of neutral molecules with unconventional structures. $106,107,108,109$ 


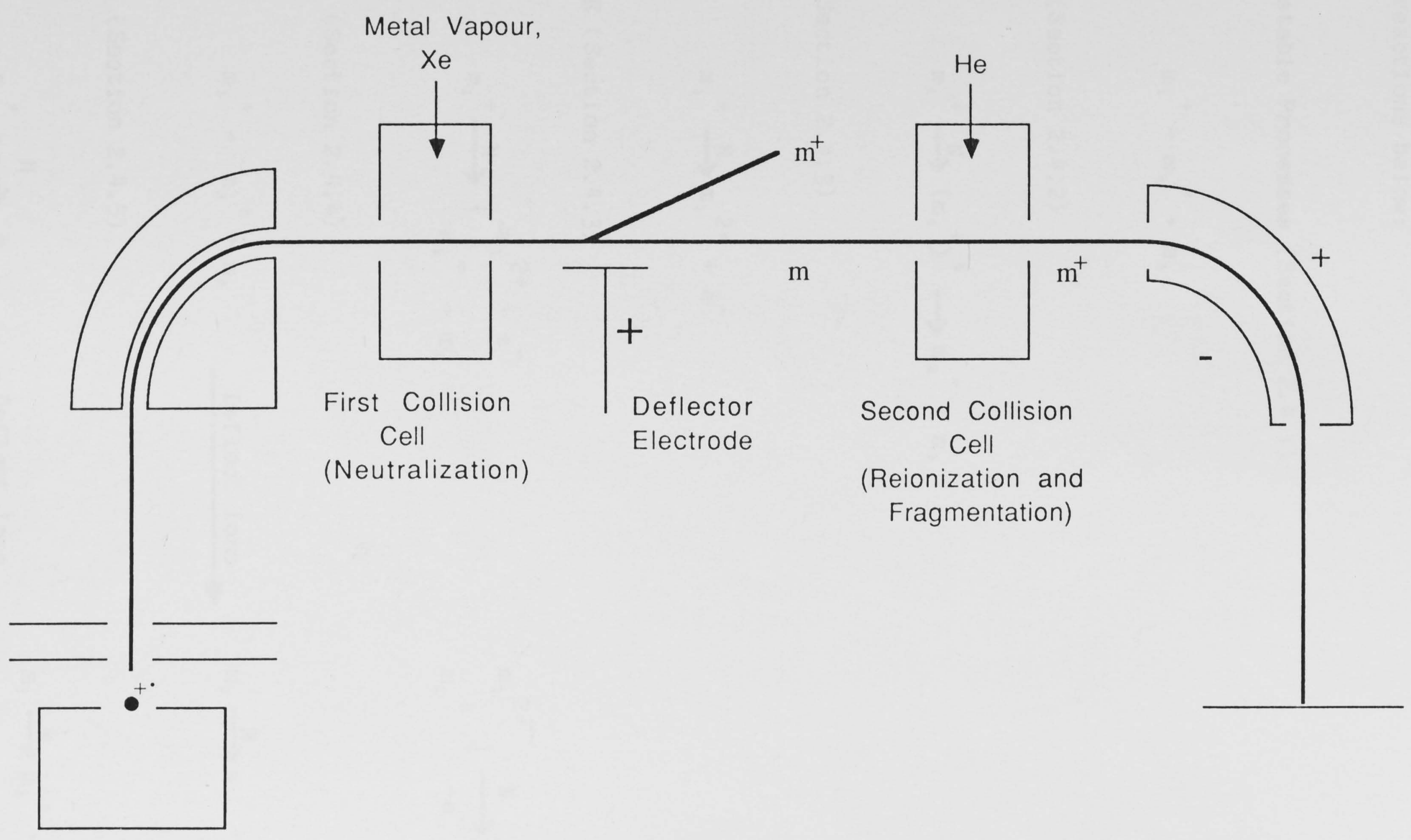




\section{4 .6 Summary}

The various techniques discussed in this chapter for

investigating the structures of gas-phase species may be summarized by the reactions below:

Metastable Processes (Section 2.4.1)

$$
\mathrm{m}_{1}^{+} \rightarrow \mathrm{m}_{2}^{+}+\mathrm{m}_{3}
$$

CAD (Section 2.4.2)

$$
\mathrm{m}_{1}^{+} \stackrel{\mathrm{N}}{\longrightarrow}\left(\mathrm{m}_{1}^{+}\right)^{*} \longrightarrow \mathrm{m}_{2}^{+}+\mathrm{m}_{3}
$$

CS (Section 2.4.3)

$$
\mathrm{m}_{1}^{+} \stackrel{\mathrm{N}}{\longrightarrow} \mathrm{m}_{1}^{2+}+\mathrm{e}^{-}
$$

CS/CE (Section 2.4.3)

$$
\mathrm{m}_{1}^{+} \longrightarrow \mathrm{m}_{\mathrm{m}^{+}}{\stackrel{\mathrm{m}}{{ }^{2+}}+\mathrm{e}^{-}}^{-}
$$

CIDI (Section 2.4.4)

$$
\mathrm{m}_{1}^{+} \rightarrow \mathrm{m}_{2}^{+}+\mathrm{m}_{3}
$$

Deflect Ions $\mathrm{m}_{2}^{+}+\underset{+e^{2+}}{\longrightarrow}\left\{\mathrm{m}_{2}^{+}\right.$

$\mathrm{m}_{3} \stackrel{\mathrm{N}}{\longrightarrow} \mathrm{m}_{4}^{+}+\mathrm{m}_{5}+\mathrm{e}^{-}$

NRMS (Section 2.4.5)

$$
\mathrm{m}_{1}^{+} \underset{+e^{-}}{\stackrel{\mathrm{N}}{\longrightarrow}} \mathrm{m}_{1}
$$

$\mathrm{m}_{1} \stackrel{\mathrm{N}}{\rightarrow} \mathrm{m}_{1}^{+}+\mathrm{e}^{-}$

$\mathrm{m}_{1} \stackrel{\mathrm{N}}{\longrightarrow} \mathrm{m}_{2}^{+}+\mathrm{m}_{3}+\mathrm{e}^{-}$ 
In many cases, a combination of the above techniques has been used by experimentalists to characterize some of the reactive species discussed in this thesis. 
36.

\section{CHAPTER THREE YLIDES}

\subsection{Introduction}

Ylides are well-known as synthetic intermediates in organic chemistry, where they feature most prominently in processes such as the Wittig reaction 110,111 and the Stevens rearrangement. 112,113 Although the broad scope of ylide chemistry has recently been extensively reviewed by Morris, ${ }^{114}$ the simplest ylides, such as $\mathrm{CH}_{2} \mathrm{PH}_{3}$ or $\mathrm{CH}_{2} \mathrm{SH}_{2}$, remain unknown in solution. In this chapter, the results from a theoretical study of the prototype ylides $\mathrm{CH}_{2} \mathrm{XH}\left(\mathrm{X}=\mathrm{NH}_{2}, \mathrm{OH}\right.$, $\mathrm{F}, \mathrm{PH}_{2}, \mathrm{SH}$ and $\mathrm{Cl}$ ) are briefly presented. It is shown that the prototype ylides are relatively unstable species and the best chance of observing them may be in the gas phase. The primary reason for carrying out the calculations is, however, for the purpose of comparing these neutral ylides with the singly-and doubly-charged species to be discussed in Chapters Four and Five.

Except for $\mathrm{CH}_{2} \mathrm{ClH}$, all of the prototype ylides have been previously investigated using theoretical methods. Early calculations on simple ylides have concentrated on the degree of bonding present and whether $\underline{d}$ orbitals might be important. Semiempirical, extended-Hückel and $a b$ initio techniques have been employed to calculate a range of properties including partially-optimized geometries, charge distributions, rotation and inversion barriers and NMR coupling constants for the $\mathrm{CH}_{2} \mathrm{NH}_{3}, 115-117 \mathrm{CH}_{2} \mathrm{OH}_{2}, 115,117$ $\mathrm{CH}_{2} \mathrm{PH}_{3}{ }^{115,117-129}$ and $\mathrm{CH}_{2} \mathrm{SH}_{2}{ }^{115,117,123,127,130-134}$ ylides. 
More recently, various aspects of ylide chemistry have also been investigated in several comprehensive studies using complete geometry optimizations and higher levels of theory. $135-142$ Using the ab initio approach, Mitchell et al. 137 investigated the structures and energies of $\mathrm{CH}_{2} \mathrm{PH}_{3}$ and $\mathrm{CH}_{2} \mathrm{SH}_{2}$ with the $4-31 \mathrm{G}^{*}$ basis set and carried out a detailed perturbational molecular orbital (PMO) analysis.

Eades et al. 140 have also reported high-level calculations for $\mathrm{CH}_{2} \mathrm{NH}_{3}$, $\mathrm{CH}_{2} \mathrm{OH}_{2}, \mathrm{CH}_{2} \mathrm{PH}_{3}$ and $\mathrm{CH}_{2} \mathrm{SH}_{2}$. They performed full geometry optimizations with double- $\zeta$ basis sets supplemented by polarization functions on heavy atoms and diffuse $\underline{s}$ and $\underline{p}$ functions on carbon. Energies relative to the conventional isomers were reported at this level (DZP + diffuse functions) and refined estimates obtained 141 through the use of the generalized-valence-bond and POL-CI approaches. In another recent paper, ${ }^{142}$ the first-row prototype ylides, $\mathrm{CH}_{2} \mathrm{XH}(\mathrm{X}=$ $\left.\mathrm{NH}_{2}, \mathrm{OH}, \mathrm{F}\right)$, and their related systems were comprehensively studied at the MP4SDQ $(\mathrm{T}) / 6-31 \mathrm{G}^{* *} / / 6-31 \mathrm{G}^{*}$ level of theory. At this level, the effect of triple substitutions on the correlation energy was evaluated with the smaller $6-31 G^{*}$ basis set.

Despite these extensive previous studies, the present set of calculations has been carried out in order that a uniform comparison among the various species can be made. Where appropriate, the present results will be compared with those of the earlier studies.

\subsection{Method and Results}

Optimized structures were obtained initially with the $3-21 \mathrm{G}^{(*)}$ and $6-31 \mathrm{G}^{*}$ basis sets. Improved relative energies were obtained with the 1 arger $6-31 G^{* *}$ basis set and with valence-electron 
correlation incorporated using Møller-Plesset perturbation theory terminated at second (MP2) and third (MP3) order. Zero-point vibrational contributions to relative energies were obtained from vibrational frequencies calculated at the $3-21 \mathrm{G}^{(*)} / / 3-21 \mathrm{G}^{(*)}$ level.

Application of these procedures yielded relative energies at a uniform level corresponding to MP $3 / 6-31 \mathrm{G}^{* *} / / 6-31 \mathrm{G}^{*}$ values with zeropoint correction, either calculated directly for first-row systems, or estimated for second-row systems by using the additivity approximation of equation (1.16). Unless otherwise noted, these are the values referred to in the text. Results at this level, which is referred to as the standard level of theory, are reported for the ylides $\left(\mathrm{CH}_{2} \mathrm{XH}\right)$, their conventional isomers $\left(\mathrm{CH}_{3} \mathrm{X}\right)$, their transition structures for rearrangement and several pairs of fragmentation products.

For most species, additional calculations at higher levels of theory were performed. Geometries were reoptimized at the MP2/6-31G* level using analytical gradients and improved relative energies were obtained, first at the MP2 level with the larger $6-311 \mathrm{G}(\underline{\mathrm{df}}, \underline{\mathrm{p}})^{143}$ and 6-31G( $\underline{\mathrm{df}}, \underline{\mathrm{p}}$ ) basis sets (for first- and second-row systems, respectively), and secondly at the MP 4 level with the $6-31 \mathrm{G}(\underline{\mathrm{d}}, \underline{\mathrm{p}})$ basis set. For these systems, the best relative energies were estimated from the additivity relationships

$$
\begin{aligned}
\Delta E(M P 4 / 6-311 G(\underline{d f}, \underline{p}))=\Delta E(M P 4 / 6-31 G(\underline{d}, \underline{p})) & +\Delta E(M P 2 / 6-311 G(\underline{d f}, \underline{p})) \\
& -\Delta E(M P 2 / 6-31 G(\underline{d}, \underline{p}))
\end{aligned}
$$

and 


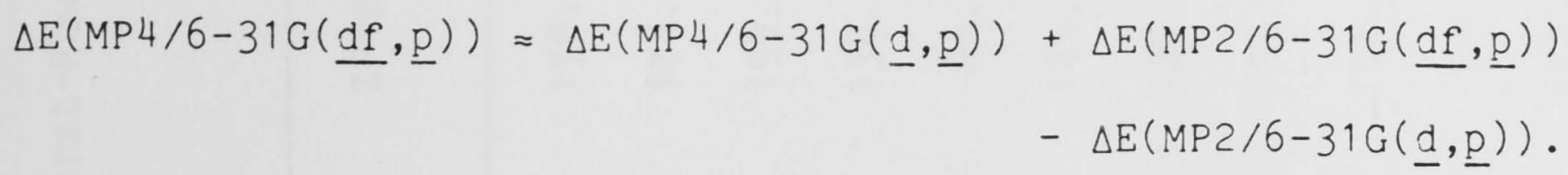

Total energies for the standard calculations are presented in Tables 3.1 and 3.2 and relative energies in Tables 3.3 and 3.4 . Schematic energy profiles (based on the best results in Tables 3.3 and 3.4) are displayed in Figures 3.1 and 3.2 for first-and second-row systems, respectively. For the higher-level calculations, total and relative energies are presented in Tables 3.5 and 3.6 , respectively, and the highest-level results incorporated in Figures 3.1 and 3.2 . Optimized $\mathrm{HF} / 6-31 \mathrm{G}^{*}$ structures for the ylides and related systems are displayed within the course of the discussion; ${ }^{a} \mathrm{HF} / 3-21 \mathrm{G}^{(*)}$ values are given in parentheses and $M P 2 / 6-31 G^{*}$ values (where available) in square brackets.

a. Optimized geometries of the fragmentation products are only displayed where hitherto unpublished. In most cases, these geometries are available from refs 6 or 144 . 
Table 3.1 Calculated Total Energies ${ }^{a}$ (hartrees) and Zero-Point Vibrational Energies (ZPVE, kJ mol ${ }^{-1}$ ) for First-Row Ylides and Related Systems

\begin{tabular}{|c|c|c|c|c|c|c|c|}
\hline & & $\mathrm{HF} / 3-21 \mathrm{G}^{\mathrm{b}}$ & $\mathrm{HF} / 6-31 \mathrm{G}^{*}$ & $\mathrm{HF} / 6-31 \mathrm{G}^{* *}$ & $\mathrm{MP} 2 / 6-31 \mathrm{G}^{* *}$ & $\mathrm{MP} 3 / 6-31 \mathrm{G}^{* *}$ & ZPVE ${ }^{\mathrm{b}}$ \\
\hline $\mathrm{CH}_{3} \mathrm{NH}_{2}$ & $1 \mathrm{a}$ & $-94.68166^{c}$ & $-95.20983^{c}$ & $-95.22185^{c}$ & -95.54991 & -95.57388 & 178.6 \\
\hline $\mathrm{CH}_{2} \mathrm{NH}_{3}$ & $2 a$ & $-94.57574^{c}$ & $-95.09269^{c}$ & $-95.10639^{c}$ & -95.43191 & -95.45668 & 174.6 \\
\hline $\operatorname{TS}(2 a \rightarrow 1 a)$ & $3 a$ & $-94.53754^{c}$ & $-95.04987^{c}$ & $-95.06828^{c}$ & -95.40661 & -95.42784 & 159.5 \\
\hline $\mathrm{CH}_{2} \mathrm{NH}_{2} \cdot$ & & $-94.06305^{c}$ & $-94.58673^{C}$ & $-94.59792^{c}$ & $-94.89614^{c}$ & $-94.91816^{c}$ & 138.2 \\
\hline $\mathrm{NH}_{3}$ & & $-55.87220^{c}$ & $-56.18436^{c}$ & $-56.19553^{d}$ & $-56.38295^{d}$ & $-56.39576^{d}$ & $94.6^{d}$ \\
\hline $\mathrm{CH}_{3} \mathrm{OH}$ & $1 \mathrm{~b}$ & $-114.39802^{c}$ & $-115.03542^{c}$ & $-115.04669^{c}$ & $-115 \cdot 38129^{c}$ & $-115.39909^{c}$ & 143.1 \\
\hline $\mathrm{CH}_{2} \mathrm{OH}_{2}$ & $2 b$ & $-114.27009^{c}$ & $-114.89662^{c}$ & $-114.91289^{c}$ & $-115.23021^{C}$ & $-115.25267^{c}$ & 129.5 \\
\hline $\operatorname{TS}(2 b+1 b)$ & $3 b$ & $-114.24802^{c}$ & $-114.87238^{c}$ & -114.89003 & -115.23832 & -115.25205 & 121.7 \\
\hline $\mathrm{CH}_{2} \mathrm{OH}^{\bullet}$ & & $-113.77382^{c}$ & $-114.40876^{c}$ & $-114.41909^{c}$ & $-114.72366^{c}$ & $-114.73932^{c}$ & $102 \cdot 3$ \\
\hline $\mathrm{OH}_{2}$ & & $-75.58596^{c}$ & $-76.01075^{c}$ & $-76.02357^{C}$ & $-76.21936^{c}$ & $-76.22583^{c}$ & 57.1 \\
\hline $\mathrm{CH}_{3} \mathrm{~F}$ & $1 \mathrm{c}$ & $-138.28189^{c}$ & $-139.03461^{c}$ & $-139.03973^{c}$ & $-139 \cdot 35951$ & $-139 \cdot 37306$ & 110.9 \\
\hline $\mathrm{H}_{2} \mathrm{CHF}$ & $2 c^{\prime}$ & $-138 \cdot 13301$ & $-138.89283^{c}$ & $-138.90500^{c}$ & $-139.20058^{c}$ & $-139 \cdot 22054^{c}$ & 84.2 \\
\hline
\end{tabular}




\begin{tabular}{|c|c|c|c|c|c|c|c|}
\hline $\operatorname{TS}\left(2 c^{\prime} \rightarrow 1 c\right)$ & $4 c$ & $-138.12779^{C}$ & $-138.87191^{c}$ & -138.88250 & -139.210128 & -139.22089 & 86.2 \\
\hline $\mathrm{FH}$ & & $-99.46022^{c}$ & $-100.00291^{c}$ & $-100.01155^{e}$ & $-100.19451^{e}$ & $-100.19634^{\mathrm{e}}$ & $24.3^{e}$ \\
\hline $\mathrm{CH}_{2}\left({ }^{1} \mathrm{~A}_{1}\right)$ & & $-38.65185^{c}$ & $-38.87237^{c}$ & $-38.87630^{c}$ & $-38.98725^{c}$ & $-39.00609^{c}$ & 46.0 \\
\hline $\mathrm{H}^{\bullet}$ & & $-0.49620^{c}$ & $-0.49823^{c}$ & -0.49823 & -0.49823 & -0.49823 & 0.0 \\
\hline
\end{tabular}

a Based on $6-31 \mathrm{G}^{*}$ optimized geometries unless otherwise noted.

b Based on 3-21G optimized geometries.

c From ref 144 .

d From ref 145 .

e From ref 146. 
Table 3.2 Calculated Total Energies ${ }^{a}$ (hartrees) and Zero-Point Vibrational Energies (ZPVE, kJ mol ${ }^{-1}$ ) for Second-Row Ylides and Related Systems

$\mathrm{HF} / 3-21 \mathrm{G}^{(*) \mathrm{b}} \quad \mathrm{HF} / 6-31 \mathrm{G}^{*} \quad \mathrm{HF} / 6-31 \mathrm{G}^{* *} \quad \mathrm{MP} 2 / 6-31 \mathrm{G}^{*} \quad \mathrm{MP} 3 / 6-31 \mathrm{G}^{*} \quad \mathrm{ZPVE}$

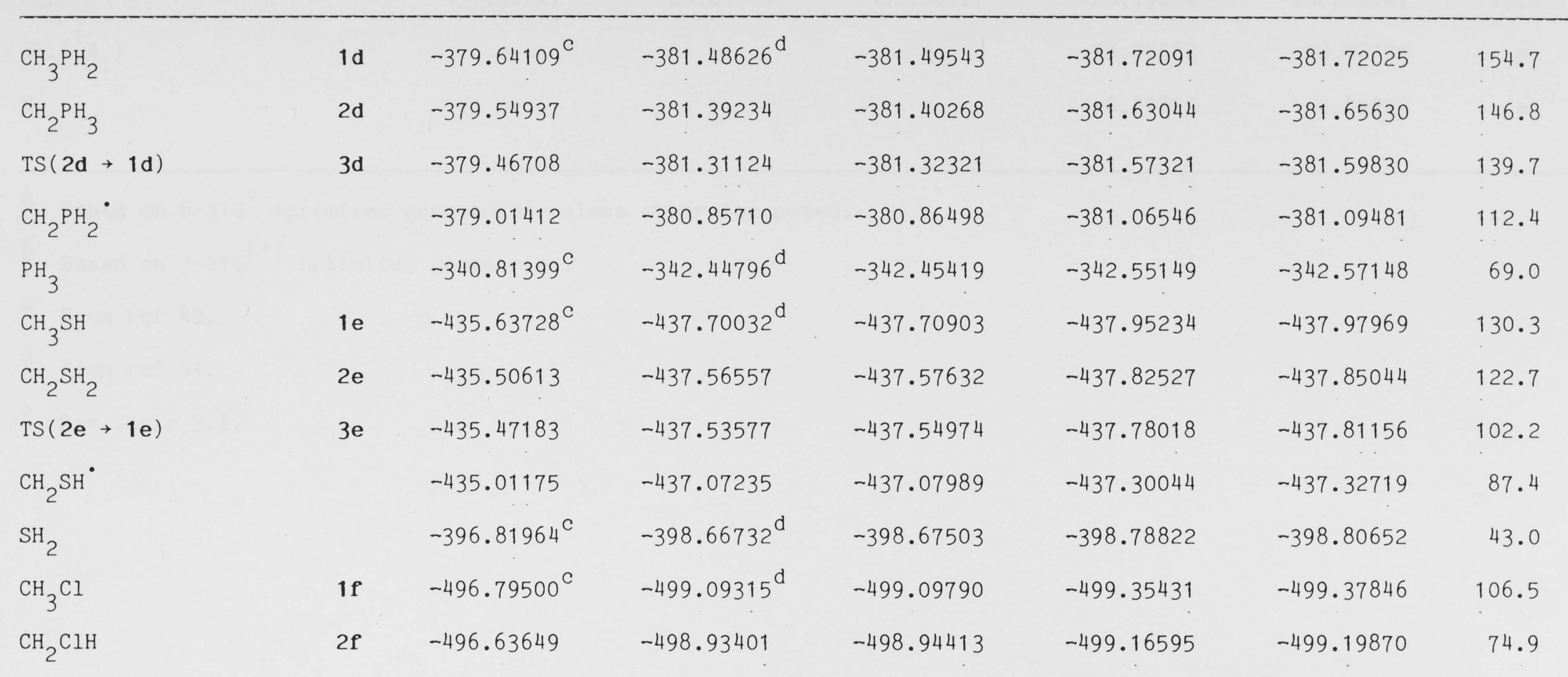




$\mathrm{H}_{2} \mathrm{CHCl}$
$\mathrm{TS}(2 \mathrm{f} \rightarrow \mathbf{f f})$
$\mathrm{TS}\left(2 \mathrm{f}^{\prime} \rightarrow \mathbf{1 f}\right)$
$\mathrm{CH}_{2} \mathrm{Cl}$
$\mathrm{ClH}^{\cdot}$
$\mathrm{CH}_{2}\left({ }^{1} \mathrm{~A}_{1}\right)$
$\mathrm{H}^{\bullet}$

$3 f$

-496.64785
-496.58301
-496.63879
-496.16429
$-457.98141^{c}$
$e$
$e$

-498.94395
-498.88369
-498.93401
-498.46108
$-460.05998^{d}$
$e$
$e$

$-498.95464$

\section{$-499.17666$}

$-499.20860$

75.9

e

e

$-498.89731$

$-499.15340$

$-499.17835$

79.0

$-498.94439$

$-499.17146$

$-499.20004$

70.6

$-498.46471$

$-498.69771$

$-498.72131$

62.5

$-460.06621$

$-460.19224$

$-460.20741$

18.8

e

$-38.96988$

$-38.98772$

e

$-0.49823$

$-0.49823$

e

a Based on $6-31 \mathrm{G}^{*}$ optimized geometries unless otherwise noted.

b Based on $3-21 \mathrm{G}^{(*)}$ optimized geometries.

c From ref 42 .

d From ref 41 .

e see Table 3.1 . 
Table 3.3 Calculated $^{\mathrm{a}}$ Relative Energies $\left(\mathrm{kJ} \mathrm{mol}^{-1}\right.$ ) for First-Row Ylides and Related Systems

$$
\mathrm{HF} / 3-21 \mathrm{G} \quad \mathrm{HF} / 6-31 \mathrm{G}^{*} \mathrm{HF} / 6-31 \mathrm{G}^{* *} \quad \mathrm{MP} 2 / 6-31 \mathrm{G}^{* *} \quad \mathrm{MP} 3 / 6-31 \mathrm{G}^{* *} \quad \mathrm{MP} 3 / 6-31 \mathrm{G}^{* * \mathrm{~b}}
$$

$\begin{array}{lcccccc}\mathrm{CH}_{3} \mathrm{NH}_{2} & 1 \mathbf{a} & 0 & 0 & 0 & 0 & 0 \\ \mathrm{CH}_{2} \mathrm{NH}_{3} & 2 \mathbf{a} & 278 & 308 & 303 & 310 & 308 \\ \mathrm{TS}(2 \mathbf{a} \rightarrow 1 \mathrm{a}) & 3 \mathbf{a} & 378 & 420 & 403 & 376 & 383 \\ \mathrm{CH}_{2} \mathrm{NH}_{2}+\mathrm{H} & & 321 & 328 & 330 & 408 & 413 \\ \mathrm{CH}_{2}+\mathrm{NH}_{3} & & 414 & 402 & 394 & 472 & 452\end{array}$

\begin{tabular}{|c|c|c|c|c|c|c|c|}
\hline $\mathrm{CH}_{3} \mathrm{OH}$ & $1 \mathrm{~b}$ & 0 & 0 & 0 & 0 & 0 & 0 \\
\hline $\mathrm{CH}_{2} \mathrm{OH}_{2}$ & $2 b$ & 336 & 364 & 351 & 397 & 384 & 372 \\
\hline $\operatorname{TS}(2 \mathrm{~b} \rightarrow 1 \mathrm{~b})$ & $3 b$ & 394 & 428 & 411 & 375 & 386 & 367 \\
\hline $\mathrm{CH}_{2} \mathrm{OH}^{\bullet}+\mathrm{H}^{\bullet}$ & & 336 & 337 & 340 & 419 & 424 & 387 \\
\hline $\mathrm{CH}_{2}+\mathrm{OH}_{2}$ & & 421 & 400 & 385 & 459 & 439 & 403 \\
\hline
\end{tabular}




$\begin{array}{llrrrrrr}\mathrm{CH}_{3} \mathrm{~F} & 1 \mathrm{c} & 0 & 0 & 0 & 0 & 0 & 0 \\ \mathrm{H}_{2} \mathrm{CHF} & 2 c^{\prime} & 391 & 372 & 354 & 417 & 400 & 376 \\ \mathrm{TS}\left(2 \mathrm{c}^{\prime} \rightarrow 1 \mathrm{c}\right) & 4 \mathrm{c} & 405 & 427 & 413 & 392 & 400 & 377 \\ \mathrm{CH}_{2}+\mathrm{FH} & & 446 & 418 & 432 & 467 & 448 & 412\end{array}$

a Based on the total energies in Table 3.1 .

b With zero-point vibrational energy correction. 
Table 3.4 Calculated $^{a}$ Relative Energies ( $\mathrm{JJ} \mathrm{mol}^{-1}$ ) for Second-Row Ylides and Related Systems

$$
\mathrm{HF} / 3-21 \mathrm{G}^{(*)} \mathrm{HF} / 6-31 \mathrm{G}^{*} \mathrm{HF} / 6-31 \mathrm{G}^{* *} \mathrm{MP} 2 / 6-31 \mathrm{G}^{*} \mathrm{MP} 3 / 6-31 \mathrm{G}^{*} \mathrm{MP}^{*} / 6-31 \mathrm{G}^{*{ }^{*} \mathrm{~b}} \mathrm{MP} 3 / 6-31 \mathrm{G}^{*{ }^{*} \mathrm{C}}
$$

\begin{tabular}{|c|c|c|c|c|c|c|c|}
\hline $\mathrm{CH}_{3} \mathrm{PH}_{2}$ & $1 \mathrm{~d}$ & 0 & 0 & 0 & 0 & 0 & 0 \\
\hline $\mathrm{CH}_{2} \mathrm{PH}_{3}$ & $2 d$ & 241 & 247 & 244 & 238 & 247 & 244 \\
\hline $\mathrm{TS}(2 \mathrm{~d} \rightarrow 1 \mathrm{~d})$ & $3 d$ & 457 & 460 & 452 & 388 & 399 & 392 \\
\hline $\mathrm{CH}_{2} \mathrm{PH}_{2}{ }^{\bullet}+\mathrm{H}^{\bullet}$ & & 343 & 344 & 347 & 413 & 413 & 416 \\
\hline $\mathrm{CH}_{2}+\mathrm{PH}_{3}$ & & 460 & 436 & 433 & 524 & 502 & 499 \\
\hline
\end{tabular}

\begin{tabular}{|c|c|c|c|c|c|c|c|c|}
\hline $\mathrm{CH}_{3} \mathrm{SH}$ & $1 \mathrm{e}$ & 0 & 0 & 0 & 0 & 0 & 0 & 0 \\
\hline $\mathrm{CH}_{2} \mathrm{SH}_{2}$ & $2 e$ & 344 & 354 & 348 & 334 & 339 & 334 & 327 \\
\hline $\operatorname{TS}(2 e+1 e)$ & $3 e$ & 434 & 432 & 418 & 452 & 441 & 428 & 402 \\
\hline $\mathrm{CH}_{2} \mathrm{SH}^{\bullet}+\mathrm{H}^{\bullet}$ & & 340 & 341 & 344 & 403 & 405 & 408 & \\
\hline $\mathrm{CH}_{2}+\mathrm{SH}_{2}$ & & 435 & 422 & 414 & 510 & 487 & 479 & \\
\hline
\end{tabular}




$$
\begin{aligned}
& \mathrm{CH}_{3} \mathrm{Cl} \\
& \mathrm{CH}_{2} \mathrm{ClH} \\
& \mathrm{H}_{2} \mathrm{CHCl} \\
& \mathrm{TS}(2 \mathrm{f} \rightarrow 1 \mathbf{f}) \\
& \mathrm{TS}\left(2 \mathrm{f}^{\prime} \rightarrow \mathbf{f}\right) \\
& \mathrm{CH}_{2} \mathrm{Cl}^{\circ}+\mathrm{H}^{\cdot} \\
& \mathrm{CH}_{2}+\mathrm{ClH}
\end{aligned}
$$

$\begin{array}{lr}\text { 1f } & 0 \\ \text { 2f } & 416 \\ \text { 2f' } & 386 \\ 3 f & 557 \\ \text { 4f } & 410 \\ & 353 \\ & 425\end{array}$

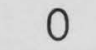

418

392

550

418

351

422
0

404

376

527

403

354

408
0

495

466

527

480

416

505
0

472

446

525

468

417

481
0

429

403

477

421

381

430

a Based on the total energies in Table 3.2 .

b Estimated using the additivity approximation of equation (1.16).

c MP $3 / 6-31 G^{* *}$ value with zero-point vibrational energy correction. 
Table 3.5 Higher-Level Calculations: Total Energies ${ }^{a}$ (hartrees)

\begin{tabular}{|c|c|c|c|c|c|c|}
\hline & & $\mathrm{MP} 2 / 6-31 \mathrm{G}^{*} \mathrm{~b}$ & $\mathrm{MP} 2 / 6-31 \mathrm{G}^{* *}$ & $M P 2 / 6-311 G(\underline{d f}, \underline{p})^{C}$ & $\mathrm{MP} 3 / 6-31 \mathrm{G}^{* *}$ & $\mathrm{MP} 4 / 6-31 \mathrm{G}^{* *}$ \\
\hline $\mathrm{CH}_{3} \mathrm{NH}_{2}$ & $1 \mathrm{a}$ & -95.51444 & -95.55020 & -95.61814 & -95.57408 & -95.58576 \\
\hline $\mathrm{CH}_{2} \mathrm{NH}_{3}$ & $2 a$ & $-95.39591^{d}$ & -95.43273 & -95.51036 & -95.45699 & -95.46956 \\
\hline $\mathrm{NH}_{3}$ & & $-56 \cdot 35738$ & -56.38315 & -56.42551 & -56.39590 & -56.40138 \\
\hline $\mathrm{CH}_{3} \mathrm{OH}$ & $1 \mathrm{~b}$ & $-115 \cdot 35329$ & $-115 \cdot 38191^{e}$ & -115.47168 & $-115.39939^{\mathrm{e}}$ & -115.41170 \\
\hline $\mathrm{CH}_{2} \mathrm{OH}_{2}$ & $2 b$ & $-115.20329^{d}$ & $-115.23560^{f}$ & -115.33007 & $-115.25510^{f}$ & -115.26944 \\
\hline $\mathrm{TS}(2 \mathrm{~b} \rightarrow 1 \mathrm{~b})$ & $3 b$ & $-115 \cdot 19829$ & -115.23237 & $-115 \cdot 32515$ & -115.24943 & -115.26618 \\
\hline $\mathrm{OH}_{2}$ & & $-76.19924^{e}$ & $-76.21967^{e}$ & -76.28375 & $-76.22589^{e}$ & $-76.23114^{\mathrm{e}}$ \\
\hline $\mathrm{CH}_{3} \mathrm{~F}$ & $1 \mathrm{c}$ & $-139 \cdot 34265$ & $-139 \cdot 36006$ & -139.47759 & $-139 \cdot 37340$ & $-139 \cdot 38658$ \\
\hline $\mathrm{H}_{2} \mathrm{CHF}$ & $2 c^{\prime}$ & $-139.17846^{d}$ & -139.20085 & $-139 \cdot 32120$ & -139.22049 & -139.23103 \\
\hline $\operatorname{TS}\left(2 c^{\prime} \rightarrow 1 c\right)$ & $4 c$ & $-139 \cdot 17654$ & $-139 \cdot 19912$ & $-139 \cdot 31897$ & $-139 \cdot 21784$ & -139.22954 \\
\hline $\mathrm{FH}$ & & $-100 \cdot 18416$ & $-100.19446^{e}$ & -100.28916 & $-100.19613^{e}$ & $-100 \cdot 20124^{e}$ \\
\hline $\mathrm{CH}_{3} \mathrm{PH}_{2}$ & $1 d$ & -381.73689 & -381.76370 & -381.79774 & -381.79553 & -381.80730 \\
\hline $\mathrm{CH}_{2} \mathrm{PH}_{3}$ & $2 d$ & -381.64696 & -381.67483 & -381.71292 & -381.70341 & -381.71656 \\
\hline $\mathrm{PH}_{3}$ & & -342.56226 & -342.57849 & -342.59722 & -342.59993 & -342.60602 \\
\hline
\end{tabular}




\begin{tabular}{|c|c|c|c|c|c|c|}
\hline $\mathrm{CH}_{3} \mathrm{SH}$ & $1 e$ & -437.96788 & -437.98771 & -438.02759 & -438.01681 & -438.02795 \\
\hline $\mathrm{CH}_{2} \mathrm{SH}_{2}$ & $2 e$ & -437.84171 & -437.86352 & -437.90741 & -437.89022 & -437.90364 \\
\hline $\mathrm{SH}_{2}$ & & -398.79870 & -398.81000 & -398.83427 & -398.82882 & -398.83379 \\
\hline $\mathrm{CH}_{3} \mathrm{Cl}$ & $1 \mathrm{f}$ & -499.36908 & $-499 \cdot 37818$ & -499.42286 & -499.40388 & -499.41371 \\
\hline $\mathrm{CH}_{2} \mathrm{ClH}$ & $2 f$ & $-499.18819^{d}$ & -499.20120 & -499.24934 & -499.22524 & -499.24032 \\
\hline $\mathrm{H}_{2} \mathrm{CHCl}$ & $2 f^{\prime}$ & $-499.19117^{d}$ & -499.20743 & -499.24645 & -499.24029 & -499.24894 \\
\hline $\operatorname{TS}(\mathbf{2 f} \rightarrow \mathbf{1 f})$ & $3 \mathrm{f}$ & -499.16343 & -499.18258 & -499.22610 & -499.21067 & -499.22372 \\
\hline $\operatorname{TS}\left(2 f^{\prime} \rightarrow 1 f\right)$ & $4 f$ & -499.18855 & -499.20538 & -499.24499 & -499.23712 & -499.24640 \\
\hline $\mathrm{ClH}$ & & $-460.20215^{\mathrm{e}}$ & -460.20537 & -460.23434 & -460.22059 & -460.22390 \\
\hline $\mathrm{CH}_{2}\left({ }^{1} \mathrm{~A}_{1}\right)$ & & $-38.97401^{e}$ & $-38.98717^{e}$ & $-39.01423^{g}$ & $-39.00629^{\mathrm{e}}$ & -39.01196 \\
\hline
\end{tabular}

a Based on $\mathrm{MP} 2 / 6-31 \mathrm{G}^{*}$ optimized geometries.

b Full range of molecular orbitals used for correlation.

c For second-row systems, the underlying $6-31 G(\underline{d f}, \underline{p})$ basis set was used.

d $M P 2 / 6-31 \mathrm{G}^{*} / / \mathrm{MP} 2 / 6-31 \mathrm{G}^{*}$ zero-point vibrational energies are $170.4\left(\mathrm{CH}_{2} \mathrm{NH}_{3}\right), 127.2\left(\mathrm{CH}_{2} \mathrm{OH}_{2}\right), 82.6\left(\mathrm{H}_{2} \mathrm{CHF}\right), 83.0$ $\left(\mathrm{CH}_{2} \mathrm{ClH}\right)$ and $74.1\left(\mathrm{H}_{2} \mathrm{CHCl}\right) \mathrm{KJ} \mathrm{mol}^{-1}$.

e From ref 144 .

f From ref 135 .

8 For second-row energy comparisons, the MP2/6-31G( $\underline{d f}, \underline{p})$ value is -38.99691 hartrees. 
Table 3.6 Higher-Level Calculations: Relative Energies ${ }^{a}$ ( $k \mathrm{~J} \mathrm{~mol}^{-1}$ )

$M P 2 / 6-31 G^{*} \quad M P 2 / 6-31 G^{* *} M P 2 / 6-311 G(\underline{d f}, \underline{p})^{b} \quad M P 3 / 6-31 G^{* *} M P 4 / 6-31 G^{* *} \quad M P 4 / 6-311 G(\underline{d f}, \underline{p})^{b, c} \quad M P 4 / 6-311 G(\underline{d f}, \underline{p})^{d}$

\begin{tabular}{|c|c|c|c|c|c|c|c|c|}
\hline $\mathrm{CH}_{3} \mathrm{NH}_{2}$ & $1 \mathrm{a}$ & 0 & 0 & 0 & 0 & 0 & 0 & 0 \\
\hline $\mathrm{CH}_{2} \mathrm{NH}_{3}$ & $2 a$ & 311 & 308 & 283 & 307 & 305 & 280 & $277^{\mathrm{e}}$ \\
\hline $\mathrm{CH}_{2}+\mathrm{NH}_{3}$ & & 481 & 472 & 468 & 451 & 453 & 449 & 415 \\
\hline
\end{tabular}

\begin{tabular}{|c|c|c|c|c|c|c|c|c|}
\hline $\mathrm{CH}_{3} \mathrm{OH}$ & $1 \mathrm{~b}$ & 0 & 0 & 0 & 0 & 0 & 0 & 0 \\
\hline $\mathrm{CH}_{2} \mathrm{OH}_{2}$ & $2 b$ & 394 & 384 & 372 & 379 & 373 & 361 & $351^{e}$ \\
\hline $\operatorname{TS}(2 b \rightarrow 1 b)$ & $3 b$ & 407 & 393 & 385 & 394 & 382 & 374 & 355 \\
\hline $\mathrm{CH}_{2}+\mathrm{OH}_{2}$ & & 473 & 460 & 456 & 439 & 443 & 439 & 403 \\
\hline
\end{tabular}

$\begin{array}{lllll}\mathrm{CH}_{3} \mathrm{~F} & 1 \mathrm{c} & 0 & 0 & 0\end{array}$

$\mathrm{H}_{2} \mathrm{CHF} \quad 2 c^{\prime} \quad 431 \quad 418 \quad 411$

$\operatorname{TS}\left(2 c^{\prime} \rightarrow 1 c\right) 4 c \quad 436 \quad 423 \quad 416$

$\begin{array}{llll}\mathrm{CH}_{2}+\mathrm{FH} & 484 & 468\end{array}$

0

0

0

$401408401 \quad 378^{e}$

408

412

406

384

$449 \quad 455 \quad 444$

408 


$\mathrm{CH}_{3} \mathrm{PH}_{2}$

$1 \mathrm{~d} \quad 0$

0

$\mathrm{CH}_{2}+\mathrm{PH}_{3}$

$\mathrm{CH}_{2}+\mathrm{SH}_{2}$

$\begin{array}{lllll}\mathrm{CH}_{3} \mathrm{Cl} & \text { 1f } & 0 & 0 & 0 \\ \mathrm{CH}_{2} \mathrm{ClH} & 2 \mathbf{f} & 475 & 465 & 456 \\ \mathrm{H}_{2} \mathrm{CHCl} & 2 \mathbf{f}^{\prime} & 467 & 448 & 463 \\ \mathrm{TS}(2 \mathbf{f} \rightarrow 1 \mathbf{f}) & 3 \mathbf{f} & 540 & 514 & 517 \\ \mathrm{TS}\left(2 \mathbf{f}^{\prime} \rightarrow 1 \mathbf{f}\right) & 4 \mathbf{f} & 474 & 454 & 467 \\ \mathrm{CH}_{2}+\mathrm{ClH} & & 507 & 487 & 503\end{array}$

$\begin{array}{cc}0 & 0 \\ 469 & 455 \\ 429 & 433 \\ 507 & 499 \\ 438 & 439 \\ 465 & 467\end{array}$

0
446
447
502
453
483

0
$427^{e}$
$421^{e}$
477
420
445

a Based on the total energies in Table 3.5 .

b For second-row systems, the underlying $6-31 G(\underline{d f}, \underline{p})$ basis set was used. 


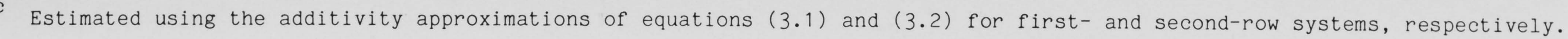
d MP4/6-311G( $(\underline{\mathrm{d}}, \underline{\mathrm{p}})$ or MP4/6-31G( $\underline{\mathrm{df}}, \underline{\mathrm{p}})$ value with zero-point vibrational energy correction.

e MP2/6-31G ${ }^{*}$ ZPVE used (after scaling by 0.93 , refs 60 and 61 ). 
a

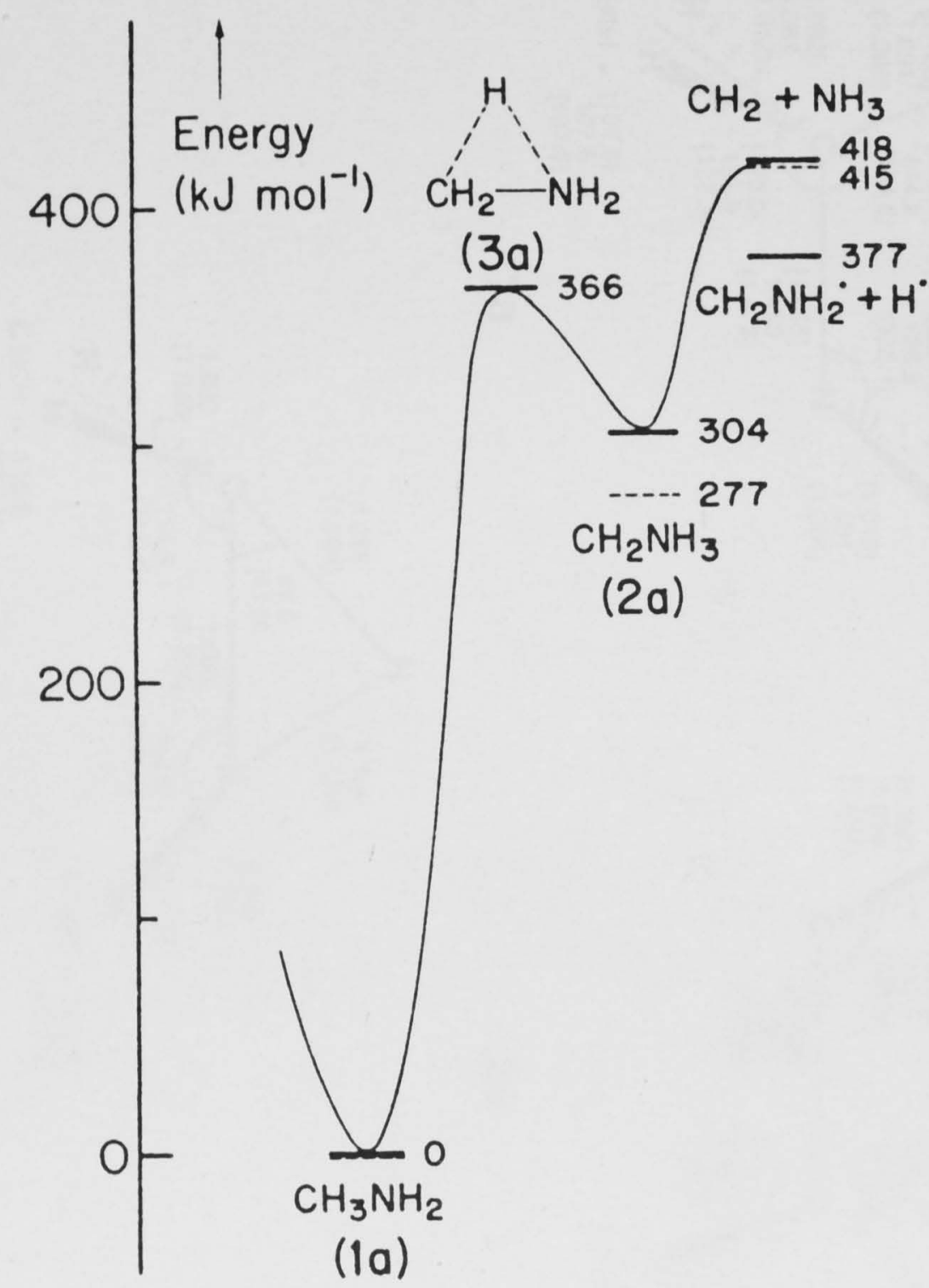

b

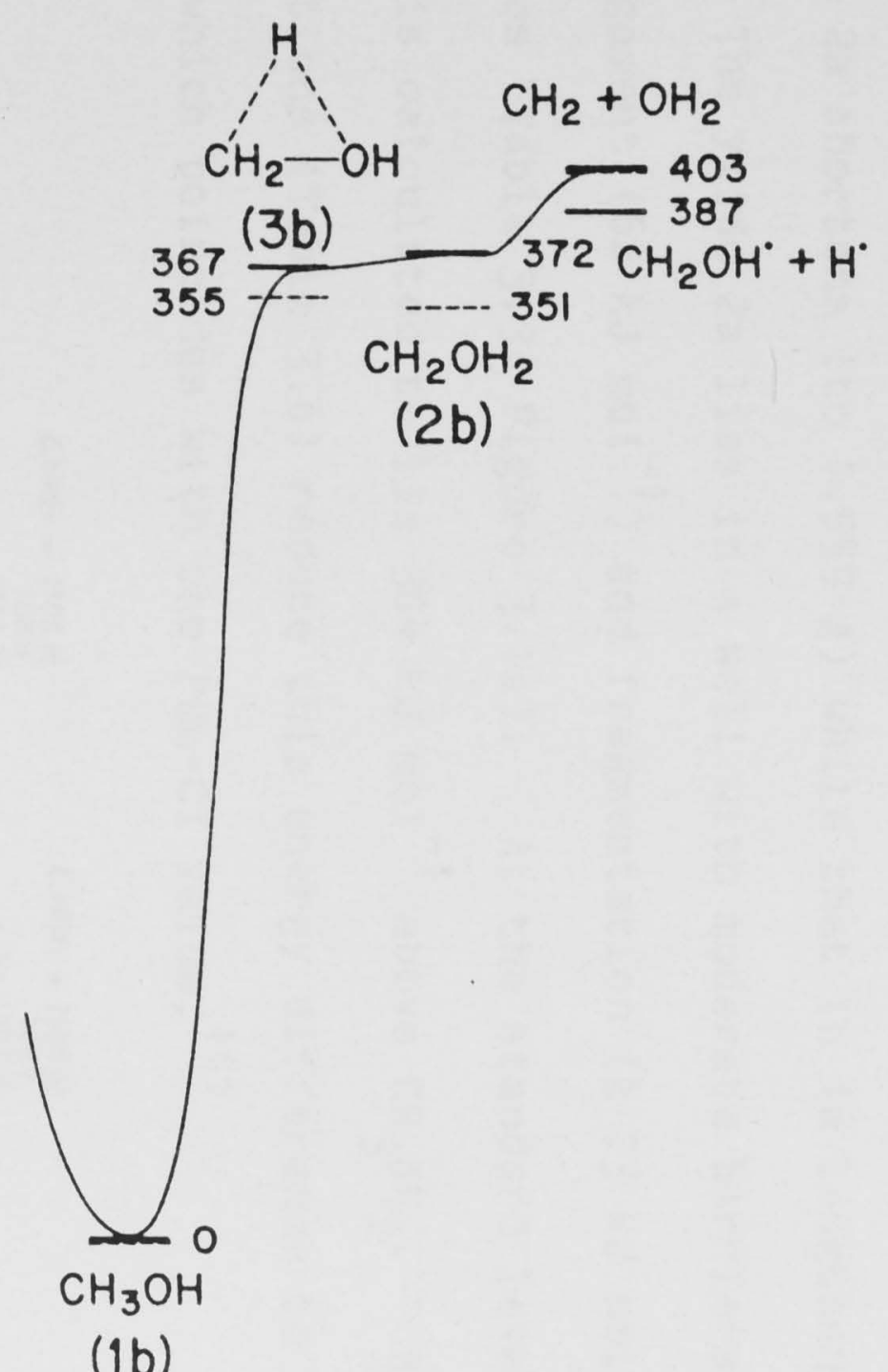

C

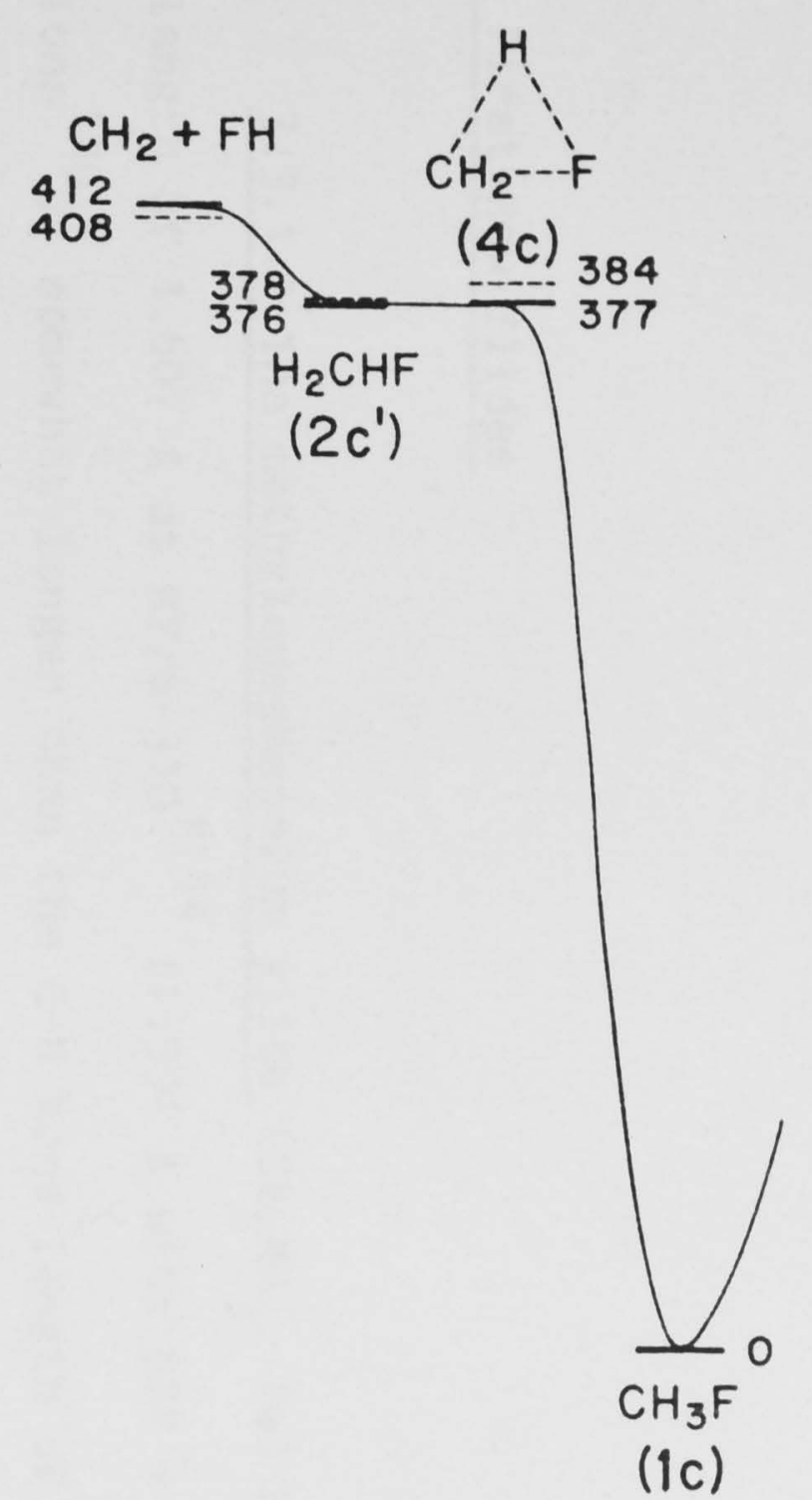

Figure 3.1 Schematic energy profiles for rearrangement and fragmentation processes of the first-row neutral ylides based on the highest-level results in Table 3.3 ( - ) and Table $3.6(-\cdots)$. 


\subsection{Discussion}

\subsubsection{First-Row Ylides}

\subsubsection{The methyleneammonium ylide $\left(\mathrm{CH}_{2} \mathrm{NH}_{3}, 2 \mathrm{a}\right)$ has a $\mathrm{C}-\mathrm{N}$} bond length of $1.607 \AA$ at $\mathrm{HF} / 6-31 \mathrm{G}^{* 144}(1.591 \AA$ with DZP + diffuse functions ${ }^{140}$ ), somewhat longer than the $\mathrm{C}-\mathrm{N}$ bond length of $1.453 \AA$ in methylamine 144 (1a). At the MP $2 / 6-31 \mathrm{G}^{*}$ level, the length of the $\mathrm{C}-\mathrm{N}$ bond in $2 \mathrm{a}$ shortens (to 1.559 \&) while that in 1a lengthens (to 1.465 $\left.\AA^{144}\right)$. The ylide $2 a$ lies in a well with moderate barriers to rearrangement ( $62 \mathrm{~kJ} \mathrm{~mol}^{-1}$ ) and fragmentation ( $\geqq 73 \mathrm{~kJ} \mathrm{~mol}^{-1}$ ) processes (Table 3.3, Figure 3.1a). At the standard level of theory, $\mathrm{CH}_{2} \mathrm{NH}_{3}$ is calculated to lie $304 \mathrm{~kJ} \mathrm{~mol}^{-1}$ above $\mathrm{CH}_{3} \mathrm{NH}_{2}$. Higher-level calculations (Table 3.6 ) reduce this energy difference to $277 \mathrm{~kJ}$ $\mathrm{mol}^{-1}$, which coincides with the POL-CI value. ${ }^{141}$

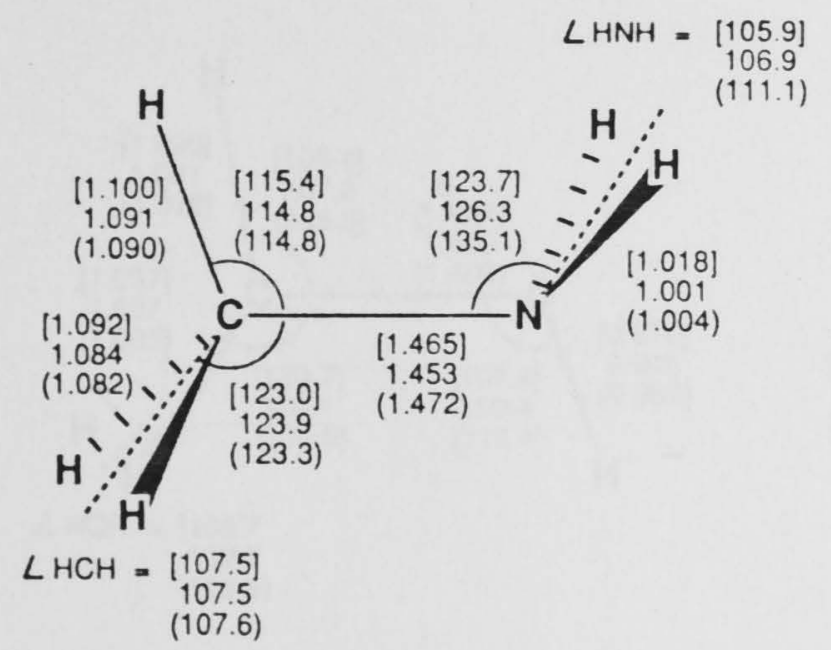

$1 \mathrm{a}$

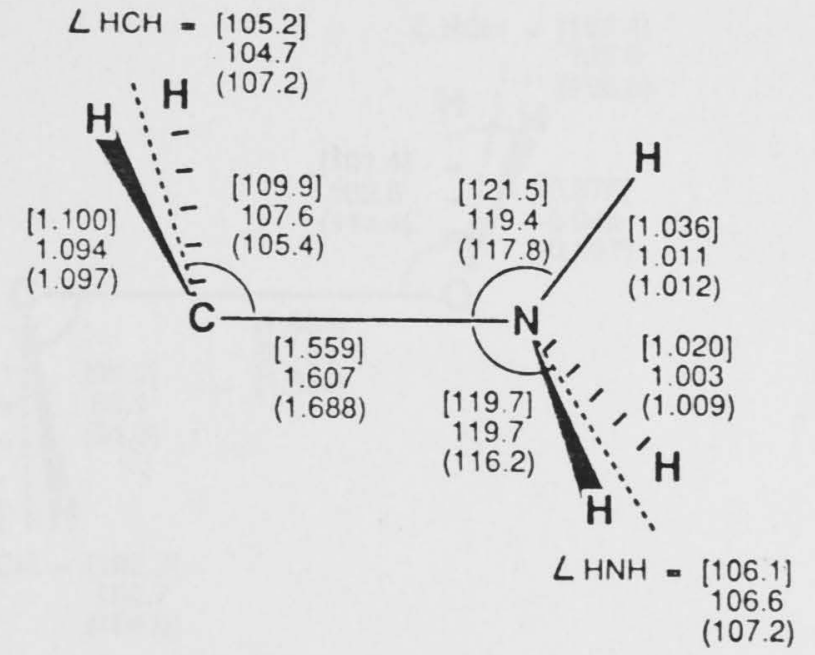

$2 a$

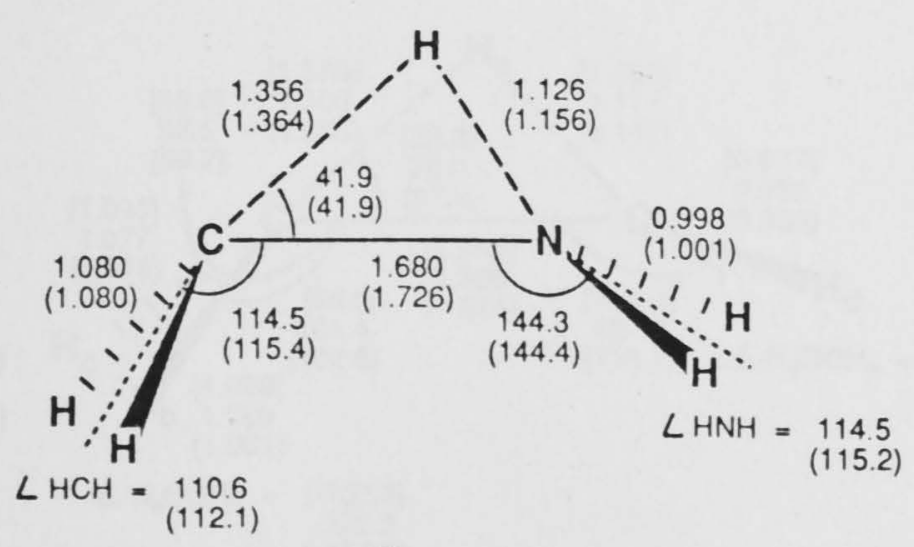


3.3.1.2 The methyleneoxonium ylide $\left(\mathrm{CH}_{2} \mathrm{OH}_{2}, 2 \mathrm{~b}\right)$ is calculated to be a minimum on the $\mathrm{HF} / 6-31 \mathrm{G}^{*}$ potential energy surface and has a $\underline{\mathrm{C}}_{\underline{\mathbf{S}}}$ structure with an anti arrangement of the hydrogen atoms. Eades et al. ${ }^{140}$ found that a $\underline{C}_{1}$ structure was $5 \mathrm{~kJ} \mathrm{~mol}^{-1}$ more stable at the SCF level, but in the present work optimization of this conformation at various levels of theory (including MP2/6-31G*) leads to a return to the $\underline{\mathrm{C}}_{\underline{S}}$ structure, $2 \mathrm{~b}$. The ylide $2 \mathrm{~b}$ has a long $\mathrm{C}-\mathrm{O}$ bond at $\mathrm{HF} / 6-31 \mathrm{G}$ * $(2.138 \AA \text { \& compared with the } \mathrm{C}-\mathrm{O} \text { bond of } 1.400 \AA \text { in methanol })^{144}$ and at the standard level of theory lies $372 \mathrm{~kJ} \mathrm{~mol}^{-1}$ above $\mathrm{CH}_{3} \mathrm{OH}$ (Figure 3.1b). Harding et al. ${ }^{135}$ found that the $\mathrm{C}-0$ bond length in $2 \mathrm{~b}$ is reduced significantly in the $M P 2 / 6-31 \mathrm{G}^{*}$ optimized structure to $1.805 \mathrm{~A}$ (which is close to the DZP + diffuse functions value of $1.825 \AA^{140}$ ). The higher-level calculations based on MP2/631G* geometries (Table 3.6) reveal, however, only a small consequential lowering in the relative energy of the ylide to $351 \mathrm{~kJ} \mathrm{~mol}^{-1}$, which may be compared with the POL-CI value of $388 \mathrm{~kJ} \mathrm{~mol}^{-1}$.

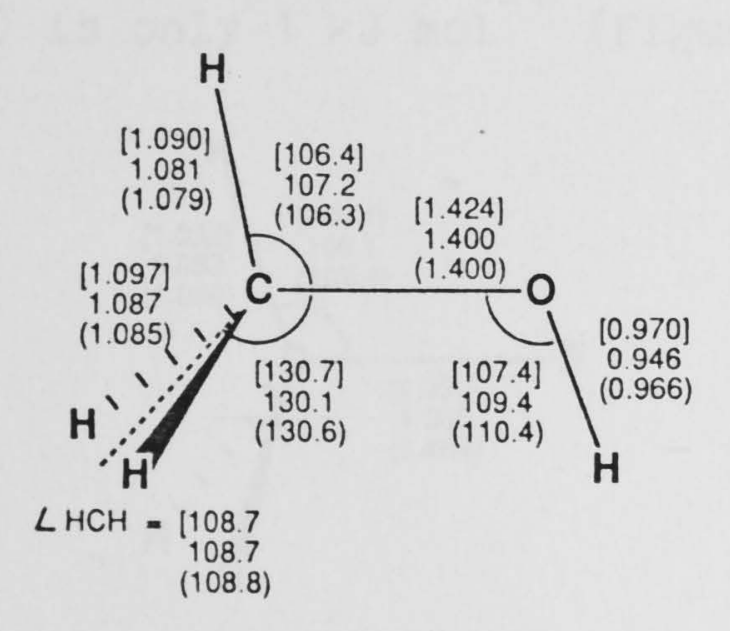

1b

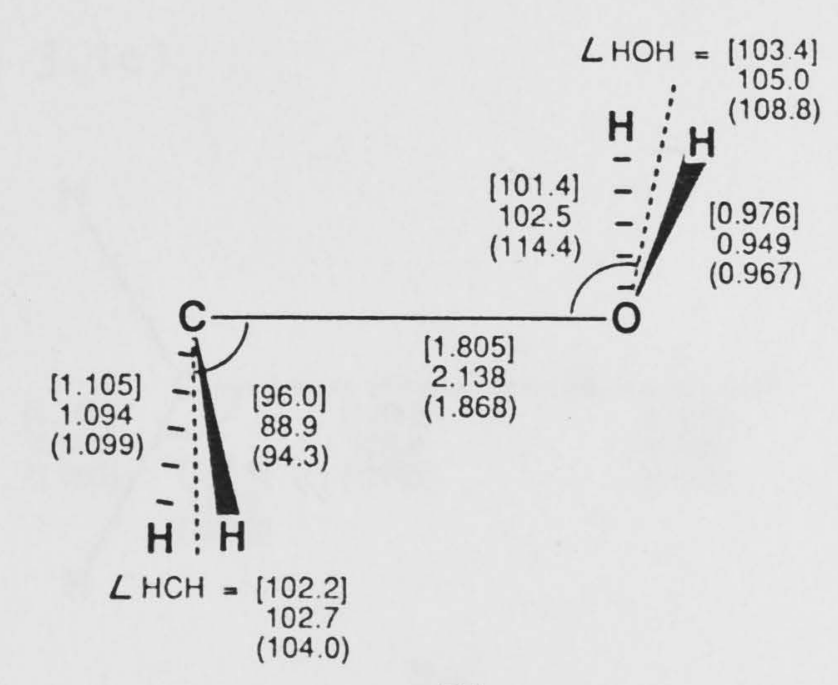

$2 b$

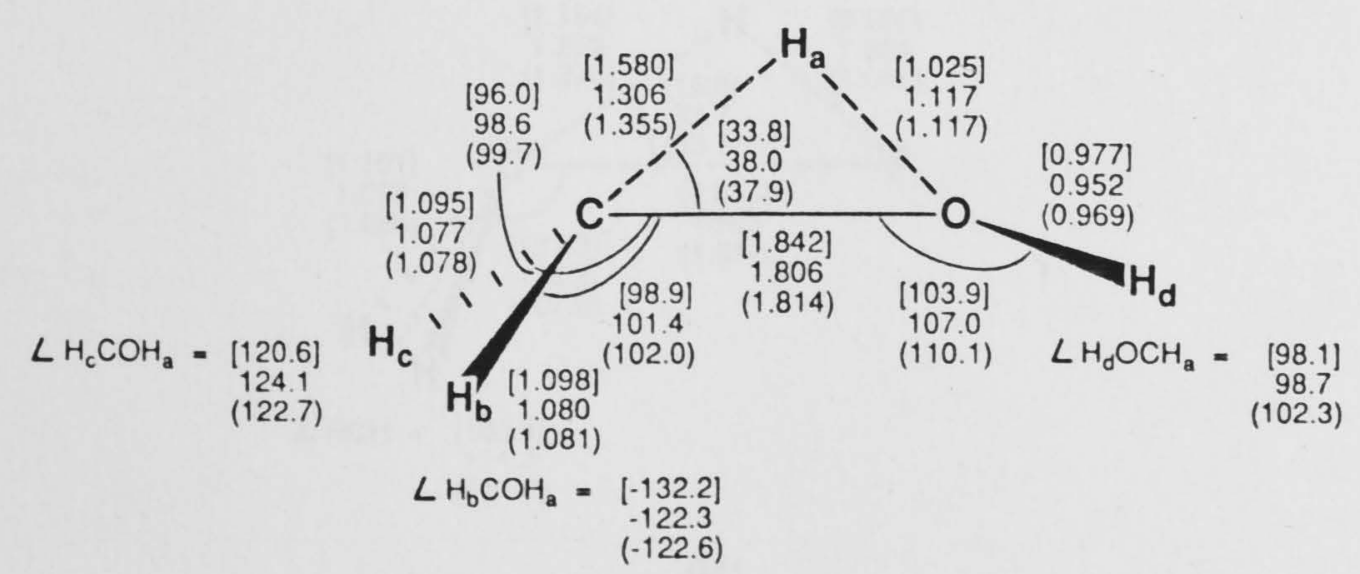


56.

Although $\mathrm{CH}_{2} \mathrm{OH}_{2}$ corresponds to a minimum on the $\mathrm{HF} / 6-31 \mathrm{G}^{*}$ surface, the barrier for rearrangement ( $v i a 3 b$ ) disappears when single-point calculations that include electron correlation are carried out (Table 3.3 and ref 142). At the highest level in Table 3.6, a barrier for rearrangement is again found, but it is only $4 \mathrm{~kJ} \mathrm{~mol}^{-1}$.

\subsubsection{The methylenefluoronium ylide $\left(\mathrm{CH}_{2} \mathrm{FH}\right)$ is found to be} unstable at $\mathrm{HF} / 6-31 \mathrm{G}^{*}$ and $\mathrm{MP} 2 / 6-31 \mathrm{G}^{*}$, rearranging without a barrier to the much lower energy isomer fluoromethane (1c). An ylide-like structure with $\underline{\mathrm{C}}_{\underline{s}}$ symmetry was found at $\mathrm{HF} / 6-31 \mathrm{G}^{*}$ and $\mathrm{MP} 2 / 6-31 \mathrm{G}^{*}$ (with C-F bond lengths of 2.514 and $2.207 \AA$, respectively) but vibrational frequency calculations show that this corresponds to a saddle point on both surfaces. Another possible minimum on the surface was investigated by Pople et al., ${ }^{142}$ corresponding to a hydrogen-bonded complex $\mathrm{H}_{2} \mathrm{C}$...HF with $\underline{\mathrm{C}}_{2 \underline{v}}$ symmetry $\left(2 \mathrm{c}^{\prime}\right)$. However, the barrier separating this structure from rearrangement (via 4c) to fluoromethane (1c) is only $1 \mathrm{~kJ} \mathrm{~mol}^{-1}$ (Figure 3.1c).

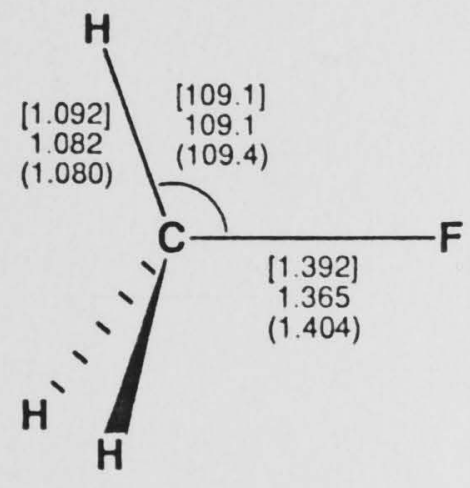

1c

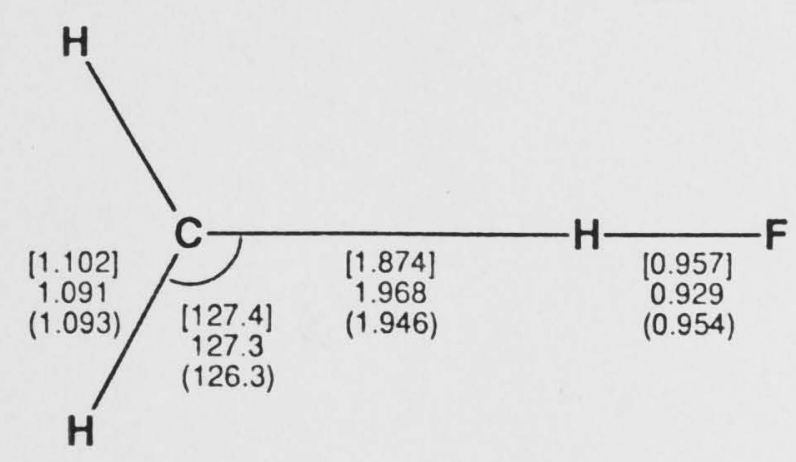

$2 c^{\prime}$

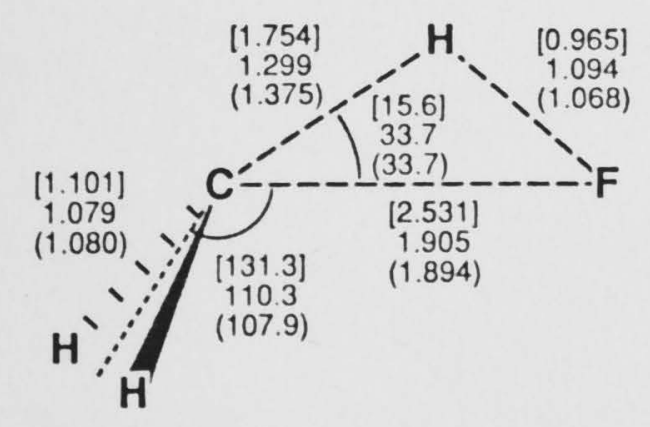

$\angle \mathrm{HCH}=[105.4]$

$(111.6)$

$4 c$ 
Single-point MP4 calculations on $4 c^{142}$ lower the 'barrier' by $30 \mathrm{~kJ}$ $\mathrm{mol}^{-1}$, with nearly half of this lowering coming from the triple substitutions in the correlation method (see column five, Table II of ref 142). MP2 optimizations and higher-level single-point calculations have little effect on the relative energy of $2 c^{\prime}$ (Table 3.6). At the highest level in Table 3.6, a barrier for rearrangement is again found, but it is only $6 \mathrm{~kJ} \mathrm{~mol}^{-1}$. 


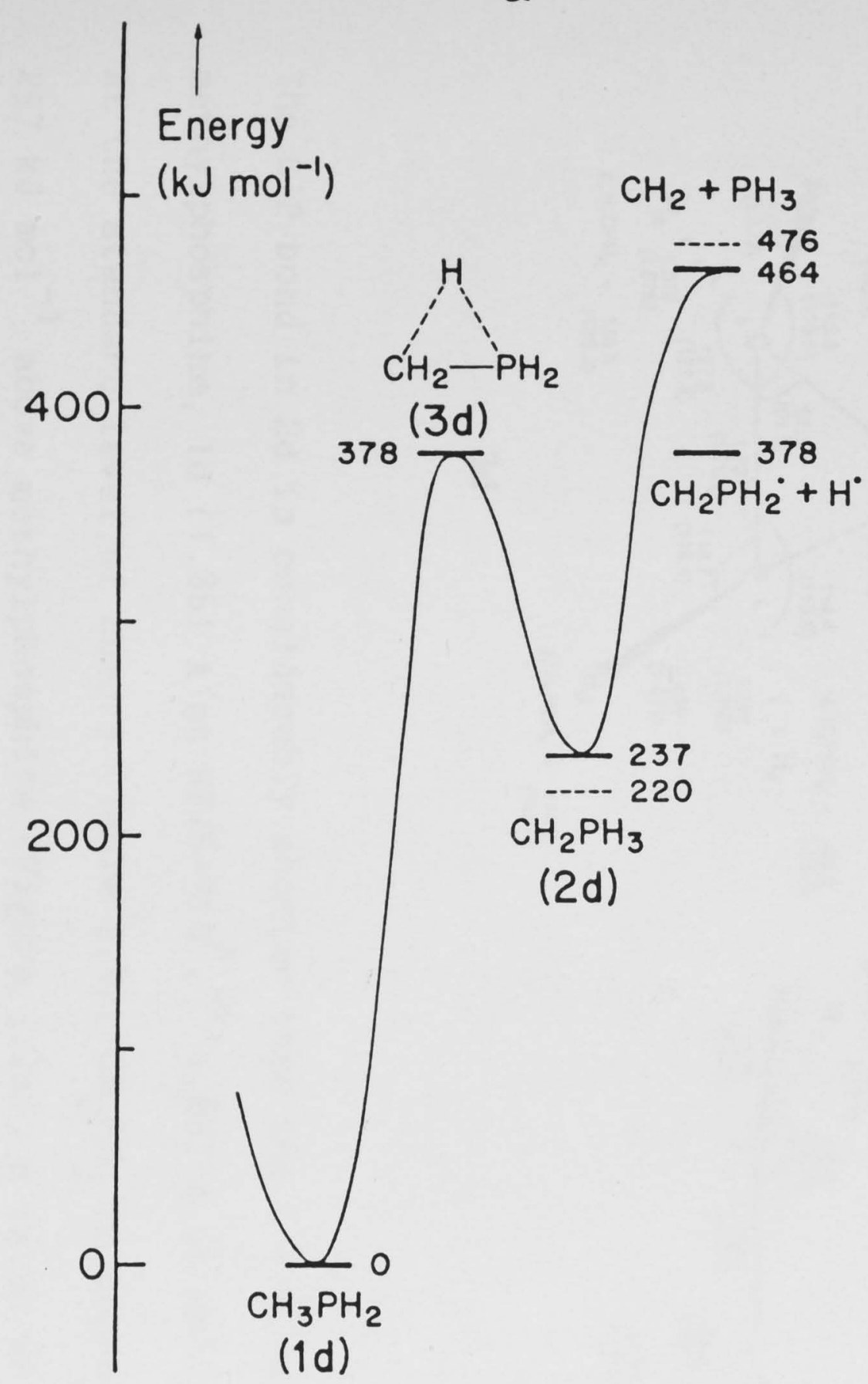

b

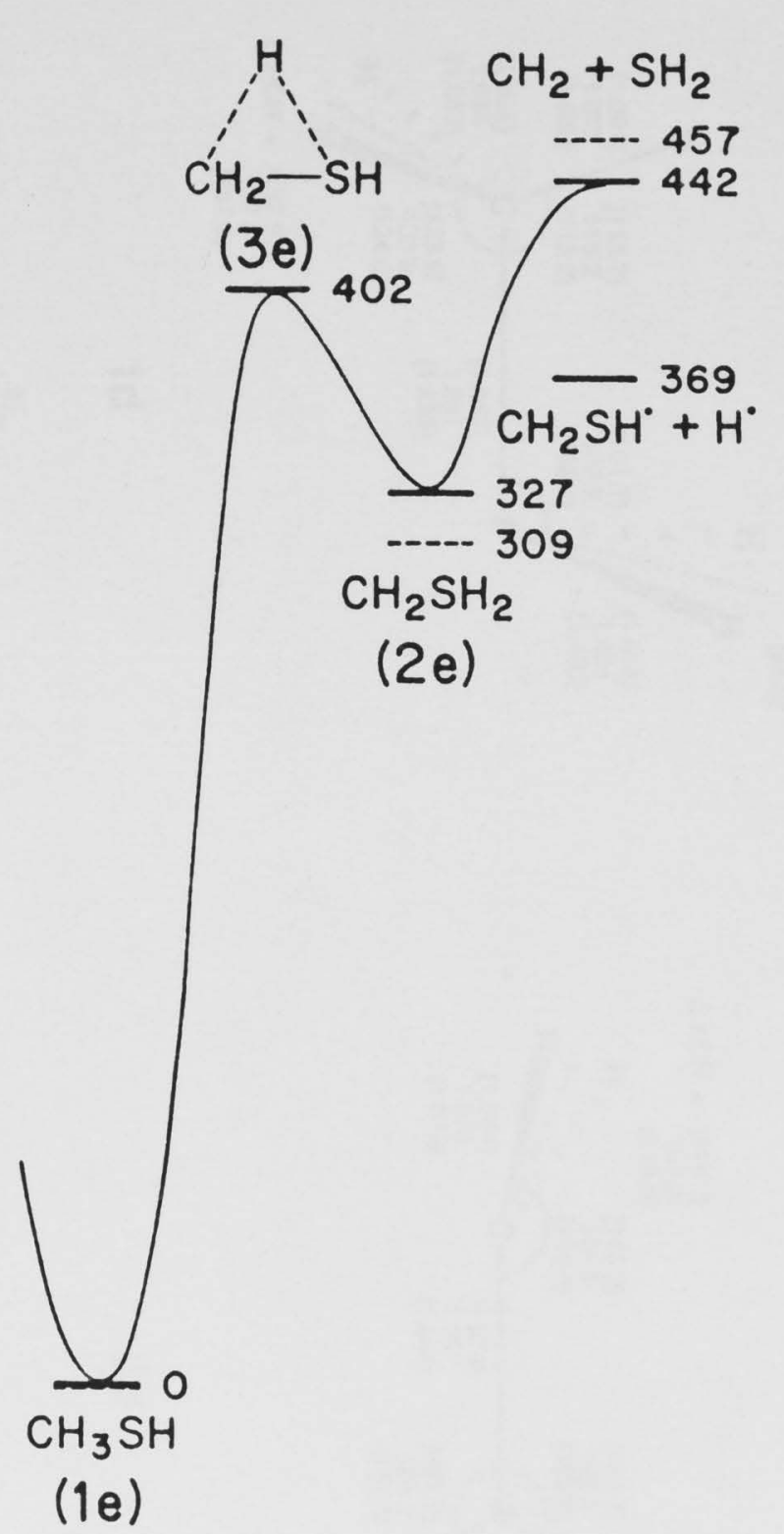

C

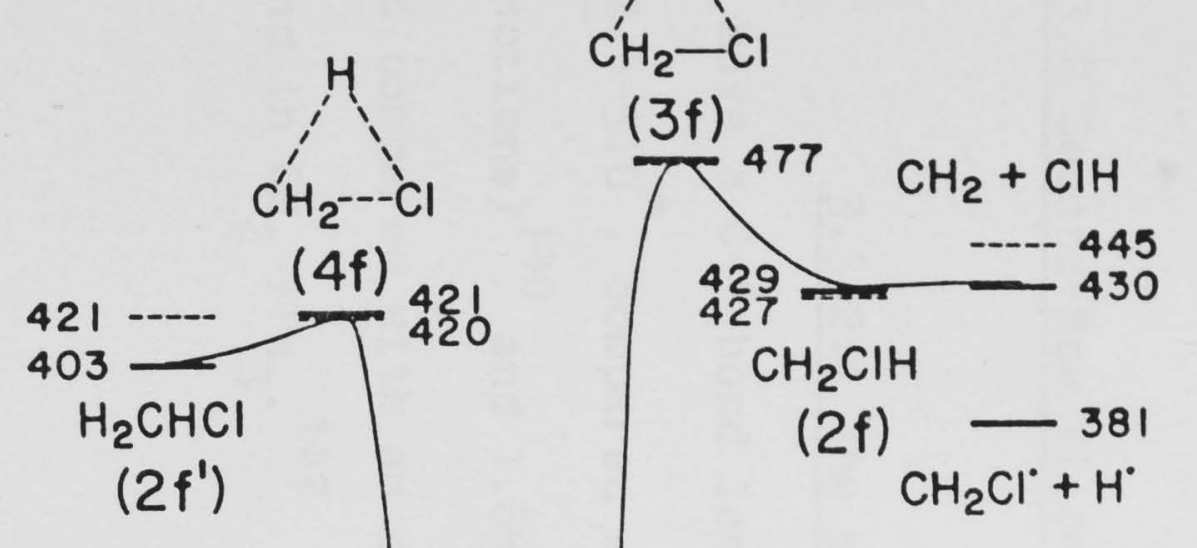

Figure 3.2 Schematic energy profiles for rearrangement and fragmentation processes of the second-row neutral ylides based on the highest-level results in Table 3.4 ( - a) and Table $3.6(\sim-)$. 


\subsubsection{Second-Row Ylides}

\subsubsection{The methylenephosphonium ylide $\left(\mathrm{CH}_{2} \mathrm{PH}_{3}, 2 \mathrm{~d}\right)$ is found} to have a C-P bond length of $1.667 \AA$ at $\mathrm{HF} / 6-31 \mathrm{G}^{*}$ and $1.674 \AA$ at MP2 $/ 6-31 \mathrm{G}^{*}$, compared with values of 1.668 \& (DZP + diffuse functions $)^{140}$ and $1.652 \AA\left(4-31 G^{*}\right)^{137}$ from other theoretical studies, and compared with an experimental value of $1.661 \AA$ for the unique $C-P$ bond in $\mathrm{CH}_{2}-\mathrm{PPh}_{3} \cdot 147$

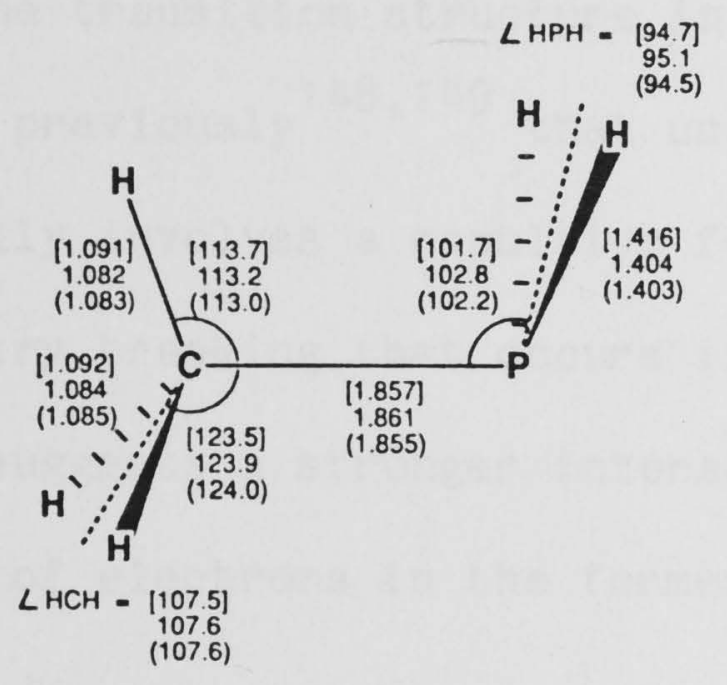

$1 d$

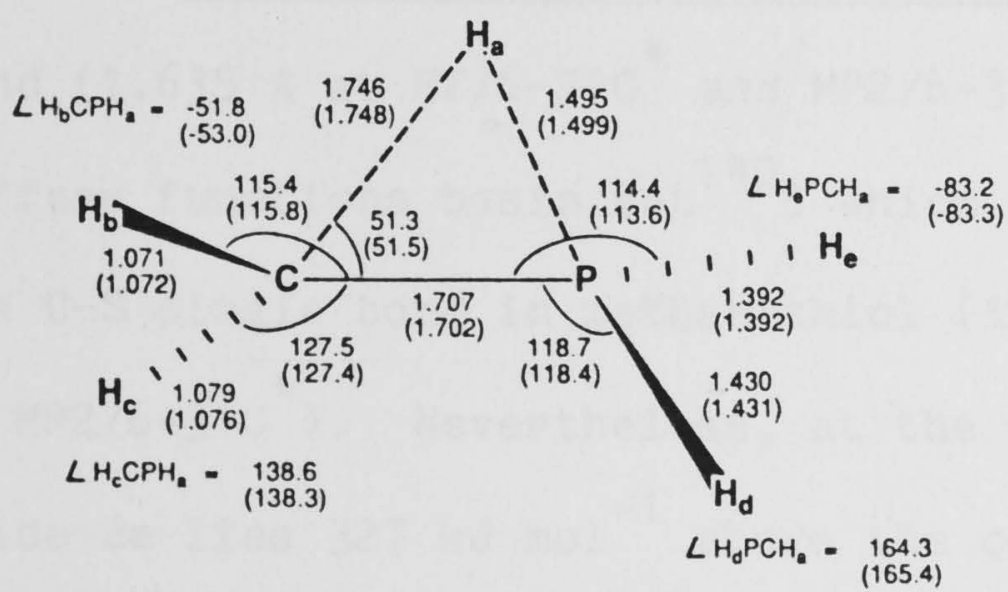

$3 d$

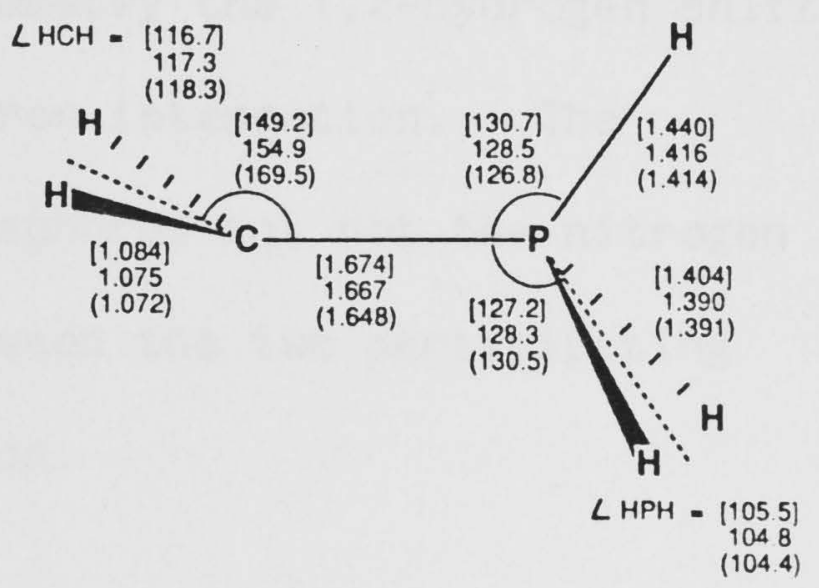

2d

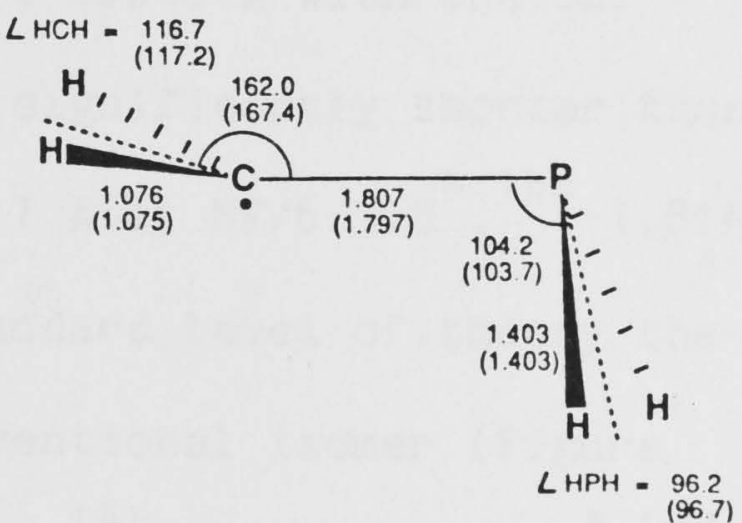

The $\mathrm{C}-\mathrm{P}$ bond in $2 \mathrm{~d}$ is considerably shorter than the $\mathrm{C}-\mathrm{P}$ single bond of methylphosphine, $1 \mathrm{~d}\left(1.861\right.$ \& at $\mathrm{HF} / 6-31 \mathrm{G}^{*}, 411.857 \AA$ at $\left.\mathrm{MP} 2 / 6-31 \mathrm{G}^{*}\right)$. At the standard level of theory (Table 3.4), $\mathrm{CH}_{2} \mathrm{PH}_{3}$ is found to lie $237 \mathrm{~kJ} \mathrm{~mol}^{-1}$ above methylphosphine (Figure $3.2 \mathrm{a}$ ), a value which is reduced slightly by higher-level calculations (Table 3.6) to $220 \mathrm{~kJ}$ 
$\mathrm{mol}^{-1}$. This may be compared with values of 220 (POL-CI) $^{141}$ and 247 $\left(4-31 \mathrm{G}^{*}\right)^{137} \mathrm{~kJ} \mathrm{~mol}^{-1}$ from other studies. There is a large barrier $\left(141 \mathrm{~kJ} \mathrm{~mol}^{-1}\right.$, Table 3.4) for the exothermic rearrangement via 3d to methylphosphine (1d), and with a binding energy with respect to $\mathrm{CH}_{2}$ $\left({ }^{1} \mathrm{~A}_{1}\right)+\mathrm{PH}_{3}$ of $227 \mathrm{~kJ} \mathrm{~mol}^{-1}\left(256 \mathrm{~kJ} \mathrm{~mol}^{-1}\right.$ at the highest level, Table 3.6), $\mathrm{CH}_{2} \mathrm{PH}_{3}$ is the most stable of the prototype ylides reported here.

The rearrangement of $2 d$ to $1 d$ proceeds via a transition structure (3d) with $\underline{C}_{1}$ symmetry, in contrast to the $\underline{\mathrm{C}}_{\underline{S}}$ symmetry found for the transition structure in the nitrogen system. It has been noted previously ${ }^{148,149}$ that under $\underline{\underline{C}}_{\underline{s}}$ symmetry the 1,2-hydrogen shift formally involves a repulsive four-electron interaction. The symmetry breaking that occurs in the phosphorus but not the nitrogen case suggests a stronger interaction between the two participating pairs of electrons in the former situation.

3.3.2.2 The methylenesulfonium ylide $\left(\mathrm{CH}_{2} \mathrm{SH}_{2}, 2 \mathrm{e}\right)$ has a $\mathrm{C}-\mathrm{S}$ bond $\left(1.635 \AA\right.$ at $\mathrm{HF} / 6-31 \mathrm{G}^{*}$ and $\mathrm{MP} 2 / 6-31 \mathrm{G}^{*}, 1.646 \AA$ with the DZP + diffuse functions basis set ${ }^{140}$, which is significantly shorter than the $\mathrm{C}-\mathrm{S}$ single bond in methanethiol $\left(1.817 \AA\right.$ at $\mathrm{HF} / 6-31 \mathrm{G}^{*}, 1441.814 \AA$ at $\left.M P 2 / 6-31 \mathrm{G}^{*}\right)$. Nevertheless, at the standard level of theory the ylide 2 e lies $327 \mathrm{~kJ} \mathrm{~mol}^{-1}$ above the conventional isomer (Figure $3.2 b)$, compared with values of $347(\mathrm{POL}-\mathrm{CI})^{141}$ and $349\left(4-31 \mathrm{G}^{*}\right)^{137} \mathrm{~kJ}$ $\mathrm{mol}^{-1}$ from other studies. This energy difference is only slightly reduced (to $309 \mathrm{~kJ} \mathrm{~mol}^{-1}$ ) by the higher-level calculations (Table 3.6). The barrier for $\mathrm{CH}_{2} \mathrm{SH}_{2}$ to rearrange to $\mathrm{CH}_{3} \mathrm{SH}$ via $3 e$ is $75 \mathrm{~kJ}$ $\mathrm{mol}^{-1}$ (Table 3.4) and the binding energy with respect to $\mathrm{CH}_{2}\left({ }^{1} \mathrm{~A}_{1}\right)+$ $\mathrm{SH}_{2}$ is $115 \mathrm{~kJ} \mathrm{~mol}^{-1}$. This binding energy is increased by the higherlevel calculations (Table 3.6 ) to $148 \mathrm{~kJ} \mathrm{~mol}^{-1}$. 
61.

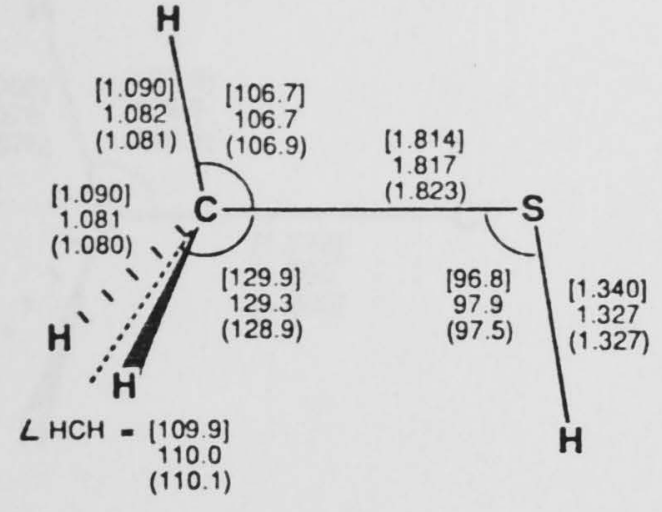

$1 e$

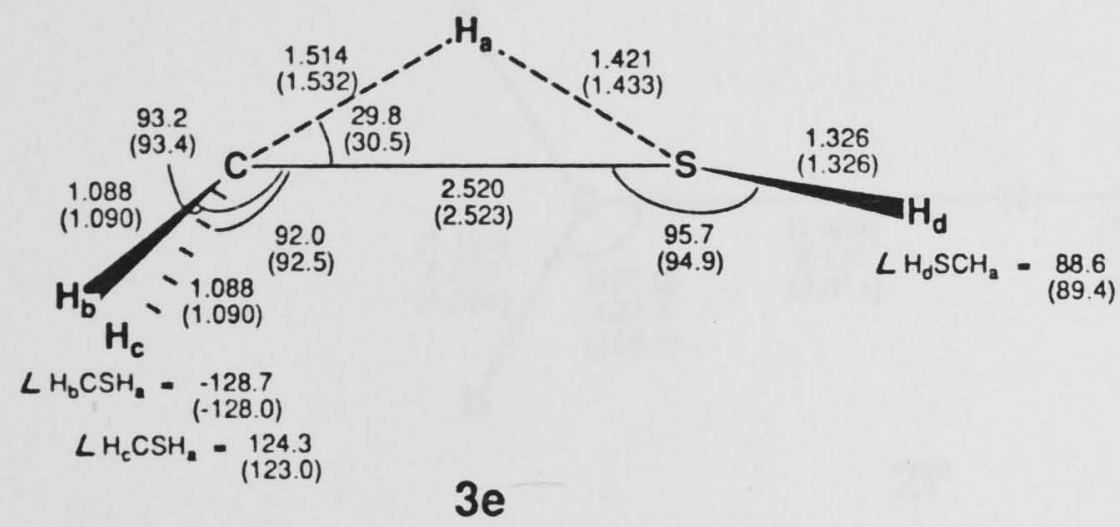

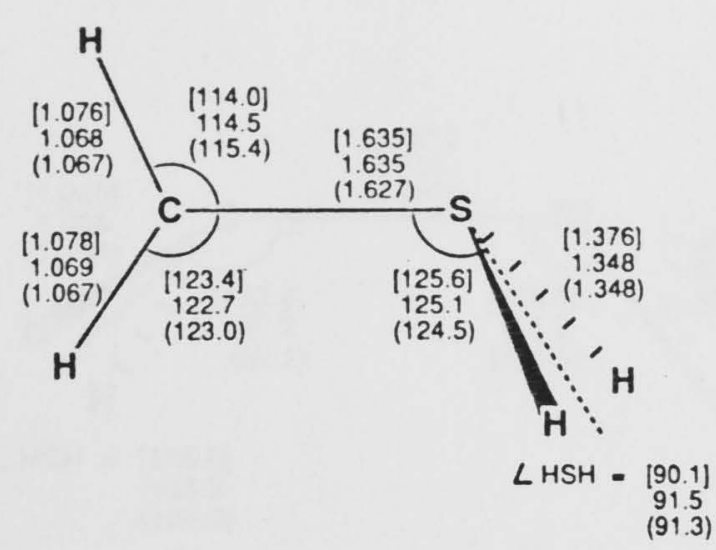

$2 e$

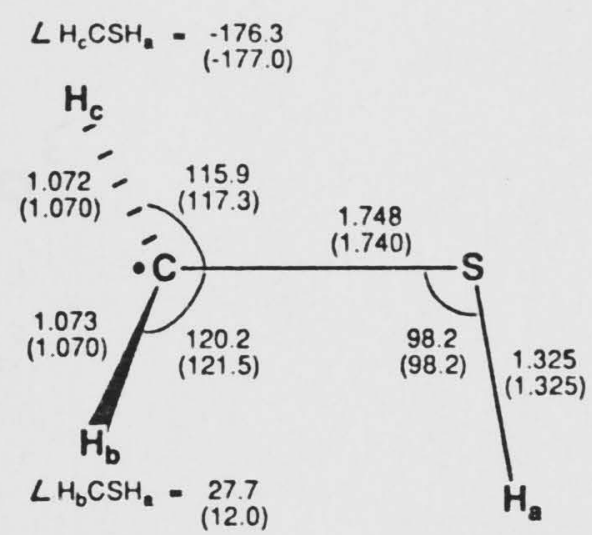

3.3.2.3 The methylenechloronium ylide $\left(\mathrm{CH}_{2} \mathrm{ClH}, 2 \mathrm{f}\right)$ has a $\underline{\mathrm{C}}_{\underline{\mathrm{S}}}$ structure with a syn arrangement of the hydrogen atoms, in contrast to the fluorine system where no ylide-like structure could be found. The $\mathrm{ylide}$ has a long $\mathrm{C}-\mathrm{Cl}$ bond length of $3.035 \AA$ at $\mathrm{HF} / 6-31 \mathrm{G}^{*}$. At the standard level of theory (Table 3.4 ), it is bound by just $1 \mathrm{~kJ}$ $\mathrm{mol}^{-1}$ with respect to $\mathrm{CH}_{2}\left({ }^{1} \mathrm{~A}_{1}\right)+\mathrm{ClH}$ and lies some $429 \mathrm{~kJ} \mathrm{~mol}^{-1}$ (Figure 3.2c) above $\mathrm{CH}_{3} \mathrm{Cl}$, 1f. Nevertheless, the barrier for $\mathrm{CH}_{2} \mathrm{ClH}$ to rearrange to $\mathrm{CH}_{3} \mathrm{Cl}$ is $46 \mathrm{~kJ} \mathrm{~mol}^{-1}$ and analytical frequency calculations show that the ylide corresponds to a true minimum on both the $\mathrm{HF} / 3-21 \mathrm{G}^{(*)}$ and $\mathrm{HF} / 6-31 \mathrm{G}^{*}$ potential surfaces. MP2/6-31G ${ }^{*}$ reoptimization has a dramatic effect on the geometry of $2 \mathbf{f}$, reducing the $\mathrm{C}-\mathrm{Cl}$ bond length to $1.691 \AA{ }^{b}$ which is even shorter than the $\mathrm{C}-\mathrm{Cl}$ bond in chloromethane $\left(1.778 \AA\right.$ at MP2/6-31 $\left.{ }^{*}\right)$.

b. This is somewhat surprising since the MP2/3-21G ${ }^{(*)}$ optimized structure for $2 \mathrm{f}$ still has a long (2.413 \&) C-Cl bond. 


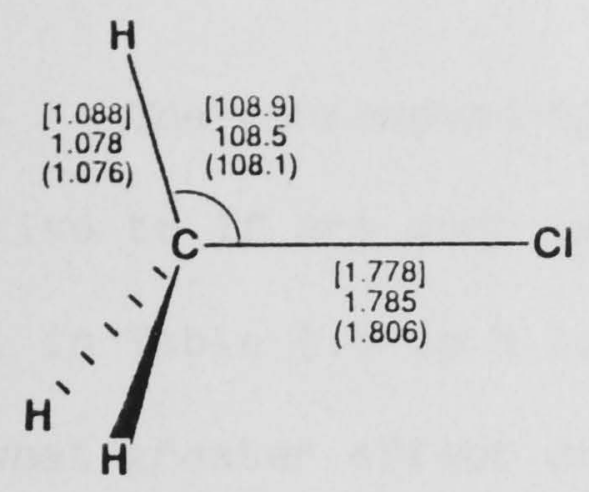

$1 f$

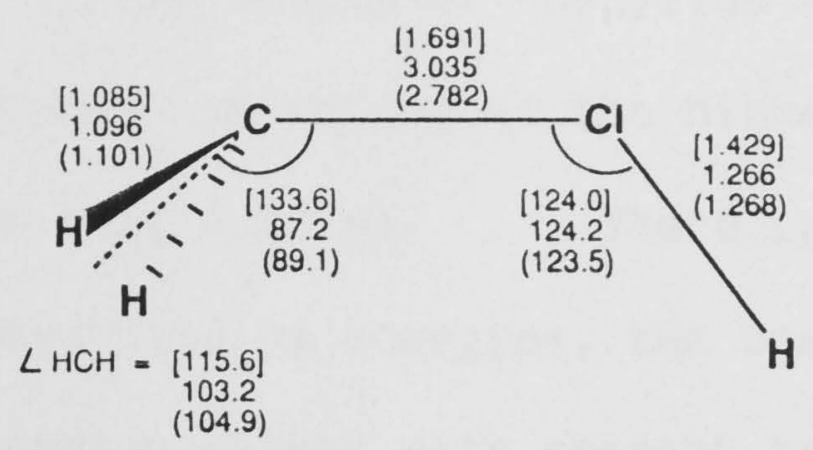

$2 f$

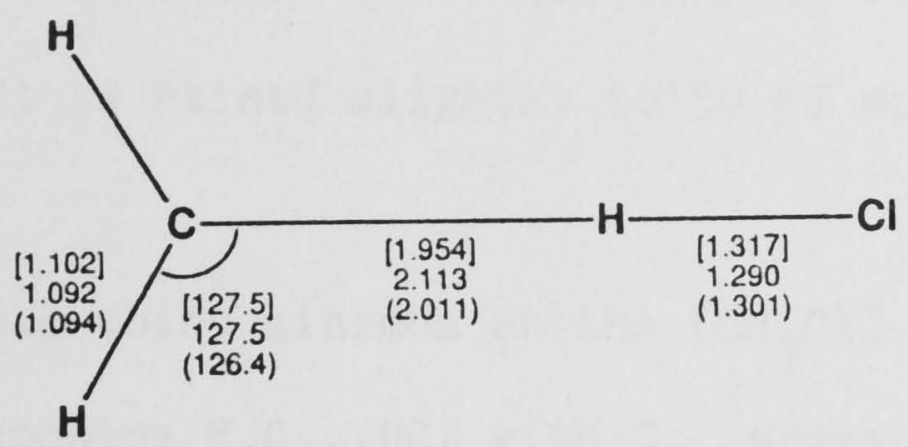

2f'

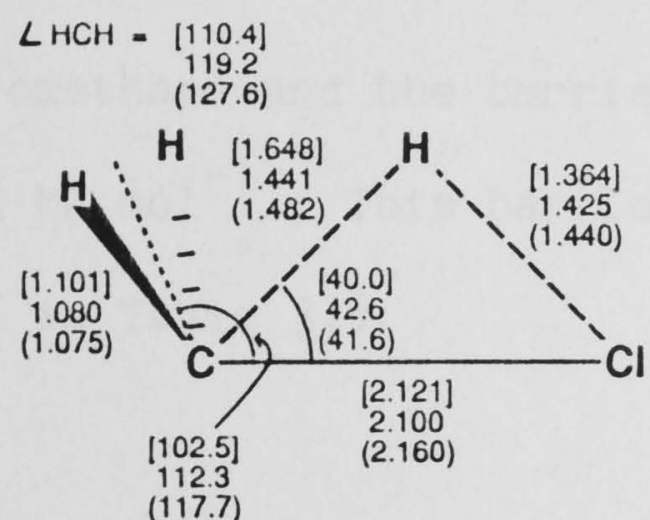

$3 f$

f

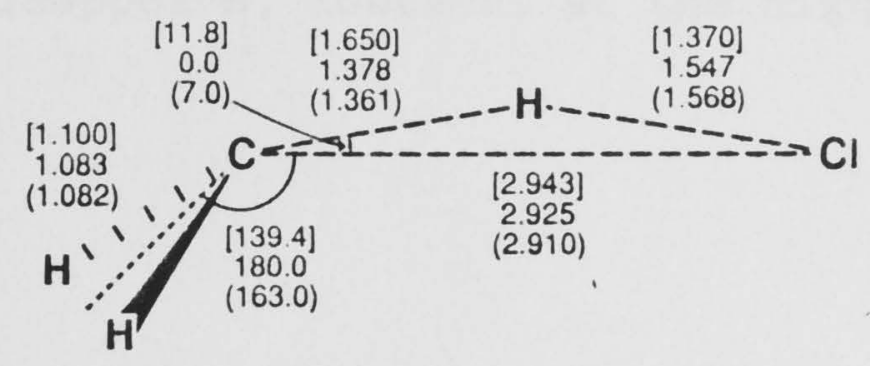

$\angle H C H=\left[\begin{array}{l}106.6] \\ 111.4\end{array}\right.$

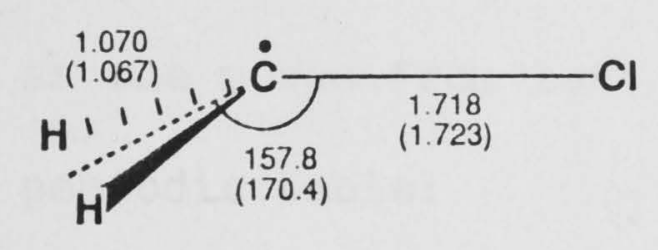

$\angle H C H=\begin{gathered}122.4 \\ (124.1)\end{gathered}$

However, this result is not maintained at still higher levels of theory which again yield long-bond structures for $\mathrm{CH}_{2} \mathrm{ClH} .{ }^{C}$ At the highest level of theory $\left(M P 4 / 6-31 G^{*}\right)$, the C-Cl length is $2.373 \AA$.

c. Optimization of $2 \mathrm{f}$ at $\mathrm{MP} 2 / 6-31+\mathrm{G}^{*}, \mathrm{MP} 2 / 6-31 \mathrm{G}^{* *}, \mathrm{CISD} / 6-31 \mathrm{G}^{*}$, $\mathrm{MP} 3 / 6-31 \mathrm{G}^{*}$ and MP4 $/ 6-31 \mathrm{G}^{*}$ yields $\mathrm{C}-\mathrm{Cl}$ lengths of $1.730,1.728$, $2.610,2.495$ and $2.373 \AA$, respectively. 
The corresponding changes in the energy of the ylide $2 \mathbf{f}$ relative to $1 \mathrm{f}$ are much less pronounced, amounting at the highest level in Table 3.6 to a lowering of only $2 \mathrm{~kJ} \mathrm{~mol}^{-1}$. There is a somewhat greater effect on calculated binding energies, the best estimate in Table 3.6 yielding a binding energy with respect to $\mathrm{CH}_{2}\left({ }^{1} \mathrm{~A}_{1}\right)+\mathrm{ClH}$ of $18 \mathrm{~kJ} \mathrm{~mol}{ }^{-1} \cdot{ }^{\mathrm{d}}$ The barrier for rearrangement of the ylide to $\mathrm{CH}_{3} \mathrm{Cl}$ is raised slightly to $50 \mathrm{~kJ} \mathrm{~mol}^{-1}$.

\section{A possible third minimum on the $\left[\mathrm{CH}_{3} \mathrm{Cl}\right]$ surface is the} hydrogen-bonded complex $\mathrm{H}_{2} \mathrm{C} \ldots \mathrm{HCl}$ with $\underline{\mathrm{C}}_{2 \underline{\mathrm{v}}}$ symmetry (2f'). At the standard level of theory (Table 3.4), this lies $403 \mathrm{~kJ} \mathrm{~mol}^{-1}$ above chloromethane and the barrier for rearrangement of $2 f^{\prime}$ to $1 f$ (via $4 f$ ) is $18 \mathrm{~kJ} \mathrm{~mol}^{-1}$. This barrier disappears, however, at the highest level in Table 3.6 .

\subsubsection{Comparisons Across the Periodic Table}

A number of general observations can be made concerning the properties of ylides as one moves from left to right across the firstor second-row of the periodic table:

(i) the $\mathrm{C}-\mathrm{X}$ bond in the $\mathrm{ylide}\left(\mathrm{CH}_{2} \mathrm{XH}\right)$ tends to get longer relative to the $\mathrm{C}-\mathrm{X}$ bond in $\mathrm{CH}_{3} \mathrm{X}$;

(ii) the energy difference between the ylide and its conventional isomer increases;

d. Use of the MP4 rather than the MP2 optimized geometry for $\mathrm{CH}_{2} \mathrm{ClH}$ in the first term of equation (3.2) increases the binding energy of $\mathrm{CH}_{2} \mathrm{ClH}$ to $22 \mathrm{~kJ} \mathrm{~mol}^{-1}$. 
(iii) the barrier for rearrangement of the ylide to its conventional isomer decreases; and

(iv) the binding energy of the ylide with respect to $\mathrm{CH}_{2}\left({ }^{1} \mathrm{~A}_{1}\right)+\mathrm{XH}$ decreases.

Overall, these trends reflect a general decrease in the stability of the ylides in the order Group V > Group VI > Group VII. This ordering is consistent with the differing ease with which the $\mathrm{XH}$ can share a lone pair of electrons (and so form the $\mathrm{C}-\mathrm{X}$ bond in the ylide).

\subsubsection{Comparisons Between First- and Second-Row Ylides}

The differences in structure and bonding between first- and second-row ylides have been discussed at some length previously $115,117,140,141,150,151$ and only a few of the more important features will be noted here.

For the first-row systems, the $\mathrm{C}-\mathrm{X}$ bonds in the $\mathrm{ylides}$ $\left(\mathrm{CH}_{2} \mathrm{XH}\right)$ are all longer than those in the conventional isomers. The $\mathrm{CH}_{2} \mathrm{X}$ groups are markedly non-planar and the ylides tend to resemble donor-acceptor complexes. The ylides lie considerably higher in energy than their conventional isomers and the barriers for rearrangement are small or non-existent. The binding energies of the ylides with respect to $\mathrm{CH}_{2}\left({ }^{1} \mathrm{~A}_{1}\right)+\mathrm{XH}$ are also generally small.

For the second-row systems, the $\mathrm{C}-\mathrm{X}$ bonds in the ylides are shorter (except possibly for $\mathrm{CH}_{2} \mathrm{ClH}$ ) than those in the conventional isomers. The bonds at carbon are more nearly coplanar than in the first-row ylides, supporting previous suggestions $118,133,140,141,151$ 
that multiple bonding might be involved (resulting from $\mathrm{p}_{\pi}-\mathrm{d}_{\pi}$ backbonding). ${ }^{e} \quad$ The ylides still lie much higher in energy than their conventional isomers but on the whole the energy difference is less than in the first-row. The barriers for rearrangement of the second-row ylides are larger than in the first-row and their binding energies also tend to be greater.

\subsubsection{Effects of the Higher-Level Calculations}

Differences between the $\mathrm{HF} / 6-31 \mathrm{G}^{*}$ and $\mathrm{MP} 2 / 6-31 \mathrm{G}^{*}$ optimized geometries are quite large in a number of the ylides $\mathrm{CH}_{2} \mathrm{XH}$ (average change in $\mathrm{C}-\mathrm{X}$ length $=0.340 \AA$, maximum $=1.344 \AA$ ) but are much less pronounced in the conventional isomers $\mathrm{CH}_{3} \mathrm{X}$ (average change in $\mathrm{C}-\mathrm{X}$ length $=0.013 \AA$, maximum $=0.027 \AA$ ). Single-point calculations on these MP2 optimized structures result in relative energies of the ylides at the MP4/6-311G( $\underline{\mathrm{df}}, \underline{p})$ or MP4/6-31G( $\underline{\mathrm{df}}, \underline{p})$ levels (Table 3.6) which are generally $10-30 \mathrm{~kJ} \mathrm{~mol}^{-1}$ lower than the values in Tables 3.3 and 3.4. This effect is largely due, however, to the larger basis set and more complete incorporation of electron correlation and only to a minor extent due to the use of the improved MP2 geometries.

e. Supporting evidence comes from comparisons of gross d-orbital populations and bond orders for the first- and second-row ylides. 


\subsection{Conclusions}

The present results confirm previous suggestions that the simple ylides $\left(\mathrm{CH}_{2} \mathrm{XH}\right)$ are generally unstable species which of ten have little or no barrier to rearrangement or fragmentation. All the ylides lie much higher in energy than their conventional isomers. The results presented here also support the established notion that the second-row ylides are in general more stable than their first-row counterparts. 
67.

\section{CHAPTER FOUR YLIDIONS}

\subsection{Introduction}

Experimental and theoretical studies have firmly established the existence in the gas phase of simple organic ions with unusual structures whose neutral counterparts are unknown or extremely reactive. One of the earliest examples to receive high-level treatment both theoretically ${ }^{152,153}$ (using ab initio calculations) and experimentally ${ }^{154,155}$ (using collisional-activation (CA) mass spectrometry) was the methyleneoxonium radical cation, $\mathrm{CH}_{2} \mathrm{OH}_{2}^{+} \cdot$.

This species has quite a short $\mathrm{C}-\mathrm{O}$ bond and, perhaps surprisingly, lies lower in energy than the methanol radical cation, $\mathrm{CH}_{3} \mathrm{OH}^{+\cdot}$. In contrast, the neutral ylide $\mathrm{CH}_{2} \mathrm{OH}_{2}$ discussed in Chapter Three resembles a weak complex of methylene with water.

The term ylidion is introduced here to describe the class of radical cations corresponding to such ionized ylides. (For recent reviews dealing with ylidions, see refs 156 and 157.) The ylidions may be written with the charge and radical sites on adjacent centres (e.g. $\dot{\mathrm{C}}_{2} \stackrel{+}{\mathrm{OH}}_{2}$ ) and are members of the more general class of distonic ${ }^{158}$ radical cations in which the charge and radical sites are formally separated. Distonic radical cations are discussed further in Chapter Seven.

In this chapter, a comprehensive survey of the first- and second-row ylidions $\dot{\mathrm{C}}_{2} \stackrel{+}{\mathrm{X}} \mathrm{H}\left(\mathrm{X}=\mathrm{NH}_{2}, \mathrm{OH}, \mathrm{F}, \mathrm{PH}_{2}, \mathrm{SH}\right.$ and $\left.\mathrm{Cl}\right)$ is 
68.

presented and comparisons are made with the results for the neutral ylides from Chapter Three. The general aim is to compare structural features and relative stabilities of the various species at uniform and moderately high levels of ab initio theory. In particular, an attempt is made to elucidate trends in these properties in three specific areas:

(i) across a row of the periodic table;

(ii) between first- and second-row compounds; and

(iii) between neutral and charged species.

\subsection{Method and Results}

The general procedure followed is similar to that outlined in the preceding chapter. Results were obtained initially at the MP3 $/ 6-31 \mathrm{G}^{* *} / / 6-31 \mathrm{G}^{*}$ level (the 'standard level of theory'), using the additivity approximation of equation (1.16) for second-row systems. Higher-level calculations were carried out for some species at $\mathrm{MP} 4 / 6-311 \mathrm{G}(\underline{\mathrm{df}}, \underline{\mathrm{p}}) / / \mathrm{MP} 2 / 6-31 \mathrm{G}^{*}$ and MP4 /6-31G( $\left.\underline{\mathrm{df}}, \underline{\mathrm{p}}\right) / / \mathrm{MP} 2 / 6-31 \mathrm{G}^{*}$ (for first- and second-row systems, respectively) using the additivity approximations of equations (3.1) and (3.2). Results are reported for the ylidions $\left(\dot{\mathrm{CH}}_{2} \stackrel{+}{\mathrm{X}} \mathrm{H}\right)$, their conventional isomers $\left(\mathrm{CH}_{3} \mathrm{X}^{+\cdot}\right)$, several pairs of fragmentation products and the various transition structures for rearrangement and fragmentation.

In the open-shell systems, calculated expectation values of $\hat{S}^{2}$ (which should be 0.75 for a pure doublet) are between 0.753 and 0.765 for equilibrium species (including fragmentation products), between 0.769 and 0.822 for the transition structures for 1,2-hydrogen rearrangement, and between 0.782 and 1.016 for the transition 
69.

structures for fragmentation. As noted in section 1.4.2, these values suggest that relative energies for the equilibrium structures are probably not significantly affected by spin contamination in the UHF wavefunction but that the barriers for rearrangement and fragmentation may be overestimated at the highest levels.

Total energies for the standard calculations are presented in Tables 4.1 and 4.2 , experimental heats of formation $56,159,160$ corrected to $0 \mathrm{~K}^{53,54}$ in Table 4.3 and relative energies in Tables 4.4 and 4.5. Schematic energy profiles (based on the best results in Tables 4.4 and 4.5 ) are displayed in Figures 4.1 and 4.2 for firstand second-row systems, respectively. For the higher-level calculations, total and relative energies are presented in Tables 4.6 and 4.7 , respectively, and the highest-level results are incorporated in Figures 4.1 and 4.2. Optimized $\mathrm{HF} / 6-31 \mathrm{G}^{*}$ structures for the ylidions and related systems are displayed within the course of the discussion; $^{a} \quad \mathrm{HF} / 3-21 \mathrm{G}^{(*)}$ values are given in parentheses and MP2 $/ 6-31 G^{*}$ values (where available) in square brackets.

a. Optimized geometries of the fragmentation products are only displayed where hitherto unpublished. In most cases, these geometries are available from refs 6 or 144 . 
Table 4.1 Calculated Total Energies ${ }^{\mathrm{a}}$ (hartrees) and Zero-Point Vibrational Energies (ZPVE, kJ mol ${ }^{-1}$ ) for First-Row Ylidions and Related Systems

$\mathrm{HF} / 3-21 \mathrm{G}^{\mathrm{b}} \quad \mathrm{HF} / 6-31 \mathrm{G}^{*} \quad \mathrm{HF} / 6-31 \mathrm{G}^{* *} \quad \mathrm{MP} 2 / 6-31 \mathrm{G}^{* *} \quad \mathrm{MP}^{*} / 6-31 \mathrm{G}^{* *} \quad \mathrm{ZPVE}$

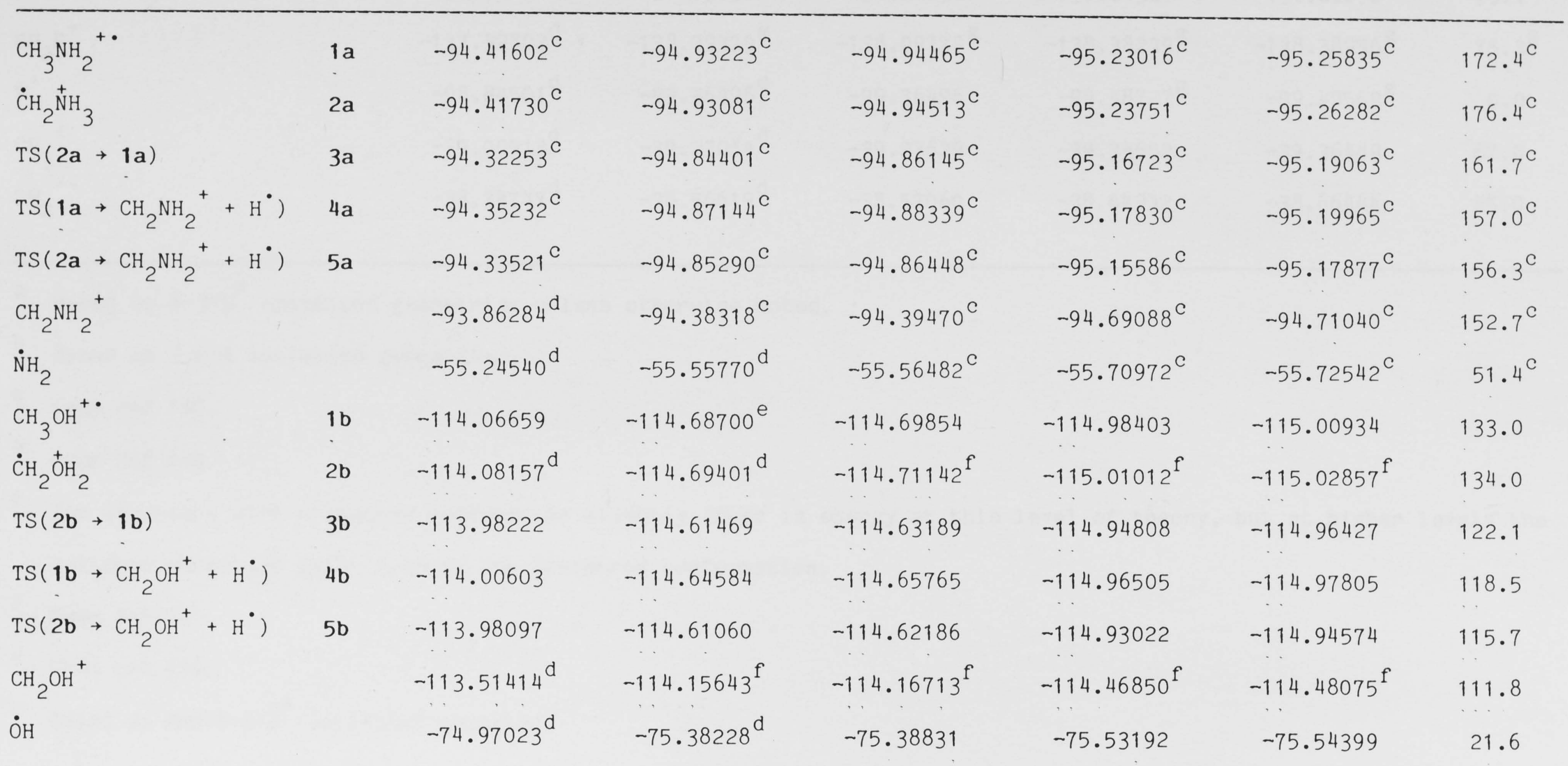




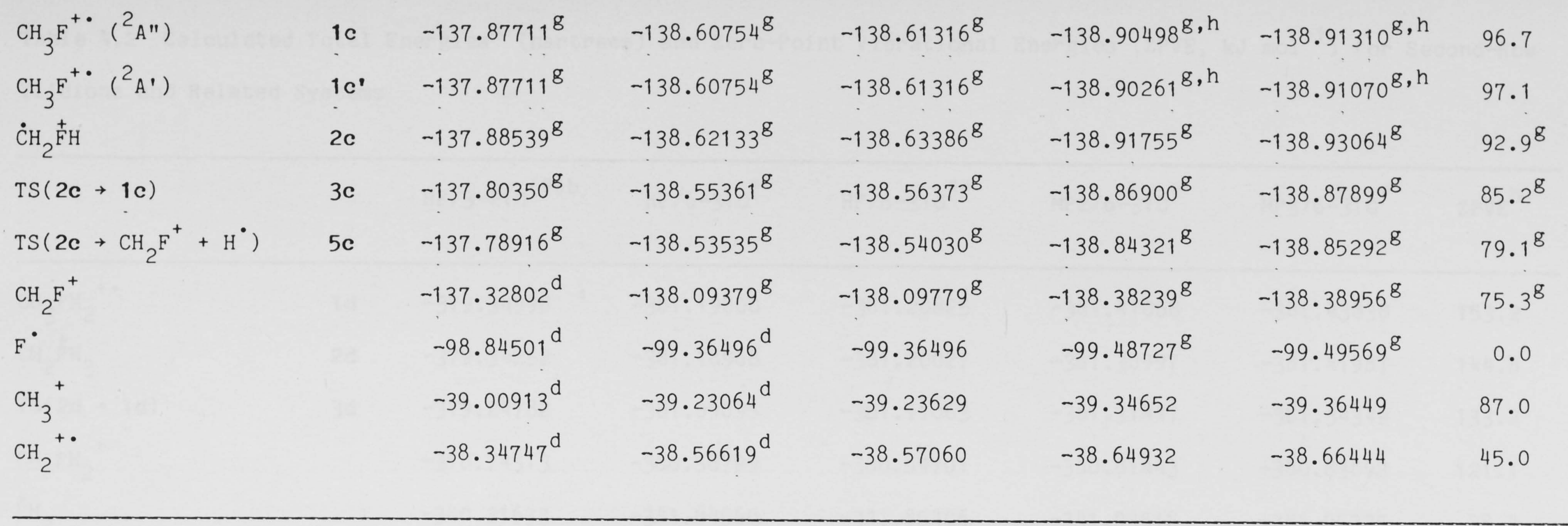

a Based on $6-31 \mathrm{G}^{*}$ optimized geometries unless otherwise noted.

b Based on 3-21G optimized geometries.

c From ref 145 .

d From ref 144 .

e The structure with staggered geometry is slightly lower in energy at this level of theory, but at higher levels the eclipsed structure again becomes the preferred conformation.

f From ref 161 .

8 From ref 146.

h Based on MP2/6-31 $\mathrm{G}^{*}$ optimized geometry. 
Table 4.2 Calculated Total Energies ${ }^{a}$ (hartrees) and Zero-Point Vibrational Energies (ZPVE, kJ mol ${ }^{-1}$ ) for Second-Row Ylidions and Related Systems

$\mathrm{HF} / 3-21 \mathrm{G}^{(*) \mathrm{b}} \quad \mathrm{HF} / 6-31 \mathrm{G}^{*} \quad \mathrm{HF} / 6-31 \mathrm{G}^{* *} \quad \mathrm{MP} 2 / 6-31 \mathrm{G}^{*} \quad \mathrm{MP} 3 / 6-31 \mathrm{G}^{*} \quad \mathrm{ZPVE}$

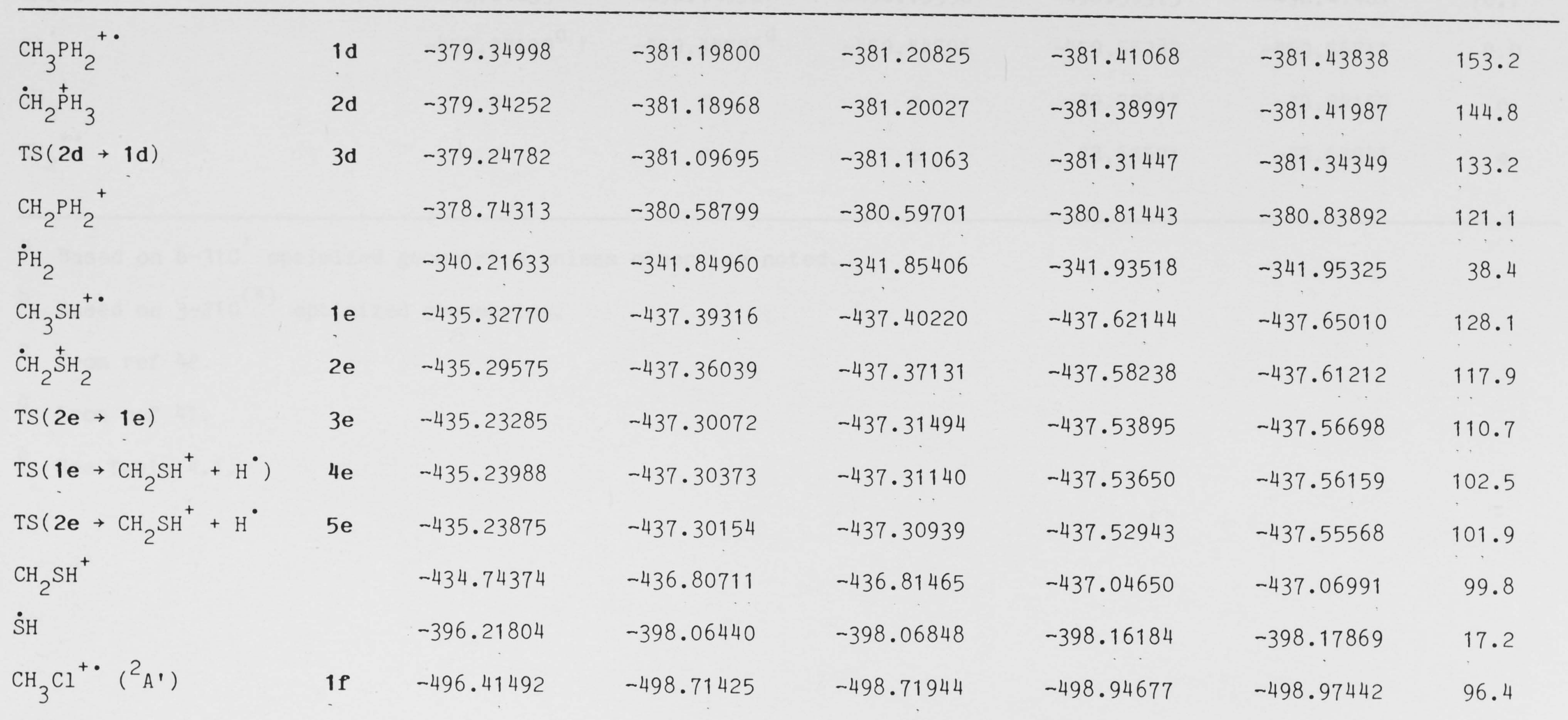




\begin{tabular}{|c|c|c|c|c|c|c|}
\hline $\mathrm{CH}_{3} \mathrm{Cl}^{+\cdot}\left({ }^{2} \mathrm{~A}^{\prime \prime}\right)$ & $1 \mathrm{f}^{\prime}$ & -496.41491 & -498.71423 & -498.71942 & -498.94673 & -498.97439 \\
\hline$\stackrel{\dot{\mathrm{C}}}{\mathrm{H}_{2}} \stackrel{+}{\mathrm{C}} \mathrm{l} \mathrm{H}$ & $2 f$ & -496.38794 & -498.68842 & -498.69820 & -498.92179 & -498.94902 \\
\hline $\mathrm{TS}(2 \mathrm{f} \rightarrow \mathbf{1 f})$ & $3 f$ & -496.33124 & -498.63611 & -498.64922 & -498.88553 & -498.91033 \\
\hline $\mathrm{TS}\left(\mathbf{2 f}+\mathrm{CH}_{2} \mathrm{Cl}^{+}+\mathrm{H}^{\bullet}\right)$ & $5 f$ & -496.33035 & -498.63136 & -498.63624 & -498.87460 & -498.89801 \\
\hline $\mathrm{CH}_{2} \mathrm{Cl}^{+}$ & & -495.84633 & -498.14992 & -498.15358 & $-498 \cdot 39373$ & -498.41401 \\
\hline $\mathrm{Cl}{ }^{\bullet}$ & & $-457.37109^{c}$ & $-459.44796^{d}$ & -459.44796 & -459.55243 & -459.56711 \\
\hline $\mathrm{CH}_{3}^{+}$ & & e & e & e & -39.32514 & $-39 \cdot 34158$ \\
\hline $\mathrm{CH}_{2}^{+\cdot}$ & & e & e & e & -38.63521 & -38.64941 \\
\hline
\end{tabular}

a Based on $6-31 \mathrm{G}^{*}$ optimized geometries unless otherwise noted.

b Based on $3-21 \mathrm{G}^{(*)}$ optimized geometries.

c From ref 42 .

d From ref 41.

e see Table 4.1 . 
Table 4.3 Experimental Heats of Formation $\left(\Delta \mathrm{H}_{\mathrm{fo}}^{0}, \mathrm{~kJ} \mathrm{~mol}{ }^{-1}\right)^{a}$ for First- and Second-Row Systems

\begin{tabular}{|c|c|c|c|}
\hline Species & $\Delta \mathrm{H}_{\mathrm{fO}}^{0}$ & Species & $\Delta \mathrm{H}_{\mathrm{fO}}^{\circ}$ \\
\hline $\mathrm{CH}_{3} \mathrm{NH}_{2}^{+\cdot}$ & $857^{b}$ & $\dot{\mathrm{C}} \mathrm{H}_{2} \stackrel{+}{\mathrm{N}} \mathrm{H}_{3}$ & $972^{b, c}$ \\
\hline $\mathrm{CH}_{2} \mathrm{NH}_{2}^{+}$ & $757^{b}$ & $\mathrm{NH}_{3}$ & -39 \\
\hline & $193^{d}$ & $\mathrm{CH}_{3} \mathrm{OH}^{+\cdot}$ & 856 \\
\hline$\dot{\mathrm{CH}}_{2}{ }_{\mathrm{O}}^{+} \mathrm{H}_{2}$ & $825^{b, e}$ & $\mathrm{CH}_{2} \mathrm{OH}^{+}$ & 720 \\
\hline $\mathrm{OH}_{2}$ & -239 & $\dot{\mathrm{O}}_{\mathrm{H}}$ & 39 \\
\hline $\mathrm{CH}_{3} \mathrm{~F}^{+\cdot}$ & $981^{b}$ & $\dot{\mathrm{C}} \mathrm{H}_{2} \stackrel{+}{\mathrm{F}} \mathrm{H}$ & $913^{b, c}$ \\
\hline $\mathrm{CH}_{2} \mathrm{~F}^{+}$ & $842^{b}$ & $\mathrm{FH}$ & -271 \\
\hline$F^{\circ}$ & 77 & $\mathrm{CH}_{3} \mathrm{SH}^{+\cdot}$ & 899 \\
\hline & $925^{b, c}$ & $\mathrm{CH}_{2} \mathrm{SH}^{+}$ & $870^{f}$ \\
\hline $\mathrm{SH}_{2}$ & -18 & $\dot{S} H$ & 142 \\
\hline $\mathrm{CH}_{3} \mathrm{Cl}^{+\cdot}$ & 1014 & $\dot{\mathrm{C}} \mathrm{H}_{2} \stackrel{+}{\mathrm{C}} 1 \mathrm{H}$ & $1034^{b, c}$ \\
\hline $\mathrm{CH}_{2} \mathrm{Cl}^{+}$ & $966^{b, g}$ & $\mathrm{ClH}$ & -92 \\
\hline $\mathrm{Cl}$ & 120 & $\mathrm{CH}_{3}^{+}$ & 1095 \\
\hline $\mathrm{CH}_{2}{ }^{+\cdot}$ & 1398 & $\mathrm{H}^{\bullet}$ & 216 \\
\hline
\end{tabular}

a From ref 56 unless otherwise noted.

b $\Delta \mathrm{H}_{\mathrm{f} 298}^{0}$ value corrected to $0 \mathrm{~K}$ using standard formulae from refs 53 and 54 and calculated vibrational frequencies.

c $\Delta \mathrm{H}_{\mathrm{f} 298}^{\circ}$ value from ref 179 .

d From ref 159.

e $\Delta \mathrm{H}_{\mathrm{f} 298}^{\circ}$ value from ref 155 .

f From ref 188 .

g $\Delta \mathrm{H}_{\mathrm{f} 298}^{\circ}$ value from ref 160 . 
Table 4.4 Calculated $^{a, b}$ and Experimental ${ }^{c}$ Relative Energies (kJ mol ${ }^{-1}$ ) for First-Row Ylidions and Related Systems $\mathrm{HF} / 3-21 \mathrm{G} \quad \mathrm{HF} / 6-31 \mathrm{G}^{*} \mathrm{HF} / 6-31 \mathrm{G}^{* *} \quad \mathrm{MP} 2 / 6-31 \mathrm{G}^{* *} \quad \mathrm{MP} 3 / 6-31 \mathrm{G}^{* *} \quad \mathrm{MP} 3 / 6-31 \mathrm{G}^{* * \mathrm{~d}} \quad \mathrm{ExptI}$

\begin{tabular}{|c|c|c|c|c|c|c|c|c|}
\hline $\mathrm{CH}_{3} \mathrm{NH}_{2}^{+\cdot}$ & $1 \mathrm{a}$ & 0 & 0 & 0 & 0 & 0 & 0 & 0 \\
\hline$\dot{\mathrm{C}}_{2} \stackrel{+}{\mathrm{N}}_{3}$ & $2 a$ & -3 & 4 & -1 & -19 & -12 & -8 & 115 \\
\hline $\mathrm{TS}(2 \mathbf{a} \rightarrow 1 \mathrm{a})$ & $3 a$ & 246 & 232 & 218 & 165 & 178 & 168 & \\
\hline $\mathrm{TS}\left(\mathbf{1} \mathbf{a} \rightarrow \mathrm{CH}_{2} \mathrm{NH}_{2}^{+}+\mathrm{H}^{\bullet}\right)$ & $4 a$ & 167 & 160 & 161 & 136 & 154 & 140 & \\
\hline $\mathrm{TS}\left(\mathbf{2} \mathbf{a}+\mathrm{CH}_{2} \mathrm{NH}_{2}^{+}+\mathrm{H}^{\bullet}\right)$ & $5 a$ & 212 & 208 & 211 & 195 & 209 & 194 & \\
\hline $\mathrm{CH}_{2} \mathrm{NH}_{2}^{+}+\mathrm{H}^{+}$ & & 150 & 133 & 136 & 108 & 131 & 113 & 116 \\
\hline $\mathrm{CH}_{3}^{+}+\dot{\mathrm{N}_{2}}$ & & 424 & 378 & 377 & 457 & 442 & 412 & 431 \\
\hline $\mathrm{CH}_{2}^{+\cdot}+\mathrm{NH}_{3}$ & & 516 & 477 & 469 & 520 & 520 & 491 & 502 \\
\hline $\mathrm{CH}_{3} \mathrm{OH}^{+\cdot}$ & $1 \mathrm{~b}$ & 0 & 0 & 0 & 0 & 0 & 0 & 0 \\
\hline$\dot{\mathrm{C}} \mathrm{H}_{2} \mathrm{O}_{2}$ & $2 b$ & -39 & -18 & -34 & -68 & -51 & -50 & -31 \\
\hline $\mathrm{TS}(2 \mathrm{~b} \rightarrow 1 \mathrm{~b})$ & $3 b$ & 222 & 190 & 175 & 94 & 118 & 108 & \\
\hline $\mathrm{TS}\left(\mathbf{1 b} \rightarrow \mathrm{CH}_{2} \mathrm{OH}^{+}+\mathrm{H}^{\bullet}\right)$ & $4 b$ & 159 & 108 & 107 & 50 & 81 & 68 & \\
\hline $\mathrm{TS}\left(\mathbf{2 b}+\mathrm{CH}_{2} \mathrm{OH}^{+}+\mathrm{H}^{\bullet}\right)$ & $5 b$ & 225 & 201 & 201 & 141 & 167 & 151 & \\
\hline
\end{tabular}




$$
\begin{aligned}
& \mathrm{CH}_{2} \mathrm{OH}^{+}+\mathrm{H}^{-} \\
& \mathrm{CH}_{3}^{+}+\dot{\mathrm{OH}} \\
& \mathrm{CH}_{2}^{+}+\mathrm{OH}_{2}
\end{aligned}
$$

$$
148
$$

$\mathrm{TS}(2 \mathrm{c} \rightarrow 1 \mathrm{c})$

$\mathrm{TS}\left(2 \mathrm{c} \rightarrow \mathrm{CH}_{2} \mathrm{~F}^{+}+\mathrm{H}^{\bullet}\right)$

$\mathrm{CH}_{2} \mathrm{~F}^{+}+\mathrm{H}^{\bullet}$

$\mathrm{CH}_{3}^{+}+\mathrm{F}^{\cdot}$

$\mathrm{CH}_{2}{ }^{+\cdot}+\mathrm{FH}$

$5 c$

193

231

139

60

182

$\begin{array}{rr}85 & 87 \\ 194 & 194 \\ 289 & 274\end{array}$

0

0

$-54$

130

$$
0
$$$$
-36
$$$$
142
$$

31

101
45

277
80

265

313

0

6

$-46$

90

158

66

139

137
61

243

285

278

7

$-49$

79

142

47

130

113

161
80

78

a Based on the total energies in Table 4.1.

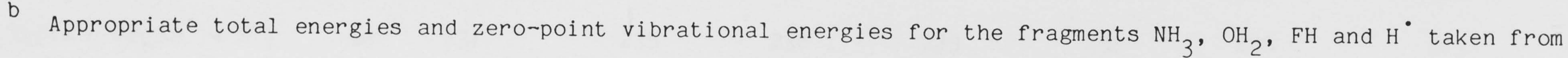
Table 3.1

c Based on the $\Delta \mathrm{H}_{\mathrm{f}}^{0}$ values in Table 4.3 .

d With zero-point vibrational energy correction. 
Table 4.5 Calculated ${ }^{a, b}$ and Experimental ${ }^{c}$ Relative Energies (kJ mol ${ }^{-1}$ ) for Second-Row Ylidions and Related Systems $\mathrm{HF} / 3-21 \mathrm{G}^{(*)} \mathrm{HF} / 6-31 \mathrm{G}^{*} \mathrm{HF} / 6-31 \mathrm{G}^{* *} \mathrm{MP} 2 / 6-31 \mathrm{G}^{*} \mathrm{MP} 3 / 6-31 \mathrm{G}^{*} \mathrm{MP} 3 / 6-31 \mathrm{G}^{* *} \mathrm{~d} \quad \mathrm{MP} 3 / 6-31 \mathrm{G}^{* *} \mathrm{e}$ ExptI

\begin{tabular}{|c|c|c|c|c|c|c|c|c|}
\hline $\mathrm{CH}_{3} \mathrm{PH}_{2}{ }^{+\cdot}$ & $1 \mathrm{~d}$ & 0 & 0 & 0 & 0 & 0 & 0 & 0 \\
\hline$\dot{\mathrm{C}} \mathrm{H}_{2} \stackrel{+}{\mathrm{P}} \mathrm{H}_{3}$ & $2 d$ & 20 & 22 & 21 & 54 & 49 & 48 & 40 \\
\hline $\operatorname{TS}(2 d \rightarrow 1 d)$ & $3 d$ & 268 & 265 & 256 & 253 & 249 & 240 & 220 \\
\hline $\mathrm{CH}_{2} \mathrm{PH}_{2}{ }^{+}+\mathrm{H}^{\bullet}$ & & 291 & 294 & 297 & 257 & 266 & 269 & 240 \\
\hline $\mathrm{CH}_{3}{ }^{+}+\dot{\mathrm{P}}_{2}$ & & 327 & 309 & 310 & 395 & 377 & 377 & 352 \\
\hline $\mathrm{CH}_{2}{ }^{+\cdot}+\mathrm{PH}_{3}$ & & 495 & 483 & 482 & 588 & 571 & 570 & 535 \\
\hline
\end{tabular}

\begin{tabular}{|c|c|c|c|c|c|c|c|c|c|}
\hline $\mathrm{CH}_{3} \mathrm{SH}^{+\cdot}$ & $1 \mathrm{e}$ & 0 & 0 & 0 & 0 & 0 & 0 & 0 & 0 \\
\hline$\dot{\mathrm{C}} \mathrm{H}_{2} \stackrel{+}{\mathrm{S}} \mathrm{H}_{2}$ & $2 e$ & 84 & 86 & 81 & 103 & 100 & 95 & 86 & 26 \\
\hline $\mathrm{TS}(2 \mathbf{e} \rightarrow 1 \mathbf{e})$ & $3 e$ & 249 & 243 & 229 & 217 & 218 & 205 & 189 & \\
\hline $\mathrm{TS}\left(\mathbf{1} \mathbf{e} \rightarrow \mathrm{CH}_{2} \mathrm{SH}^{+}+\mathrm{H}^{\bullet}\right)$ & $4 e$ & 231 & 235 & 238 & 223 & 232 & 236 & 213 & \\
\hline $\mathrm{TS}\left(2 \mathbf{e} \rightarrow \mathrm{CH}_{2} \mathrm{SH}^{+}+\mathrm{H}^{\bullet}\right)$ & $5 e$ & 234 & 241 & 244 & 242 & 248 & 251 & 227 & \\
\hline $\mathrm{CH}_{2} \mathrm{SH}^{+}+\mathrm{H}^{\bullet}$ & & 231 & 231 & 235 & 201 & 215 & 219 & 194 & 187 \\
\hline $\mathrm{CH}_{3}{ }^{+}+\dot{\mathrm{S}} \mathrm{H}$ & & 264 & 258 & 256 & 353 & 341 & 339 & 318 & 338 \\
\hline $\mathrm{CH}_{2}{ }^{+\cdot}+\mathrm{SH}_{2}$ & & 422 & 419 & 411 & 520 & 510 & 502 & 466 & 481 \\
\hline
\end{tabular}




\begin{tabular}{|c|c|c|c|c|c|c|c|c|c|}
\hline $\mathrm{CH}_{3} \mathrm{Cl}^{+\cdot}\left({ }^{2} \mathrm{~A}^{\prime}\right)$ & $1 f$ & 0 & 0 & 0 & 0 & 0 & 0 & 0 & 0 \\
\hline $\mathrm{CH}_{3} \mathrm{Cl}^{+\cdot}\left({ }^{2} \mathrm{~A}^{\prime \prime}\right)$ & $1 \mathrm{f}^{\prime}$ & 0.0 & 0.1 & 0.1 & 0.1 & 0.1 & 0.1 & & \\
\hline$\dot{\mathrm{C}} \mathrm{H}_{2} \stackrel{+}{\mathrm{C}} \mathrm{lH}$ & $2 f$ & 71 & 68 & 56 & 66 & 67 & 55 & 46 & 20 \\
\hline $\mathrm{TS}(2 \mathrm{f} \rightarrow \mathbf{1 f})$ & $3 f$ & 220 & 205 & 184 & 161 & 168 & 148 & 133 & \\
\hline $\mathrm{TS}\left(2 \mathbf{f}+\mathrm{CH}_{2} \mathrm{Cl}^{+}+\mathrm{H}^{\bullet}\right)$ & $5 f$ & 222 & 218 & 218 & 190 & 201 & 201 & 182 & \\
\hline $\mathrm{CH}_{2} \mathrm{Cl}^{+}+\mathrm{H}^{\bullet}$ & & 190 & 174 & 178 & 144 & 163 & 167 & 144 & 168 \\
\hline $\mathrm{CH}_{3}{ }^{+}+\mathrm{Cl}^{\bullet}$ & & 91 & 94 & 92 & 182 & 173 & 171 & 163 & 201 \\
\hline $\mathrm{CH}_{2}{ }^{+\cdot}+\mathrm{ClH}$ & & 226 & 231 & 217 & 313 & 309 & 294 & 265 & 292 \\
\hline
\end{tabular}

Based on the total energies in Table 4.2 .

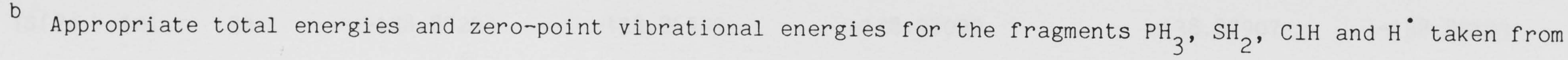
Table 3.2 .

c Based on the $\Delta \mathrm{H}_{\mathrm{fo}}^{\circ}$ values in Table 4.3 .

d Estimated using the additivity approximation of equation (1.16).

e MP3/6-31G** value with zero-point vibrational energy correction. 
Table 4.6 Higher-Level Calculations: Total Energies ${ }^{a}$ (hartrees)

$$
\mathrm{MP} 2 / 6-31 \mathrm{G}^{* \mathrm{~b}} \quad \mathrm{MP} 2 / 6-31 \mathrm{G}^{* *} \quad \mathrm{MP} 2 / 6-311 \mathrm{G}(\underline{\mathrm{df}}, \underline{\mathrm{p}})^{\mathrm{C}} \quad \mathrm{MP} 3 / 6-31 \mathrm{G}^{* *} \quad \mathrm{MP}^{*} / 6-31 \mathrm{G}^{* *}
$$

\begin{tabular}{|c|c|c|c|c|c|c|}
\hline $\mathrm{CH}_{3} \mathrm{NH}_{2}^{+\cdot}$ & $1 \mathrm{a}$ & -95.19932 & $-95.23078^{d}$ & $-95.29083^{d}$ & $-95.25863^{d}$ & -95.26948 \\
\hline$\dot{\mathrm{C}}_{2} \stackrel{+}{\mathrm{N}} \mathrm{H}_{3}$ & $2 a$ & -95.20540 & $-95.23780^{d}$ & $-95.29882^{d}$ & $-95.26295^{d}$ & -95.27301 \\
\hline $\mathrm{CH}_{3} \mathrm{OH}^{+\cdot}$ & $1 \mathrm{~b}$ & -114.96160 & -114.98666 & -115.07073 & -115.01027 & -115.02307 \\
\hline$\dot{\mathrm{C}}_{2} \stackrel{+}{\mathrm{O}}_{2}$ & $2 \mathrm{~b}$ & -114.98155 & -115.01035 & -115.09585 & -115.02837 & -115.03967 \\
\hline $\mathrm{CH}_{3} \mathrm{~F}^{+\cdot}\left({ }^{2} \mathrm{~A}^{\prime \prime}\right)$ & $1 c$ & $-138.89121^{e}$ & $-138 \cdot 90498^{f}$ & -139.02099 & $-138.91310^{f}$ & -138.93103 \\
\hline$\dot{\mathrm{C}} \mathrm{H}_{2} \stackrel{+}{\mathrm{F}} \mathrm{H}$ & $2 c$ & -138.89900 & $-138.91796^{f}$ & -139.02692 & $-138.93063^{f}$ & -138.94367 \\
\hline $\operatorname{TS}(2 c \rightarrow 1 c)$ & $3 \mathrm{c}$ & -138.85204 & -138.86943 & -138.98099 & -138.87907 & -138.89693 \\
\hline $\mathrm{CH}_{3} \mathrm{PH}_{2}^{+\cdot}$ & $1 d$ & -381.42663 & -381.45078 & -381.48223 & -381.48064 & -381.49130 \\
\hline$\stackrel{\mathrm{C}}{\mathrm{C}}{ }_{2} \stackrel{+}{\mathrm{P}} \mathrm{H}_{3}$ & $2 d$ & -381.40581 & -381.43048 & -381.46300 & -381.46288 & -381.47280 \\
\hline $\mathrm{CH}_{3} \mathrm{SH}^{+\cdot}$ & $1 \mathrm{e}$ & -437.63727 & -437.65474 & -437.69041 & -437.68485 & -437.69602 \\
\hline$\dot{\mathrm{C}}_{2}{ }_{2} \stackrel{\mathrm{S}}{\mathrm{H}_{2}}$ & $2 e$ & -437.59799 & -437.61723 & -437.65444 & -437.64840 & -437.65875 \\
\hline $\mathrm{CH}_{3} \mathrm{Cl}^{+\cdot}\left({ }^{2} \mathrm{~A}^{\prime}\right)$ & $1 f$ & -498.96369 & -498.97141 & -499.01313 & -498.99974 & -499.01016 \\
\hline$\dot{\mathrm{C}} \mathrm{H}_{2} \stackrel{+}{\mathrm{C}} 1 \mathrm{H}$ & $2 f$ & -498.93687 & -498.94908 & -498.99187 & -498.97718 & -498.98645 \\
\hline
\end{tabular}


a Based on $\mathrm{MP} 2 / 6-31 \mathrm{G}^{*}$ optimized geometries.

b Full range of molecular orbitals used for correlation.

c For second-row systems, the underlying 6-31G( $\underline{\mathrm{df}}, \underline{\mathrm{p}})$ basis set was used.

d From ref 57 .

e $\mathrm{MP} 2 / 6-31 \mathrm{G}^{*} / / \mathrm{MP} 2 / 6-31 \mathrm{G}^{*}$ zero-point vibrational energy is $89.5 \mathrm{~kJ} \mathrm{~mol}^{-1}$.

f From ref 146 . 
Table 4.7 Higher-Level Calculations: Relative Energies ${ }^{\mathrm{a}}\left(\mathrm{kJ} \mathrm{mol}^{-1}\right.$ )

$M P 2 / 6-31 G^{*} \quad M P 2 / 6-31 G^{* *} \quad M P 2 / 6-311 G(\underline{d f}, \underline{p})^{b} \quad M P 3 / 6-31 G^{* *} M P 4 / 6-31 G^{* *} \quad M P 4 / 6-311 G(\underline{d f}, \underline{p})^{b, c} \quad M P 4 / 6-311 G(\underline{d f}, \underline{p})^{d}$

\begin{tabular}{|c|c|c|c|c|c|c|c|c|}
\hline $\mathrm{CH}_{3} \mathrm{NH}_{2}{ }^{+\cdot}$ & $1 \mathrm{a}$ & 0 & 0 & 0 & 0 & 0 & 0 & 0 \\
\hline$\dot{\mathrm{C}}_{2} \stackrel{+}{\mathrm{N}}_{3}$ & $2 a$ & -16 & -18 & -21 & -11 & -9 & -12 & -8 \\
\hline $\mathrm{CH}_{3} \mathrm{OH}^{+\cdot}$ & $1 \mathrm{~b}$ & 0 & 0 & 0 & 0 & 0 & 0 & 0 \\
\hline$\dot{\mathrm{C}} \mathrm{H}_{2} \stackrel{+}{\mathrm{O}}_{2}$ & $2 b$ & -52 & -62 & -66 & -48 & -44 & -47 & -46 \\
\hline
\end{tabular}

$\begin{array}{lcccr}\mathrm{CH}_{3} \mathrm{~F}^{+\cdot} & 1 \mathrm{c} & 0 & 0 & 0 \\ \underset{\mathrm{C}}{\mathrm{C}}{ }_{2}^{+}{ }^{+} \mathrm{H} & 2 \mathrm{c} & -20 & -34 & -16 \\ \mathrm{TS}(2 \mathrm{c} \rightarrow 1 \mathrm{c}) & 3 \mathrm{c} & 103 & 93 & 105\end{array}$

$\begin{array}{rrr}0 & 0 & 0 \\ -46 & -33 & -1 \\ 89 & 90 & 10\end{array}$

$0 \quad 0^{e}$

$-15 \quad-14$

101

95

$\begin{array}{lllll}\mathrm{CH}_{3} \mathrm{PH}_{2}^{+\cdot} & 1 \mathrm{~d} & 0 & 0 & 0 \\ \dot{\mathrm{CH}}_{2}{ }_{2}^{+} \mathrm{PH}_{3} & 2 \mathrm{~d} & 55 & 53 & 50\end{array}$

\section{0}

47

0

0

46 


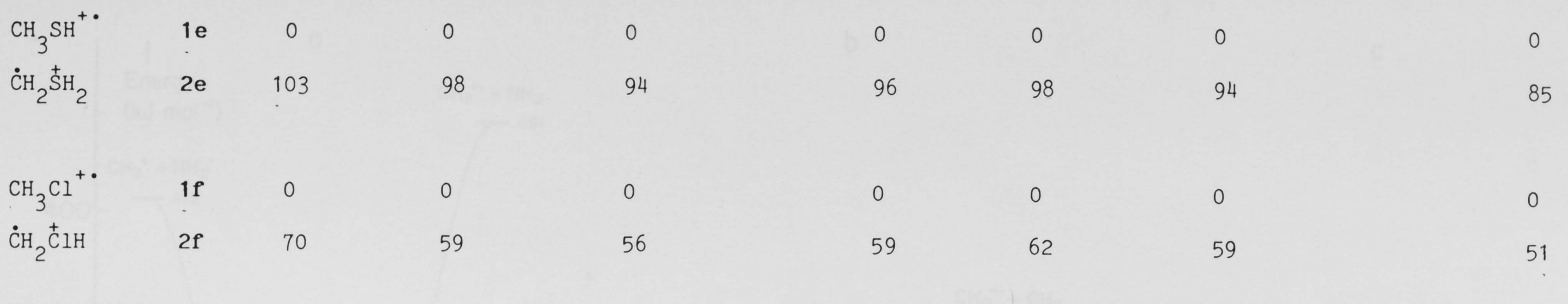

a Based on the total energies in Table 4.6.

b For second-row systems, the underlying $6-31 \mathrm{G}(\underline{\mathrm{df}}, \underline{\mathrm{p}})$ basis set was used.

C Estimated using the additivity approximations of equations (3.1) and (3.2) for first-and second-row systems, respectively.

d $M P 4 / 6-311 G(\underline{d f}, \underline{p})$ or MP4/6-31G( $(\underline{d f}, \underline{p})$ value with zero-point vibrational energy correction.

e MP2/6-31G ${ }^{*}$ ZPVE used (after scaling by 0.93 , ref 60 ). 


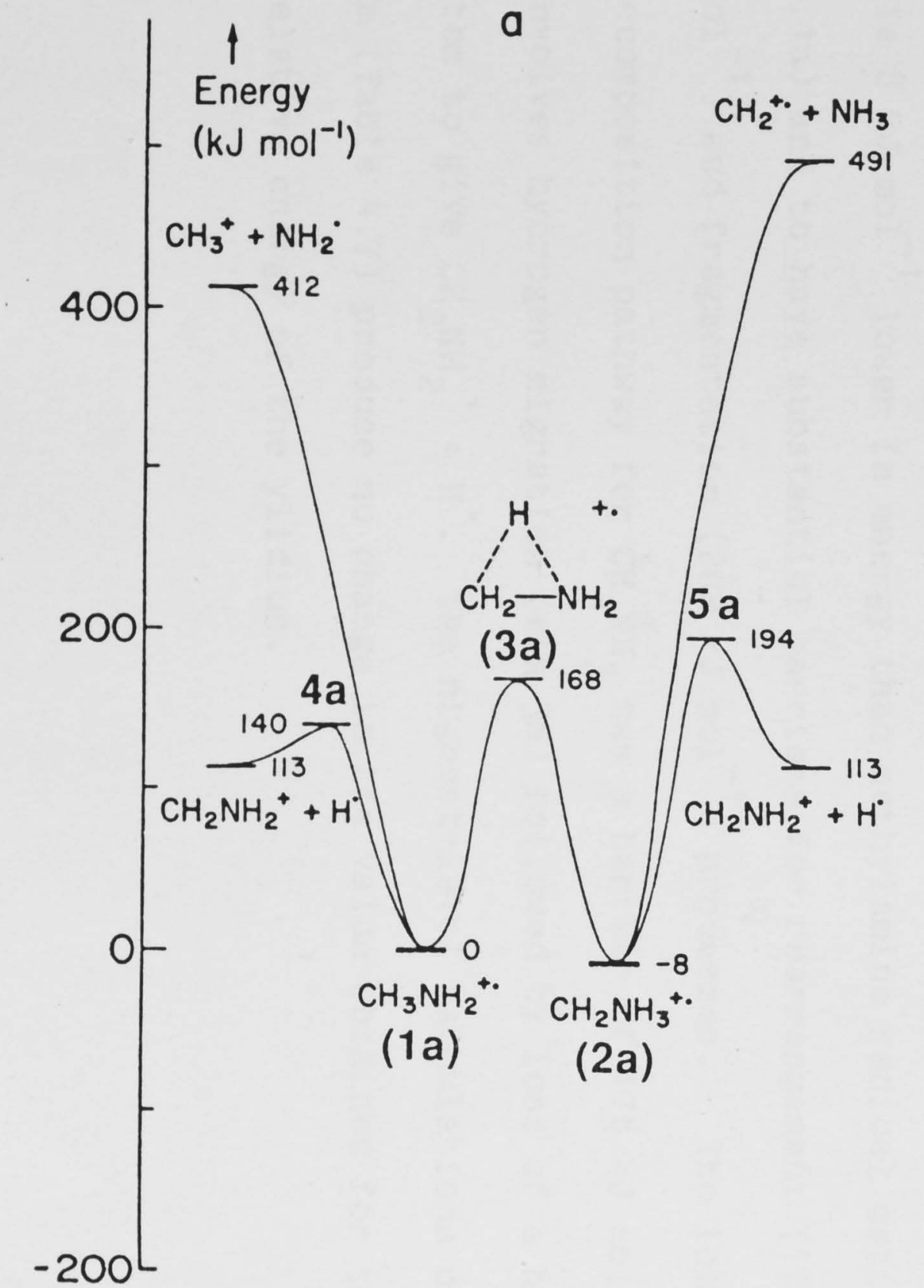

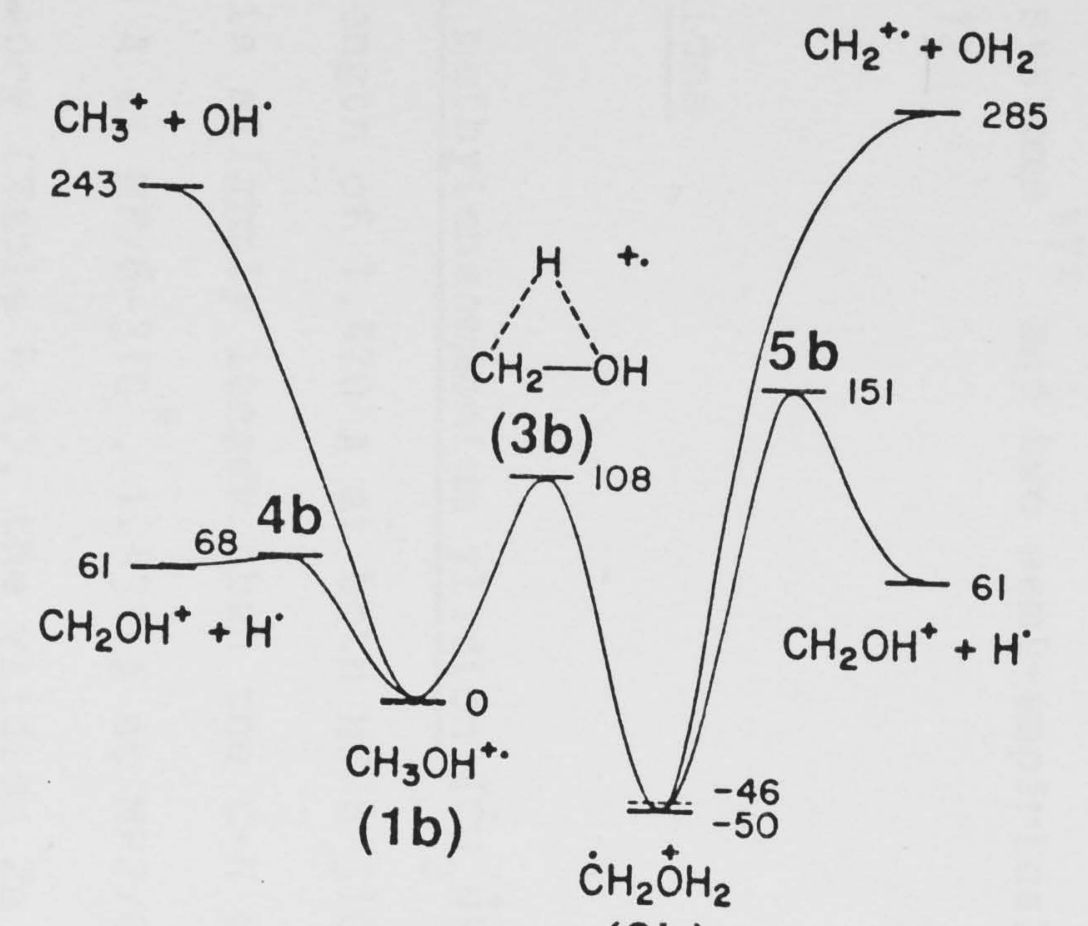

(2b)

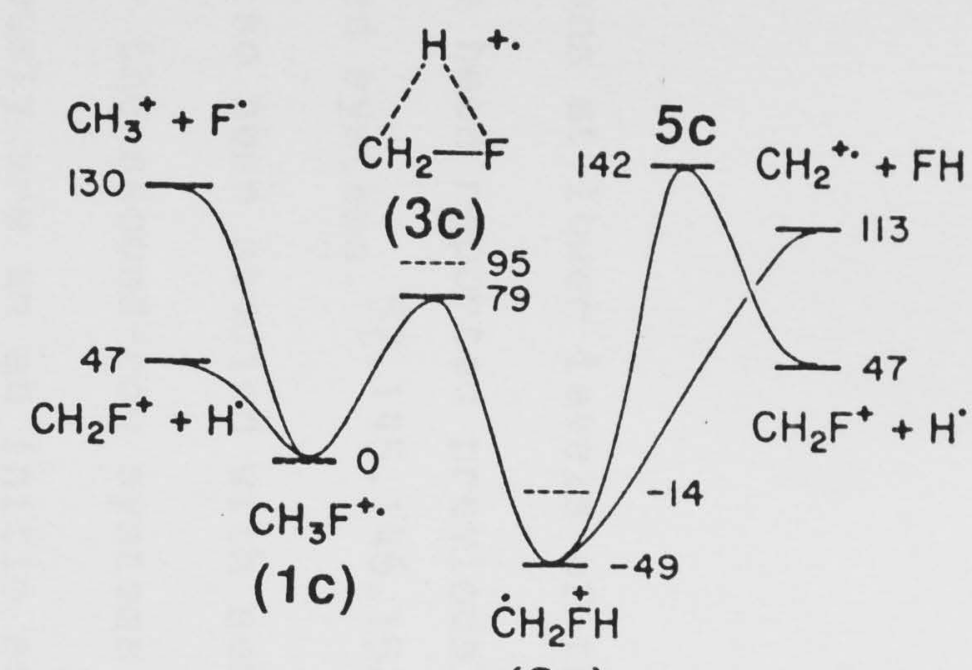

(2C)

Figure 4.1 Schematic energy profiles for rearrangement and fragmentation processes of the first-row ylidions and their conventional isomers based on the highest-level results in Table 4.4 (- - ) and Table 4.7 ( $-\sim-$ ). 


\subsection{Discussion}

Ab initio calculations at lower levels of theory than those used in the present work have been reported previously for all of the first-row ylidions and related systems. $57,145,146,152,153,161-167$

Some of these systems have also been studied with semi-empirical methods. $164,166,168-170$ For the second-row systems, the only calculations published previously are an ab initio study of the $\dot{\mathrm{CH}}_{2} \stackrel{+}{\mathrm{S}} \mathrm{H}_{2}$ ylidion and related systems ${ }^{171}$ and two semi-empirical studies on the $\stackrel{\mathrm{C}}{\mathrm{C}}{ }_{2} \stackrel{+}{\stackrel{+}{\mathrm{P}}} \mathrm{H}_{3}$ ylidion. 128,172

\subsubsection{First-Row Ylidions}

\subsubsection{The methyleneammonium ylidion $\left(\dot{\mathrm{C}}_{2}{ }_{2}^{\mathrm{N}} \mathrm{H}_{3}, 2 \mathrm{a}\right)$ is found} to have a $\mathrm{C}-\mathrm{N}$ bond length of $1.470 \AA$ at both $\mathrm{HF} / 6-31 \mathrm{G}^{* 145,153}$ and MP2/6-31G*57, which is slightly longer than the $\mathrm{C}-\mathrm{N}$ bond length in $\mathrm{CH}_{3} \mathrm{NH}_{2}^{+\cdot}$ (1a) $\left(1.458 \AA\right.$ at $\mathrm{HF} / 6-31 \mathrm{G}^{*}, 1.431$ \& at $\left.\mathrm{MP} 2 / 6-31 \mathrm{G}^{*}\right)$. At the standard level of theory (Table 4.4), the ylidion $2 a$ is predicted to lie $8 \mathrm{~kJ} \mathrm{~mol}^{-1}$ lower in energy than methylamine radical cation (Figure 4.1a) and to have substantial barriers for rearrangement (176 kJ $\mathrm{mol}^{-1}$ ) and fragmentation (202 $\left.\mathrm{kJ} \mathrm{mol}^{-1}\right)$ processes. The lowest-energy decomposition pathway for $\dot{\mathrm{CH}}_{2} \stackrel{+}{\mathrm{N}}_{3}$ has a barrier of $176 \mathrm{~kJ} \mathrm{~mol}^{-1}$ and involves hydrogen migration (via 3a) followed by loss of a hydrogen atom to give $\mathrm{CH}_{2} \mathrm{NH}_{2}^{+}+\mathrm{H}^{\circ}$. The highest-level calculations on $1 \mathrm{a}$ and $2 a$ (Table 4.7 ) produce no change in the value obtained for the relative energy of the ylidion. 


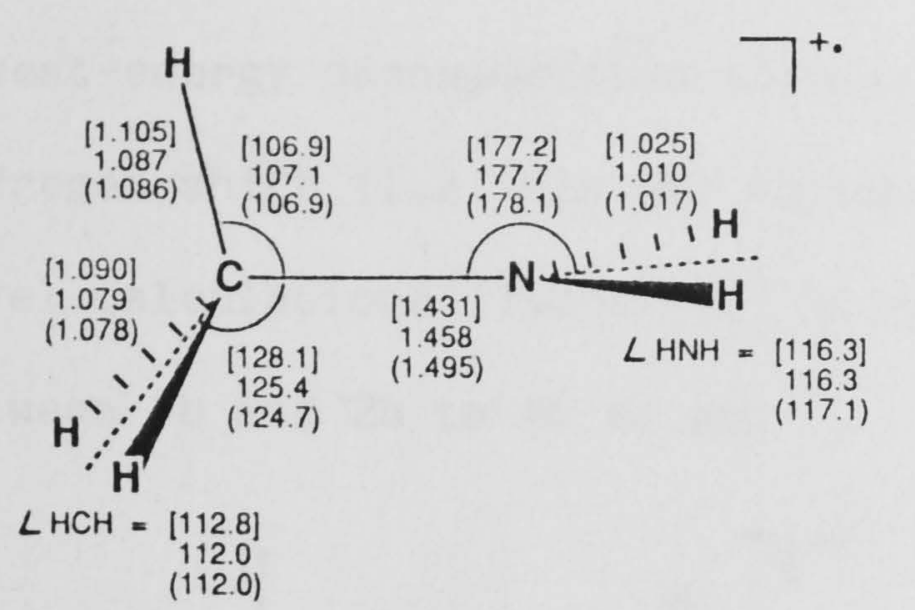

$1 \mathrm{a}$

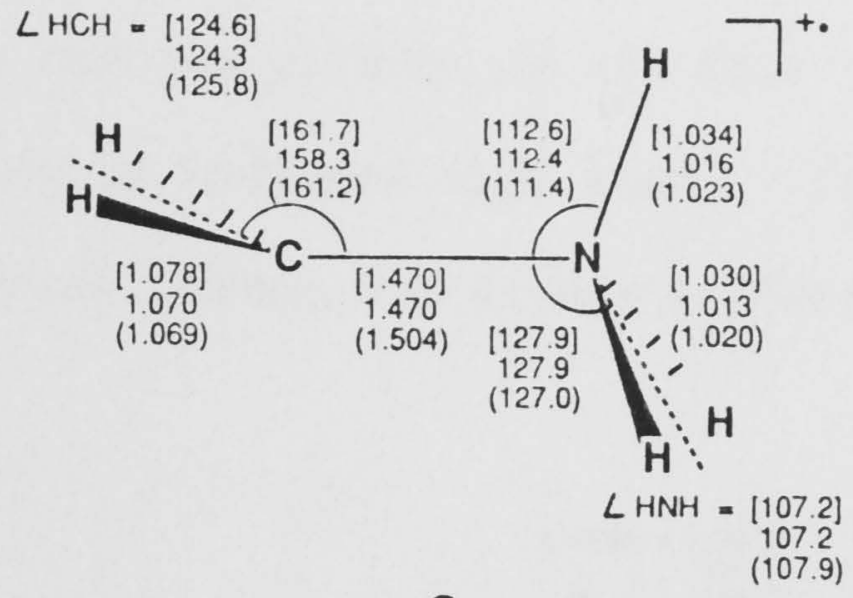

$2 a$

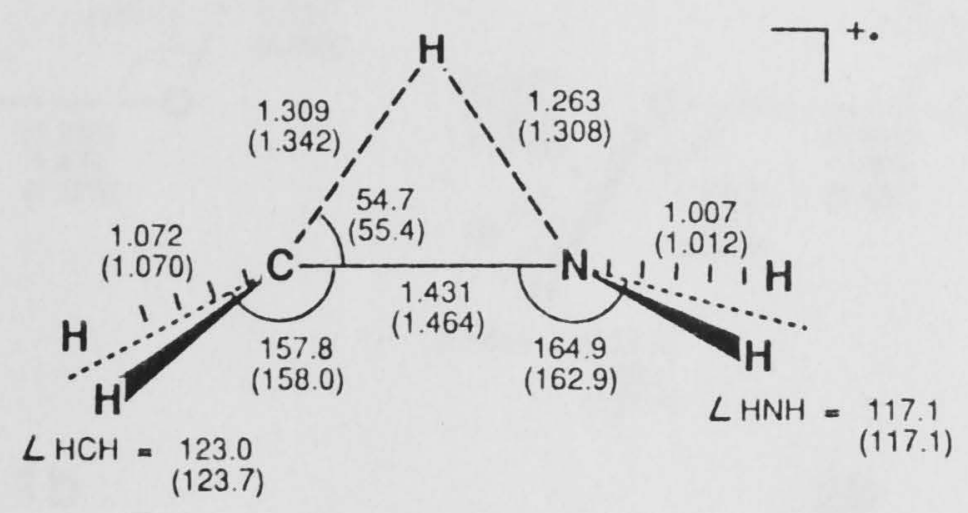

$3 a$

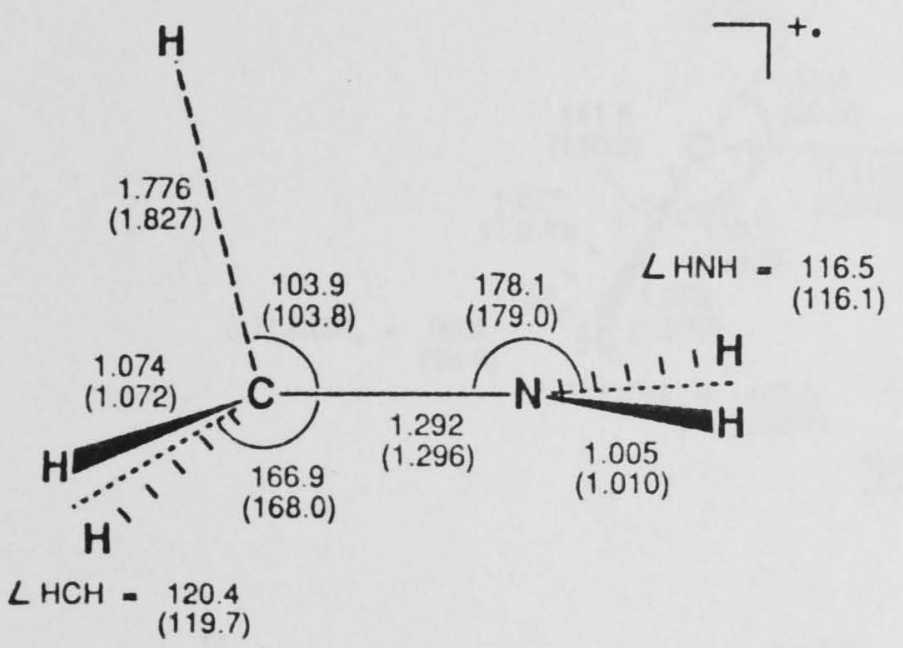

$4 a$

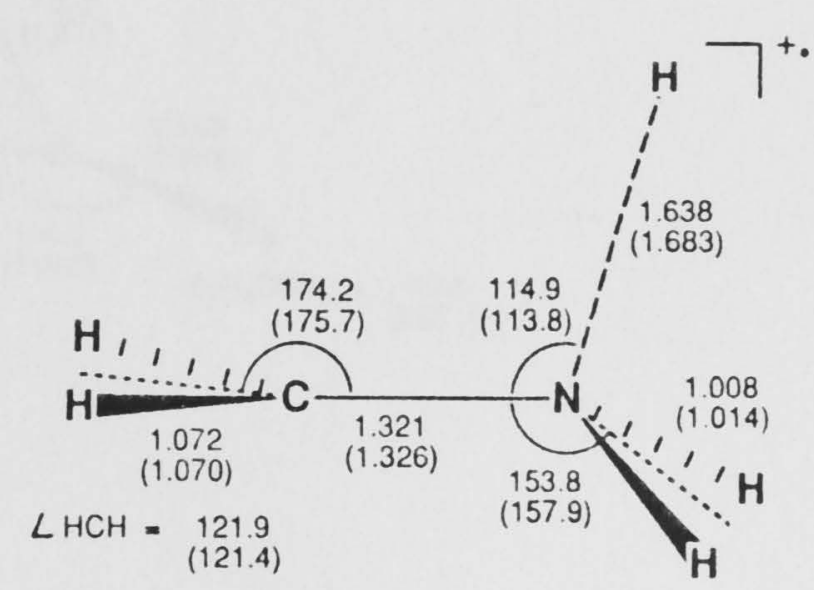

$5 a$

4.3.1.2 The methyleneoxonium ylidion $\left(\dot{\mathrm{C}}_{2} \stackrel{+}{\mathrm{O}}_{2}\right.$, 2b) has a $\mathrm{C}-\mathrm{O}$ bond length $\left(1.459 \AA\right.$ at $\mathrm{HF} / 6-31 \mathrm{G}^{*}, 1521.468$ \& at $\left.\mathrm{MP} 2 / 6-31 \mathrm{G}^{*}\right)$ which is only slightly different from that in the methanol radical cation $1 \mathrm{~b}$ $\left(1.474\right.$ \& at $\mathrm{HF} / 6-31 \mathrm{G}^{*}, 1.383$ \& at $\left.\mathrm{MP} 2 / 6-31 \mathrm{G}^{*}\right)$ but which is considerably shorter than the $\mathrm{C}-\mathrm{O}$ bond in neutral $\mathrm{CH}_{2} \mathrm{OH}_{2}$. At the standard level of theory (Table 4.4), the ylidion $2 \mathrm{~b}$ is calculated to lie $50 \mathrm{~kJ} \mathrm{~mol}^{-1}$ below the methanol radical cation (Figure $4.1 \mathrm{~b}$ ). The barrier for rearrangement of $\dot{\mathrm{CH}}_{2} \mathrm{OH}_{2}$ to $\mathrm{CH}_{3} \mathrm{OH}^{+\cdot}$ is $158 \mathrm{~kJ} \mathrm{~mol}^{-1}$ and the 
86.

lowest-energy decomposition pathway for the ylidion is via this 1,2hydrogen shift (i.e. via 3b) followed by hydrogen atom loss. Higherlevel calculations (Table 4.7) slightly reduce the energy difference between $1 \mathrm{~b}$ and $2 \mathrm{~b}$ to $46 \mathrm{~kJ} \mathrm{~mol}^{-1}$.

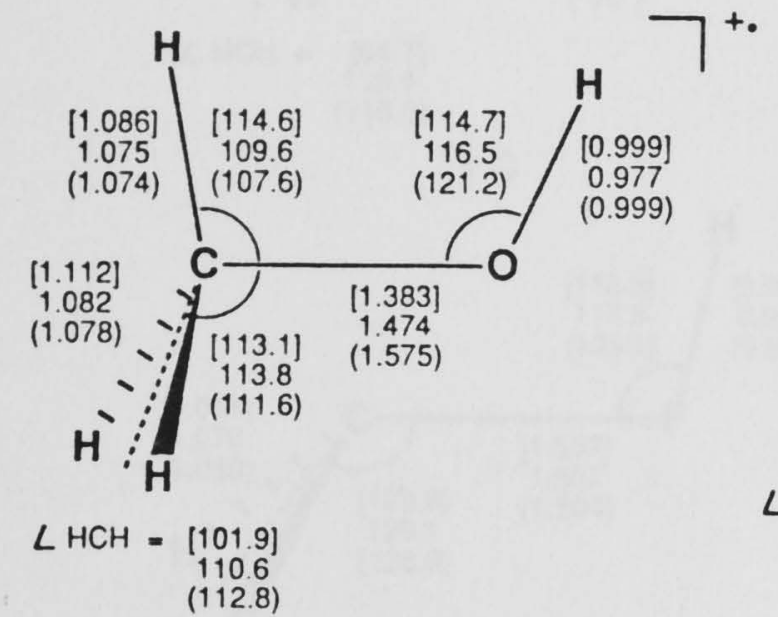

1b

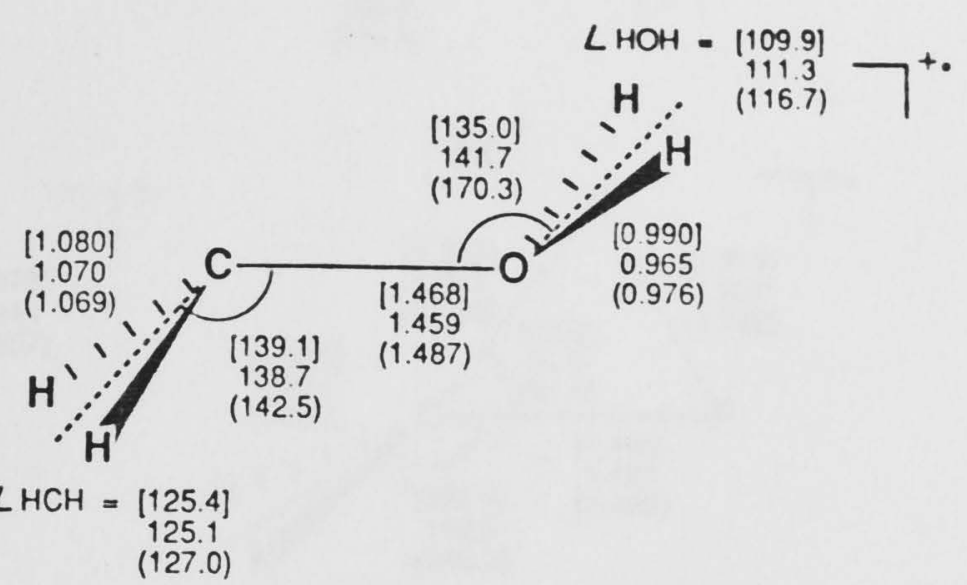

$2 b$

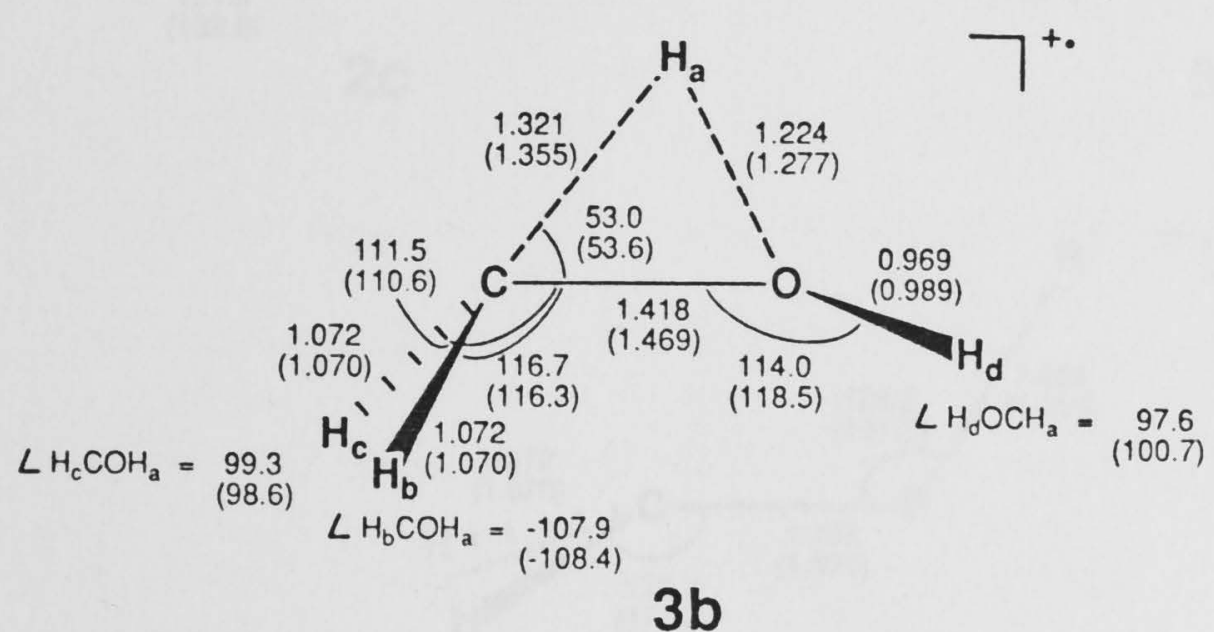

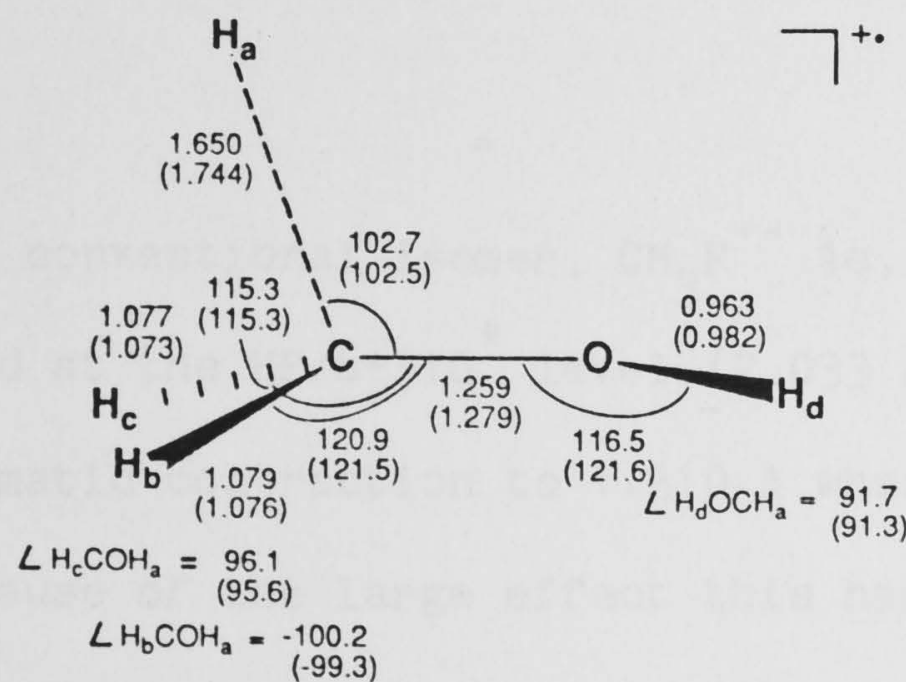

$4 b$

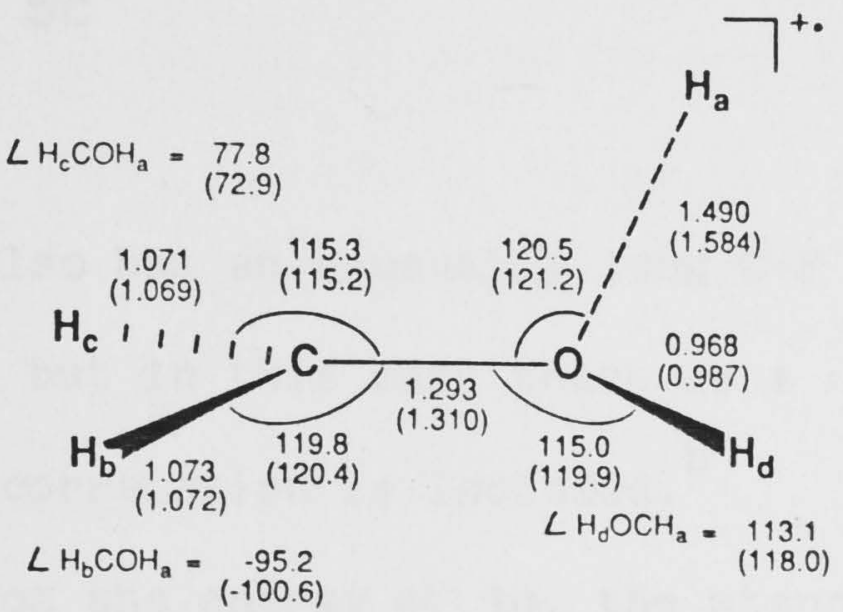

$5 b$

\subsubsection{The methylenefluoronium ylidion $\left(\dot{\mathrm{C}} \mathrm{H}_{2} \stackrel{+}{\mathrm{F}} \mathrm{H}, 2 \mathrm{c}\right)$ has a} moderately long $\mathrm{C}-\mathrm{F}$ bond at the $\mathrm{HF} / 6-31 \mathrm{G}^{*}$ level $\left(1.587 \AA^{146}\right)$ compared with that in neutral fluoromethane $(1.365 \AA)$ and there is a slight shortening (to $1.557 \AA$ ) upon reoptimization at MP2/6-31G* . 

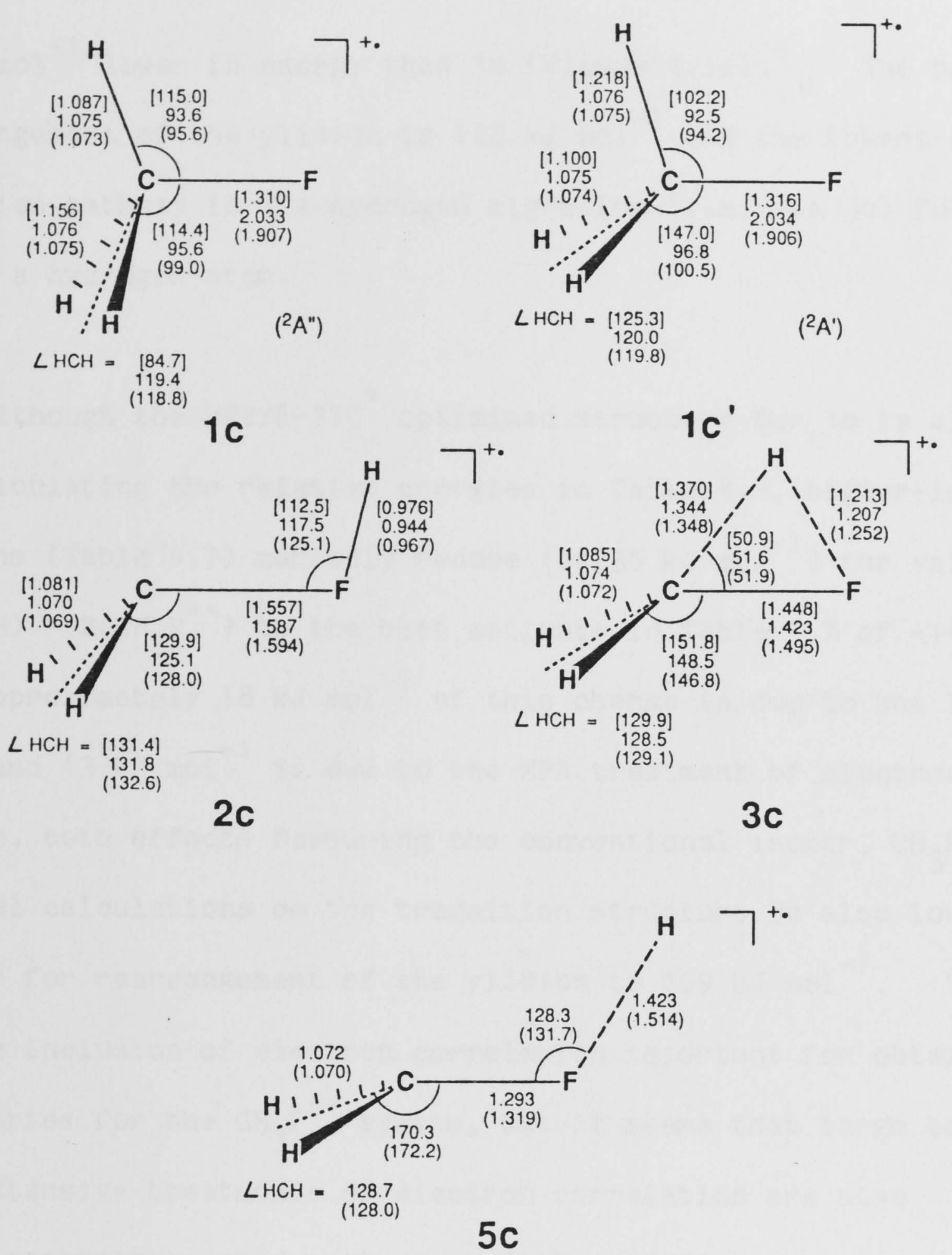

The conventional isomer, $\mathrm{CH}_{3} \mathrm{~F}^{+\cdot} 1 \mathrm{c}$, also has an unusually long $\mathrm{C}-\mathrm{F}$ bond at the $\mathrm{HF} / 6-31 \mathrm{G}^{*}$ level $(2.033 \AA$ ) but in this case there is a dramatic contraction to 1.310 \& when correlation is included. b Because of the large effect this has on the energy of $1 \mathrm{c}$, the standard calculations (Table 4.4) have been based on the MP2/6-31G* optimized structure for $\mathrm{CH}_{3} \mathrm{~F}^{+\cdot}$. At this level, the ylidion $2 \mathrm{c}$ is calculated to

b. Reoptimization at $\mathrm{MP} 3 / 6-31 \mathrm{G}^{*}$ of the five stationary points on the $\left[\mathrm{CH}_{3} \mathrm{~F}^{+\cdot}\right]$ surface leads to only minor further structural changes. See ref 50 . 
lie $49 \mathrm{~kJ} \mathrm{~mol}^{-1}$ lower in energy than 1c (Figure 4.1c). ${ }^{c}$ The barrier for rearrangement of the ylidion is $128 \mathrm{~kJ} \mathrm{~mol}^{-1}$ and the lowest-energy decomposition pathway is via hydrogen migration (i.e. via 3c) followed by loss of a hydrogen atom.

Although the MP2/6-31G* optimized structure for $1 \mathrm{c}$ is already used in calculating the relative energies in Table 4.4, higher-level calculations (Table 4.7) markedly reduce (by $35 \mathrm{~kJ} \mathrm{~mol}^{-1}$ ) the value for $\mathrm{E}\left(\dot{\mathrm{CH}}_{2}{ }_{\mathrm{FH}}^{+}\right)-\mathrm{E}\left(\mathrm{CH}_{3} \mathrm{~F}^{+\cdot}\right)$ to the best estimate in Table 4.7 of $-14 \mathrm{~kJ}$ $\mathrm{mol}^{-1}$. Approximately $18 \mathrm{~kJ} \mathrm{~mol}^{-1}$ of this change is due to the larger basis set and $13 \mathrm{~kJ} \mathrm{~mol}^{-1}$ is due to the MP4 treatment of electron correlation, both effects favouring the conventional isomer, $\mathrm{CH}_{3} \mathrm{~F}^{+\cdot}$. Higher-level calculations on the transition structure $3 \mathrm{c}$ also lower the barrier for rearrangement of the ylidion to $109 \mathrm{~kJ} \mathrm{~mol}^{-1}$. Thus, not only is inclusion of electron correlation important for obtaining good geometries for the $\mathrm{CH}_{3} \mathrm{~F}^{+\cdot}$ system, but it seems that large basis sets and extensive treatments of electron correlation are also important in obtaining good estimates of the relative energies involved. The possibility that more sophisticated calculations will further change these relative energies cannot be excluded. ${ }^{d}$

c. A zero-point vibrational energy correction for this relative energy was not included in an earlier study ( $r$ ef 146) due to difficulties in calculating numerically the vibrational frequencies for 1c. A detailed discussion of the theoretical problem has been presented by Colwell et al. ( $r$ ef 173) for the isoelectronic methoxy radical.

d. Stilf higher level calculations give a preliminary value of $-23 \mathrm{~kJ}$ $\mathrm{mol}^{-1}$ for the energy of $2 \mathrm{c}$ relative to $1 \mathrm{c}$. 
Although attention in this chapter is focused on the ylidions, it is appropriate at this juncture to point out some additional unusual features of $\mathrm{CH}_{3} \mathrm{~F}^{+\cdot}$. This species is expected $^{174,175}$ to have two Jahn-Teller distorted forms ( $1 \mathrm{c}$ and $1 \mathrm{c}^{\prime}$ ), since in the neutral fluoromethane molecule the highest occupied molecular orbital (HOMO) is doubly degenerate. In fact, due to the poor description of the C-F bond at the HF level, the two forms of $\mathrm{CH}_{3} \mathrm{~F}^{+\cdot}$ are barely distinguishable with this method and both are characterized through analytical calculation of vibrational frequencies as being minima on the HF/3-21G potential surface. With the inclusion of electron correlation, the C-F bond shortens and the Jahn-Teller distortion is consequently much larger.

The poor geometries obtained at $\mathrm{HF} / 3-21 \mathrm{G}$ for $\mathrm{CH}_{3} \mathrm{~F}^{+\cdot}$ suggest that the vibrational frequency analyses at this level may be inappropriate. However, it turns out that after recalculating vibrational frequencies at $M P 2 / 6-31 G^{*}$ for the ${ }^{2} A^{\prime \prime}$ form and scaling by an appropriate factor $(0.93),{ }^{60}$ the calculated ZPVE is only $4 \mathrm{~kJ} \mathrm{~mol}^{-1}$ lower than the HF/3-21G value. These MP2/6-31G ${ }^{*}$ calculations also confirm that the ${ }^{2} \mathrm{~A}$ " state of $\mathrm{CH}_{3} \mathrm{~F}^{+\cdot}$ corresponds to a minimum on the potential surface. At the highest level in Table 4.7 (without inclusion of zero-point correction), the ${ }^{2} \mathrm{~A}^{\prime}$ state $\left(1 \mathrm{c}^{\prime}\right)$ lies $8.7 \mathrm{~kJ}$ mol $^{-1}$ higher than the ${ }^{2} A "$ state $(1 c)$. By analogy with the methoxy radical, 173 this higher state would probably have one imaginary frequency at $M P 2 / 6-31 G^{*}$ (i.e. it represents the transition structure for rearrangement between two equivalent ${ }^{2} A$ " forms). 


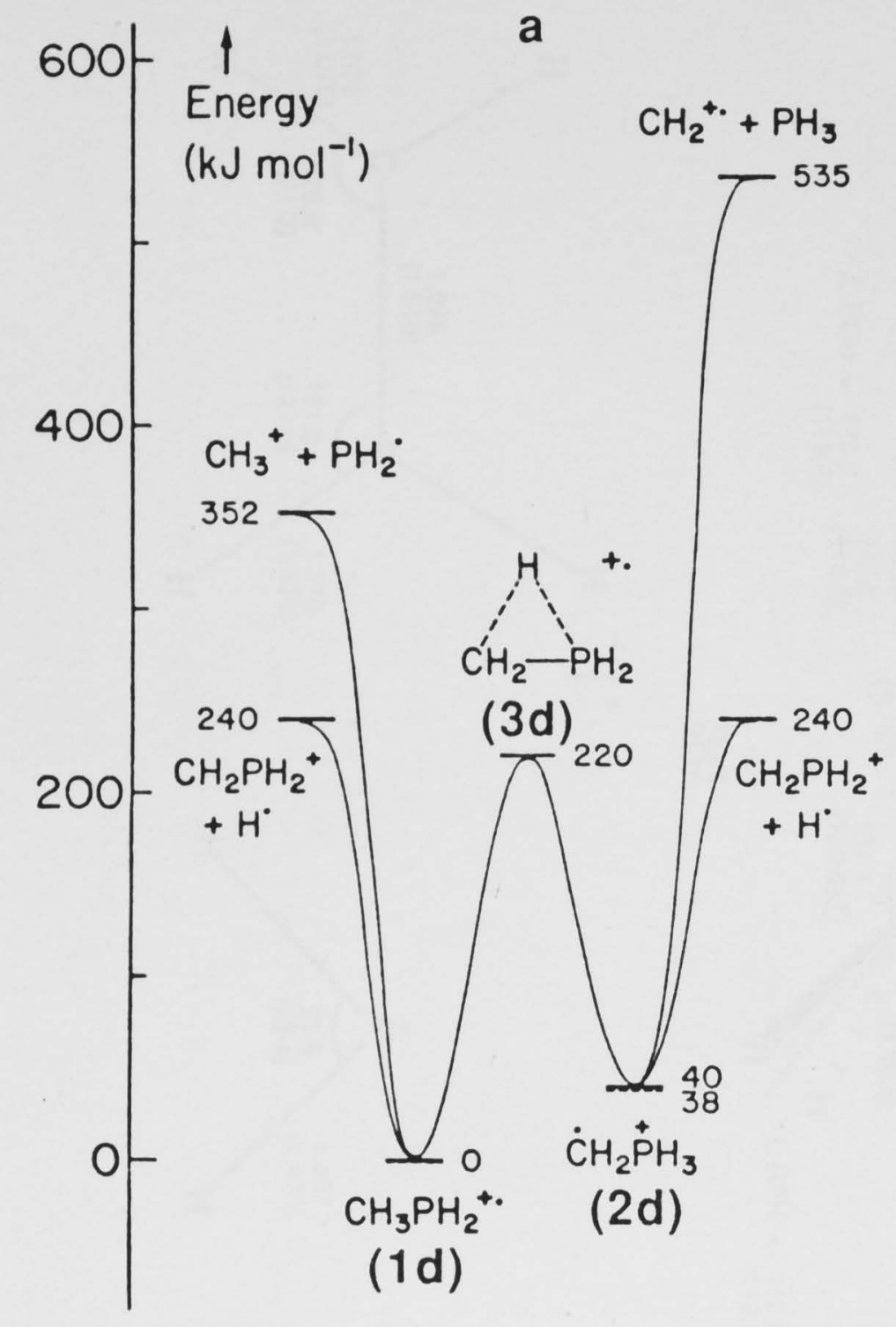

b

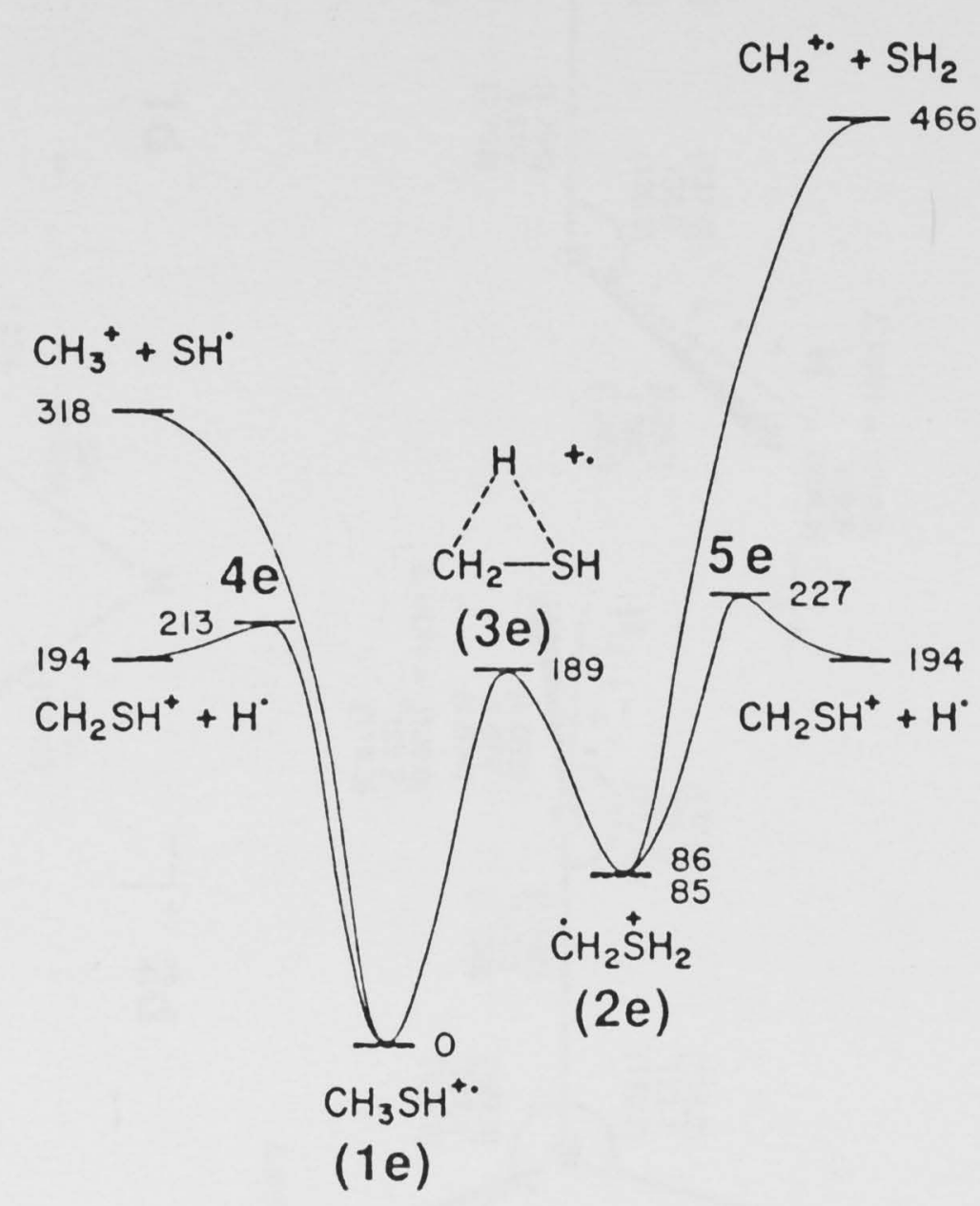

C

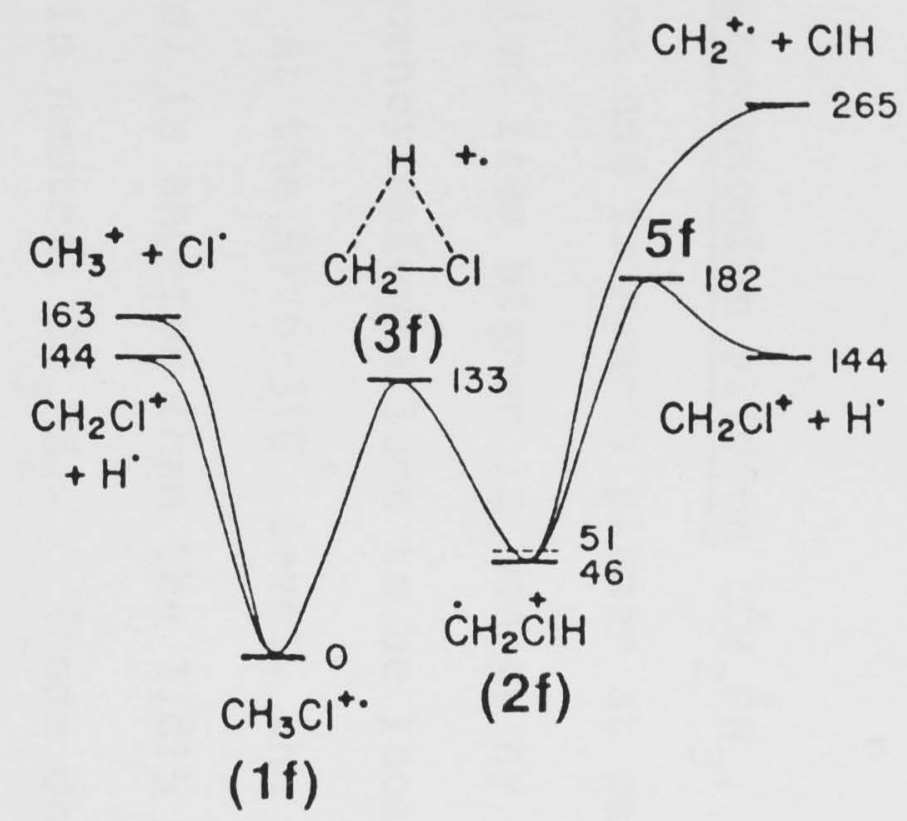

Figure 4.2 Schematic energy profiles for rearrangement and fragmentation processes of the second-row ylidions and their conventional isomers based on the highest-level results in Table 4.5 (- - ) and Table 4.7 ( - - ) 


\subsubsection{Second-Row Ylidions}

\subsubsection{The methylenephosphonium ylidion $\left(\dot{\mathrm{C}}_{2} \stackrel{+}{P}_{3}, 2 \mathrm{~d}\right)$ has a}

preferred staggered conformation and is nearly planar at carbon. The alternative eclipsed conformation lies higher in energy by just $0.1 \mathrm{~kJ}$ $\mathrm{mol}^{-1}$ and is confirmed by frequency calculations to be located at a saddle point on the surface. At the HF/6-31 G* level, the $\mathrm{C}-\mathrm{P}$ bond length of $1.772 \AA$ in $\dot{\mathrm{C}}_{2} \mathrm{P}_{2} \mathrm{P}_{3}(2 \mathrm{~d})$ is shorter than the $1.815 \AA$ in $\mathrm{CH}_{3} \mathrm{PH}_{2}^{+\cdot}$ (1d) and the $1.861 \AA$ in neutral $\mathrm{CH}_{3} \mathrm{PH}_{2}$. These observations are confirmed with MP2/6-31G* reoptimization (where there is a slight
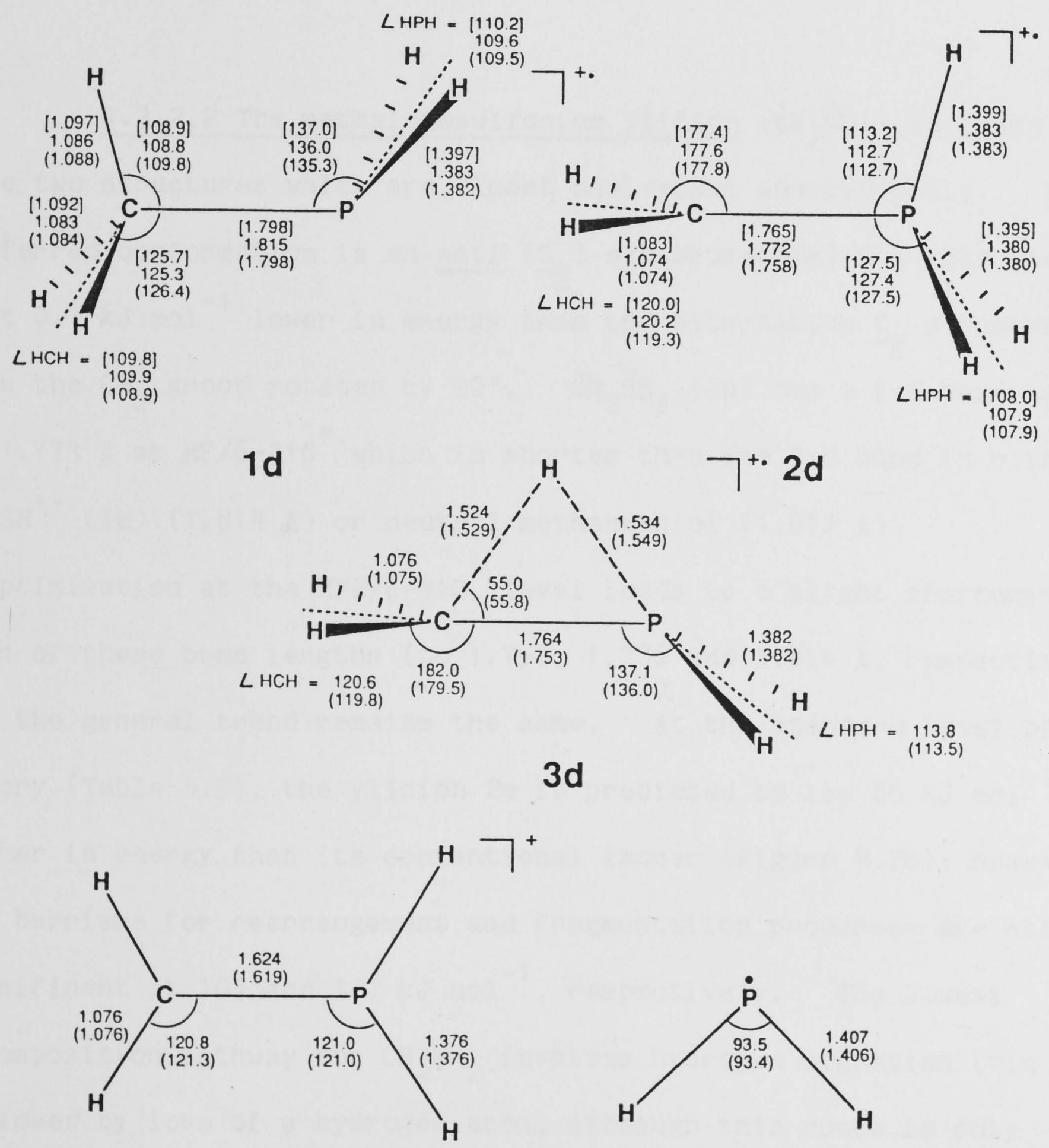
shortening of each of these bond lengths). At the standard level of theory (Table 4.5), $\dot{\mathrm{C}}_{2} \stackrel{+}{\mathrm{P}}_{3}$ is found to lie higher in energy than its conventional isomer (1d) by $40 \mathrm{~kJ} \mathrm{~mol}^{-1}$ (Figure $4.2 \mathrm{a}$ ), which is nearly double the value obtained from MNDO calculations. ${ }^{128}$ The ylidion lies in a deep potential well with substantial barriers for rearrangement and fragmentation processes (180 and $200 \mathrm{~kJ} \mathrm{~mol}^{-1}$, respectively). Decomposition of $\dot{\mathrm{C}}_{2}{ }_{2} \stackrel{+}{\mathrm{P}}_{3}$ is predicted to occur most easily by loss of a hydrogen atom, either directly or via an initial isomerization (i.e. via 3d). The higher-level calculations on $1 d$ and 2d (Table 4.7) result in a slight lowering of the relative energy of the ylidion to $38 \mathrm{~kJ} \mathrm{~mol}^{-1}$.

\subsubsection{The methylenesulfonium ylidion $\left(\dot{\mathrm{C}}_{2} \stackrel{+}{\mathrm{S}} \mathrm{H}_{2}\right)$ is found to} have two structures which are almost equivalent energetically. The preferred conformation is an anti $\left(\underline{C}_{\underline{S}}\right)$ structure (2e) but this lies just $0.1 \mathrm{~kJ} \mathrm{~mol}^{-1}$ lower in energy than the alternative $\underline{\mathrm{C}}_{\underline{\underline{S}}}$ structure with the $\mathrm{CH}_{2}$ group rotated by $90^{\circ} \cdot \quad \dot{\mathrm{C}}_{2}{\stackrel{+}{\mathrm{S}} \mathrm{H}_{2}}_{2}$ (2e) has a $\mathrm{C}-\mathrm{S}$ bond length of $1.773 \AA$ at $\mathrm{HF} / 6-31 \mathrm{G}^{*}$ which is shorter than the $\mathrm{C}-\mathrm{S}$ bond in either $\mathrm{CH}_{3} \mathrm{SH}^{+\cdot}(1 \mathrm{e})(1.814 \AA)$ or neutral methanethiol $(1.817 \AA)$.

Reoptimization at the MP2/6-31G* level leads to a slight shortening of each of these bond lengths (to $1.759,1.786$ and $1.814 \AA$, respectively) but the general trend remains the same. At the standard level of theory (Table 4.5), the ylidion $2 \mathrm{e}$ is predicted to lie $86 \mathrm{~kJ} \mathrm{~mol}^{-1}$ higher in energy than its conventional isomer (Figure 4.2b); however, the barriers for rearrangement and fragmentation processes are still significant at 103 and $127 \mathrm{~kJ} \mathrm{~mol}^{-1}$, respectively. The lowest decomposition pathway for $\dot{\mathrm{C}}_{2} \mathrm{H}_{2} \mathrm{H}_{2}$ involves hydrogen migration (via $3 e$ ) followed by loss of a hydrogen atom, although this route is only slightly preferable to direct loss of $\mathrm{H}^{*}$. Higher-level calculations 
on $1 \mathbf{e}$ and $2 \mathbf{e}$ (Table 4.7 ) have a negligible effect on the relative energy of the ylidion, lowering it to $85 \mathrm{~kJ} \mathrm{~mol}^{-1}$.
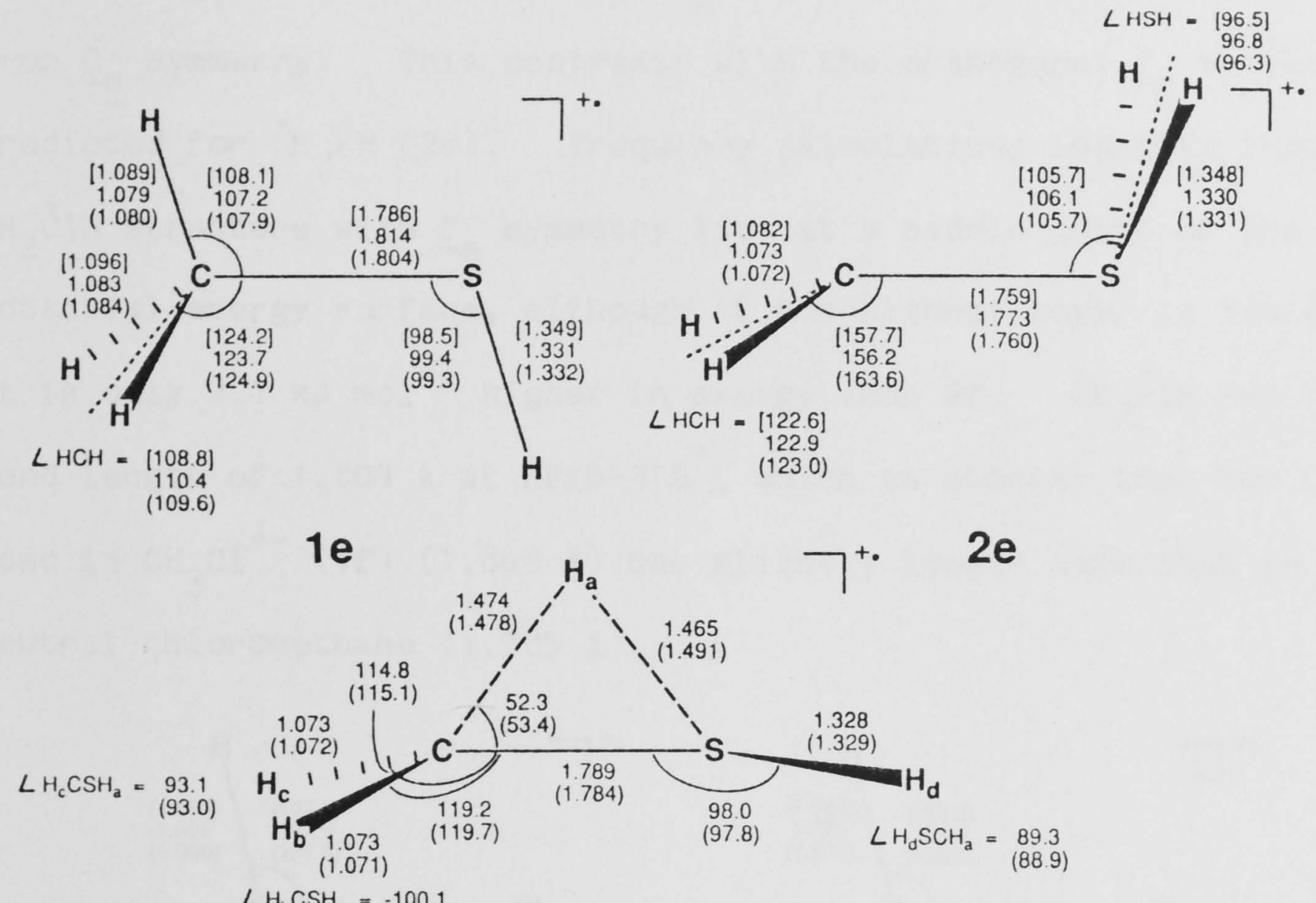

$\angle H_{0} \mathrm{CSH}_{\mathrm{a}}=-{ }_{-100.1}^{-1096)}$

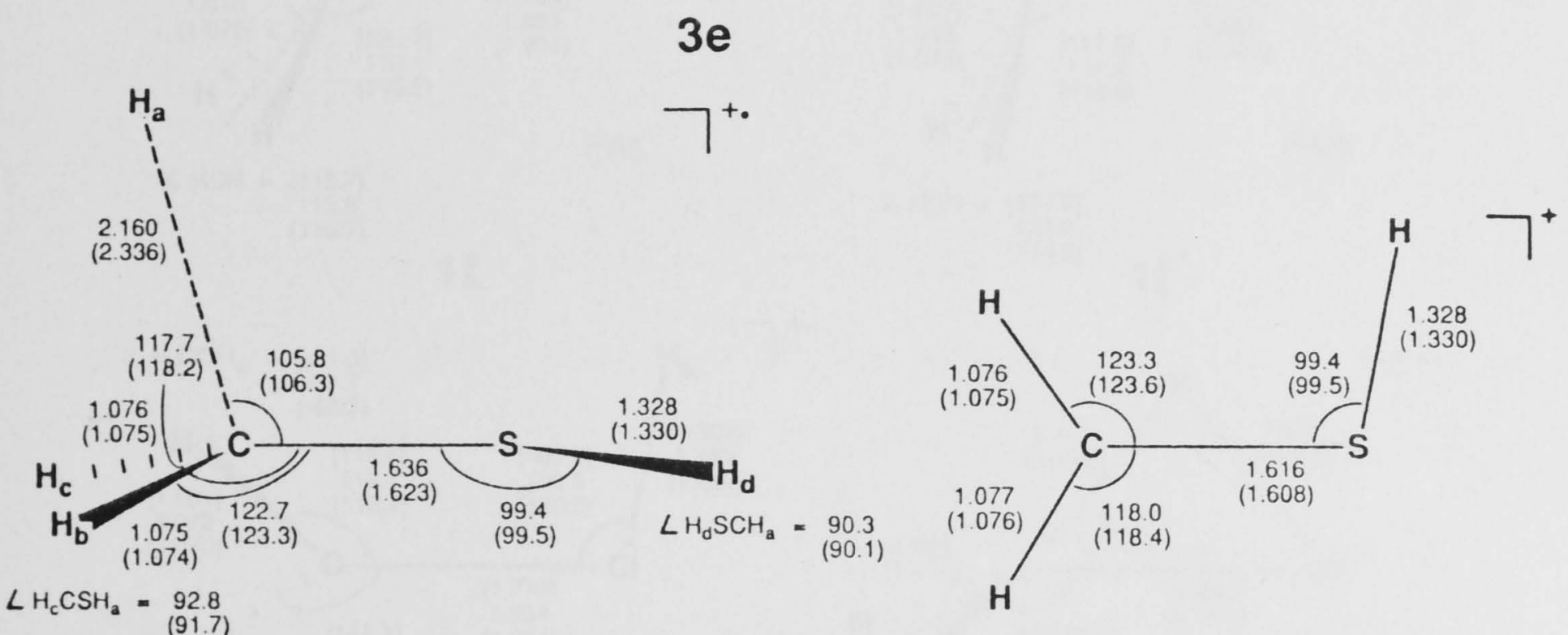

$\angle \mathrm{H}_{\mathrm{c}} \mathrm{CSH}_{\mathrm{a}}=\frac{92.8}{(91.7)}$

$L \mathrm{H}_{\mathrm{b}} \mathrm{CSH}_{\mathrm{a}}=\begin{gathered}-94.6 \\ (-93.0)\end{gathered}$

$4 e$
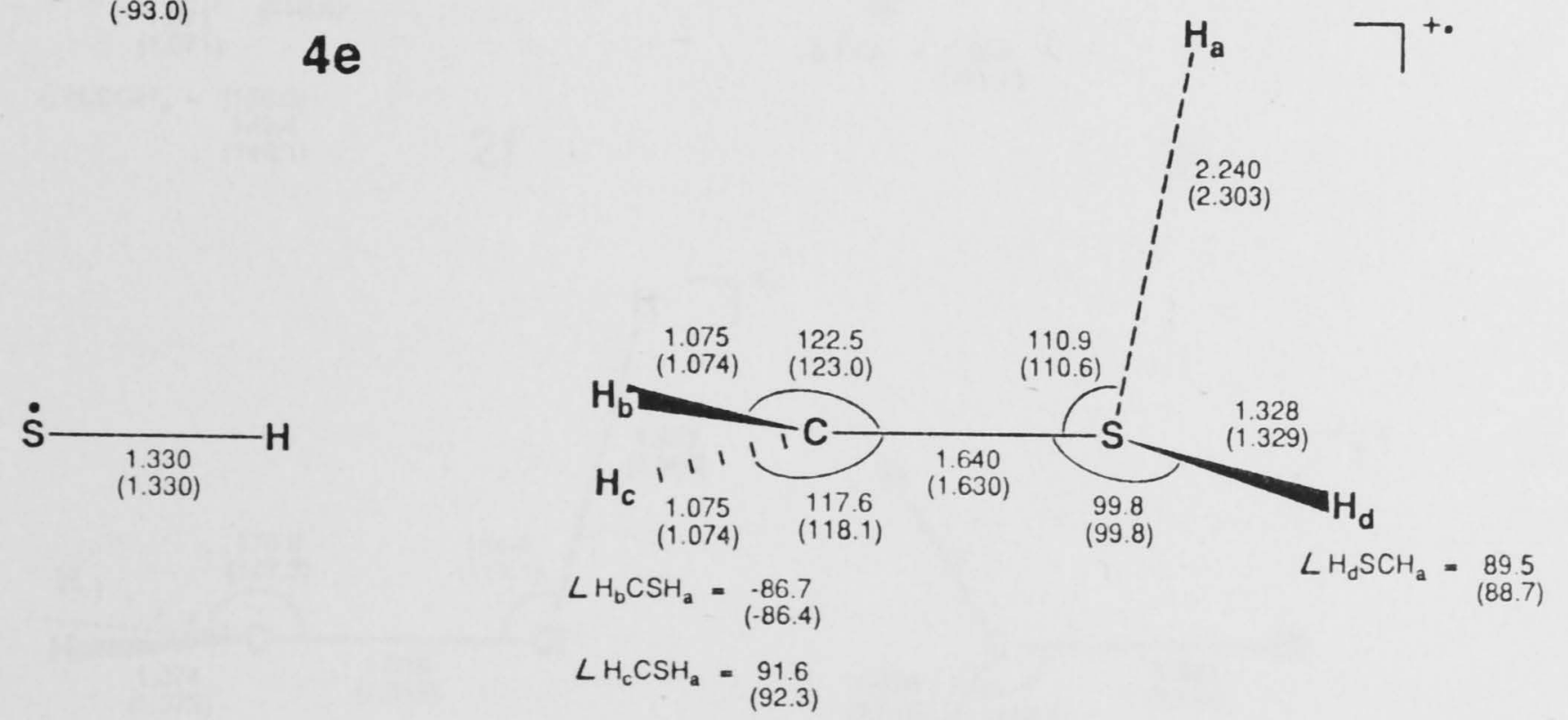


\subsubsection{The methylenechloronium ylidion $\left(\dot{\mathrm{C}}_{2} \stackrel{+}{\mathrm{C}} 1 \mathrm{H}, 2 \mathbf{f}\right)$ is found}

to have a $\underline{\mathrm{C}}_{1}$ structure with the $\mathrm{CH}_{2}$ group twisted significantly away from $\underline{C}_{\underline{s}}$ symmetry. This contrasts with the orthogonal $\underline{C}_{\underline{s}}$ structure predicted for $\dot{\mathrm{CH}}_{2}{ }_{\mathrm{F}}^{\mathrm{F}} \mathrm{H}(2 \mathrm{c})$. Frequency calculations indicate that the $\dot{\mathrm{C}}_{2} \stackrel{+}{\mathrm{C}} 1 \mathrm{H}$ structure with $\underline{\mathrm{C}}_{\underline{\mathrm{S}}}$ symmetry lies at a saddle point on the potential energy surface, although at the highest level in Table 4.7 it is only $2.1 \mathrm{~kJ} \mathrm{~mol}^{-1}$ higher in energy than $2 \mathrm{f} . \quad \dot{\mathrm{C}}_{2} \stackrel{+}{\mathrm{C}} \mathrm{lH}$ has a $\mathrm{C}-\mathrm{Cl}$ bond length of $1.804 \AA$ at $\mathrm{HF} / 6-31 \mathrm{G}^{*}$, which is shorter than the $\mathrm{C}-\mathrm{Cl}$ bond in $\mathrm{CH}_{3} \mathrm{Cl}^{+\cdot}$ (1f) $(1.869 \AA)$ but slightly longer than that in neutral chloromethane $(1.785 \AA)$.

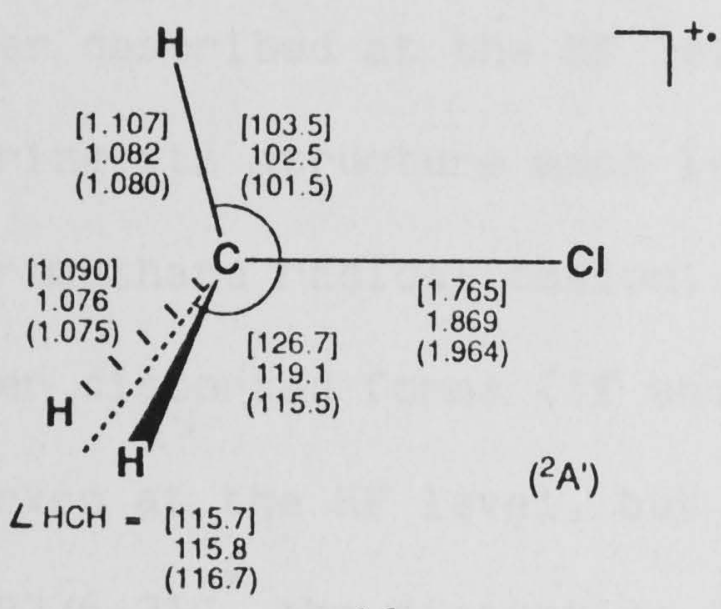

$1 f$

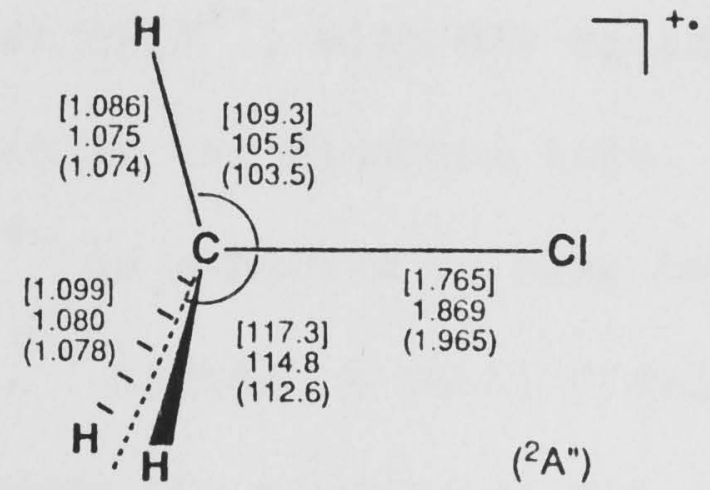

$\angle H C H=\left[\begin{array}{c}107.7] \\ 112.6\end{array}\right]$ (114.2)

$1 f^{\prime}$
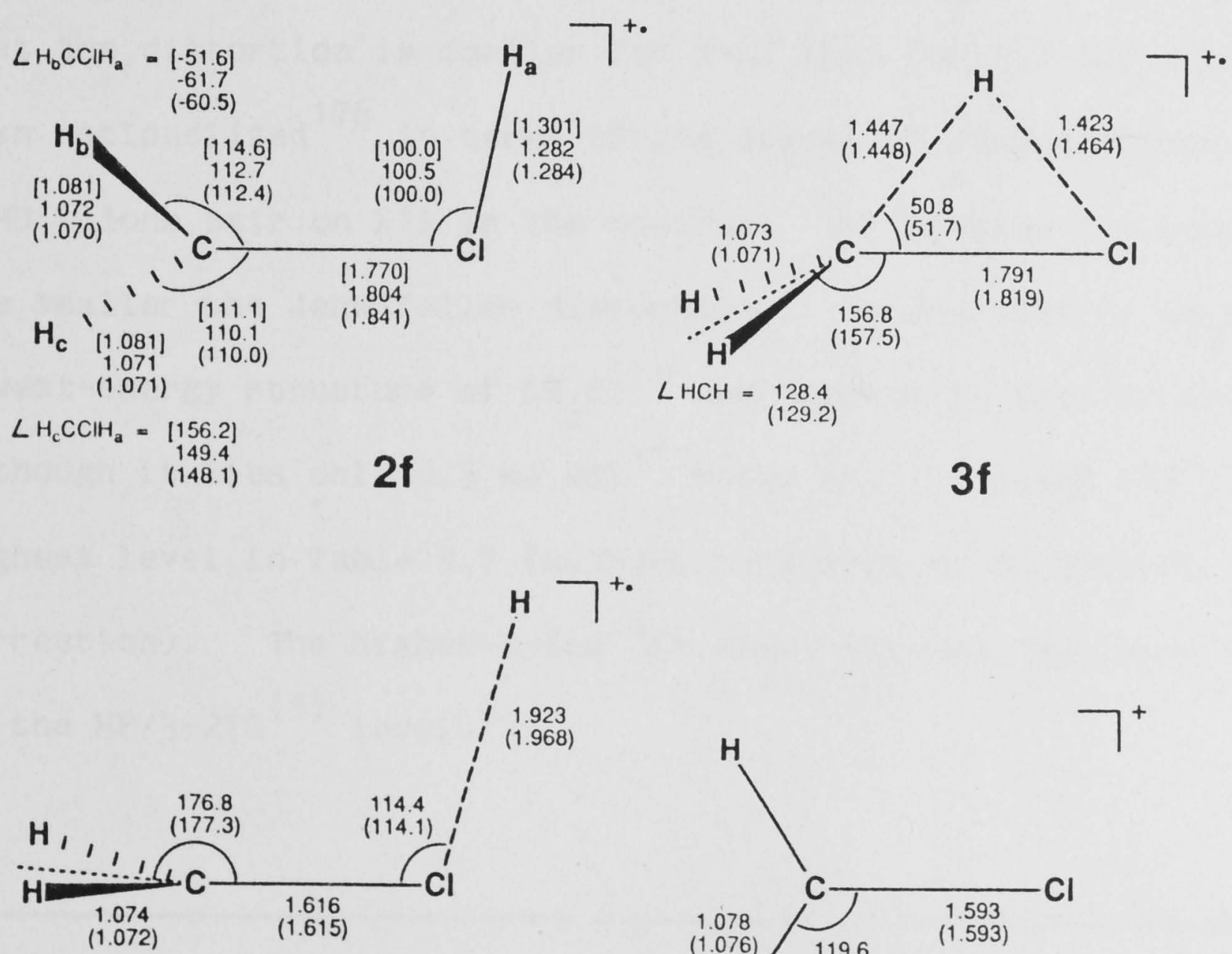

$\mathrm{LHCH}=\frac{123.1}{(122.4)}$

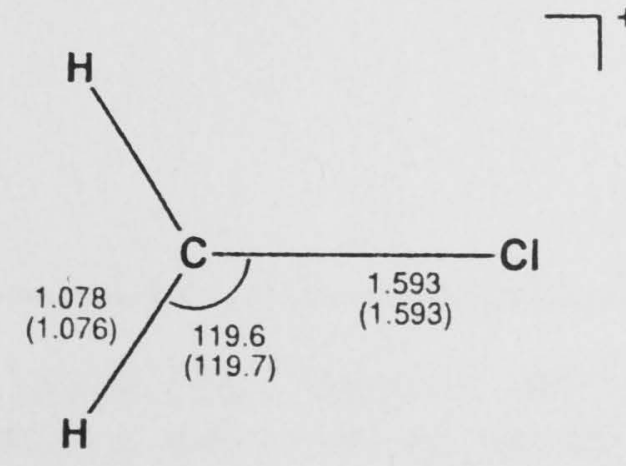


MP2/6-31G* optimizations shorten each of these bonds (to $1.770,1.765$ and $1.778 \AA$, respectively) but the effect is largest for $\mathrm{CH}_{3} \mathrm{Cl}^{+\cdot}$ and the ordering of the $\mathrm{C}-\mathrm{Cl}$ bond lengths is reversed. The ylidion is predicted (Table 4.5) to lie $46 \mathrm{~kJ} \mathrm{~mol}^{-1}$. higher in energy than if (Figure $4.2 \mathrm{c}$ ) and the barriers for rearrangement and fragmentation processes are 87 and $98 \mathrm{~kJ} \mathrm{~mol}^{-1}$, respectively. Higher-level calculations (Table 4.7) slightly increase the energy difference between $1 \mathrm{f}$ and $2 \mathrm{f}$ to $51 \mathrm{~kJ} \mathrm{~mol}^{-1}$.

The chloromethane radical cation $\left(\mathrm{CH}_{3} \mathrm{Cl}^{+\cdot}\right)$ is apparently better described at the $\mathrm{HF}$ level than $\mathrm{CH}_{3} \mathrm{~F}^{+\cdot}$, with MP2 optimizations altering its structure much less than in the fluorine case. Like the fluoromethane radical cation, $\mathrm{CH}_{3} \mathrm{Cl}^{+}$is expected to have two JahnTeller distorted forms ( $1 \mathbf{f}$ and $\left.\mathbf{f}^{\prime}\right)$. Indeed, a small distortion is observed at the HF level, but even when the structures are reoptimized at MP2/6-31G the distortion is less than in $\mathrm{CH}_{3} \mathrm{~F}^{+*}$. The observation that the distortion is smaller for $\mathrm{X}=\mathrm{Cl}$ than for $\mathrm{X}=\mathrm{F}$ has previously been rationalized ${ }^{176}$ in terms of the degree of localization of the HOMO ('lone pair on $\mathrm{X}^{\prime}$ ) in the neutral: the greater the localization, the smaller the Jahn-Teller distortion. In contrast to $\mathrm{CH}_{3} \mathrm{~F}^{+\cdot}$, the lowest-energy structure of $\mathrm{CH}_{3} \mathrm{Cl}^{+}$corresponds to the ${ }^{2} \mathrm{~A}^{\prime}$ state (1f), although it lies only $0.3 \mathrm{~kJ} \mathrm{~mol}^{-1}$ below the ${ }^{2} \mathrm{Al}^{\prime \prime}$ state (1/') at the highest level in Table 4.7 (wi thout inclusion of zero-point correction). The higher-lying ${ }^{2} \mathrm{~A}$ " state has one imaginary frequency at the $\mathrm{HF} / 3-21 \mathrm{G}^{(*)}$ level. ${ }^{\mathrm{e}}$

e. Frequencies calculated using a numerical second derivative procedure are, however, all real, a deficiency which has been previously noted for the methoxy radical (ref 173). 
It may be noted in passing that the lower-energy structure $\left({ }^{2} \mathrm{Al}^{\prime \prime}\right)$ of $\mathrm{CH}_{3} \mathrm{~F}^{+\cdot}$ resembles a complex of $\mathrm{H}_{2}$ with $\mathrm{HCF}^{+}$, in that the two symmetry-equivalent $\mathrm{C}-\mathrm{H}$ bonds are quite long (1.156 \&) and the angle between them is just $84.7^{\circ}$ (at MP2 $/ 6-31 \mathrm{G}^{*}$ ). When viewed in this manner, the geometry of $\mathrm{CH}_{3} \mathrm{~F}^{+\cdot}$ is analogous to the preferred $\underline{\mathrm{C}}_{2 \mathrm{v}}$ structure of $\mathrm{CH}_{4}^{+} \cdot 177$ This resemblance does not carry over, however, to the MP2 optimized structures of $\mathrm{CH}_{3} \mathrm{NH}_{2}^{+\cdot}, \mathrm{CH}_{3} \mathrm{OH}^{+\cdot}$, $\mathrm{CH}_{3} \mathrm{PH}_{2}^{+\cdot}, \mathrm{CH}_{3} \mathrm{SH}^{+\cdot}$ and $\mathrm{CH}_{3} \mathrm{Cl}^{+\cdot}$, where the angles between the symmetryequivalent $\mathrm{C}-\mathrm{H}$ bonds are $112.8^{\circ}, 101.9^{\circ}, 109.8^{\circ}, 108.8^{\circ}$ and $107.7^{\circ}$, respectively. Indeed, these species resemble the less stable $\underline{C}_{3 \underline{v}}$ structure of $\mathrm{CH}_{4}{ }^{+\cdot}$. It would seem that for $\mathrm{X}=\mathrm{NH}_{2}, \mathrm{OH}, \mathrm{PH}_{2}, \mathrm{SH}$ and $\mathrm{Cl}$, the positive charge in $\mathrm{CH}_{3} \mathrm{X}^{+\cdot}$ tends to be localized on the substituent $X$, reversing the relative stabilities that exist in $\mathrm{CH}_{4}{ }^{+}$. of the $\underline{\mathrm{C}}_{2 \underline{\mathrm{v}}}$ and $\underline{\mathrm{C}}_{3 \underline{\mathrm{v}}}$ forms. For the more electronegative $\mathrm{X}=\mathrm{F}$, however, significant electron depletion occurs in the $\mathrm{CH}_{3}$ moiety.

\subsubsection{Comparisons Across the Periodic Table}

From left to right across the first-and second-rows of the periodic table, the following trends in the ylidions may be noted:

(i) the $\mathrm{C}-\mathrm{X}$ bond in the ylidion $\left(\dot{\mathrm{C}}_{2}{ }_{2}+\underset{\mathrm{X}}{\mathrm{H}}\right)$ becomes longer relative to the $\mathrm{C}-\mathrm{X}$ bond in $\mathrm{CH}_{3} \mathrm{X}^{+\cdot}$;

(ii) the degree of non-planarity at carbon in the ylidion increases;

(iii) the barrier for rearrangement of the ylidion to its conventional isomer decreases;

(iv) the barrier for the lowest-energy decomposition of the ylidion decreases; and

(v) the binding energy of the ylidion with respect to $\mathrm{CH}_{2}{ }^{+\cdot}+\mathrm{XH}$ dramatically decreases. 
These trends reflect a decrease in the overall stability of the ylidions in the order Group V > Group VI > Group VII.

\subsubsection{Comparisons Between First- and Second-Row Ylidions}

For the first-row systems, the $C-X$ bonds in the ylidions $\left(\dot{\mathrm{C}}_{2} \stackrel{+}{\mathrm{X}} \mathrm{H}\right)$ are all longer than those in the conventional isomers (provided MP2 optimized structures are used for the comparison). These ylidions are all substantially pyramidal at carbon. They are lower in energy than their conventional isomers and the barriers to rearrangement are quite large.

For the second-row systems, the $\mathrm{C}-\mathrm{X}$ bonds in the ylidions tend to be shorter than those in the conventional isomers. These ylidions have a greater tendency to be planar at carbon than their first-row counterparts. They lie higher in energy than their conventional isomers and the barriers to rearrangement tend to be lower than in the first-row.

These comparisons can lead to two different conclusions. On the one hand, the relative bond lengths suggest that the ylidions are more tightly bound in the second-row than in the first-row. Thus, whereas $\dot{\mathrm{C}}_{2} \stackrel{+}{\mathrm{P}} \mathrm{H}_{3}$ appears to have quite a strong $\mathrm{C}-\mathrm{P}$ bond, the $\dot{\mathrm{C}} \mathrm{H}_{2} \stackrel{+}{\mathrm{F}} \mathrm{H}$ ylidion might be regarded as more of a complex between $\mathrm{CH}_{2}{ }^{+\cdot}$ and $\mathrm{FH}^{\mathrm{f}}$ On the other hand, comparison of the energy data suggests that the first-row ylidions are relatively more stable than their second-row counterparts.

f. This stability ordering based on relative bond lengths may be rationalized in terms of the donor ability of XH (see ref 167). 


\subsubsection{Effects of the Higher-Level Calculations}

Differences between the $\mathrm{HF} / 6-31 \mathrm{G}^{*}$ and $\mathrm{MP} 2 / 6-31 \mathrm{G}^{*}$ optimized geometries are much larger in the conventional isomers $\mathrm{CH}_{3} \mathrm{X}^{+\cdot}$ (average change in $\mathrm{C}-\mathrm{X}$ length $=0.165 \AA$, maximum $=0.723 \AA$ ) than in the ylidions $\dot{\mathrm{C}} \mathrm{H}_{2} \stackrel{+}{\mathrm{X}} \mathrm{H}$ (average change in $\mathrm{C}-\mathrm{X}$ length $=0.016 \AA$, maximum $=$ $0.034 \AA$ ). (This may be contrasted with the results of Chapter Three where the effects of electron correlation on optimized geometries were found to be more important for the ylides.) Single-point calculations on these MP2 optimized structures have a rather small effect on the relative energies of the ylidions, with the exception of the fluorine system (as already noted).

\subsubsection{Comparisons with Experiment}

Experimental confirmation of the stability of the ylidions in the gas phase has come from several collisional-activation (CA) mass spectrometric studies. $154,155,166,178-182$ The CA mass spectra of all the ylidions $\left(\dot{\mathrm{C}}_{2} \stackrel{+}{\mathrm{X}} \mathrm{H}\right)$ show intense peaks corresponding to $\mathrm{CH}_{2}^{+\cdot}$ and $\mathrm{XH}^{+}$fragments and show little or no sign of $\mathrm{CH}_{3}^{+}$. There is greater evidence for formation of $\mathrm{CH}_{3}{ }^{+}$for the second-row ylidions, consistent with the theoretical finding that the fragmentation to $\mathrm{CH}_{3}{ }^{+}+\mathrm{x}^{\cdot}$ compared with $\mathrm{CH}_{2}{ }^{+\cdot}+\mathrm{XH}$ is more favourable in the second-row than in the first-row systems (see Figures 4.1 and 4.2). Furthermore, measurement of the kinetic energy release for loss of $\mathrm{H}^{\circ}$ from the ylidions ${ }^{179}$ confirms that this process tends to occur indirectly. Other experimental evidence for the existence of the ylidions has come from ion cyclotron resonance ${ }^{183-187}$ and photoionization ${ }^{188}$ studies. In addition to these gas-phase studies, electron paramagnetic 
99.

resonance (EPR) techniques have been used to study the $\dot{\mathrm{C}} \mathrm{H}_{2} \stackrel{+}{\mathrm{N}} \mathrm{H}_{3} 164,189,190$ and $\dot{\mathrm{CH}}_{2} \stackrel{+}{\mathrm{O}}_{2}{ }^{191}$ ylidions in low-temperature lattices.

The best values from the present work for the relative energies of the ylidions and their conventional isomers are compared with experimental estimates in Table 4.8 .

Table 4.8 Comparison of Theoretical and Experimental Relative Energies ( $\mathrm{KJ} \mathrm{mol}^{-1}$ ) of the Ylidions and their Conventional Isomers

Best $\operatorname{Calc}^{a} \quad \operatorname{Exptl}^{\mathrm{b}}$

\begin{tabular}{|c|c|c|c|}
\hline $\mathrm{CH}_{3} \mathrm{NH}_{2}^{+\cdot}$ & $\dot{\mathrm{C}} \mathrm{H}_{2} \stackrel{+}{\mathrm{N}} \mathrm{H}_{3}$ & -8 & 115 \\
\hline $\mathrm{CH}_{3} \mathrm{OH}^{+\cdot}$ & $\dot{\mathrm{C}} \mathrm{H}_{2} \stackrel{+}{\mathrm{O}} \mathrm{H}_{2}$ & -46 & -31 \\
\hline $\mathrm{CH}_{3} \mathrm{~F}^{+\cdot}$ & $\dot{\mathrm{C}}_{2}{ }_{2}^{+} \mathrm{F}$ & -14 & -68 \\
\hline $\mathrm{CH}_{3} \mathrm{PH}_{2}^{+\cdot}$ & $\dot{\mathrm{C}} \mathrm{H}_{2} \stackrel{+}{\mathrm{P}} \mathrm{H}_{3}$ & 38 & - \\
\hline $\mathrm{CH}_{3} \mathrm{SH}^{+\cdot}$ & $\stackrel{\mathrm{C}}{\mathrm{C}}{ }_{2} \stackrel{+}{\mathrm{S}} \mathrm{H}_{2}$ & 85 & 26 \\
\hline $\mathrm{CH}_{3} \mathrm{Cl}^{+\cdot}$ & $\dot{\mathrm{C}} \mathrm{H}_{2} \stackrel{+}{\mathrm{C}} 1 \mathrm{H}$ & 51 & 20 \\
\hline
\end{tabular}

\footnotetext{
a From Table 4.7 .

b From Tables 4.4 and 4.5 .
}

The agreement can at best be described as fair. The discrepancies are somewhat surprising since it has been shown in preceding sections that, with the exception of the fluorine system, the theoretical 
energy differences do not change greatly as increasingly more sophisticated levels of theory are used. The disagreement is extreme in the case of the $\mathrm{CH}_{3} \mathrm{NH}_{2}^{+} / \dot{\mathrm{CH}}_{2}{ }^{+} \mathrm{NH}_{3}$ pair, for which it is suggested that a reinterpretation of the experimental data may be in order.

Better agreement between theory and experiment is found for the various fragmentation products in Tables 4.4 and 4.5 , particularly for the nitrogen system. For the oxygen, fluorine and chlorine systems, the theoretical relative energies of the fragments are consistently lower than the experimental values, suggesting that in these cases the absolute energy of the $\mathrm{CH}_{3} \mathrm{X}^{+}$species may be too high. To some extent, this error is corrected by the more sophisticated calculations.

\subsection{Comparisons Between the Ylides and the Ylidions}

From the comparisons already presented, it is apparent that some of the trends in the ylides (Chapter Three) and ylidions (Chapter Four) are very similar. For example, the trends in relative bond lengths, rearrangement barriers and binding energies observed for the ylidions parallel those observed for the ylides. However, quantitatively the neutral and charged species behave quite distinctly.

The ylides $\left(\mathrm{CH}_{2} \mathrm{XH}\right)$ have long $\mathrm{C}-\mathrm{X}$ bonds in the first-row systems and in extreme cases resemble very weak complexes of methylene and $\mathrm{XH}$. All the ylides lie much higher in energy than their conventional isomers (the smallest energy difference is still $220 \mathrm{~kJ}$ $\left.\mathrm{mol}^{-1}\right)$. The binding energies of the ylides with respect to $\mathrm{CH}_{2}\left({ }^{1} \mathrm{~A}_{1}\right)$ 
$+\mathrm{XH}$ are generally modest (ranging from 18 to $256 \mathrm{~kJ} \mathrm{~mol}^{-1}$ ) and the lowest-energy decomposition barriers are quite small.

The ylidions $\left(\dot{\mathrm{C}}_{2}{ }_{2}^{+} \mathrm{H}\right.$ ) from the first-row have shorter $\mathrm{C}-\mathrm{X}$ bonds than their corresponding ylides, while those from the second-row have longer $\mathrm{C}-\mathrm{X}$ bonds. All the ylidions lie fairly close in energy to their conventional isomers (the largest energy difference being 85 $\mathrm{kJ} \mathrm{mol}^{-1}$ ) and they tend to have large barriers to rearrangement. The binding energies of the ylidions with respect to $\mathrm{CH}_{2}{ }^{+}+\mathrm{XH}_{\text {are }}$ quite substantial (the largest is $499 \mathrm{~kJ} \mathrm{~mol}^{-1}$ ) and the lowest-energy decomposition barriers are fairly large.

The overall impression is that the ylides $\left(\mathrm{CH}_{2} \mathrm{XH}\right)$, with some exceptions, are rather unstable species compared to their conventional isomers. In contrast, the ylidions $\left(\dot{\mathrm{C}}_{2} \stackrel{+}{\mathrm{X}} \mathrm{H}\right)$ lie in moderately deep potential wells and are of comparable stability to their conventional isomers. For both ylides and ylidions, the stability decreases in progressing from Group V to Group VII of the periodic table. On moving from the first-row to the second-row, the stability (based on energy criteria) appears to increase for the neutral ylides but to decrease for the charged ylidions.

The results presented in Chapters Three and Four also reveal the importance of including electron correlation in calculating the structural features of some of the systems considered here, particularly those involving the more electronegative elements. The effect is most noticeable in the $\mathrm{CH}_{2} \mathrm{XH}$ and $\mathrm{CH}_{3} \mathrm{X}^{+\cdot}$ species. On the whole, MP2/6-31G ${ }^{*}$ optimizations tend to shorten the $C-X$ bonds (relative to $\mathrm{HF} / 6-31 \mathrm{G}^{*}$ ) with the largest reductions being $1.344 \mathrm{~A}$ in 
$\mathrm{CH}_{2} \mathrm{ClH}$ and $0.723 \AA$ in $\mathrm{CH}_{3} \mathrm{~F}^{+\cdot}$. On the other hand, the effects on the relative energies of using large basis sets and of using MP4 instead of MP3 are much less dramatic.

\subsection{Concluding Remarks}

The ylidions are found to lie in reasonably deep potential wells, consistent with their observation in the gas phase. There are significant discrepancies, however, between the calculated and experimental values for the energies of the ylidions relative to their conventional isomers. These discrepancies remain with high-level calculations and suggest a re-examination of the experimental data in some cases. 
103.

\section{CHAPTER FIVE YLIDE DICATIONS}

\subsection{Introduction}

The results presented in Chapters Three and Four show that, whereas the simple ylides $\left(\mathrm{CH}_{2} \mathrm{XH}\right)$ are not particularly stable species and typically lie considerably higher in energy than their conventional isomers $\left(\mathrm{CH}_{3} \mathrm{X}\right)$, the corresponding ylidions $\left(\mathrm{CH}_{2} \mathrm{XH}^{+\cdot}\right)$, on the other hand, are generally quite stable and frequently lie lower in energy than their conventional isomers $\left(\mathrm{CH}_{3} \mathrm{X}^{+}\right)$. It has been shown for the oxygen system $(\mathrm{X}=\mathrm{OH})$ that a continuation of this trend accompanies further ionization. ${ }^{192}$ Thus, whereas the methyleneoxonium dication $\left(\mathrm{CH}_{2} \mathrm{OH}_{2}{ }^{2+}\right)$ lies in a deep potential well, the methanol dication $\left(\mathrm{CH}_{3} \mathrm{OH}^{2+}\right)$ is not a stable entity, consistent with experimental results. $155,179,181$

In this chapter, the generality of the above result is explored through calculations on the ylide dications $\left(\mathrm{CH}_{2} \mathrm{XH}^{2+}\right)$ and their conventional isomers $\left(\mathrm{CH}_{3} \mathrm{x}^{2+}\right)$ for a variety of first-and second-row substituents $\left(\mathrm{X}=\mathrm{NH}_{2}, \mathrm{OH}, \mathrm{F}, \mathrm{PH}_{2}, \mathrm{SH}\right.$ and $\left.\mathrm{Cl}\right)$. $^{\mathrm{a}}$

Although gas-phase dications were originally regarded as a curiosity and only observed incidentally in the course of normal mass

a. An extension of the first-row substituents to include $\mathrm{X}=\mathrm{CH}_{3}$ would give rise to the $\mathrm{C}_{2} \mathrm{H}_{6}{ }^{2+}$ species, for which it is well established that the global minimum corresponds to an ylide dication with a $\mathrm{CH}_{2} \mathrm{CH}_{4}{ }^{2+}$ structure. See refs 193 and 194. 
spectrometric and collisional-activation studies, there has been considerable recent interest in such species. ${ }^{195,196}$ This has arisen to a large extent through advances in experimental techniques which are designed specifically for the study of dications and which utilize charge-stripping (Section 2.4.3), double-charge-transfer, ${ }^{77,197}$ photon double ionization ${ }^{198}$ and Auger ${ }^{199}$ processes.

\subsection{Method and Results}

As in previous chapters, optimized structures were obtained initially with the $3-21 \mathrm{G}^{(*)}$ and $6-31 \mathrm{G}^{*}$ basis sets and improved relative energies determined through single-point calculations with the $6-31 \mathrm{G}^{* *}$ basis set and with valence-electron correlation incorporated using Møller-Plesset perturbation theory terminated at second (MP2) and third (MP3) order. Zero-point vibrational contributions to relative energies were obtained from vibrational frequencies calculated at the $3-21 \mathrm{G}^{(*)} / / 3-21 \mathrm{G}^{(*)}$ level. The best relative energies correspond to $\mathrm{MP} 3 / 6-31 \mathrm{G}^{* *} / / 6-31 \mathrm{G}^{*}$ values with zeropoint correction, calculated directly for first-row systems, or estimated for second-row systems by using the additivity approximation of equation (1.16). Unless otherwise noted, these are the values given in the text.

Calculations are reported for the ylide dications $\left(\mathrm{CH}_{2} \mathrm{XH}^{2+}\right)$, their conventional isomers $\left(\mathrm{CH}_{3} \mathrm{X}^{2+}\right)$, five pairs of possible fragmentation products $\left(\mathrm{CH}_{2}^{+}+\mathrm{XH}^{+}, \mathrm{CH}_{3}^{+}+\mathrm{X}^{+}, \mathrm{CH}_{2} \mathrm{X}^{+}+\mathrm{H}^{+}, \mathrm{CHX}{ }^{+\cdot}+\right.$ $\mathrm{H}_{2}^{+}$, and $\mathrm{CHX}^{2+}+\mathrm{H}_{2}$ ), and the various transition structures for rearrangement and dissociation. The spin-unrestricted Hartree-Fock 
(UHF) formalism was used for open-shell species and also for those transition structures connecting singlet molecules with their doublet fragments. The search for transition structures for $\mathrm{C}-\mathrm{X}$ fragmentation in the $\mathrm{CH}_{3} \mathrm{x}^{2+}$ dications (e.g. $\mathrm{CH}_{3} \mathrm{PH}_{2}{ }^{2+} \rightarrow \mathrm{CH}_{3}^{+}+\mathrm{PH}_{2}^{+}$) was restricted to the singlet surface. The optimized transition structures were found to be stable with respect to allowing spin contamination.

Ionization energies were calculated, for comparison with experimental charge-stripping data, both in a conventional manner, as a difference in energies of the doubly-charged ions (from the present work) and the singly-charged ions (from Chapter Four), and using an equations-of-motion approach. 200 The latter calculations were carried out at the partial third-order level ${ }^{201}$ using the MOLECULE, 202 EPSCF$^{203}$ and $\mathrm{EOM}^{204}$ packages. The core orbitals and virtual orbitals lying above 2 hartrees in energy were neglected in the EOM calculations. Such an approach has been previously found to be successful in the calculation of ionization energies. 205

Calculated total energies are presented in Tables 5.1 and 5.2 and relative energies in Tables 5.3 and 5.4. Schematic energy profiles based on the best relative energies are displayed in Figures 5.1 and 5.2 for first- and second-row systems, respectively. Optimized structures $\left(6-31 \mathrm{G}^{*}\right.$ with $3-21 \mathrm{G}^{(*)}$ values in parentheses) are displayed within the course of the discussion. ${ }^{b}$ The ylide dications

b. Optimized geometries of the fragmentation products are only displayed where hitherto unpublished. In most cases, these geometries are available from refs 6 or 144 . 
106.

and their conventional isomers where appropriate were reoptimized at MP2/6-31G ${ }^{*}$ to allow geometric comparisons at this level of theory with the results in Chapters Three and Four for the corresponding neutral and monocationic species. Optimized bond lengths (MP2/6-31G* with $\mathrm{HF} / 6-31 \mathrm{G}^{*}$ values in parentheses) for the central $\mathrm{C}-\mathrm{X}$ bond in $\mathrm{CH}_{3} \mathrm{X}^{\mathrm{n}}$ and $\mathrm{CH}_{2} \mathrm{XH}^{-} \underline{\mathrm{n}}^{+}(\underline{\mathrm{n}}=0,1$ and 2$)$ are presented in Table 5.5. Unless otherwise stated, geometric comparisons in the text refer to the MP2 $/ 6-31 G^{*}$ values. 
Table 5.1 Calculated Total Energies ${ }^{a}$ (hartrees) and Zero-Point Vibrational Energies (ZPVE, kJ mol ${ }^{-1}$ ) for First-Row Systems

$\mathrm{HF} / 3-21 \mathrm{G}^{\mathrm{b}} \mathrm{HF} / 6-31 \mathrm{G}^{*} \quad \mathrm{HF} / 6-31 \mathrm{G}^{* *} \quad \mathrm{MP} 2 / 6-31 \mathrm{G}^{* *} \quad \mathrm{MP} 3 / 6-31 \mathrm{G}^{* *} \quad \mathrm{ZPVE}$

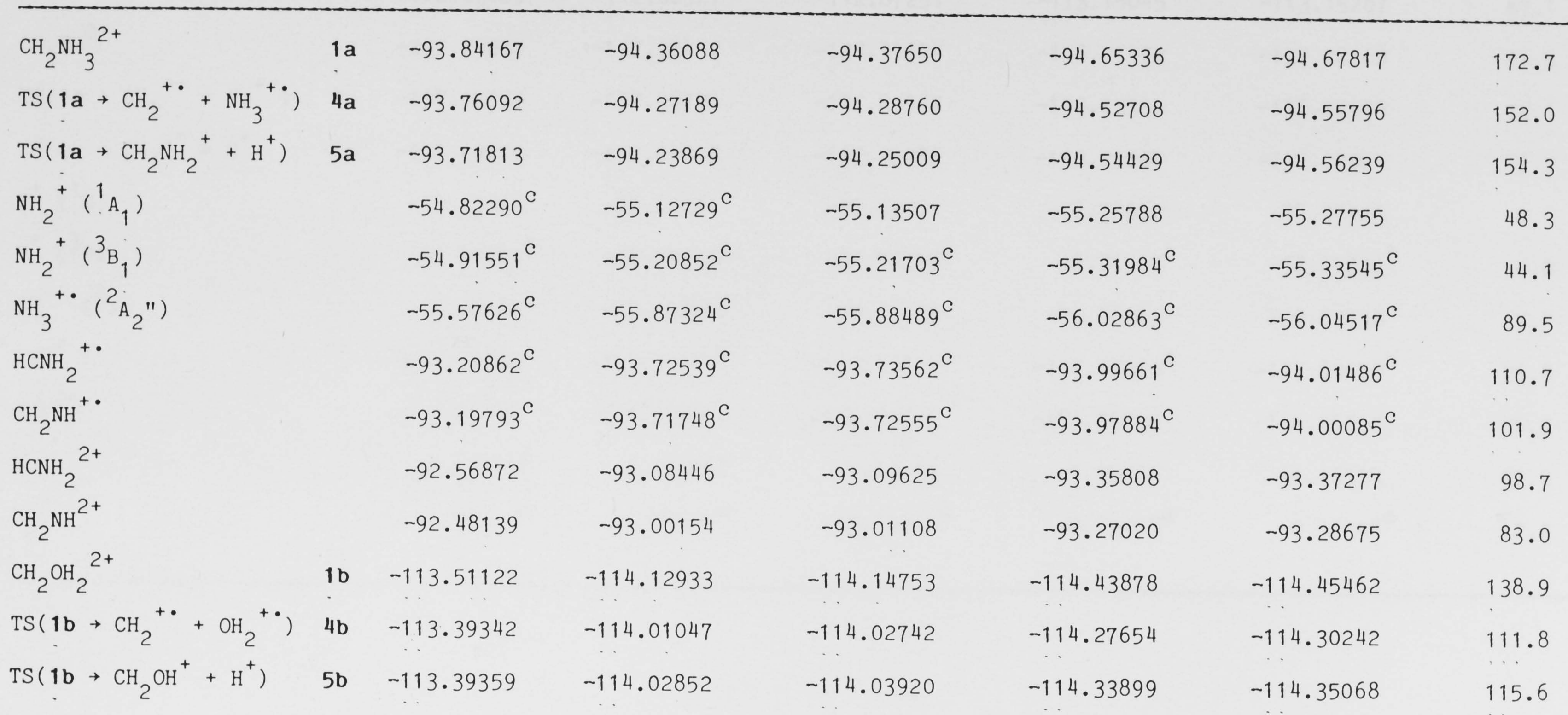




\begin{tabular}{|c|c|c|c|c|c|c|c|}
\hline $\mathrm{OH}^{+}\left(I^{1} \Sigma^{+}\right)$ & & $-74.43429^{c}$ & $-74.83025^{c}$ & $-74.83691^{c}$ & $-74.95453^{c}$ & $-74.97290^{C}$ & 17.7 \\
\hline $\mathrm{OH}^{+}\left({ }^{3} \Sigma^{-}\right)$ & & $-74.56991^{c}$ & $-74.96875^{c}$ & $-74.97463^{c}$ & $-75.07466^{c}$ & $-75.08924^{c}$ & 17.4 \\
\hline $\mathrm{OH}_{2}{ }^{+\cdot}\left({ }^{2} \mathrm{~B}_{1}\right)$ & & $-75.20789^{c}$ & $-75.61531^{c}$ & $-75.62820^{c}$ & $-75.77397^{c}$ & $-75.78728^{c}$ & 48.6 \\
\hline $\mathrm{HCOH}^{+}$ & & $-112.86489^{c}$ & $-113.50367^{c}$ & $-113.51303^{c}$ & $-113.78548^{c}$ & $-113.79440^{c}$ & 71.0 \\
\hline $\mathrm{HCOH}^{2+}$ & & -112.23409 & -112.86321 & -112.87251 & -113.15045 & -113.15207 & 67.1 \\
\hline $\mathrm{CH}_{2} \mathrm{FH}^{2+}$ & $1 c$ & -137.24247 & -137.98457 & -137.99644 & $-138 \cdot 27492$ & -138.28560 & 91.5 \\
\hline $\mathrm{TS}\left(1 \mathrm{c}+\mathrm{CH}_{2}^{+\cdot}+\mathrm{FH}^{+\cdot}\right)$ & $4 c$ & -137.15159 & -137.88790 & -137.89947 & -138.13333 & $-138 \cdot 15468$ & 74.1 \\
\hline $\mathrm{TS}\left(1 \mathrm{c} \rightarrow \mathrm{CH}_{2} \mathrm{~F}^{+}+\mathrm{H}^{+}\right)$ & $5 c$ & -137.19975 & -137.94808 & -137.95286 & -138.23209 & -138.24054 & 76.3 \\
\hline $\mathrm{F}^{+}\left({ }^{1} \mathrm{D}\right)$ & & -98.12367 & -98.63261 & -98.63261 & -98.72860 & -98.74429 & 0.0 \\
\hline $\mathrm{F}^{+}\left({ }^{3} \mathrm{P}\right)$ & & $-98.27875^{c}$ & $-98.79206^{C}$ & $-98.79206^{c}$ & $-98.86963^{c}$ & $-98.87992^{C}$ & 0.0 \\
\hline $\mathrm{FH}^{+\cdot}\left({ }^{2} \pi\right)$ & & $-98.96743^{c}$ & $-99.48960^{c}$ & -99.49680 & -99.62613 & -99.63530 & 17.4 \\
\hline $\mathrm{HCF}^{+\cdot}$ & & $-136.66803^{c}$ & $-137.43377^{c}$ & $-137.43612^{c}$ & $-137.69360^{c}$ & $-137.69670^{c}$ & 35.8 \\
\hline $\mathrm{HCF}^{2+}$ & & -135.86139 & -136.69858 & -136.70186 & -136.96725 & -136.96250 & 35.9 \\
\hline $\mathrm{H}_{2}$ & & $-1 \cdot 12296^{c}$ & $-1 \cdot 12683^{c}$ & -1.13133 & -1.15765 & -1.16314 & 27.9 \\
\hline $\mathrm{H}_{2}^{+\cdot}$ & & $-0.58315^{c}$ & $-0.58407^{c}$ & $-0.59448^{c}$ & $-0.59448^{c}$ & $-0.59448^{C}$ & 12.4 \\
\hline
\end{tabular}


a Based on $6-31 \mathrm{G}^{*}$ optimized geometries unless otherwise noted.

b Based on 3-21G optmized geometries.

c From ref 144 . 
Table 5.2 Calculated Total Energies ${ }^{a}$ (hartrees) and Zero-Point Vibrational Energies ZPVE (kJ mol ${ }^{-1}$ ) for Second-Row Systems

\begin{tabular}{|c|c|c|c|c|c|c|c|}
\hline & & $\mathrm{HF} / 3-21 \mathrm{G}^{(*) \mathrm{b}}$ & $\mathrm{HF} / 6-31 \mathrm{G}^{*}$ & $\mathrm{HF} / 6-31 \mathrm{G}^{* *}$ & $\mathrm{MP} 2 / 6-31 \mathrm{G}^{*}$ & $\mathrm{MP} 3 / 6-31 \mathrm{G}^{*}$ & $\mathrm{ZPVE}^{\mathrm{b}}$ \\
\hline $\mathrm{CH}_{2} \mathrm{PH}_{3}^{2+}$ & $1 \mathrm{~d}$ & -378.77551 & -380.63010 & -380.64160 & -380.81591 & -380.84727 & 142.1 \\
\hline $\mathrm{CH}_{3} \mathrm{PH}_{2}^{2+}$ & $2 d$ & $-378 \cdot 75220$ & -380.60193 & -380.61371 & -380.81426 & -380.84027 & 143.7 \\
\hline $\mathrm{TS}(2 \mathrm{~d} \rightarrow 1 \mathrm{~d})$ & $3 d$ & -378.73702 & -380.59297 & -380.60764 & -380.80662 & -380.83382 & 139.2 \\
\hline $\mathrm{TS}\left(\mathbf{1 d}+\mathrm{CH}_{2}^{+\cdot}+\mathrm{PH}_{3}^{+\cdot}\right)$ & $4 d$ & -378.70497 & -380.55887 & -380.57073 & $-380 \cdot 71945$ & -380.75192 & 124.4 \\
\hline $\mathrm{TS}\left(\mathbf{1} \mathbf{d} \rightarrow \mathrm{CH}_{2} \mathrm{PH}_{2}^{+}+\mathrm{H}^{+}\right)$ & $5 d$ & -378.62578 & -380.47309 & $-380 \cdot 48195$ & -380.69261 & -380.71509 & 120.4 \\
\hline $\mathrm{TS}\left(2 \mathbf{d} \rightarrow \mathrm{CH}_{3}^{+}+\mathrm{PH}_{2}^{+}\right)$ & $6 d$ & -378.73095 & $-380 \cdot 58660$ & $-380 \cdot 59759$ & -380.77724 & -380.80846 & 141.4 \\
\hline $\mathrm{TS}\left(2 \mathbf{d} \rightarrow \mathrm{CH}_{2} \mathrm{PH}_{2}^{+}+\mathrm{H}^{+}\right)$ & $7 d$ & -378.62548 & -380.47118 & -380.48037 & -380.70254 & -380.72198 & 123.4 \\
\hline $\mathrm{PH}_{2}^{+}\left({ }^{1} \mathrm{~A}_{1}\right)$ & & -339.87101 & $-341 \cdot 50655$ & -341.51144 & -341.58622 & -341.60527 & 39.5 \\
\hline $\mathrm{PH}_{2}{ }^{+}\left({ }^{3} \mathrm{~B}_{1}\right)$ & & -339.87031 & -341.50642 & -341.51179 & -341.57146 & -341.58645 & 38.7 \\
\hline $\mathrm{PH}_{3}{ }^{+\cdot}\left({ }^{2} \mathrm{~A}_{1}\right)$ & & -340.49397 & $-342 \cdot 13156$ & -342.13900 & $-342 \cdot 21346$ & -342.23105 & 68.5 \\
\hline $\mathrm{HCPH}_{2}^{+\cdot}$ & & $-378 \cdot 10587$ & -379.94791 & -379.95491 & -380.11753 & -380.14422 & $81 \cdot 3$ \\
\hline $\mathrm{CH}_{2} \mathrm{PH}^{+\cdot}$ & & -378.13097 & -379.97504 & -379.98126 & -380.16277 & -380.18957 & 91.1 \\
\hline $\mathrm{HCPH}_{2}{ }^{2+}$ & & -377.48044 & -379.32645 & -379.33459 & -379.51618 & -379.54392 & 79.5 \\
\hline
\end{tabular}




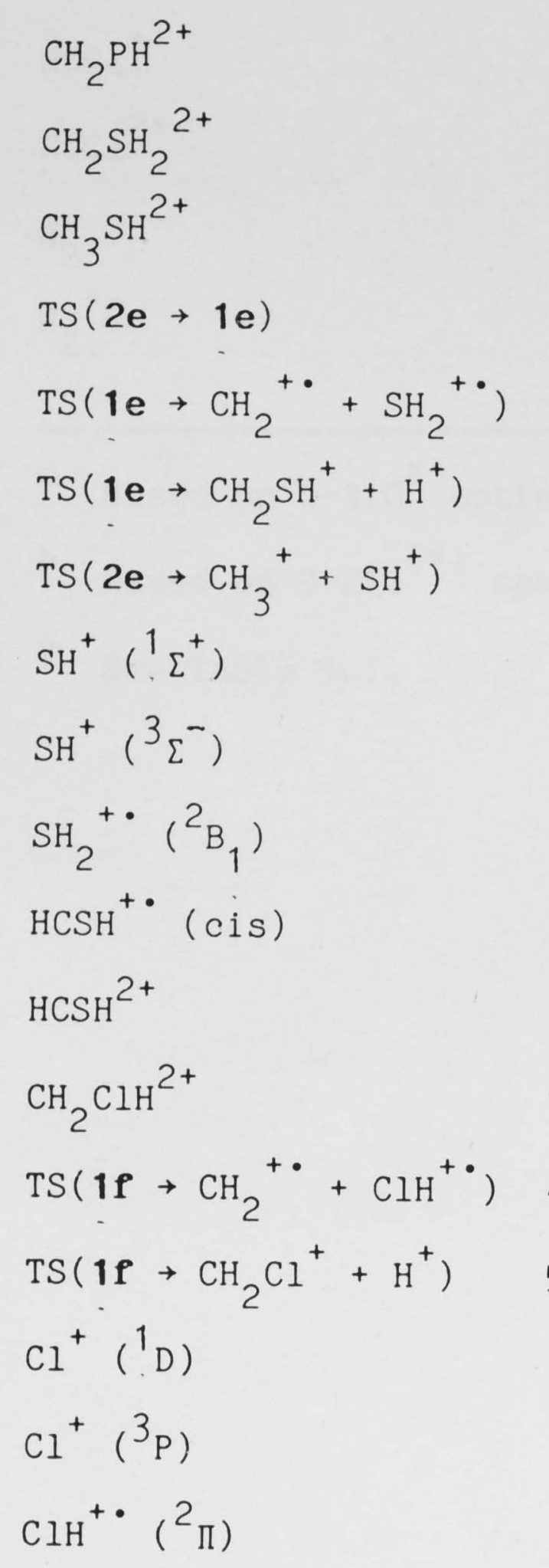

\begin{tabular}{llll} 
& -377.53462 & -379.38335 & -379.39023 \\
1e & -434.72504 & -436.79619 & -436.80797 \\
3e & -434.64424 & -436.70918 & -436.72050 \\
4e & -434.64251 & -436.70909 & -436.72036 \\
5e & -434.62242 & -436.68627 & -436.69416 \\
6e & -434.62296 & -436.69222 & -436.70238 \\
& -395.78787 & -397.63581 & -397.64026 \\
& -395.87866 & -397.72788 & -397.73188 \\
& -396.47639 & -398.32699 & -398.33466 \\
& -434.09334 & -436.15369 & -436.15970 \\
\hline 1f & -495.79112 & -498.10011 & -498.11035 \\
\hline 4f & -495.73825 & -498.03502 & -498.04561 \\
5f & -495.71617 & -498.01981 & -498.02393 \\
& -456.83630 & -458.91415 & -458.91415 \\
& -456.93594 & -459.01502 & -459.01502 \\
& -457.55304 & -459.63397 & -459.64028
\end{tabular}

-379.55857
-437.01275
-436.95876
-436.95734
-436.91924
-436.92279
-436.90372
-397.72744
-397.80616
-398.42531
-436.35618
-435.74386
-498.33324
-498.22953
-498.26106
-459.01343
-459.10049
-459.74217

$-379.58807$

84.8

$-437.04158$

119.8

$-436.98448$

112.5

$-436.98326$

110.3

$-436.95272$

103.1

$-436.94557$

99.5

$-436.93641$

115.2

$-397.74736$

16.9

$-397.82299$

16.9

$-398.44416$

42.1

$-436.38126$

59.1

$-435.76299$

54.9

$-498.35868$

92.6

$-498.26128$

75.5

$-498.28149$

72.4

$-459.03321$

0.0

$-459.11627$

0.0

$-459.75935$

17.2 
$\mathrm{HCCl}^{+}$

$-495.19505$

$-497.49695$

$-497.49916$

$-497.71916$

$-497.73735$

32.5

$\mathrm{HCCl}^{2+}$

$-494.54182$

$-496.84867$

$-496.85126$

$-497.09458$

$-497.10391$

36.9

$\mathrm{H}_{2}$

c

c

$-1.14410$

$-1.14924$

c

c

$-0.58407$

$-0.58407$

a Based on $6-31 \mathrm{G}^{*}$ optimized geometries unless otherwise noted.

b Based on $3-21 \mathrm{G}^{(*)}$ optimized geometries.

c See Table 5.1 . 
Table 5.3 Calculated Relative Energies ${ }^{\mathrm{a}, \mathrm{b}}\left(\mathrm{kJ} \mathrm{mol}^{-1}\right)$ for First-Row Systems

\begin{tabular}{|c|c|c|c|c|c|c|c|}
\hline & & $\mathrm{HF} / 3-21 \mathrm{G}$ & $\mathrm{HF} / 6-31 \mathrm{G}^{*}$ & $\mathrm{HF} / 6-31 \mathrm{G}^{* *}$ & $\mathrm{MP} 2 / 6-31 \mathrm{G}^{* *}$ & $\mathrm{MP} 3 / 6-31 \mathrm{G}^{* *}$ & $\mathrm{MP} 3 / 6-31 \mathrm{G}^{* * \mathrm{C}}$ \\
\hline $\mathrm{CH}_{2} \mathrm{NH}_{3}^{2+}$ & $1 \mathrm{a}$ & 0 & 0 & 0 & 0 & 0 & 0 \\
\hline $\mathrm{TS}\left(1 \mathrm{a} \rightarrow \mathrm{CH}_{2}^{+\cdot}+\mathrm{NH}_{3}^{+\cdot}\right)$ & $4 a$ & 212 & 234 & 233 & 332 & 316 & 297 \\
\hline $\mathrm{TS}\left(\mathbf{1} \mathbf{a} \rightarrow \mathrm{CH}_{2} \mathrm{NH}_{2}^{+}+\mathrm{H}^{+}\right)$ & $5 a$ & 324 & 321 & 332 & 286 & 304 & 287 \\
\hline $\mathrm{CH}_{2}^{+\cdot}+\mathrm{NH}_{3}^{+\cdot}$ & & -215 & -206 & -207 & -65 & -83 & -117 \\
\hline $\mathrm{CH}_{2} \mathrm{NH}_{2}^{+}+\mathrm{H}^{+}$ & & -56 & -59 & -48 & -98 & -85 & -103 \\
\hline $\mathrm{CH}_{3}^{+}+\mathrm{NH}_{2}^{+}\left({ }^{1} \mathrm{~A}_{1}\right)$ & & 25 & 8 & 13 & 129 & 95 & 61 \\
\hline $\mathrm{CH}_{3}^{+}+\mathrm{NH}_{2}^{+}\left({ }^{3} \mathrm{~B}_{1}\right)$ & & -218 & -206 & -202 & -34 & -57 & -95 \\
\hline $\mathrm{HCNH}_{2}^{+\cdot}+\mathrm{H}_{2}^{+\cdot}$ & & 131 & 135 & 122 & 164 & 181 & 136 \\
\hline $\mathrm{CH}_{2} \mathrm{NH}^{+\cdot}+\mathrm{H}_{2}^{+\cdot}$ & & 159 & 156 & 148 & 210 & 218 & 165 \\
\hline $\mathrm{HCNH}_{2}^{2+}+\mathrm{H}_{2}$ & & 394 & 393 & 391 & 361 & 373 & 332 \\
\hline $\mathrm{CH}_{2} \mathrm{NH}^{2+}+\mathrm{H}_{2}$ & & 623 & 610 & 615 & 592 & 599 & 544 \\
\hline $\mathrm{CH}_{2} \mathrm{OH}_{2}^{2+}$ & $1 \mathrm{~b}$ & 0 & 0 & 0 & 0 & 0 & 0 \\
\hline $\mathrm{TS}\left(\mathbf{1 b} \rightarrow \mathrm{CH}_{2}^{+\cdot}+\mathrm{OH}_{2}^{+\bullet}\right)$ & $4 b$ & 309 & 312 & 315 & 426 & 400 & 375 \\
\hline
\end{tabular}




\begin{tabular}{|c|c|c|c|c|c|c|c|}
\hline $\mathrm{TS}\left(1 \mathrm{~b} \rightarrow \mathrm{CH}_{2} \mathrm{OH}^{+}+\mathrm{H}^{+}\right)$ & $5 b$ & 309 & 265 & 284 & 262 & 273 & 252 \\
\hline $\mathrm{CH}_{2}^{+\cdot}+\mathrm{OH}_{2}^{+\cdot}$ & & -116 & -137 & -135 & 41 & 8 & -33 \\
\hline $\mathrm{CH}_{2} \mathrm{OH}^{+}+\mathrm{H}^{+}$ & & -8 & -71 & -51 & -78 & -69 & -103 \\
\hline $\mathrm{CH}_{3}^{+}+\mathrm{OH}^{+}\left(\Sigma^{+} \Sigma^{+}\right)$ & & 178 & 180 & 195 & 362 & 308 & 277 \\
\hline $\mathrm{CH}_{3}^{+}+\mathrm{OH}^{+}\left({ }^{3} \Sigma^{-}\right)$ & & -178 & -184 & -166 & 46 & 2 & -29 \\
\hline $\mathrm{HCOH}^{+\cdot}+\mathrm{H}_{2}^{+\cdot}$ & & 166 & 109 & 105 & 155 & 173 & 123 \\
\hline $\mathrm{HCOH}^{2+}+\mathrm{H}_{2}$ & & 405 & 366 & 377 & 343 & 366 & 326 \\
\hline $\mathrm{CH}_{2} \mathrm{FH}^{2+}$ & $1 c$ & 0 & 0 & 0 & 0 & 0 & 0 \\
\hline $\mathrm{TS}\left(1 \mathrm{c}+\mathrm{CH}_{2}^{+\cdot}+\mathrm{FH}^{+\cdot}\right)$ & $4 c$ & 239 & 254 & 255 & 372 & 344 & 328 \\
\hline $\mathrm{TS}\left(1 \mathrm{c} \rightarrow \mathrm{CH}_{2} \mathrm{~F}^{+}+\mathrm{H}^{+}\right)$ & $5 c$ & 112 & 96 & 114 & 112 & 118 & 105 \\
\hline $\mathrm{CH}_{2}^{+\cdot}+\mathrm{FH}^{+\cdot}$ & & -190 & -187 & -186 & -1 & -37 & -63 \\
\hline $\mathrm{CH}_{2} \mathrm{~F}^{+}+\mathrm{H}^{+}$ & & -225 & -287 & -266 & -282 & -273 & -288 \\
\hline $\mathrm{CH}_{3}^{+}+\mathrm{F}^{+}\left({ }^{1} \mathrm{D}\right)$ & & 288 & 319 & 335 & 525 & 464 & 460 \\
\hline $\mathrm{CH}_{3}^{+}+\mathrm{F}^{+}\left({ }^{3} \mathrm{P}\right)$ & & -119 & -100 & -84 & 154 & 108 & 104 \\
\hline $\mathrm{HCF}^{+\cdot}+\mathrm{H}_{2}^{+\cdot}$ & & -23 & -87 & -90 & -35 & -15 & -54 \\
\hline $\mathrm{HCF}^{2+}+\mathrm{H}_{2}$ & & 678 & 418 & 429 & 394 & 420 & 395 \\
\hline
\end{tabular}


a Based on the total energies in Table 5.1 .

b Appropriate total energies and zero-point vibrational energies for the fragments $\mathrm{CH}_{2} \mathrm{NH}_{2}^{+}, \mathrm{CH}_{2} \mathrm{OH}^{+}, \mathrm{CH}_{2} \mathrm{~F}^{+}$, $\mathrm{CH}_{3}{ }^{+}$and $\mathrm{CH}_{2}{ }^{+\cdot}$ taken from Table 4.1.

c With zerompoint correction. 
Table 5.4 Calculated Relative Energies ${ }^{\mathrm{a}, \mathrm{b}}\left(\mathrm{kJ} \mathrm{mol}^{-1}\right)$ for Second-Row Systems

$$
\mathrm{HF} / 3-21 \mathrm{G}^{(*)} \quad \mathrm{HF}_{6} 6-31 \mathrm{G}^{*} \quad \mathrm{HF} / 6-31 \mathrm{G}^{* *} \quad \mathrm{MP} 2 / 6-31 \mathrm{G}^{*} \quad \mathrm{MP} 3 / 6-31 \mathrm{G}^{*} \quad \mathrm{MP} 3 / 6-31 \mathrm{G}^{* * \mathrm{C}} \quad \mathrm{MP} 3 / 6-31 \mathrm{G}^{* * \mathrm{~d}}
$$

\begin{tabular}{|c|c|c|c|c|c|c|c|c|}
\hline $\mathrm{CH}_{2} \mathrm{PH}_{3}{ }^{2+}$ & $1 d$ & 0 & 0 & 0 & 0 & 0 & 0 & 0 \\
\hline $\mathrm{CH}_{3} \mathrm{PH}_{2}^{2+}$ & $2 d$ & 61 & 74 & 73 & 4 & 18 & 18 & 19 \\
\hline $\operatorname{TS}(2 d \rightarrow 1 d)$ & $3 d$ & 101 & 97 & 89 & 24 & 35 & 27 & 24 \\
\hline $\mathrm{TS}\left(\mathbf{1 d}+\mathrm{CH}_{2}^{+\cdot}+\mathrm{PH}_{3}^{+\bullet}\right)$ & $4 d$ & 185 & 187 & 187 & 253 & 250 & 249 & 233 \\
\hline $\mathrm{TS}\left(\mathbf{1 d} \rightarrow \mathrm{CH}_{2} \mathrm{PH}_{2}^{+}+\mathrm{H}^{+}\right)$ & $5 d$ & 393 & 412 & 419 & 324 & 347 & 354 & 334 \\
\hline $\mathrm{TS}\left(2 \mathrm{~d} \rightarrow \mathrm{CH}_{3}^{+}+\mathrm{PH}_{2}^{+}\right)$ & $6 d$ & 117 & 114 & 116 & 102 & 102 & 103 & 103 \\
\hline $\mathrm{TS}\left(2 \mathbf{d} \rightarrow \mathrm{CH}_{2} \mathrm{PH}_{2}^{+}+\mathrm{H}^{+}\right)$ & $7 d$ & 394 & 417 & 423 & 298 & 329 & 335 & 318 \\
\hline $\mathrm{CH}_{2}^{+\cdot}+\mathrm{PH}_{3}^{+\cdot}$ & & -173 & -178 & -179 & -86 & -87 & -88 & -114 \\
\hline $\mathrm{CH}_{2} \mathrm{PH}_{2}^{+}+\mathrm{H}^{+}$ & & 85 & 111 & 117 & 4 & 22 & 28 & 10 \\
\hline $\mathrm{CH}_{3}^{+}+\mathrm{PH}_{2}^{+}\left(\mathrm{CA}_{1}\right)$ & & -275 & -281 & -279 & -251 & -261 & -259 & -273 \\
\hline $\mathrm{CH}_{3}^{+}+\mathrm{PH}_{2}^{+}\left({ }^{3} \mathrm{~B}_{1}\right)$ & & -273 & -281 & -280 & -212 & -212 & -211 & -226 \\
\hline $\mathrm{HCPH}_{2}^{+\cdot}+\mathrm{H}_{2}^{+\cdot}$ & & 227 & 258 & 242 & 300 & 312 & 297 & 242 \\
\hline $\mathrm{CH}_{2} \mathrm{PH}^{+\cdot}+\mathrm{H}_{2}^{+\cdot}$ & & 161 & 186 & 173 & 181 & 193 & 180 & 134 \\
\hline
\end{tabular}




$$
\begin{aligned}
& \mathrm{HCPH}_{2}{ }^{2+}+\mathrm{H}_{2} \\
& \mathrm{CH}_{2} \mathrm{PH}^{2+}+\mathrm{H}_{2}
\end{aligned}
$$

$\mathrm{CH}_{2} \mathrm{SH}_{2}{ }^{2+}$

$$
\mathrm{CH}_{3} \mathrm{SH}^{2+}
$$

$\operatorname{TS}(2 \mathbf{e} \rightarrow 1 \mathbf{e})$

$\mathrm{TS}\left(\mathbf{e} \rightarrow \mathrm{CH}_{2}^{+}+\mathrm{SH}_{2}^{+\cdot}\right)$

$\mathrm{TS}\left(1 \mathbf{e} \rightarrow \mathrm{CH}_{2} \mathrm{SH}^{+}+\mathrm{H}^{+}\right) \quad 5 \mathbf{e}$

$\mathrm{TS}\left(2 \mathbf{e} \rightarrow \mathrm{CH}_{3}^{+}+\mathrm{SH}^{+}\right)$

$\mathrm{CH}_{2}^{+\cdot}+\mathrm{SH}_{2}^{+\cdot}$

$\mathrm{CH}_{2} \mathrm{SH}^{+}+\mathrm{H}^{+}$

$\mathrm{CH}_{3}^{+}+\mathrm{SH}^{+}\left({ }^{1} \Sigma^{+}\right)$

$\mathrm{CH}_{3}^{+}+\mathrm{SH}^{+}\left({ }^{3} \Sigma^{-}\right)$

$\mathrm{HCSH}^{+\cdot}+\mathrm{H}_{2}^{+\cdot}$

$\mathrm{HCSH}^{2+}+\mathrm{H}_{2}$

$\mathrm{CH}_{2} \mathrm{ClH}^{2+}$

$\mathrm{TS}\left(\mathbf{1 f}+\mathrm{CH}_{2}^{+\cdot}+\mathrm{ClH}^{+\cdot}\right) \quad 4 \mathrm{f}$

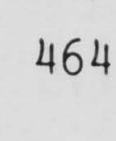

315

461

315

0

230

230

154

142

269

268

$-259$

$-189$

$-427$

128

397

0

139

273

$-255$

$-29$

$-184$

$-426$

154

403

0

171

299

277

$-255$

$-18$

$-180$

$-421$

141

403

0

170
409

297

0

142

145

245

236

286

272
405

289
402

289

263

0

145

146

218

244

276

$-167$

$-81$

$-134$

$-332$

145

307

0
0

256 


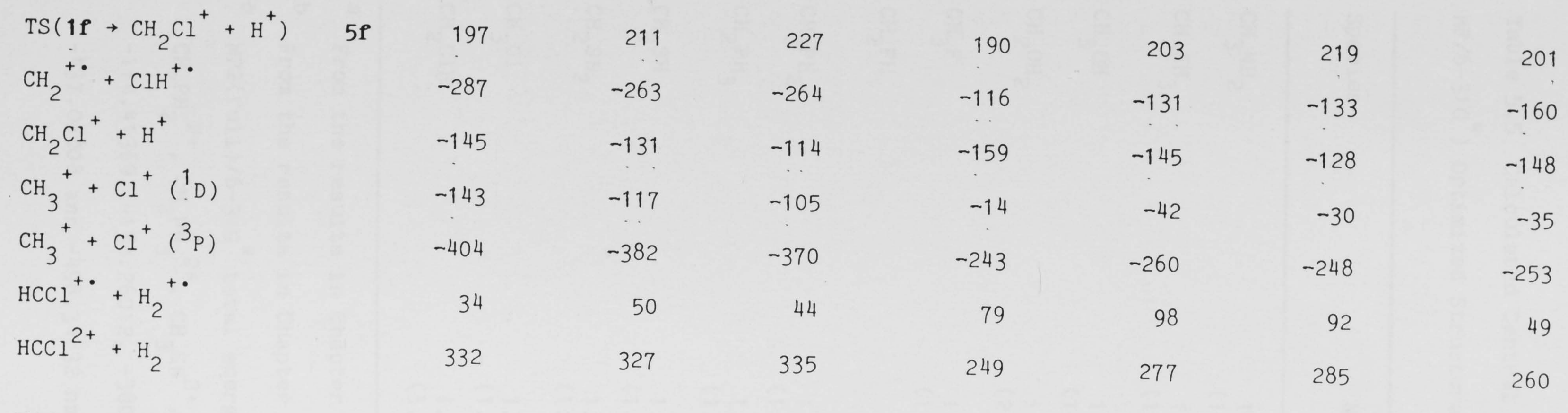

a

Based on the total energies in Table 5.2 .

b Appropriate total energies and zero-point $\mathrm{CH}_{2}{ }^{+\cdot}$ taken from Table 4.2 .

c Estimated using the additivity approximation of equation (1.16).

d $M P 3 / 6-31 \mathrm{G}^{* *}$ value with zero-point correction. 
119.

Table 5.5 Calculated Central Bond Lengths ( $\AA$ ) for MP2/6-31G* (and $\mathrm{HF} / 6-31 \mathrm{G}^{*}$ ) Optimized Structures

\begin{tabular}{|c|c|c|c|}
\hline Species & Neutral ${ }^{a}$ & Monocation ${ }^{b}$ & Dication $^{C}$ \\
\hline $\mathrm{CH}_{3} \mathrm{NH}_{2}$ & $\begin{array}{c}1.465 \\
(1.453)\end{array}$ & $\begin{array}{c}1.431 \\
(1.458)\end{array}$ & - \\
\hline $\mathrm{CH}_{2} \mathrm{NH}_{3}$ & $\begin{array}{c}1.559 \\
(1.606)\end{array}$ & $\begin{array}{c}1.470 \\
(1.470)\end{array}$ & $\begin{array}{c}1.420 \\
(1.420)\end{array}$ \\
\hline $\mathrm{CH}_{3} \mathrm{OH}$ & $\begin{array}{c}1.424 \\
(1.400)\end{array}$ & $\begin{array}{c}1.405 \\
(1.477)\end{array}$ & - \\
\hline $\mathrm{CH}_{2} \mathrm{OH}_{2}$ & $\begin{array}{c}1.805 \\
(2.138)\end{array}$ & $\begin{array}{c}1.468 \\
(1.459)\end{array}$ & $\begin{array}{c}1.314 \\
(1.305)\end{array}$ \\
\hline $\mathrm{CH}_{3} \mathrm{~F}$ & $\begin{array}{c}1.392 \\
(1.365)\end{array}$ & $\begin{array}{c}1.310 \\
(2.033)\end{array}$ & - \\
\hline $\mathrm{CH}_{2} \mathrm{FH}$ & - & $\begin{array}{c}1.557 \\
(1.587)\end{array}$ & $\begin{array}{c}1.366 \\
(1.348)\end{array}$ \\
\hline $\mathrm{CH}_{3} \mathrm{PH}_{2}$ & $\begin{array}{c}1.857 \\
(1.861)\end{array}$ & $\begin{array}{c}1.798 \\
(1.815)\end{array}$ & $\begin{array}{c}1.712 \\
(1.754)\end{array}$ \\
\hline $\mathrm{CH}_{2} \mathrm{PH}_{3}$ & $\begin{array}{c}1.674 \\
(1.667)\end{array}$ & $\begin{array}{c}1.765 \\
(1.772)\end{array}$ & $\begin{array}{c}1.865 \\
(1.879)\end{array}$ \\
\hline $\mathrm{CH}_{3} \mathrm{SH}$ & $\begin{array}{c}1.814 \\
(1.817)\end{array}$ & $\begin{array}{c}1.786 \\
(1.814)\end{array}$ & $\begin{array}{c}1.649 \\
(1.654)\end{array}$ \\
\hline $\mathrm{CH}_{2} \mathrm{SH}_{2}$ & $\begin{array}{c}1.635 \\
(1.635)\end{array}$ & $\begin{array}{c}1.759 \\
(1.773)\end{array}$ & $\begin{array}{c}1.674 \\
(1.738)\end{array}$ \\
\hline $\mathrm{CH}_{3} \mathrm{Cl}$ & $\begin{array}{c}1.778 \\
(1.785)\end{array}$ & $\begin{array}{c}1.765 \\
(1.869)\end{array}$ & - \\
\hline $\mathrm{CH}_{2} \mathrm{ClH}$ & $\begin{array}{c}1.691 \\
(3.035)\end{array}$ & $\begin{array}{c}1.770 \\
(1.804)\end{array}$ & $\begin{array}{c}1.656 \\
(1.673)\end{array}$ \\
\hline
\end{tabular}
From the results in Chapter Three.

b From the results in Chapter Four.

c $\operatorname{MP} 2(\mathrm{full}) / 6-31 \mathrm{G}^{*}$ total energies for $\mathrm{CH}_{2} \mathrm{NH}_{3}{ }^{2+}, \mathrm{CH}_{2} \mathrm{OH}_{2}{ }^{2+}, \mathrm{CH}_{2} \mathrm{FH}^{2+}$, $\mathrm{CH}_{3} \mathrm{PH}_{2}{ }^{2+}, \mathrm{CH}_{2} \mathrm{PH}_{3}{ }^{2+}, \mathrm{CH}_{3} \mathrm{SH}^{2+}, \mathrm{CH}_{2} \mathrm{SH}_{2}{ }^{2+}$ and $\mathrm{CH}_{2} \mathrm{ClH}^{2+}$ are -94.62440 , $-114.41369,-138.26012,-380.83167,-381.83159,-436.98359$, -437.03008 and -498.34832 hartrees, respectively. 


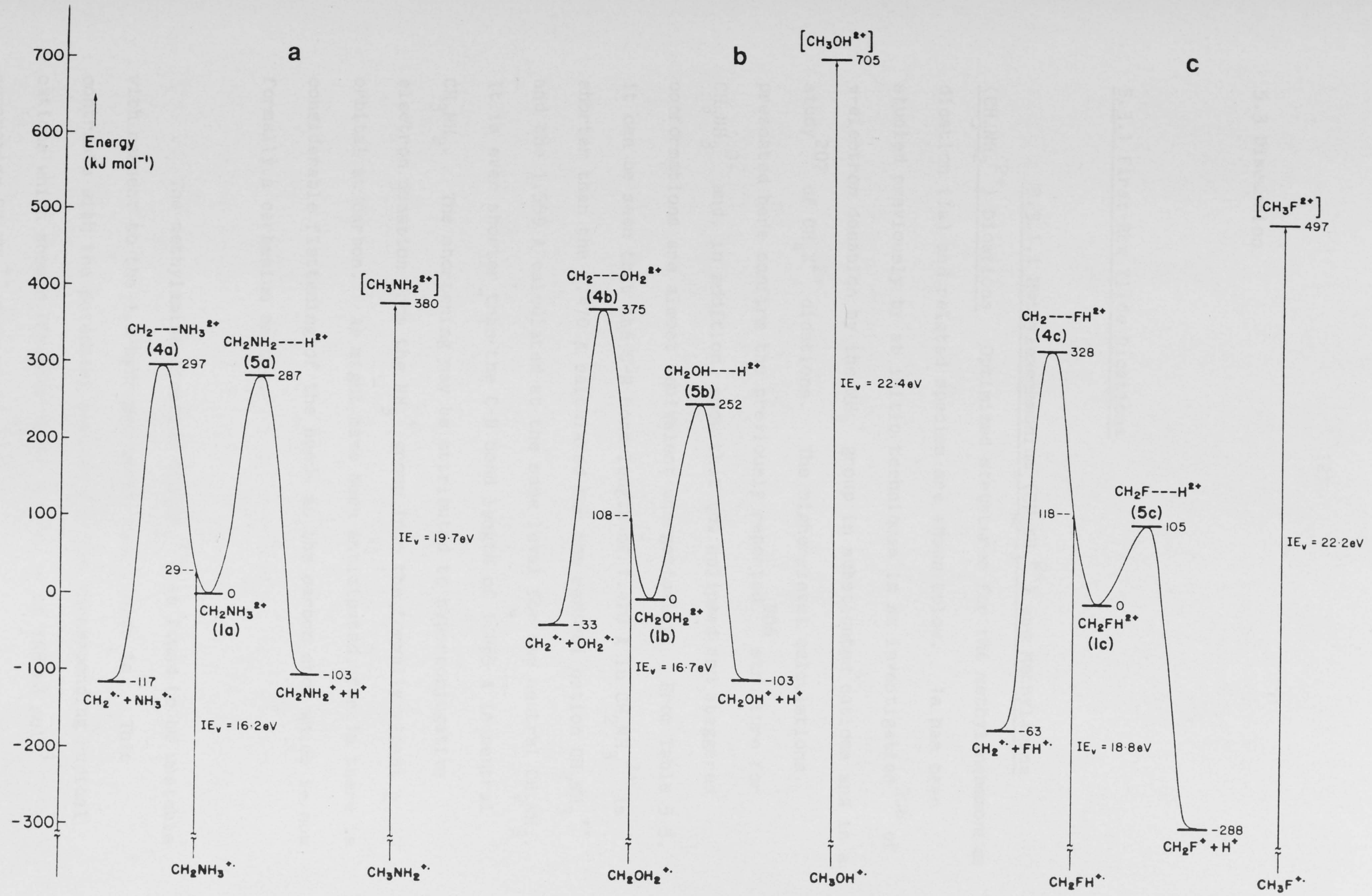

Figure 5.1 Schematic energy profiles for dissociative processes of the first-row ylide dications. 
121.

\subsection{Discussion}

\subsubsection{First-Row Ylide Dications}

$\left(\mathrm{CH}_{3} \mathrm{NH}_{2}{ }^{2+} \stackrel{5 \cdot 3 \cdot 1.1 \text { Methyl eneammoni um }\left(\mathrm{CH}_{2} \mathrm{NH}^{2+}\right) \text { and Methylamine }}{\left.{ }^{2+}\right)}\right.$ dication (1a) and related species are shown below. 1a has been studied previously by ab initio techniques in an investigation ${ }^{206}$ of $\pi$-electron donation by the $\mathrm{NH}_{3}{ }^{+}$group in substituted cations and in a study 207 of $\mathrm{CH}_{4} \mathrm{x}^{2+}$ dications. The higher-level calculations presented here confirm the previously reported 206 structure for $\mathrm{CH}_{2} \mathrm{NH}_{3}{ }^{2+}$ and, in addition, show that the eclipsed and staggered conformations are almost equivalent energetically. From Table 5.5, it can be seen that the $\mathrm{C}-\mathrm{N}$ bond length of $1.420 \mathrm{~A}$ in $\mathrm{CH}_{2} \mathrm{NH}_{3}{ }^{2+}$ is shorter than the $1.470 \mathrm{~A}$ calculated for the radical cation $\mathrm{CH}_{2} \mathrm{NH}_{3}{ }^{+}$ and the $1.559 \mathrm{~A}$ calculated at the same level for the neutral $\mathrm{CH}_{2} \mathrm{NH}_{3}$. It is even shorter than the $\mathrm{C}-\mathrm{N}$ bond length of 1.465 \& in neutral $\mathrm{CH}_{3} \mathrm{NH}_{2}$. The shortening may be attributed to hyperconjugative electron donation from the $\mathrm{NH}_{3}{ }^{+}$group into the formally vacant $\underline{p}$ orbital at carbon. As might have been anticipated, for 1 a there is considerable flattening of the bonds at the carbon atom which is now formally a carbenium centre.

The methylamine dication $\left(\mathrm{CH}_{3} \mathrm{NH}_{2}{ }^{2+}\right)$ is found to be unstable with respect to the 1,2-hydrogen shift that yields 1a. This contrasts with the potential surface for the corresponding radical cations which showed (Chapter Four) a barrier of $168 \mathrm{~kJ} \mathrm{~mol}^{-1}$ separating $\mathrm{CH}_{3} \mathrm{NH}_{2}^{+\cdot}$ from $\mathrm{CH}_{2} \mathrm{NH}_{3}{ }^{+\cdot}$. 


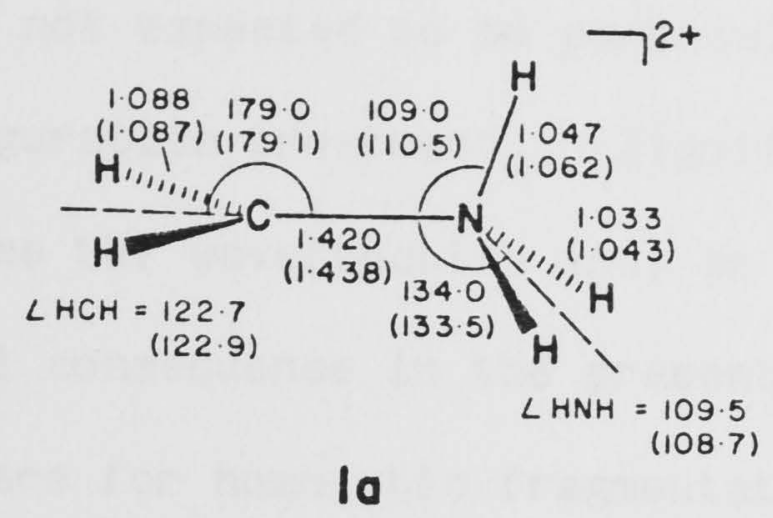

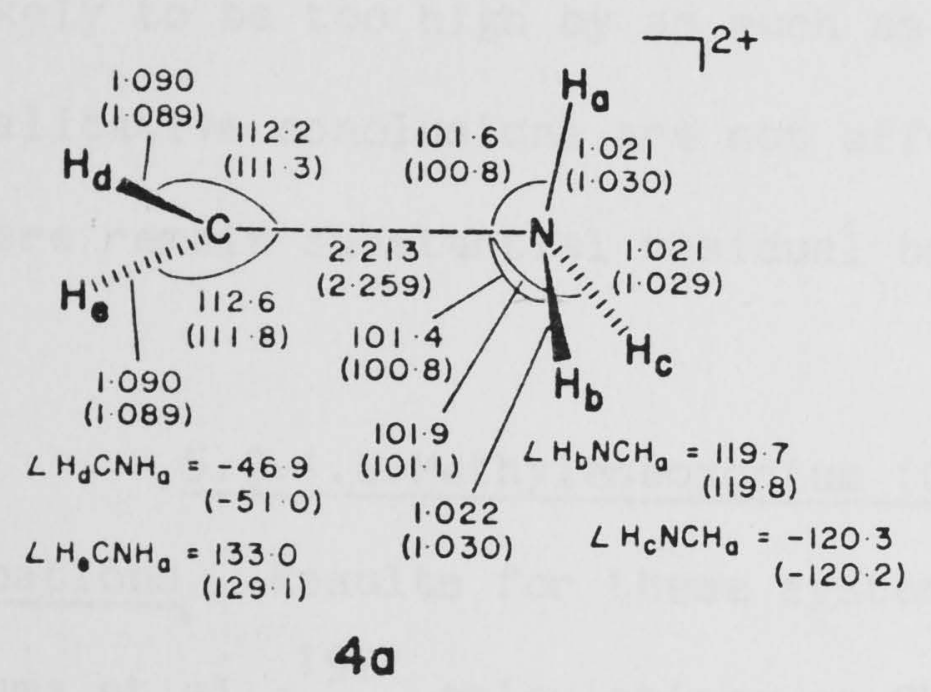

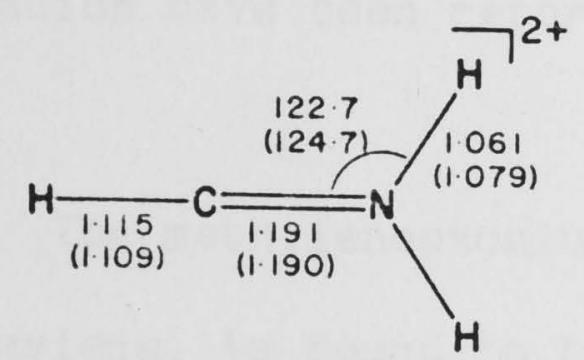

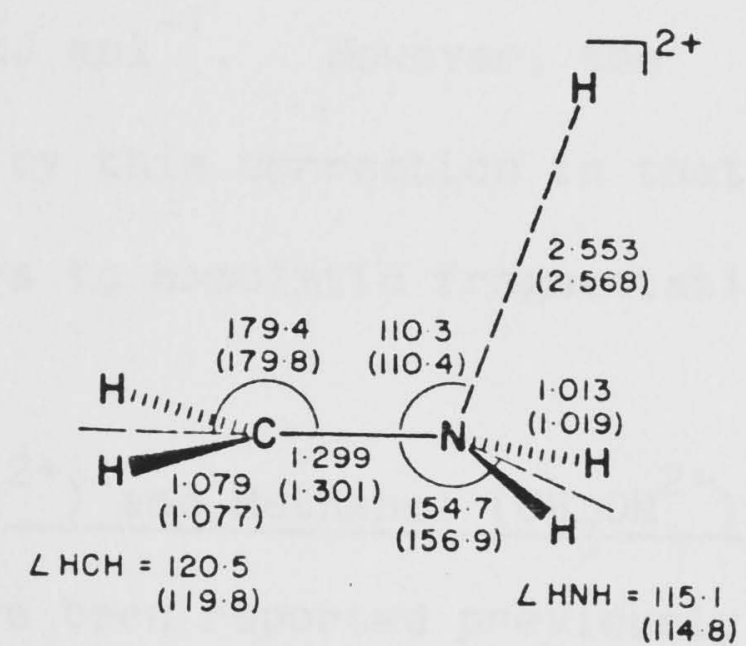

50

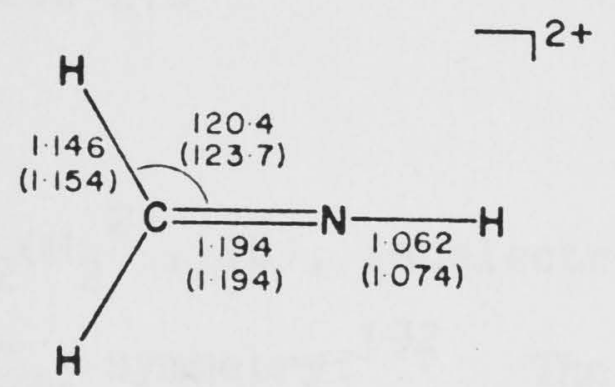

The schematic potential energy profile of Figure 5.1 a shows that $\mathrm{CH}_{2} \mathrm{NH}_{3}{ }^{2+}$ is thermodynamically unstable with respect to the fragmentation products $\mathrm{CH}_{2}{ }^{+}+\mathrm{NH}_{3}{ }^{+}$(by $117 \mathrm{~kJ} \mathrm{~mol}^{-1}$ ) and $\mathrm{CH}_{2} \mathrm{NH}_{2}{ }^{+}+$ $\mathrm{H}^{+}$(by $103 \mathrm{~kJ} \mathrm{~mol}^{-1}$ ). However, the barriers to such dissociations are substantial (297 and $287 \mathrm{~kJ} \mathrm{~mol}^{-1}$, respectively). Thus $\mathrm{CH}_{2} \mathrm{NH}_{3}{ }^{2+}$ lies in a deep potential well, consistent with its experimental observation in charge-stripping mass spectrometry experiments; $155,179,181$ these are discussed in more detail below. 
It is worth noting that homolytic bond fission of the type $\mathrm{CH}_{2} \mathrm{NH}_{3}{ }^{2+} \rightarrow \mathrm{CH}_{2}{ }^{+\cdot}+\mathrm{NH}_{3}^{+\cdot}$ is not expected to be particularly well described by a single-configuration treatment. Significant spin contamination is found in the UHF wavefunction and, as discussed in Section 1.4.2, the principal consequence in the present series of molecules is that the barriers for homolytic fragmentation, $\mathrm{CH}_{2} \mathrm{XH}^{2+} \rightarrow$ $\mathrm{CH}_{2}{ }^{+\cdot}+\mathrm{XH}^{+\cdot}$, as calculated at the highest theoretical level, are likely to be too high by as much as $100 \mathrm{~kJ} \mathrm{~mol}^{-1}$. However, the qualitative conclusions are not affected by this correction in that there remain substantial residual barriers to homolytic fragmentation.

\subsubsection{Methyleneoxonium $\left(\mathrm{CH}_{2} \mathrm{OH}_{2}{ }^{2+}\right)$ and Methanol $\left(\mathrm{CH}_{3} \mathrm{OH}^{2+}\right)$} Dications Results for these systems have been reported previously by Bouma et al.; ${ }^{192}$ calculations on $\mathrm{CH}_{2} \mathrm{OH}_{2}{ }^{2+}$ with limited geometry optimization have been reported by others. ${ }^{208-210}$

The methyleneoxonium dication $\left(\mathrm{CH}_{2} \mathrm{OH}_{2}{ }^{2+}, 1 \mathrm{~b}\right)$, isoelectronic with ethylene, is found to be planar with $\underline{\mathrm{C}}_{2 \underline{\mathrm{v}}}$ symmetry. ${ }^{192}$ The C-0 bond is quite short with a length (1.314 $\AA$, Table 5.5) between that of a normal C-O single bond (e.g. $1.424 \AA$ in methanol) and a C-O double bond (e.g. $1.221 \AA$ in formaldehyde). ${ }^{144}$ The $\mathrm{C}-0$ length is similar to that of the ethylenic $\mathrm{C}=\mathrm{C}$ double bond $(1.336 \AA))^{144}$ The shortness of the $\mathrm{C}-\mathrm{O}$ bond may be attributed to strong delocalization from the lone pair on oxygen into the formally vacant $\underline{p}$ orbital at carbon. 


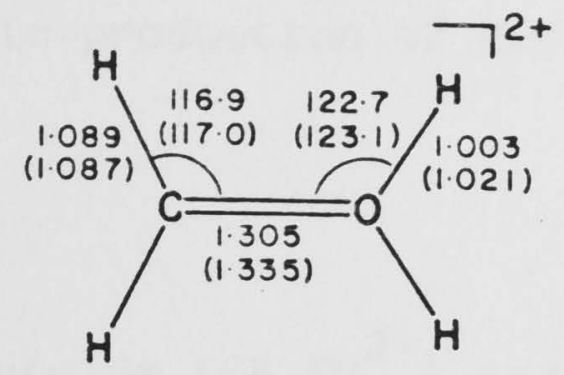

Ib

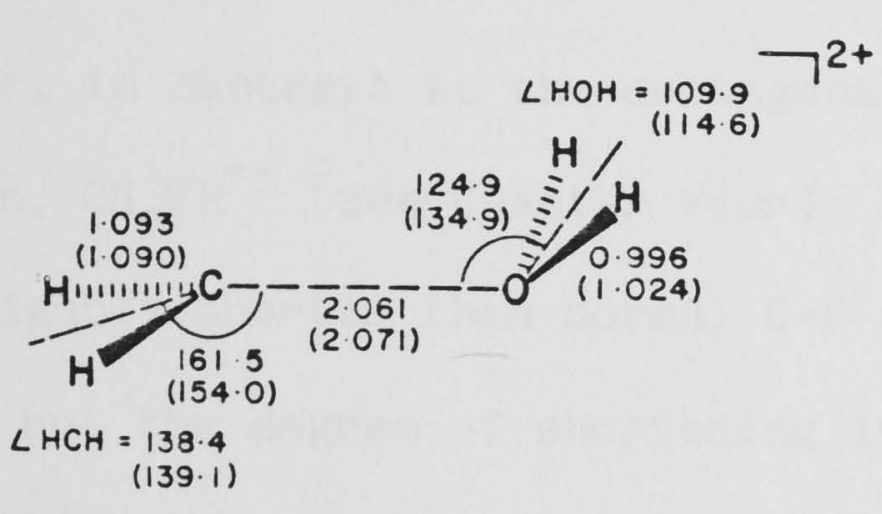

$4 b$

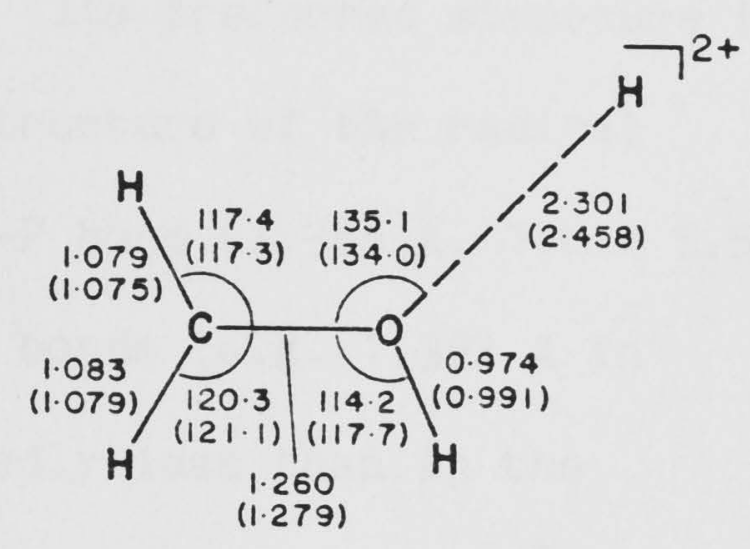

$5 b$

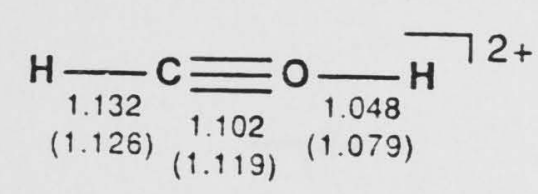

As with $\mathrm{CH}_{2} \mathrm{NH}_{3}{ }^{2+}, \mathrm{CH}_{2} \mathrm{OH}_{2}{ }^{2+}$ is thermodynamically unstable with respect to fragmentation products (Figure 5.1b), lying $33 \mathrm{~kJ} \mathrm{~mol}{ }^{-1}$ above $\mathrm{CH}_{2}{ }^{+\cdot}+\mathrm{OH}_{2}{ }^{+\cdot}$ and $103 \mathrm{~kJ} \mathrm{~mol}^{-1}$ above $\mathrm{CH}_{2} \mathrm{OH}^{+}+\mathrm{H}^{+}$. However, the barriers to such dissociation processes are large, the lower-energy decomposition pathway, i.e. via $5 \mathrm{~b}$ to give $\mathrm{CH}_{2} \mathrm{OH}^{+}+\mathrm{H}^{+}$, requiring 252 $\mathrm{kJ} \mathrm{mol}{ }^{-1} \mathrm{c}$

The methanol dication $\left(\mathrm{CH}_{3} \mathrm{OH}^{2+}\right)$ is found to fall apart on both the $3-21 \mathrm{G}$ and $6-31 \mathrm{G}^{*}$ surfaces. Geometry optimization, starting with the $\mathrm{CH}_{3} \mathrm{OH}^{+\cdot}$ structure, leads under an RHF constraint to a weak complex ( $8 \mathbf{b}$ ) of $\mathrm{HCOH}^{2+}$ and $\mathrm{H}_{2}$ but this no longer bears any resemblance

c. Similar results were obtained recently (ref 210 ) but at a less precise level of theory. 
to methanol. The complex $8 \mathrm{~b}$ lies substantially higher in energy (by $312 \mathrm{~kJ} \mathrm{~mol}^{-1}$ ) than 1b. With UHF calculations, such an optimization results in the highly exothermic production of $\mathrm{HCOH}^{+}$plus $\mathrm{H}_{2}^{+\cdot}$ (lying $170 \mathrm{~kJ} \mathrm{~mol}^{-1}$ below $\left.8 \mathrm{~b}\right)$.

\subsubsection{Methylenefluoroni um $\left(\mathrm{CH}_{2} \mathrm{FH}^{2+}\right)$ and Fluoromethane}

\section{$\left(\mathrm{CH}_{3} \mathrm{~F}^{2+}\right)$ Dications The methylenefluoronium dication (1c) is}

isoelectronic with formaldimine $\left(\mathrm{CH}_{2}=\mathrm{NH}\right)$. Its preferred structure is planar, in contrast to the orthogonal $\underline{C}_{\underline{S}}$ structure of the radical cation, $\mathrm{CH}_{2} \mathrm{FH}^{+}$(see Chapter Four); the C-F bond (1.366 凡, Table 5.5) is slightly shorter than normal C-F single bonds (e.g. 1.392 \& in $\mathrm{CH}_{3} \mathrm{~F}$ ) but the degree of shortening is markedly less than in the $\mathrm{CH}_{2} \mathrm{OH}_{2}{ }^{2+}$ case. Thus, although the planar structure of $\mathrm{CH}_{2} \mathrm{FH}^{+}$

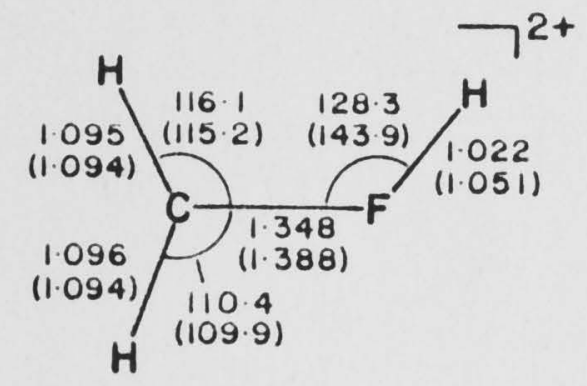

Ic

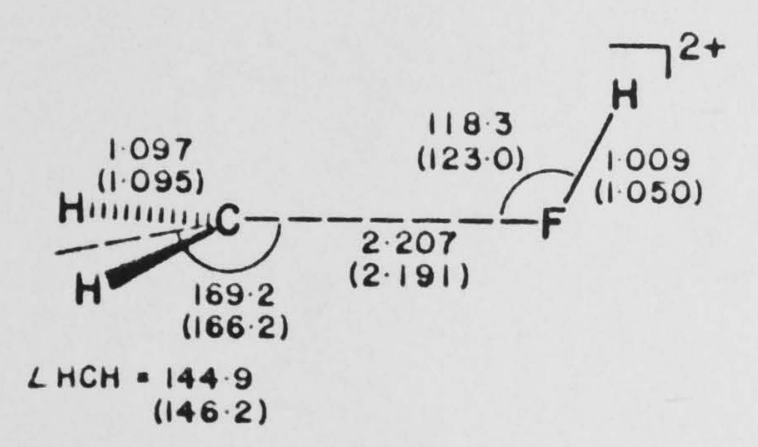

$4 c$

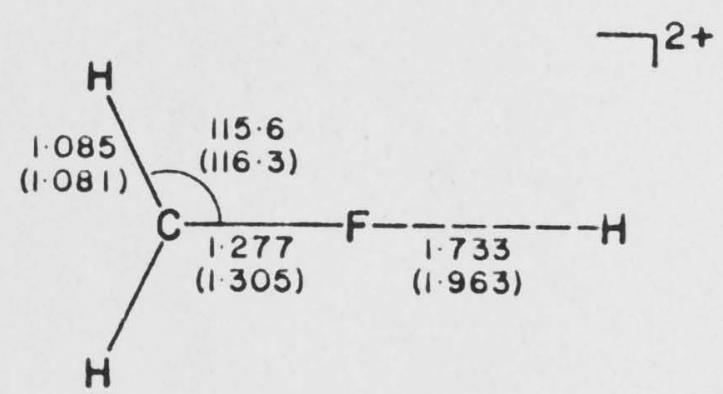

$5 c$

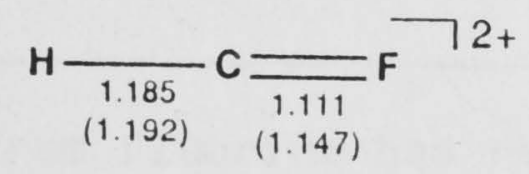


suggests that one of the lone pairs on fluorine is involved in $\pi$ bonding to carbon, ${ }^{d}$ coulombic repulsion appears to play a larger role here than in the oxygen case.

The methylenefluoronium dication (1c) lies in a somewhat shallower well (Figure 5.1c) than does $\mathrm{CH}_{2} \mathrm{NH}_{3}{ }^{2+}$ and $\mathrm{CH}_{2} \mathrm{OH}_{2}{ }^{2+}$. The barrier to the highly exothermic (by $288 \mathrm{~kJ} \mathrm{~mol}^{-1}$ ) fragmentation via $5 \mathrm{c}$ to $\mathrm{CH}_{2} \mathrm{~F}^{+}+\mathrm{H}^{+}$is reduced to $105 \mathrm{~kJ} \mathrm{~mol}^{-1}$.

The fluoromethane dication is found to be unstable. With RHF calculations, dissociation to give $\mathrm{H}^{+}+\mathrm{CH}_{2} \mathrm{~F}^{+}$can take place without a barrier.

d. Strong $\pi$ donation from fluorine has recently been invoked to explain the calculated shortening of $\mathrm{C}-\mathrm{F}$ lengths in the series $\mathrm{CF}_{2}, \mathrm{CF}_{2}^{+\cdot}$ and $\mathrm{CF}_{2}{ }^{2+}$. See ref 211 . 



Figure 5.2 Schematic energy profiles for dissociative processes of the second-row ylide dications. 


\subsubsection{Methylenephosphoni um $\left(\mathrm{CH}_{2} \mathrm{PH}_{3}{ }^{2+}\right)$ and Methylphosphine} $\left(\mathrm{CH}_{3} \mathrm{PH}_{2}{ }^{2+}\right)$ Dications The methylenephosphonium dication has a preferred staggered conformation (1d) with a near-planar carbenium centre. The alternative eclipsed conformation ( $1 \mathrm{~d}^{\mathrm{e}}-$ ) lies higher in energy by just $0.2 \mathrm{~kJ} \mathrm{~mol}^{-1}$ and is confirmed by frequency calculations to be located at a saddle point on the surface, i.e. it represents the transition structure for internal rotation.

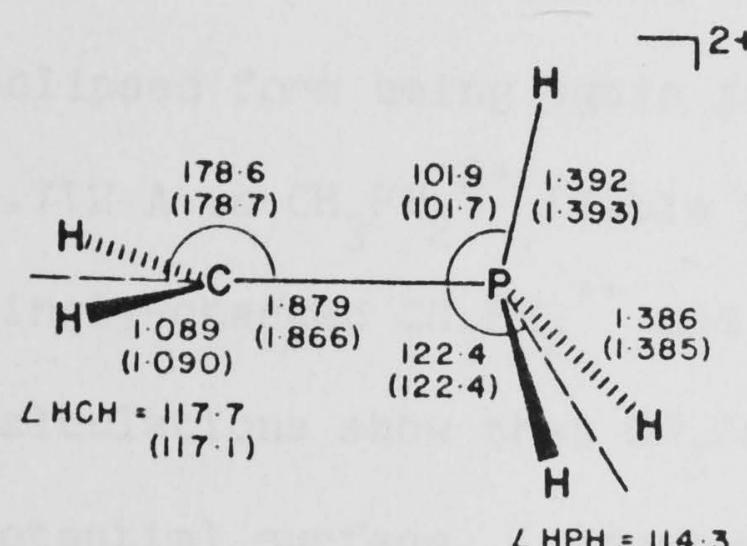

Id

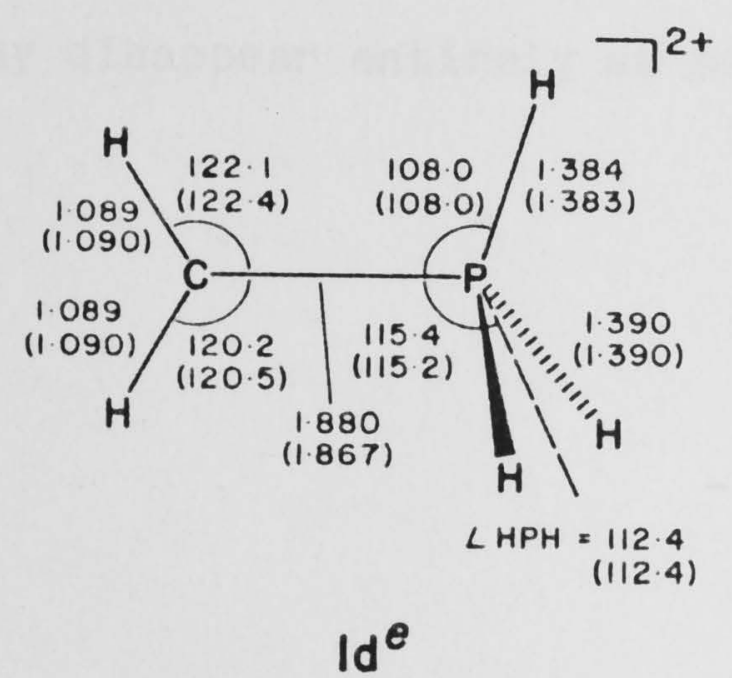

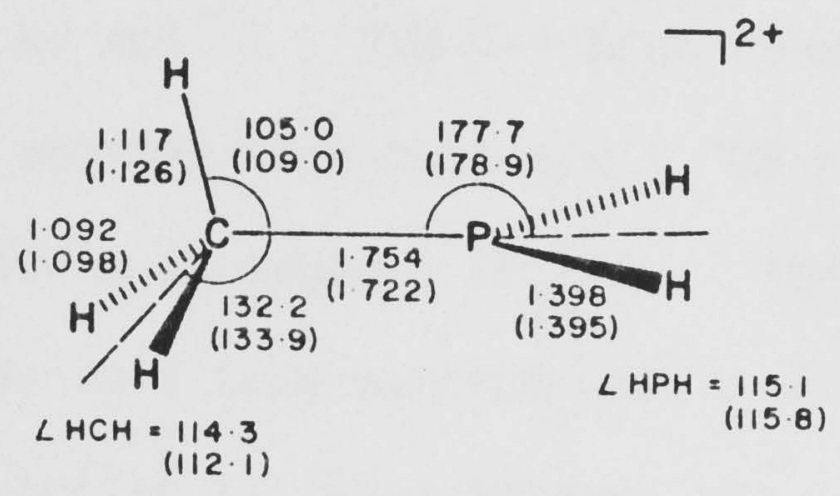

2d

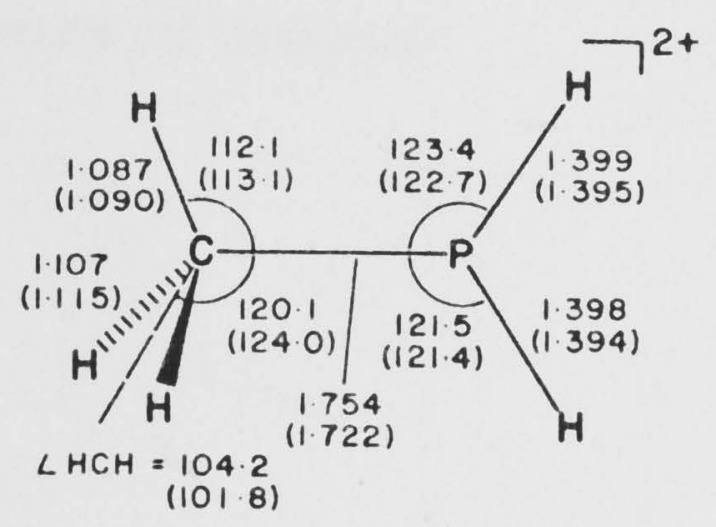

$2 d^{e}$

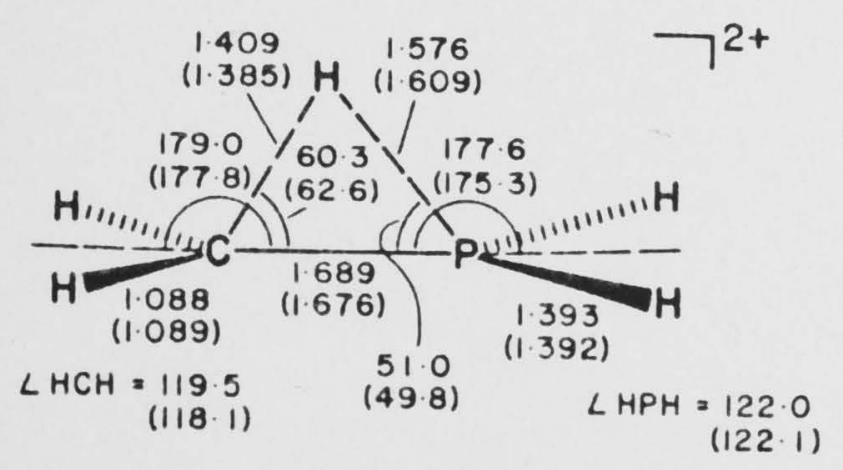

$3 d$ 
The $\mathrm{C}-\mathrm{P}$ bond length in $\mathrm{CH}_{2} \mathrm{PH}_{3}{ }^{2+}$ is predicted to be $1.865 \AA$ (Table $5.5)$, which is longer than the $\mathrm{C}-\mathrm{P}$ bond in the ylidion (1.765 \&) and longer than a normal $\mathrm{C}-\mathrm{P}$ single bond (e.g. $1.857 \AA$ in $\mathrm{CH}_{3} \mathrm{PH}_{2}$ ). Hyperconjugative interactions in $\mathrm{CH}_{2} \mathrm{PH}_{3}{ }^{2+}$ appear to be less important than in $\mathrm{CH}_{2} \mathrm{NH}_{3}{ }^{2+}$, as might have been anticipated.

For the methylphosphine dication, the eclipsed conformation $\left(2 d^{\mathrm{e}}\right)$ is marginally favoured at the $3-21 \mathrm{G}^{(*)}$ level of theory. However, it is found that at the highest level the preferred conformation is staggered (2d), with the barrier to rotation via the eclipsed form being again just $0.2 \mathrm{~kJ} \mathrm{~mol}^{-1}$. The $\mathrm{C}-\mathrm{P}$ bond length of $1.712 \AA$ in $\mathrm{CH}_{3} \mathrm{PH}_{2}^{2+}$ (Table 5.5) is shorter than both the $1.798 \AA$ in singly-charged $\mathrm{CH}_{3} \mathrm{PH}_{2}^{+\cdot}$ and the $1.857 \AA$ in neutral $\mathrm{CH}_{3} \mathrm{PH}_{2}$. Frequency calculations show that $\mathrm{CH}_{3} \mathrm{PH}_{2}{ }^{2+}$ (2d) is a true minimum on the $6-31 \mathrm{G}^{*}$ potential surface. However, the barrier to rearrangement via transition structure $3 \mathrm{~d}$ is very small (Figure $5.2 \mathrm{a}$ ) and the barrier may disappear entirely at higher levels of theory. 
130.

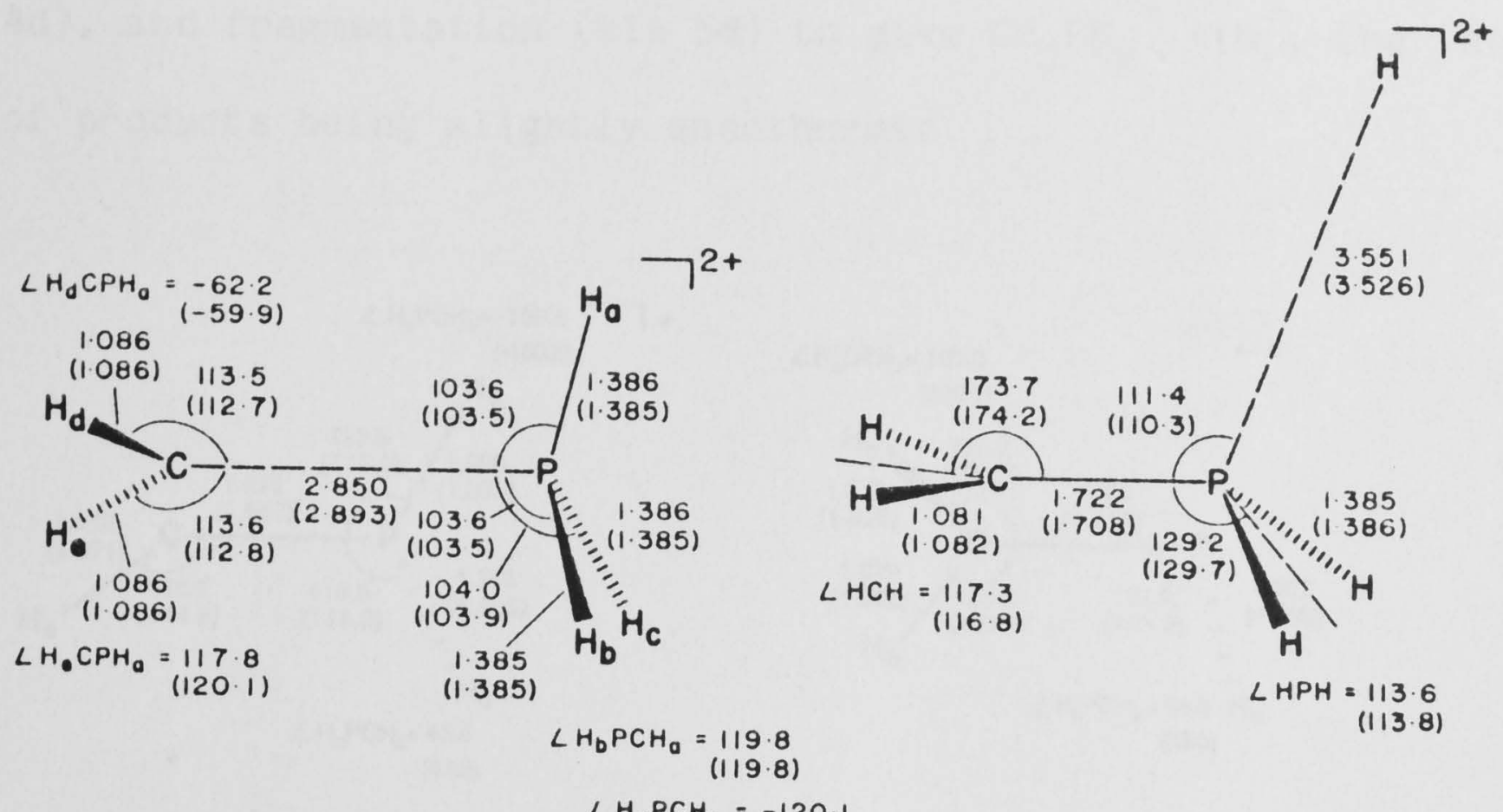

$4 d$

$\angle H_{c} P C H_{0}=-120 \cdot 1$

$5 d$
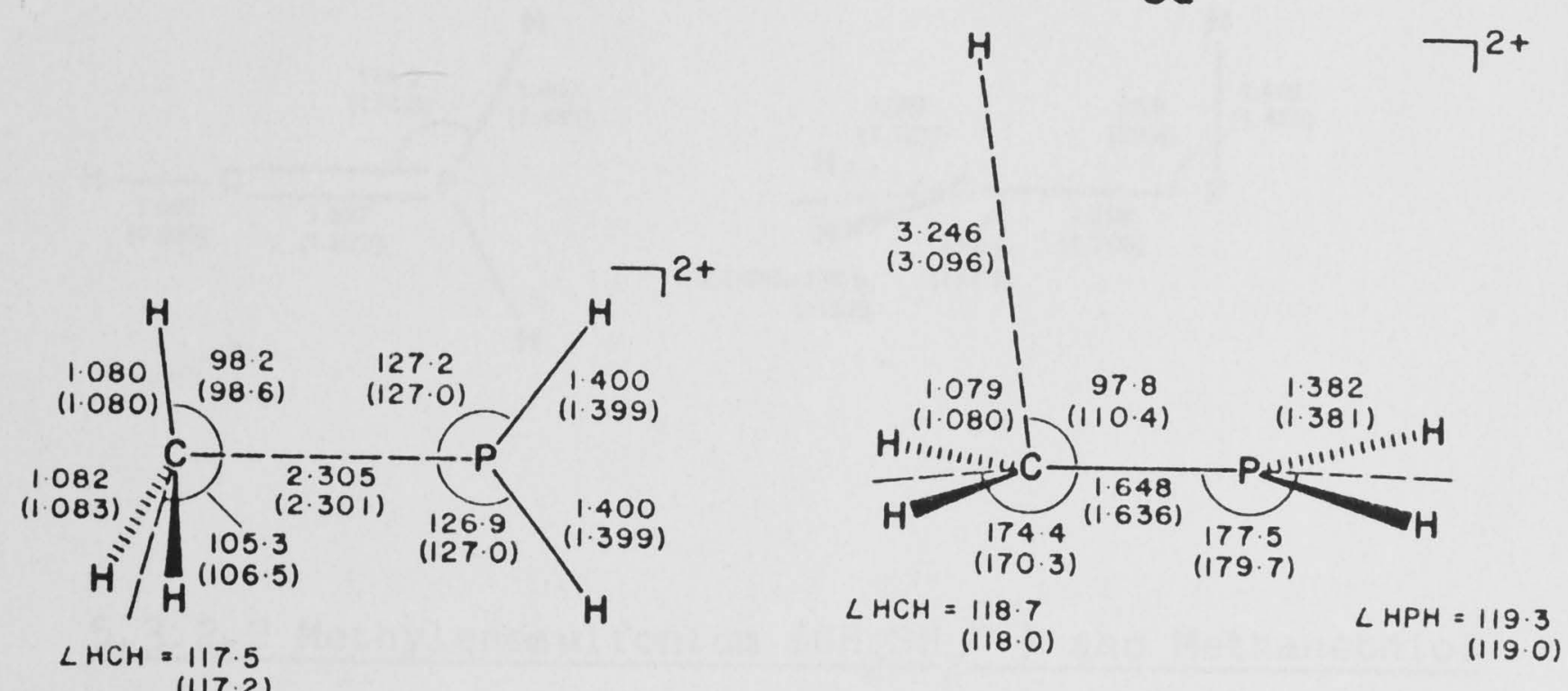

$6 d$

$7 d$
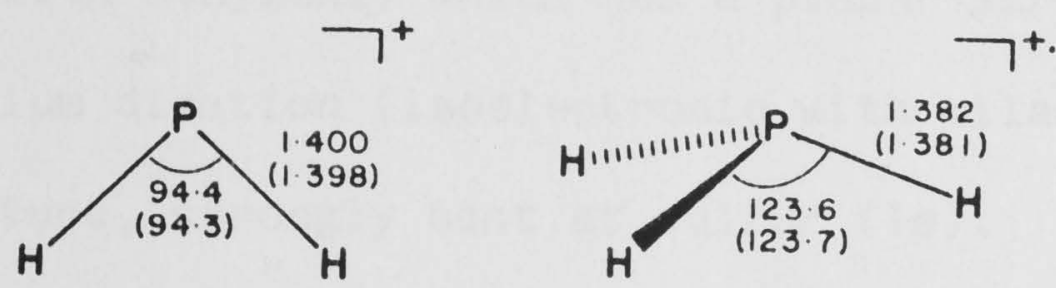

The lowest-energy decomposition pathway for $\mathrm{CH}_{2} \mathrm{PH}_{3}{ }^{2+}$ (1d) involves hydrogen migration (via 3d) followed by C-P bond rupture (via 6d) to give $\mathrm{CH}_{3}^{+}+\mathrm{PH}_{2}^{+}$. This process has a barrier of $103 \mathrm{~kJ} \mathrm{~mol}^{-1}$ and an exothermicity of $273 \mathrm{~kJ} \mathrm{~mol}^{-1}$. Higher-energy processes include direct breakage of the $\mathrm{C}-\mathrm{P}$ bond in $1 \mathrm{~d}$ to give $\mathrm{CH}_{2}{ }^{+}+\mathrm{PH}_{3}{ }^{+} \cdot$ 
(via 4d), and fragmentation (via 5d) to give $\mathrm{CH}_{2} \mathrm{PH}_{2}^{+}+\mathrm{H}^{+}$, the latter pair of products being slightly endothermic.
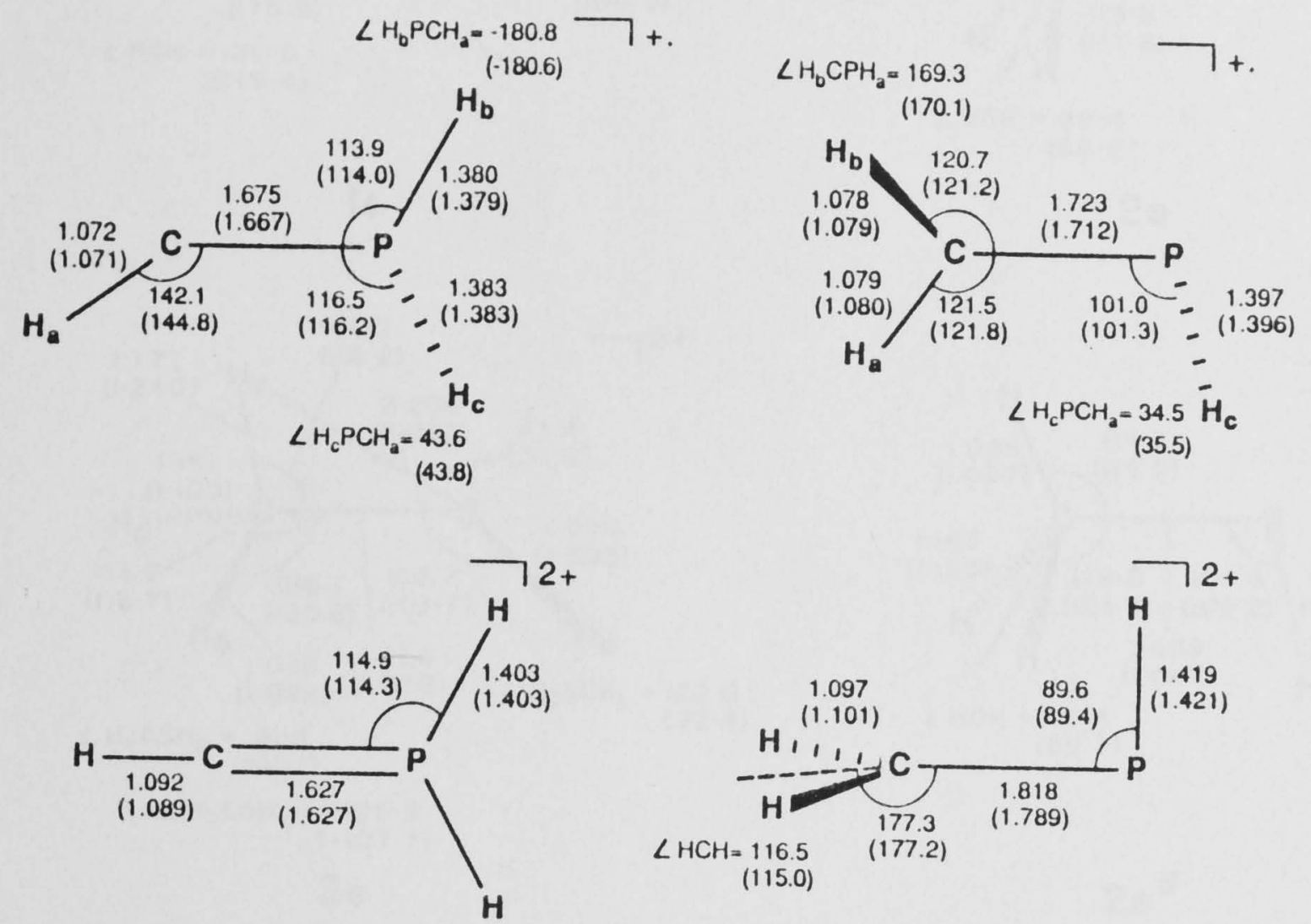

\subsubsection{Methylenesulfoni um $\left(\mathrm{CH}_{2} \mathrm{SH}_{2}{ }^{2+}\right)$ and Methanethiol}

$\left(\mathrm{CH}_{3} \mathrm{SH}^{2+}\right)$ Dications In contrast to the methyleneoxonium dication (isoelectronic with ethylene) which has a planar structure (1b), the methylenesulfonium dication (isoelectronic with silaethylene) has an $\underline{\text { anti }}\left(\underline{C}_{S}\right)$ structure, strongly bent at sulfur (1e). Although this result might appear surprising at first glance, it is consistent with the greater pyramidality of $\mathrm{H}_{3} \mathrm{~S}^{+}$compared with $\mathrm{H}_{3} \mathrm{O}^{+}$(bond angles of $96.9^{\circ}$ and $113.1^{\circ}$, respectively, at $\mathrm{HF} / 6-31 \mathrm{G}^{*}$ ) and also reflects a reduced tendency for delocalization of the lone pair on sulfur into the formally vacant $\underline{p}$ orbital on the adjacent carbon. Nevertheless, the $\mathrm{C}-\mathrm{S}$ bond in $\mathrm{CH}_{2} \mathrm{SH}_{2}{ }^{2+}$ is quite short with a length $(1.674 \AA$, Table 5.5) which is considerably less than that of the $C-S$ bond in neutral methanethiol (1.814 月). 


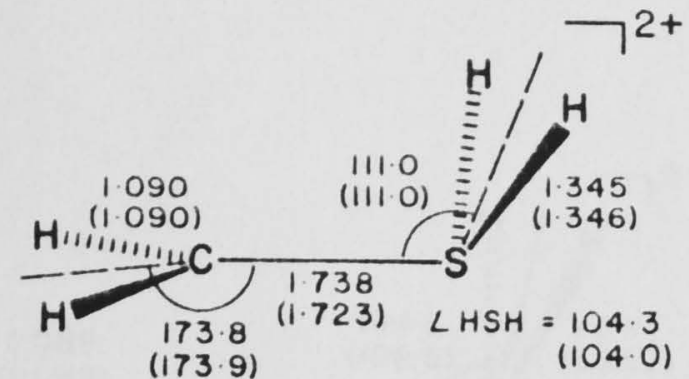

$\begin{aligned} \angle H C H & =120.5 \\ & (119.4)\end{aligned}$

$1 \mathrm{e}$

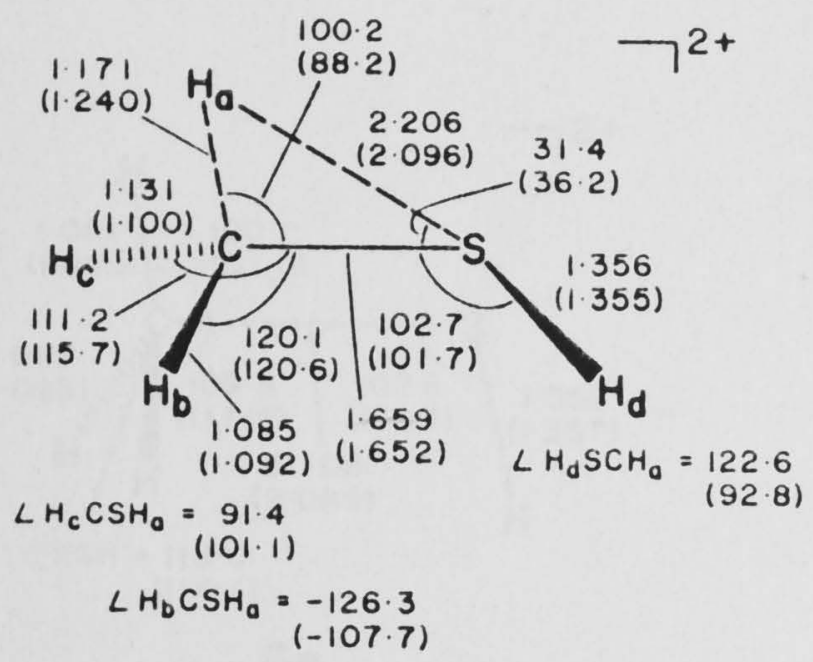

30

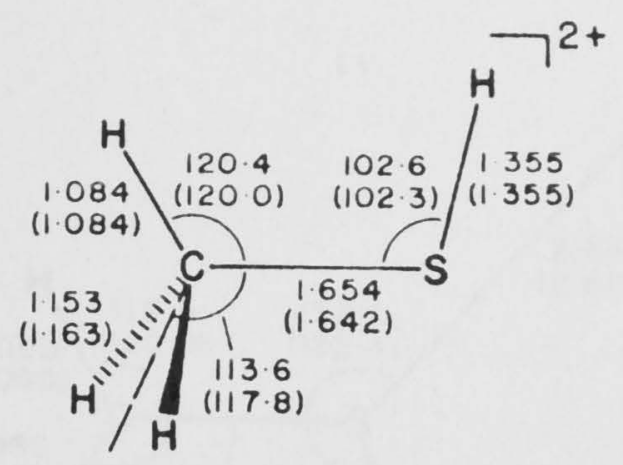

$\angle H C H=84.4$ (86.0).

20

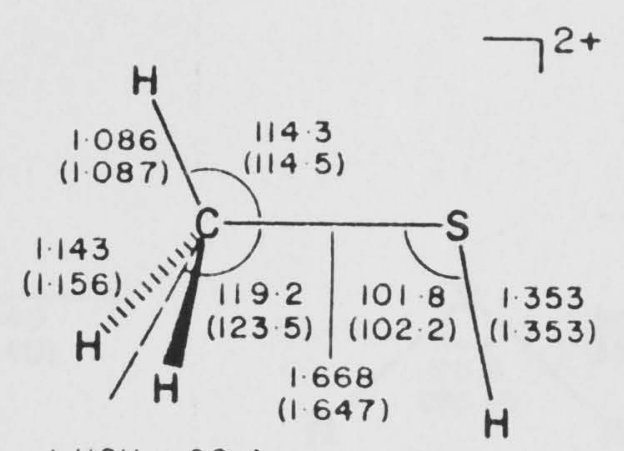

$\angle H C H=90 \cdot 4$

The preferred conformation of the methanethiol dication is eclipsed ( $2 \mathbf{e})$, the barrier to internal rotation via the staggered structure $\left(2 \mathrm{e}^{\mathrm{S}}\right)$ being $11 \mathrm{~kJ} \mathrm{~mol}^{-1}$. The calculated structure (2e) resembles a complex of $\mathrm{HCSH}^{2+}+\mathrm{H}_{2}$ (or of $\mathrm{HCSH}^{+\cdot}+\mathrm{H}_{2}^{+\cdot}$ ) in that the $\mathrm{C}-\mathrm{S}$ bond is short $(1.649 \AA$, Table 5.5) and the symmetry-equivalent $\mathrm{C}-\mathrm{H}$ bonds are unusually long ( $1.217 \AA$ ).

Although $\mathrm{CH}_{3} \mathrm{SH}^{2+}$ (2e) is found to be a minimum in this study, its rearrangement to $\mathrm{CH}_{2} \mathrm{SH}_{2}{ }^{2+}$ (1e) via a 1,2-hydrogen shift (3e) requires only $1 \mathrm{~kJ} \mathrm{~mol}^{-1}$ (Figure $5.2 \mathrm{~b}$ ) and it is quite probable that at higher levels of theory this barrier for rearrangement would disappear altogether. For its part, $\mathrm{CH}_{2} \mathrm{SH}_{2}{ }^{2+}$ lies in a moderately deep well, with barriers of 218 and $244 \mathrm{~kJ} \mathrm{~mol}^{-1}$ to fragmentation to $\mathrm{CH}_{2}{ }^{+\cdot}+\mathrm{SH}_{2}^{+\cdot}$ (via $4 \mathrm{e}$ ) and $\mathrm{CH}_{2} \mathrm{SH}^{+}+\mathrm{H}^{+}$(via $5 \mathrm{e}$ ), respectively. 


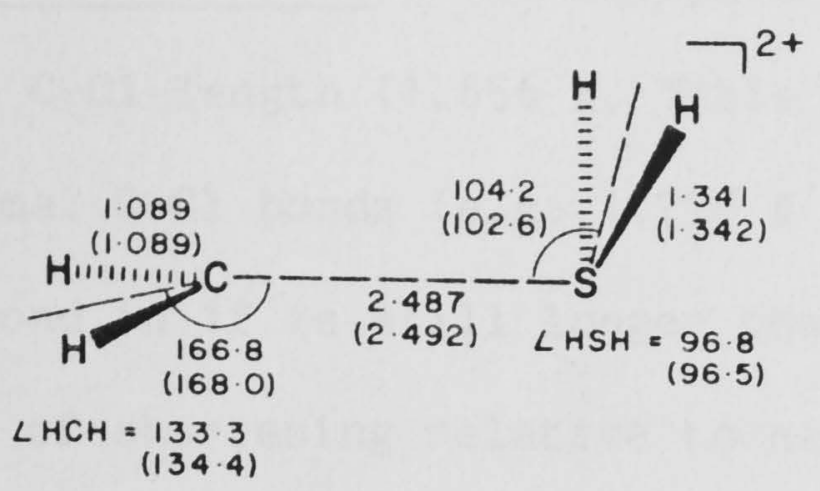

4 .

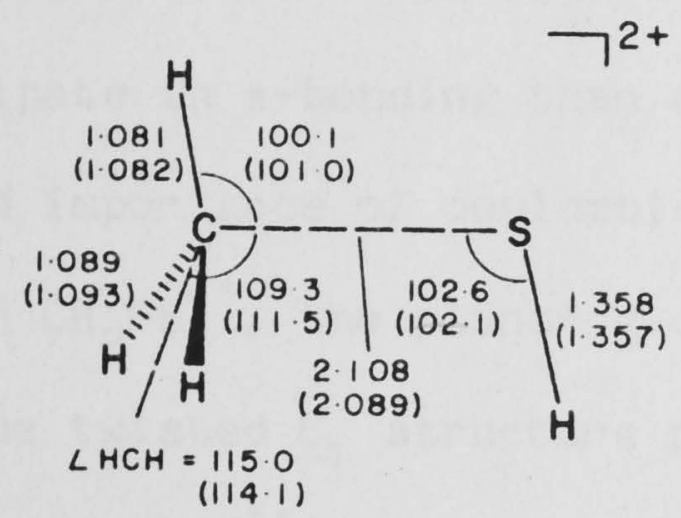

68
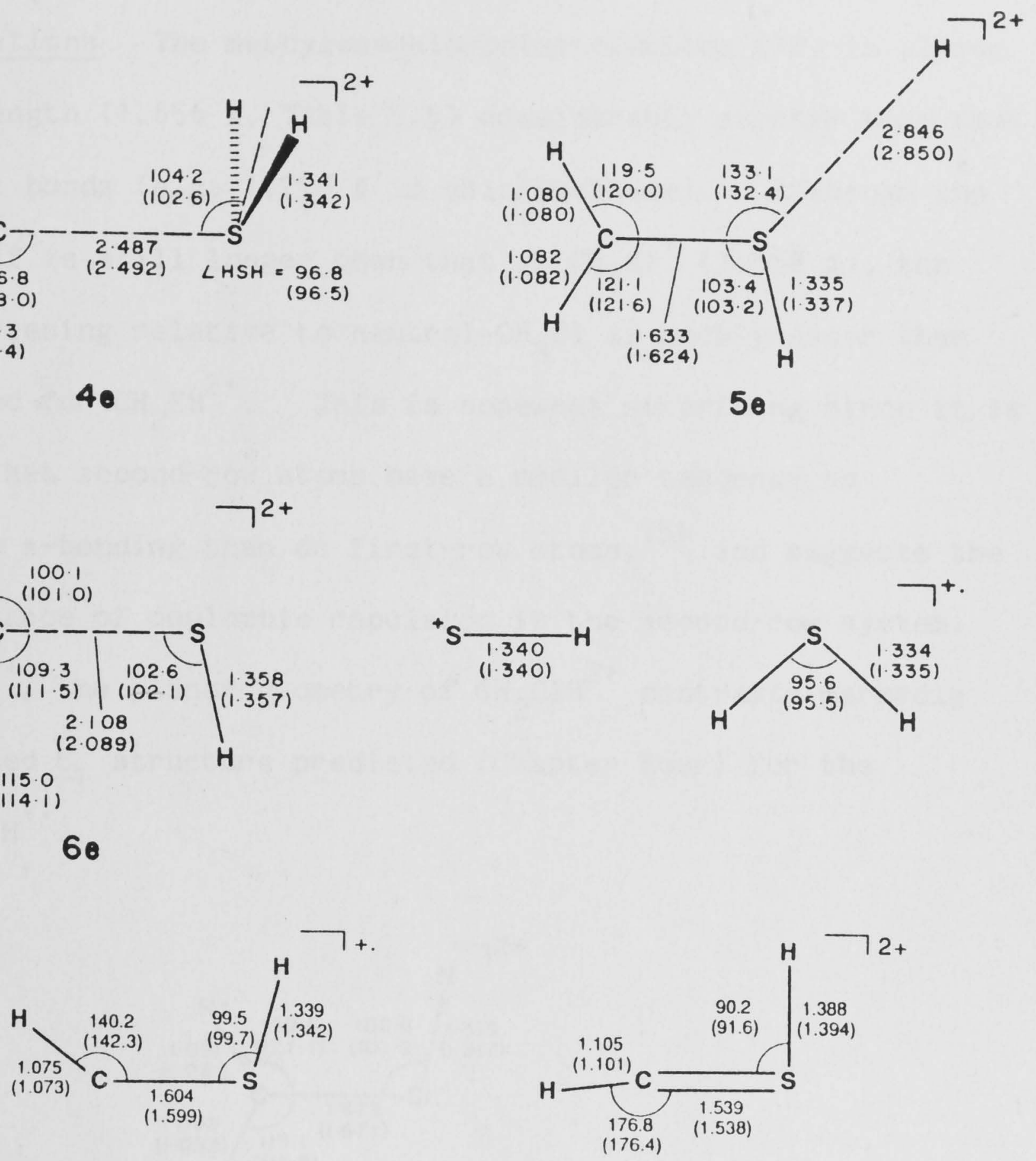

In contrast to the situation for $\mathrm{CH}_{2} \mathrm{PH}_{3}{ }^{2+}$, hydrogen migration in $\mathrm{CH}_{2} \mathrm{SH}_{2}{ }^{2+}$ followed by $\mathrm{C}-\mathrm{S}$ bond rupture to give $\mathrm{CH}_{3}{ }^{+}+\mathrm{SH}^{+}$is not expected to be a competitive process for decomposition of $\mathrm{CH}_{2} \mathrm{SH}_{2}{ }^{2+}$ since this would require $58 \mathrm{~kJ} \mathrm{~mol}^{-1}$ more energy than direct rupture of the $\mathrm{C}-\mathrm{S}$ bond.

The search for a transition structure for formation of $\mathrm{CH}_{2} \mathrm{SH}^{+}$ $+\mathrm{H}^{+}$from $\mathrm{CH}_{3} \mathrm{SH}^{2+}$ was unsuccessful. Test calculations suggest that there is a very large barrier to proton lass from the carbon of $\mathrm{CH}_{3} \mathrm{SH}^{2+}$. Indeed, the lower energy pathway probably involves a $1,2-$ hydrogen shift (via 3e), followed by proton loss from the sulfur. 


\subsubsection{Methylenechlor oni um $\left(\mathrm{CH}_{2} \mathrm{ClH}^{2+}\right)$ and Chloromethane}

$\left(\mathrm{CH}_{3} \mathrm{Cl}^{2+}\right)$ Dications The methylenechloronium dication (1f) is planar with a C-Cl length (1.656 月, Table 5.5) considerably shorter than that of normal $\mathrm{C}-\mathrm{Cl}$ bonds (e.g. $1.778 \AA$ in chloromethane). Although the C-Cl bond in $1 \mathrm{f}$ is still longer than that in $\mathrm{CH}_{2} \mathrm{Cl}^{+}(1.588 \AA)$, the degree of shortening relative to neutral $\mathrm{CH}_{3} \mathrm{Cl}$ is much greater than that calculated for $\mathrm{CH}_{2} \mathrm{FH}^{2+}$. This is somewhat surprising since it is usually held that second-row atoms have a smaller tendency to participate in $\pi$-bonding than do first-row atoms, ${ }^{151}$ and suggests the reduced importance of coulombic repulsion in the second-row system. As with $\mathrm{CH}_{2} \mathrm{FH}^{2+}$, the planar geometry of $\mathrm{CH}_{2} \mathrm{ClH}^{2+}$ contrasts markedly with the twisted $\underline{C}_{1}$ structure predicted (Chapter Four) for the ylidion, $\mathrm{CH}_{2} \mathrm{ClH}^{+} \cdot$.

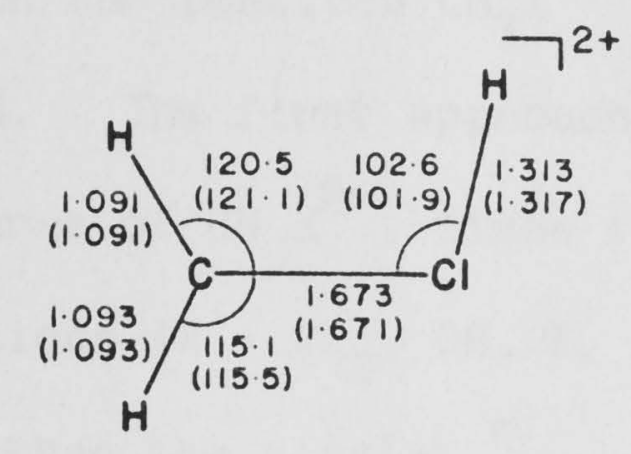

\section{If}

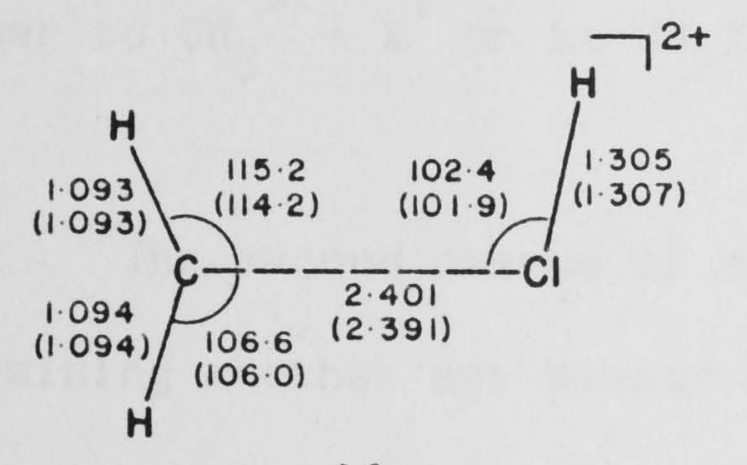

$4 f$

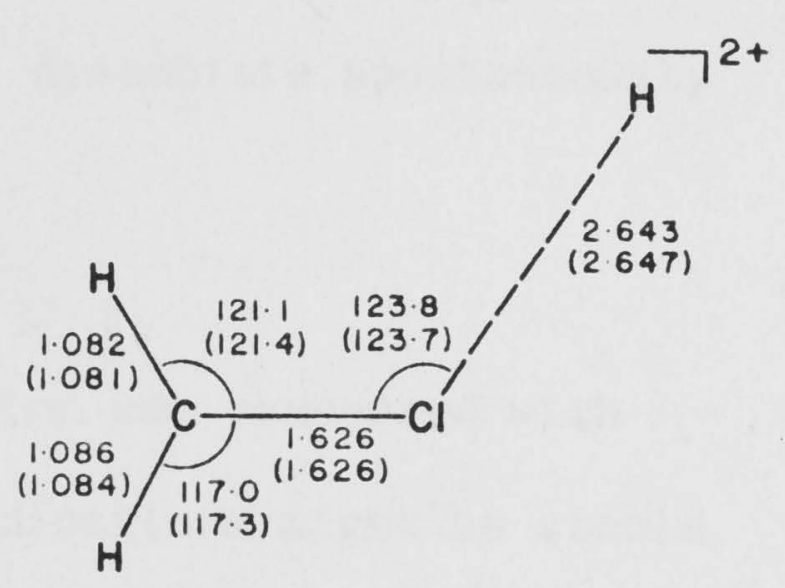

$5 f$
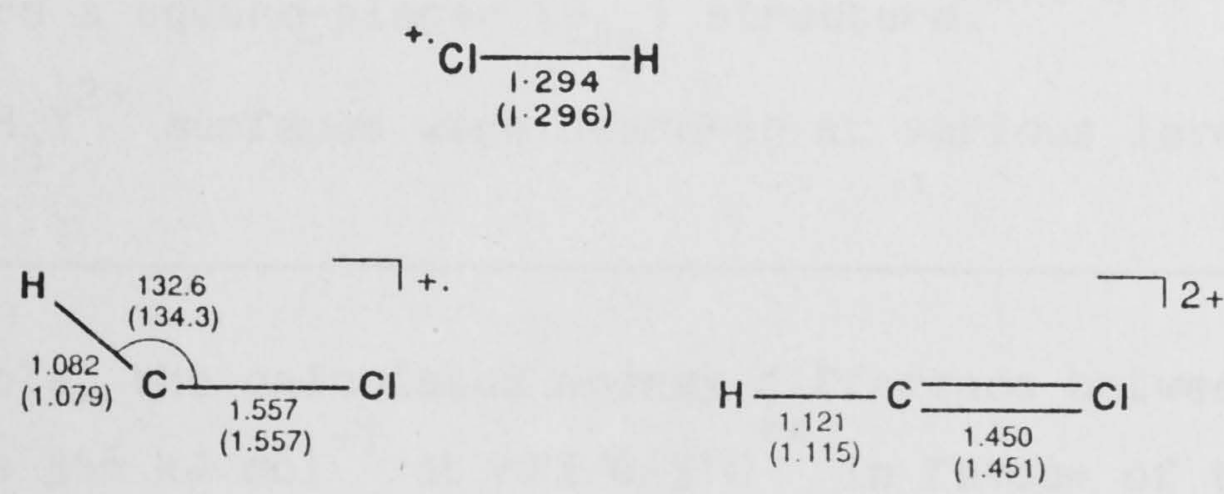
The methylenechloronium dication (1f) lies in a much deeper potential well than $\mathrm{CH}_{2} \mathrm{FH}^{2+}$ with barriers to decomposition to $\mathrm{CH}_{2}{ }^{+} \cdot+$ $\mathrm{ClH}^{+\cdot}$ (via 4f) and $\mathrm{CH}_{2} \mathrm{Cl}^{+}+\mathrm{H}^{+}$(via 5f) of 239 and $201 \mathrm{~kJ} \mathrm{~mol}^{-1}$, respectively (Figure 5.2c).

The chloromethane dication is not stable and any structure bearing some resemblance to neutral chloromethane lies very high in energy on the potential surface at both $3-21 \mathrm{G}^{(*)}$ and $6-31 \mathrm{G}^{*}$. Optimizations at these levels show that $\mathrm{CH}_{3} \mathrm{Cl}^{2+}$ dissociates without a barrier to $\mathrm{CH}_{3}^{+}+\mathrm{Cl}^{+}$.

\subsubsection{The $\mathrm{CH}_{3} \mathrm{x}^{2+}$ Dications}

In the search for possible $\mathrm{CH}_{3} \mathrm{x}^{2+}$ structures, two further avenues were explored. The first approach involved looking for lowlying triplet structures of $\mathrm{CH}_{3} \mathrm{x}^{2+}$, since it was found that for several of the $X^{+}$cations $\left(X=\mathrm{NH}_{2}, \mathrm{OH}, \mathrm{F}, \mathrm{SH}\right.$ and $\left.\mathrm{Cl}\right)$ the triplet lies much lower in energy than the singlet. ${ }^{e}$ In each case, however, the triplet $\mathrm{CH}_{3} \mathrm{x}^{2+}$ dications were found to dissociate spontaneously (either to $\mathrm{CH}_{3}^{+}+\mathrm{X}^{+}$or to $\mathrm{CH}_{2} \mathrm{X}^{+}+\mathrm{H}^{+}$).

The second avenue of exploration was concerned with determining whether any planar $\mathrm{CH}_{3} \mathrm{x}^{2+}$ dications might be stable structures. It is well established that the parent methane dication, $\mathrm{CH}_{4}{ }^{2+}$, prefers a square-planar $\left(\underline{\mathrm{D}}_{4 \underline{h}}\right)$ structure. ${ }^{212-214}$ The individual $\mathrm{CH}_{3} \mathrm{X}^{2+}$ surfaces were searched at various levels of theory

e. For example, the calculated energy difference between $\mathrm{F}^{+}\left({ }^{1} \mathrm{D}\right)$ and $\mathrm{F}^{+}\left({ }^{3} \mathrm{P}\right)$ is $356 \mathrm{~kJ} \mathrm{~mol}^{-1}$ at $\mathrm{MP} 3 / 6-31 \mathrm{G}^{* *}$ in favour of the triplet. 
(including optimizations at the MP2/6-31G ${ }^{*}$ level) but no planar structures which are located at minima on these surfaces were found.

It would appear that the $\mathrm{CH}_{3} \mathrm{x}^{2+}$ dications are not particularly stable species. For those systems that do reside at a local minimum on the potential surface $\left(X=\mathrm{PH}_{2}, \mathrm{SH}\right)$, the positive charge is concentrated on $\mathrm{X}$ (e.g. for $\mathrm{CH}_{3} \mathrm{PH}_{2}{ }^{2+}$ the Mulliken charges are distributed $+1.64\left(\mathrm{PH}_{2}\right)$ and $\left.+0.36\left(\mathrm{CH}_{3}\right)\right)$. For more electronegative $X\left(X=\mathrm{NH}_{2}, \mathrm{OH}, \mathrm{F}, \mathrm{Cl}\right)$, double ionization becomes more difficult and the $\mathrm{CH}_{3} \mathrm{x}^{2+}$ dications become unstable with respect to dissociation.

\subsubsection{Comparisons Across the Periodic Table}

On moving from left to right across the first- or second-row of the periodic table, the following general observations may be made:

(i) the energy difference between the ylide dication and its (exothermic) fragmentation products $\mathrm{CH}_{2} \mathrm{X}^{+}+\mathrm{H}^{+}$ tends to increase; and

(ii) the barrier to the lowest-energy decomposition pathway for the ylide dication tends to decrease.

These two trends reflect a general decrease in the stability of the ylide dications in the order Group V > Group VI > Group VII.

\subsubsection{Comparisons Between First- and Second-Row Ylide Dications}

For first-row systems, the $\mathrm{C}-\mathrm{X}$ bonds in the $\mathrm{yl}$ ide dications $\left(\mathrm{CH}_{2} \mathrm{XH}^{2+}\right)$ are all shorter than those in neutral $\mathrm{CH}_{3} \mathrm{X}$. The ylide dications appear to be the only minima on their respective $\left[\mathrm{CH}_{3} \mathrm{x}^{2+}\right]$ 
surfaces and the barriers to the lowest-energy decomposition pathways are quite large.

For second-row systems, the degree of shortening of the $\mathrm{C}-\mathrm{X}$ bonds in the ylide dications (relative to those in the neutral $\mathrm{CH}_{3} \mathrm{X}$ ) is generally less than in the first-row species. The ylide dications in the second-row also tend to have lower barriers to decomposition than in the first-row. Additional minima corresponding to the conventional isomers $\left(\mathrm{CH}_{3} \mathrm{X}^{2+}\right)$ are found in some cases, although they lie higher in energy and have small barriers to rearrangement.

\subsubsection{Small Dication Fragments}

Several small dications were investigated during this study in order to ascertain the thermodynamics of the process $\mathrm{CH}_{2} \mathrm{XH}^{2+} \rightarrow$ $\mathrm{CHX}^{2+}+\mathrm{H}_{2}$. Although representing only a minor part of this present work, it is worth noting two interesting features of the $\mathrm{CHX}^{2+}$ dications. First, they nearly all have very short $\mathrm{C}-\mathrm{X}$ bond lengths. In the case of $\mathrm{HCOH}^{2+}$, the $\mathrm{C}-\mathrm{O}$ length of 1.102 \& at $\mathrm{HF} / 6-31 \mathrm{G}^{*}$ is close to that of carbon monoxide $(1.114 \AA)^{144}$ and somewhat shorter than the $\mathrm{C} \equiv \mathrm{C}$ triple bond of acetylene $(1.185 \AA)^{144}$ calculated at the same level. Some of the second-row systems also have short $\mathrm{C}-\mathrm{X}$ bonds. For example, the $\mathrm{HCCl}^{2+}$ dication has a C-Cl length of $1.450 \AA$ at $\mathrm{HF} / 6-31 \mathrm{G}^{*}$ which is much shorter than the $\mathrm{C}-\mathrm{Cl}$ bond in chloromethane $(1.785 \AA)$ and significantly shorter than the CミSi bond in silaacetylene $(1.564 \AA) .^{144}$ 
Secondly, there are some marked differences in structure between the first- and second-row species. For example, in contrast to the planar structure of $\mathrm{H}_{2} \mathrm{CNH}^{2+}$, the $\mathrm{H}_{2} \mathrm{CPH}^{2+}$ dication is orthogonal. Similarly, while $\mathrm{HCOH}^{2+}$ is linear, $\mathrm{HCSH}^{2+}$ prefers a bent structure. An extensive discussion of these and other features of the $\mathrm{CHX}^{2+}$ dications is contained in ref 215 .

\subsubsection{Comparative Data for Possible Fragmentation Products of Ylide}

\section{Dications}

It is of interest to compare theoretical and experimental relative energies for the possible fragmentation products of the ylide dications, as shown in Table 5.6. For the first-row substituents $(X)$, the thermodynamically preferred fragmentation products correspond to $\mathrm{CH}_{2} \mathrm{X}^{+}+\mathrm{H}^{+}$, whereas for the second-row substituents the $\mathrm{CH}_{3}^{+}+\mathrm{X}^{+}$ pair is preferred. It should be noted with respect to the latter situation that, except for $\mathrm{PH}_{2}^{+}$, the ground state for all the $\mathrm{X}^{+}$ cations is a triplet.

There is good agreement between the calculated relative energies of the $\mathrm{CH}_{2}{ }^{+} \cdot \mathrm{XH}^{+\cdot}$ and $\mathrm{CH}_{3}{ }^{+}+\mathrm{X}^{+}$pairs and experimental values. These comparisons (with the exception of $\mathrm{X}=\mathrm{PH}_{2}$ for which $\mathrm{PH}_{2}{ }^{+}$is a ground-state singlet) are all isogyric, ${ }^{216}$ i.e. the number of electron pairs is conserved, and are handled well at the MP $3 / 6-31 \mathrm{G}^{* *}$ level of theory. 
Table 5.6 Theoretical ${ }^{a}$ and Experimental ${ }^{b}$ Relative energies (kJ $\mathrm{mol}^{-1}$ ) for Possible Fragmentation Products of Ylide Dications

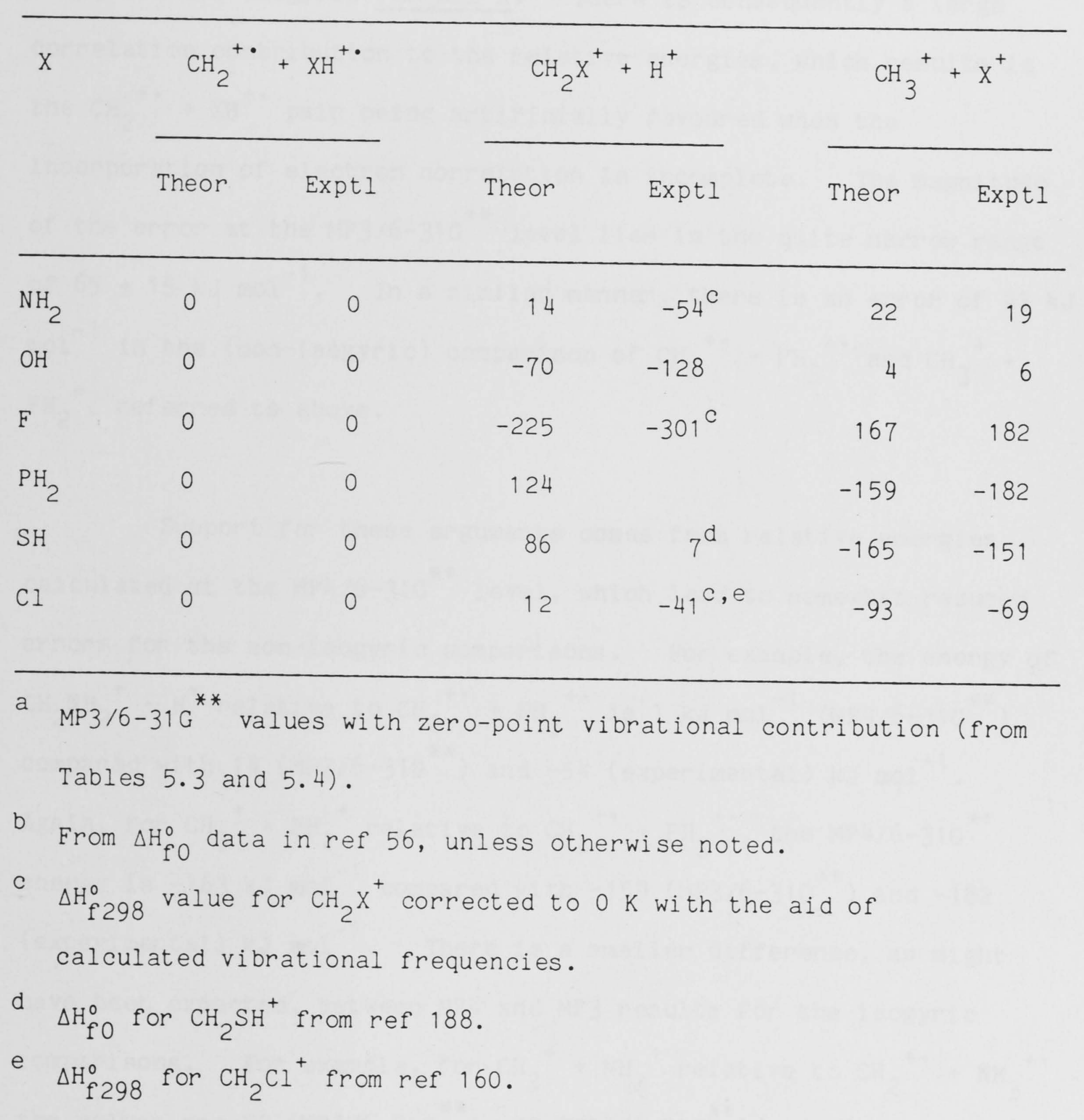


The comparisons of $\mathrm{CH}_{2}^{+\cdot}+\mathrm{XH}^{+}$with $\mathrm{CH}_{2} \mathrm{X}^{+}+\mathrm{H}^{+}$, on the other hand, are non-isogyric for all $\mathrm{X}$. There is consequently a large correlation contribution to the relative energies, which results in the $\mathrm{CH}_{2}^{+\cdot}+\mathrm{XH}^{+\cdot}$ pair being artificially favoured when the incorporation of electron correlation is incomplete. The magnitude of the error at the MP $3 / 6-31 \mathrm{G}^{* *}$ level lies in the quite narrow range of $65 \pm 15 \mathrm{~kJ} \mathrm{~mol}^{-1}$. In a similar manner, there is an error of $23 \mathrm{~kJ}$ $\mathrm{mol}^{-1}$ in the (non-isogyric) comparison of $\mathrm{CH}_{2}{ }^{+\cdot}+\mathrm{PH}_{3}^{+\cdot}$ and $\mathrm{CH}_{3}{ }^{+}+$ $\mathrm{PH}_{2}^{+}$, referred to above.

Support for these arguments comes from relative energies calculated at the $\mathrm{MP} 4 / 6-31 \mathrm{G}^{* *}$ level, which lead to somewhat reduced errors for the non-isogyric comparisons. For example, the energy of $\mathrm{CH}_{2} \mathrm{NH}_{2}^{+}+\mathrm{H}^{+}$relative to $\mathrm{CH}_{2}{ }^{+\cdot}+\mathrm{NH}_{3}^{+}$is $1 \mathrm{~kJ} \mathrm{~mol}^{-1}\left(\mathrm{MP} 4 / 6-31 \mathrm{G}^{* *}\right.$ ) compared with $14\left(\mathrm{MP} 3 / 6-31 \mathrm{G}^{* *}\right.$ ) and -54 (experimental) $\mathrm{kJ} \mathrm{mol}^{-1}$. Again, for $\mathrm{CH}_{3}{ }^{+}+\mathrm{PH}_{2}{ }^{+}$relative to $\mathrm{CH}_{2}{ }^{+\cdot}+\mathrm{PH}_{3}{ }^{+\cdot}$, the MP4/6-31G ${ }^{* *}$ energy is $-163 \mathrm{~kJ} \mathrm{~mol}^{-1}$. compared with $-159\left(\mathrm{MP} 3 / 6-31 \mathrm{G}^{*}\right)$ and -182 (experimental) $\mathrm{kJ} \mathrm{mol}^{-1}$. There is a smaller difference, as might have been expected, between MP4 and MP3 results for the isogyric comparisons. For example, for $\mathrm{CH}_{3}{ }^{+}+\mathrm{NH}_{2}{ }^{+}$relative to $\mathrm{CH}_{2}{ }^{+}+\mathrm{NH}_{3}{ }^{+} \cdot$ the values are $22\left(\mathrm{MP} 3 / 6-31 \mathrm{G}^{* *}\right), 22\left(\mathrm{MP} 4 / 6-31 \mathrm{G}^{* *}\right)$ and 19 (experimental) $\mathrm{kJ} \mathrm{mol}^{-1}$.

\subsubsection{Calculated Ionization Energies and Relationship With Charge-}

\section{Stripping Mass Spectrometry Experiments}

Charge-stripping mass spectrometry experiments have been carried out $155,179,181$ for most of the systems examined in the present study. In general, intense peaks corresponding to $\left[\mathrm{CH}_{3} \mathrm{x}^{2+}\right]$ were 
found ${ }^{155,179}$ in the spectra of $\mathrm{CH}_{2} \mathrm{XH}^{+}$but not in the spectra of $\mathrm{CH}_{3} \mathrm{X}^{+\cdot}$ f Experimental $Q_{\text {min }}$ values have been reported ${ }^{181}$ for $\mathrm{X}=$ $\mathrm{NH}_{2}, \mathrm{OH}, \mathrm{F}, \mathrm{SH}$ and $\mathrm{Cl}$ and vertical ionization energies calculated ${ }^{181}$

for the fluorine and oxygen systems. It is of interest to make comparisons with the present theoretical predictions. Vertical and adiabatic ionization energies and calculated energy differences $\left(\Delta E=I E_{v}-I E_{a}\right)$ obtained in the present study are presented in Table 5.7 (on the next page), together with the available experimental $Q_{m i n}$ values.

It can be seen immediately from Table 5.7 that, whereas the experimental $Q_{\text {min }}$ values are generally quite similar for $\mathrm{CH}_{2} \mathrm{XH}^{+\cdot}$ and $\mathrm{CH}_{3} \mathrm{X}^{+\cdot}$ isomers (with $\mathrm{Q}_{\min }\left(\mathrm{CH}_{2} \mathrm{XH}^{+\cdot}\right)>\mathrm{Q}_{\min }\left(\mathrm{CH}_{3} \mathrm{X}^{+\cdot}\right.$ ) for first-row systems), the theoretical ionization energies for the two isomers are significantly different (with $\left.\mathrm{IE}\left(\mathrm{CH}_{2} \mathrm{XH}^{+\cdot}\right)<\mathrm{IE}\left(\mathrm{CH}_{3} \mathrm{X}^{+\cdot}\right)\right)$. The results support the suggestion ${ }^{181}$ that $\mathrm{CH}_{2} \mathrm{XH}^{2+}$ ions are formed from both $\mathrm{CH}_{2} \mathrm{XH}^{+\cdot}$ and $\mathrm{CH}_{3} \mathrm{X}^{+\cdot}$ in the charge-stripping experiments. A possible rationalization is that formation of $\mathrm{CH}_{2} \mathrm{XH}^{2+}$ dications from $\mathrm{CH}_{3} \mathrm{X}^{+\cdot}$ arises through prior rearrangement of $\mathrm{CH}_{3} \mathrm{X}^{+\cdot}$ to give vibrationally excited $\mathrm{CH}_{2} \mathrm{XH}^{+\cdot}$ radical cations. This would be consistent with the generally smaller values of $\mathrm{Q}_{\mathrm{min}}$ observed for $\mathrm{CH}_{3} \mathrm{X}^{+\cdot}$ compared with $\mathrm{CH}_{2} \mathrm{XH}^{+\cdot}$.

f. An intense charge-stripping peak was observed, however, in the spectrum of $\mathrm{CH}_{3} \mathrm{SH}^{+}$(ref 179). 
Table 5.7 Calculated ${ }^{a}$ Vertical ( $\mathrm{IE}_{\mathrm{v}}$, eV) and Adiabatic ( $\mathrm{E}_{\mathrm{a}}$, eV) Ionization Energies, Calculated ${ }^{a}$ Energy Differences $\left(\Delta E, \mathrm{~kJ} \mathrm{~mol}^{-1}\right.$ ) and Experimental ${ }^{b} Q_{\text {min }}$ Values (eV)

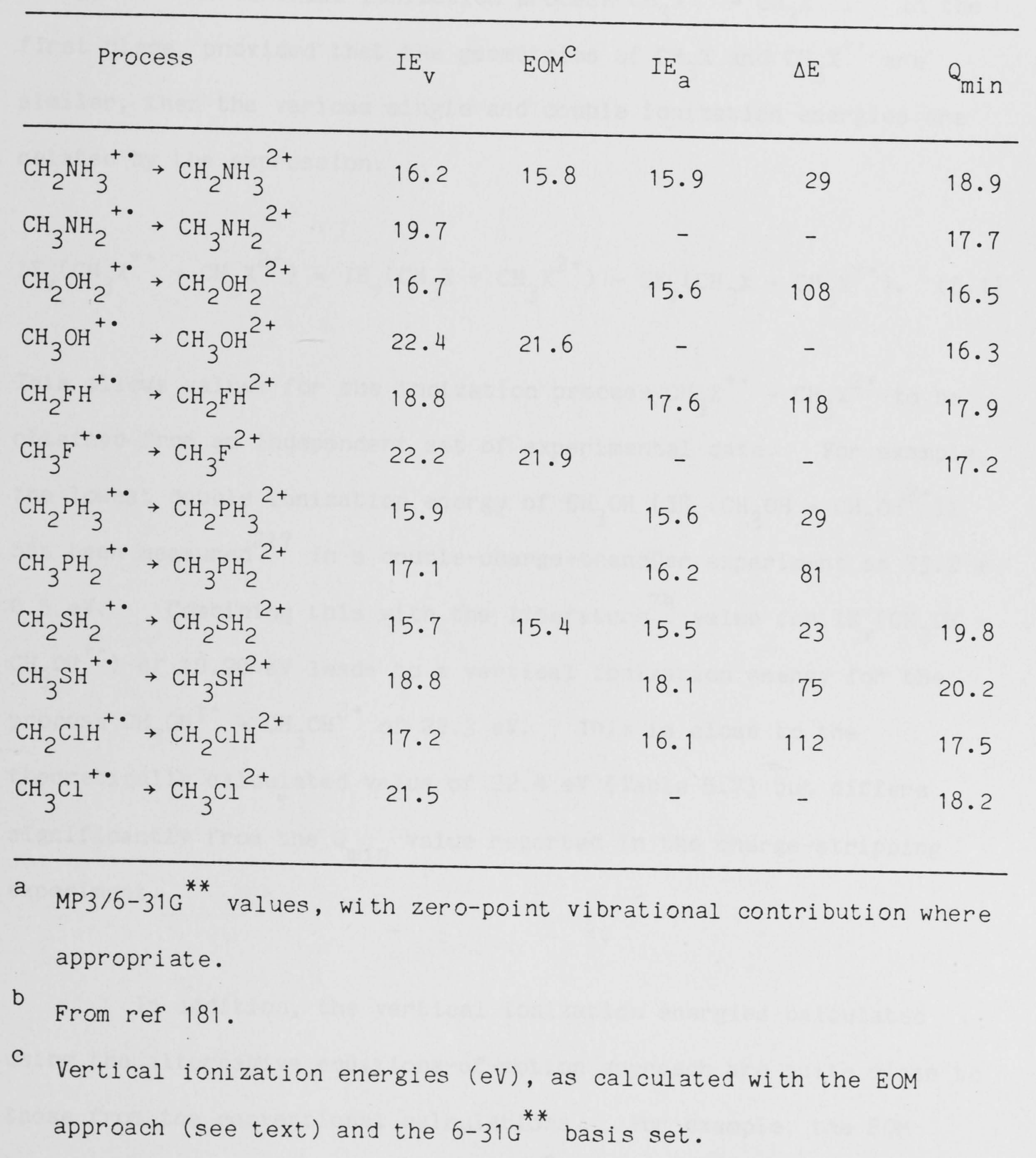


Additional evidence that the $Q_{\text {min }}$ values obtained through charge stripping of $\mathrm{CH}_{3} \mathrm{X}^{+}$ions do not correspond to formation of $\mathrm{CH}_{3} \mathrm{X}^{2+}$ dications comes from alternative procedures for calculating the energy for the vertical ionization process $\mathrm{CH}_{3} \mathrm{X}^{+\cdot} \rightarrow \mathrm{CH}_{3} \mathrm{X}^{2+}$. In the first place, provided that the geometries of $\mathrm{CH}_{3} \mathrm{X}$ and $\mathrm{CH}_{3} \mathrm{X}^{+\cdot}$ are similar, then the various single and double ionization energies are related by the expression:

$\mathrm{IE}_{\mathrm{v}}\left(\mathrm{CH}_{3} \mathrm{X}^{+\cdot}+\mathrm{CH}_{3} \mathrm{X}^{2+}\right)=\mathrm{IE}_{\mathrm{v}}\left(\mathrm{CH}_{3} \mathrm{X} \rightarrow \mathrm{CH}_{3} \mathrm{X}^{2+}\right)-\mathrm{IE}_{\mathrm{v}}\left(\mathrm{CH}_{3} \mathrm{X} \rightarrow \mathrm{CH}_{3} \mathrm{X}^{+\cdot}\right)$ This allows values for the ionization process $\mathrm{CH}_{3} \mathrm{X}^{+\cdot}+\mathrm{CH}_{3} \mathrm{X}^{2+}$ to be obtained from an independent set of experimental data. For example, the lowest double ionization energy of $\mathrm{CH}_{3} \mathrm{OH}\left(\mathrm{IE}_{\mathrm{V}}\left(\mathrm{CH}_{3} \mathrm{OH} \rightarrow \mathrm{CH}_{3} \mathrm{OH}^{2+}\right)\right.$ ) has been measured ${ }^{217}$ in a double-charge-transfer experiment as $33.2 \pm$ $0.5 \mathrm{eV}$. Combining this with the literature ${ }^{74}$ value for $\mathrm{IE}_{\mathrm{V}}\left(\mathrm{CH}_{3} \mathrm{OH} \rightarrow\right.$ $\mathrm{CH}_{3} \mathrm{OH}^{+\cdot}$ ) of $10.90 \mathrm{eV}$ leads to a vertical ionization energy for the process $\mathrm{CH}_{3} \mathrm{OH}^{+\cdot} \rightarrow \mathrm{CH}_{3} \mathrm{OH}^{2+}$ of $22.3 \mathrm{eV}$. This is close to the theoretically calculated value of $22.4 \mathrm{eV}$ (Table 5.7) but differs significantly from the $Q_{m i n}$ value reported in the charge-stripping experiment.

In addition, the vertical ionization energies calculated using the alternative equations-of-motion approach are quite close to those from the conventional calculations. For example, the EOM procedure leads to $\mathrm{IE}_{\mathrm{V}}\left(\mathrm{CH}_{3} \mathrm{OH}^{+\cdot} \rightarrow \mathrm{CH}_{3} \mathrm{OH}^{2+}\right)=21.6 \mathrm{eV}$ and $\mathrm{IE}_{\mathrm{v}}\left(\mathrm{CH}_{3} \mathrm{~F}^{+\cdot} \rightarrow\right.$ $\left.\mathrm{CH}_{3} \mathrm{~F}^{2+}\right)=21.9 \mathrm{eV}$, results which are close to the directly calculated values of $22.4 \mathrm{eV}$ and $22.2 \mathrm{eV}$, respectively (Table 5.7). Thus, both theory and experiment indicate that the energies for the process 
$\mathrm{CH}_{3} \mathrm{X}^{+\cdot} \rightarrow \mathrm{CH}_{3} \mathrm{X}^{2+}$ are considerably higher than the $Q_{\text {min }}$ values obtained through charge stripping of $\mathrm{CH}_{3} \mathrm{X}^{+}$cations. ${ }^{\mathrm{g}}$

\section{Comparison of the experimental $Q_{\min }$ values with the} calculated ionization energies shows moderate (though by no means perfect) agreement for the ylide dications $\mathrm{CH}_{2} \mathrm{XH}^{2+}$ when $\mathrm{X}=\mathrm{OH}\left(\mathrm{Q}_{\min }=\right.$ 16.5, $\left.I E_{\mathrm{v}}=16.7, I E_{\mathrm{a}}=15.6 \mathrm{eV}\right), \mathrm{X}=\mathrm{F}\left(\mathrm{Q}_{\min }=17.9, \mathrm{IE}_{\mathrm{v}}=18.8, I \mathrm{E}_{\mathrm{a}}=\right.$ $17.6 \mathrm{eV})$, and $X=C I\left(Q_{\min }=17.5, I E_{v}=17.2, I E_{a}=16.1 \mathrm{eV}\right)$.

However, there are major discrepancies for $X=\mathrm{NH}_{2}\left(Q_{\min }=18.9, I E_{\mathrm{v}}=\right.$ 16.2, $\left.I E_{a}=15.9 \mathrm{eV}\right)$ and $X=S H\left(Q_{\min }=19.8, \quad I E_{v}=15.7, I E_{a}=15.5\right.$ $\mathrm{eV})$. The theoretical values in these two instances are supported by EOM calculations and by higher-level conventional calculations.

Thus, for $X=\mathrm{NH}_{2}$ the calculated $I E_{\mathrm{V}}$ values are 16.2 (MP3/6-31 $\mathrm{G}^{* *}$ ), 16.2 $\left(\mathrm{MP} 4 / 6-31 \mathrm{G}^{* *}\right), 15.8\left(\mathrm{EOM} / 6-31 \mathrm{G}^{* *}\right)$ and $16.3\left(\mathrm{MP} 3 / 6-311 \mathrm{G}^{* *}\right)$ eV compared with the experimental $Q_{\text {min }}$ of $18.9 \mathrm{eV}$, while for $\mathrm{X}=\mathrm{SH}$ the calculated $\mathrm{IE}_{\mathrm{V}}$ values are $15.7\left(\mathrm{MP} 3 / 6-31 \mathrm{G}^{* *}\right)$ and $15.4\left(\mathrm{EOM} / 6-31 \mathrm{G}^{* *}\right)$ eV compared with the experimental $Q_{\text {min }}$ value of $19.8 \mathrm{eV}$. The disagreement between theory and experiment is sufficiently large that reinterpretation of the experimental data could be in order.

Finally, it may be noted that the significant differences between $I E_{v}$ and $I E_{a}$ values for a number of systems $\left(X=O H, F, P_{2}\right.$ and C1) reflect a marked difference between the geometry of the ylidion $\left(\stackrel{\mathrm{C}}{\mathrm{H}_{2}} \stackrel{+}{\mathrm{X}} \mathrm{H}\right)$ and ylide dication $\left(\mathrm{CH}_{2} \mathrm{XH}^{2+}\right)$ in these cases. This effect would not, however, account for the discrepancy noted above between the theoretical and experimental ionization energies.

g. Further information on the stabilities and lifetimes of the $\mathrm{CH}_{3} \mathrm{x}^{2+}$ species might be obtained from state-of-the-art photoionization or Auger spectroscopy experiments. 


\subsubsection{Comparisons With the Ylides and Ylidions}

Comparisons of individual ylide dications with their corresponding neutral or monocationic species have been noted above. Some general observations are summarized in this section.

On going from the neutral to the singly-charged to the doubly-charged species, there is a progressive shortening of the $\mathrm{C}-\mathrm{X}$ bonds (in both $\mathrm{CH}_{2} \mathrm{XH}$ and $\mathrm{CH}_{3} \mathrm{X}$, Table 5.5). (Exceptions to this trend occur, however, for $\mathrm{CH}_{2} \mathrm{PH}_{3}$ and $\mathrm{CH}_{2} \mathrm{SH}_{2}$, where the bonds in the ylides are already unusually short.) The shortening of the $C-X$ bond in $\mathrm{CH}_{2} \mathrm{XH}^{2+}$ relative to that in $\dot{\mathrm{C}}_{2}{ }_{2}^{+} \mathrm{H}$ is least for $\mathrm{X}=\mathrm{PH}_{2}$ and becomes greater as $X$ becomes more electronegative. As one moves from the ylides to the ylidions to the ylide dications, there is also a greater tendency for the bonds at carbon to be coplanar.

It was shown earlier that whereas the ylides lie much higher in energy than their conventional isomers, the ylidions are comparable in energy to the $\mathrm{CH}_{3} \mathrm{X}^{+\cdot}$ species. The results presented in this chapter confirm that this trend continues in the doubly-charged species: the ylide dications generally lie much lower in energy than any species resembling the conventional isomers $\left(\mathrm{CH}_{3} \mathrm{X}^{2+}\right)$. It may also be noted that, whereas the ylides $\left(\mathrm{CH}_{2} \mathrm{XH}\right)$ and ylidions $\left(\dot{\mathrm{C}}_{2} \stackrel{+}{\mathrm{X}} \mathrm{H}\right)$ generally have positive binding energies with respect to possible fragmentation products (such as $\mathrm{CH}_{2}\left({ }^{1} \mathrm{~A}_{1}\right)+\mathrm{XH}$ and $\mathrm{CH}_{2}{ }^{+\cdot}+\mathrm{XH}$, respectively), the ylide dications $\left(\mathrm{CH}_{2} \mathrm{XH}^{2+}\right)$ have highly exothermic fragmentation products $\left(\mathrm{e} . \mathrm{g} \cdot \mathrm{CH}_{2}^{+}+\mathrm{XH}^{+\cdot}\right)$. Despite this, the barriers to the lowest-energy decomposition pathways tend to increase on going from $\mathrm{CH}_{2} \mathrm{XH}$ to $\stackrel{\mathrm{C}}{\mathrm{H}_{2}} \stackrel{+}{\mathrm{X}} \mathrm{H}$ to $\mathrm{CH}_{2} \mathrm{XH}^{2+}$. 


\subsection{Concluding Remarks}

Ylide dications $\left(\mathrm{CH}_{2} \mathrm{XH}^{2+}\right)$, although thermodynamically unstable with respect to fragmentation products, are found to lie in moderately deep potential wells and should be observable species. In contrast, their conventional isomers $\left(\mathrm{CH}_{3} \mathrm{x}^{2+}\right)$ can rearrange or fragment with little or no barrier. The calculated ionization energies corresponding to production of ylide dications from ylidions are generally in moderate agreement with experimental $Q_{\min }$ values. However, there are a number of discrepancies and a re-examination of the experimental data is suggested in these cases. The calculations indicate that production of $\mathrm{CH}_{3} \mathrm{x}^{2+}$ dications from $\mathrm{CH}_{3} \mathrm{X}^{+\cdot}$ is a highenergy process and the experimental $Q_{\text {min }}$ values for such systems are likely to correspond to production of the isomeric $\mathrm{CH}_{2} \mathrm{XH}^{2+}$ dications. 
CHAPTER SIX

\author{
POSSIBLE DETECTION OF PROTOYPE YLIDES BY \\ NEUTRALIZATION-REIONIZATION MASS \\ SPECTROMETRY: A THEORETICAL PREDICTION
}

\subsection{Introduction}

In Section 2.4 .5 , brief mention was made of an exciting recent development in mass-spectrometric techniques called

'neutralization-reionization mass spectrometry' (NRMS). 106 Among its possible applications, NRMS may in particular be used to study unstable and reactive neutrals whose parent ions are stable (e.g. $\left.\mathrm{CH}_{2}=\mathrm{CHOH} / \mathrm{CH}_{2}=\mathrm{CHOH}^{+\cdot}\right)$. In the ideal experiment, the stable parent ion is generated uniquely, neutralized, and the neutral which is produced is reionized and characterized using collision-induced dissociative ionization (CIDI). Observation of a mass spectrum which coincides with that of the parent ion demonstrates the stability of the neutral within the timeframe $\left(-10^{-6} \mathrm{~s}\right)$ of the NRMS experiment.

The prototype ylidions discussed in chapter Four turn out to be ideally suited for examination by the NRMS procedure, since they are stable ions whose neutral counterparts (the ylides) are either unstable or reactive. In this chapter it is shown how theory may be used to predict whether a particular neutral of this type is likely to be 'detectable' by NRMS. Since it may be assumed ${ }^{218}$ that neutralization of ions via collision with a target gas is a vertical process, such vertically neutralized species should only be detectable if their energy is lower than that of transition structures for 
148.

subsequent rearrangement or fragmentation. The theoretical approach is illustrated initially for the prototype phosphonium $\left(\mathrm{CH}_{2} \mathrm{PH}_{3}\right)$, sulfonium $\left(\mathrm{CH}_{2} \mathrm{SH}_{2}\right)$ and chloronium $\left(\mathrm{CH}_{2} \mathrm{ClH}\right)$ ylides.

\subsection{Method and Results}

Using the $\mathrm{HF} / 6-31 \mathrm{G}^{*}$ structures presented in Chapter Four, energies of $\mathrm{CH}_{3} \mathrm{X}$ and $\mathrm{CH}_{2} \mathrm{XH}$ were calculated at the optimum geometries of $\mathrm{CH}_{3} \mathrm{X}^{+\cdot}$ and $\dot{\mathrm{C}}_{2}{ }_{2}^{\mathrm{X}} \mathrm{H}$, respectively (corresponding to vertically neutralized species) for $\mathrm{X}=\mathrm{PH}_{2}, \mathrm{SH}$ and $\mathrm{Cl}$. In combination with the results from Chapters Three and Four, best relative energies were obtained at the MP3/6-31G** level (using the additivity approximation of equation (1.16)) with zero-point correction. Unless otherwise noted, these are the values used in the discussion.

Relative energies of the vertically neutralized species and neutralization energies (NE) of $\mathrm{CH}_{3} \mathrm{X}^{+\cdot}$ and $\dot{\mathrm{C}}_{2} \stackrel{+}{\mathrm{X}} \mathrm{H}$ are presented in Table 6.1. Schematic energy profiles (incorporating results from Tables 3.4 and 4.5 ) for the neutralization processes are displayed in Figures 6.1-6.3. 
149.

Table 6.1 Calculated Relative Energies ( $\left.\mathrm{J} \mathrm{mol}^{-1}\right)^{\mathrm{a}}$

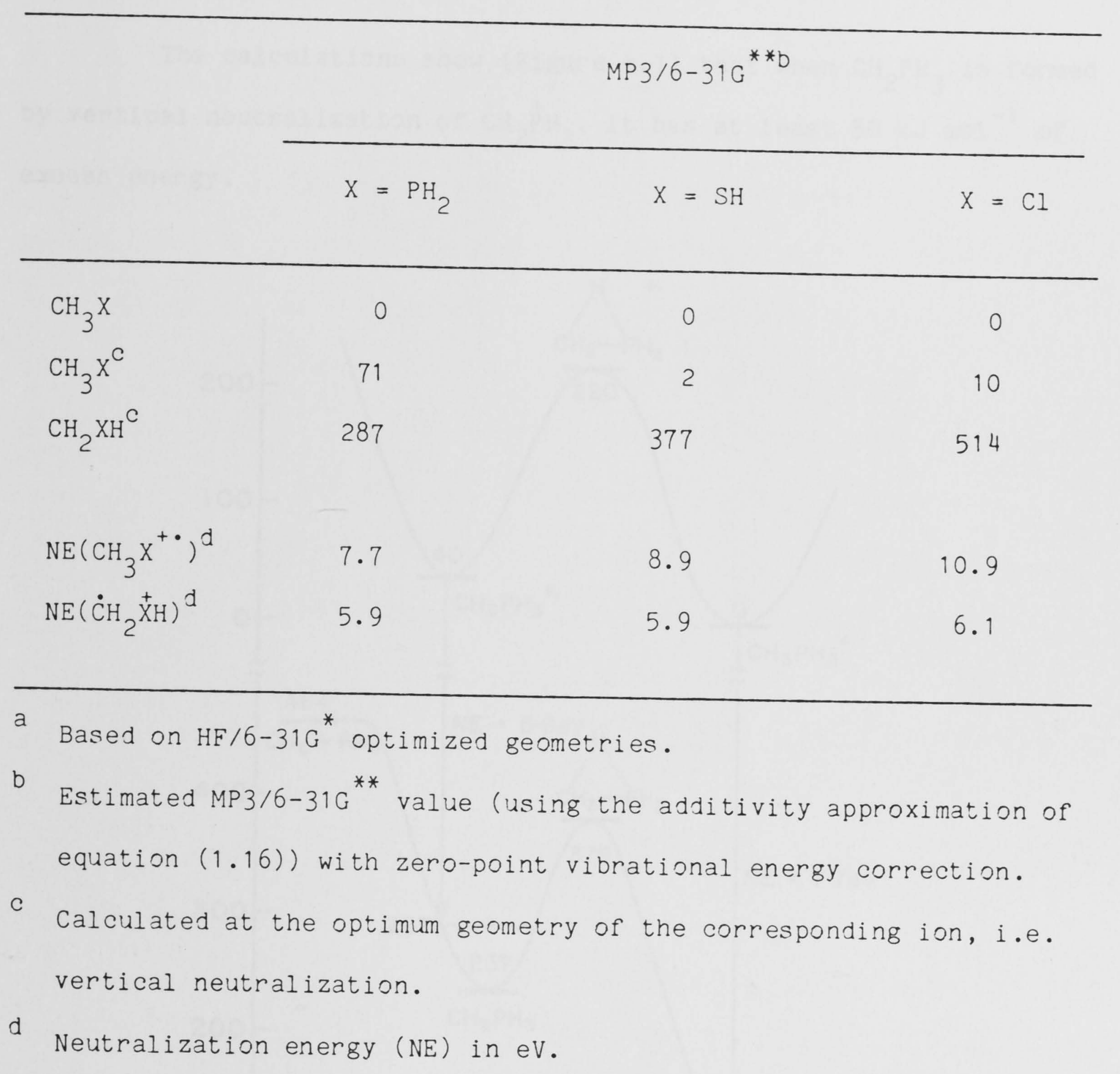




\subsection{Discussion}

The calculations show (Figure 6.1) that when $\mathrm{CH}_{2} \mathrm{PH}_{3}$ is formed by vertical neutralization of $\dot{\mathrm{CH}}_{2}{ }_{2}^{+} \mathrm{P}_{3}$, it has at least $50 \mathrm{~kJ} \mathrm{~mol}^{-1}$ of excess energy.

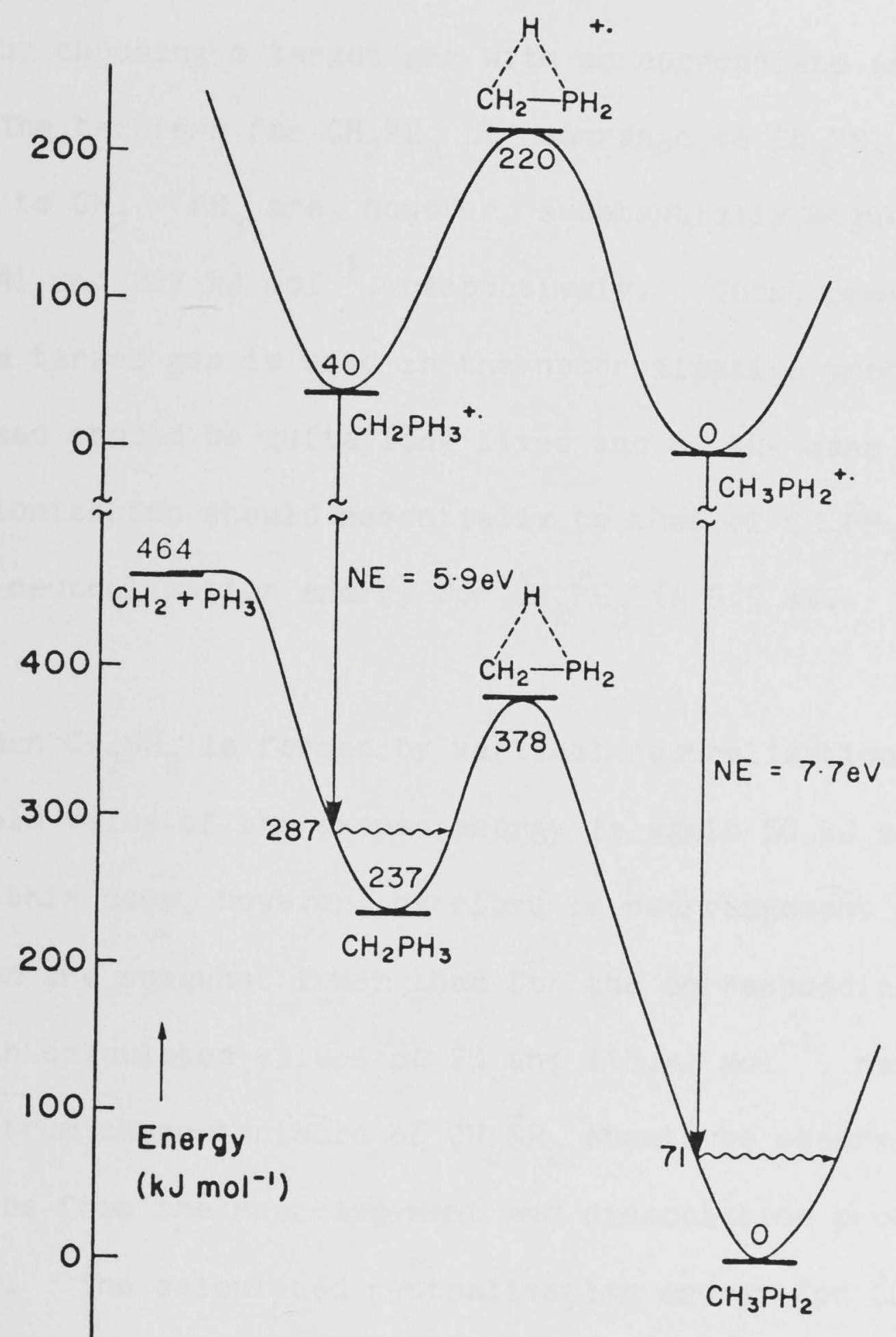

Figure 6.1 Schematic potential energy profile showing the production of $\mathrm{CH}_{2} \mathrm{PH}_{3}$ by vertical neutralization of $\dot{\mathrm{C}}_{2}{ }_{2} \stackrel{+}{\mathrm{P}} \mathrm{H}_{3}$, and possible rearrangement and fragmentation reactions. 
In an NRMS experiment, the total amount of excess energy would consist partly of the energy cost of distortion of $\mathrm{CH}_{2} \mathrm{PH}_{3}$ from its optimum structure to the equilibrium structure of $\dot{\mathrm{C}}_{2}{ }_{2}^{\stackrel{+}{\mathrm{P}} \mathrm{H}_{3}}$ (amounting to $50 \mathrm{~kJ}$ $\mathrm{mol}^{-1}$ ) and partly of the difference between the neutralization energy of $\dot{\mathrm{C}}_{2}{ }_{2}{ }_{\mathrm{P}} \mathrm{H}_{3}$ and the ionization energy of the target gas used in the neutralization process. The latter contribution can be reduced to near zero by choosing a target gas with an appropriate ionization energy. The barriers for $\mathrm{CH}_{2} \mathrm{PH}_{3}$ to rearrange to $\mathrm{CH}_{3} \mathrm{PH}_{2}$ or to dissociate to $\mathrm{CH}_{2}+\mathrm{PH}_{3}$ are, however, substantially higher than $50 \mathrm{~kJ}$ $\mathrm{mol}^{-1}$ at 141 and $227 \mathrm{~kJ} \mathrm{~mol}^{-1}$, respectively. Thus, provided an appropriate target gas is used in the neutralization process, the $\mathrm{CH}_{2} \mathrm{PH}_{3}$ formed should be quite long $\mathrm{li}$ ved and so the mass spectrum following ionization should essentially be that of $\dot{\mathrm{C}} \mathrm{H}_{2} \stackrel{+}{\mathrm{P}} \mathrm{H}_{3}$. The calculated neutralization energy for $\dot{\mathrm{C}}_{2} \stackrel{+}{\mathrm{P}}_{3}$ is $5.9 \mathrm{eV}$.

When $\mathrm{CH}_{2} \mathrm{SH}_{2}$ is formed by vertical neutralization from $\dot{\mathrm{C}}_{2}{ }_{2} \mathrm{~S}_{2}$, the threshold value of the excess energy is again $50 \mathrm{~kJ} \mathrm{~mol}^{-1}$ (Figure 6.2). In this case, however, barriers to rearrangement and dissociation are somewhat lower than for the corresponding phosphorus system, with calculated values of 75 and $115 \mathrm{~kJ} \mathrm{~mol}^{-1}$, respectively. A mass spectrum characteristic of $\stackrel{\mathrm{C}}{\mathrm{H}_{2}} \stackrel{+}{\mathrm{S}} \mathrm{H}_{2}$ should be observable but contributions from the rearrangement and dissociation processes would be expected. The calculated neutralization energy for $\dot{\mathrm{C}}_{2}{ }_{2}^{+} \mathrm{H}_{2}$ ( NE = $5.9 \mathrm{eV}$ ) is the same as for $\dot{\mathrm{C}}_{2} \stackrel{\mathrm{P}}{\mathrm{P}}_{3}$. 


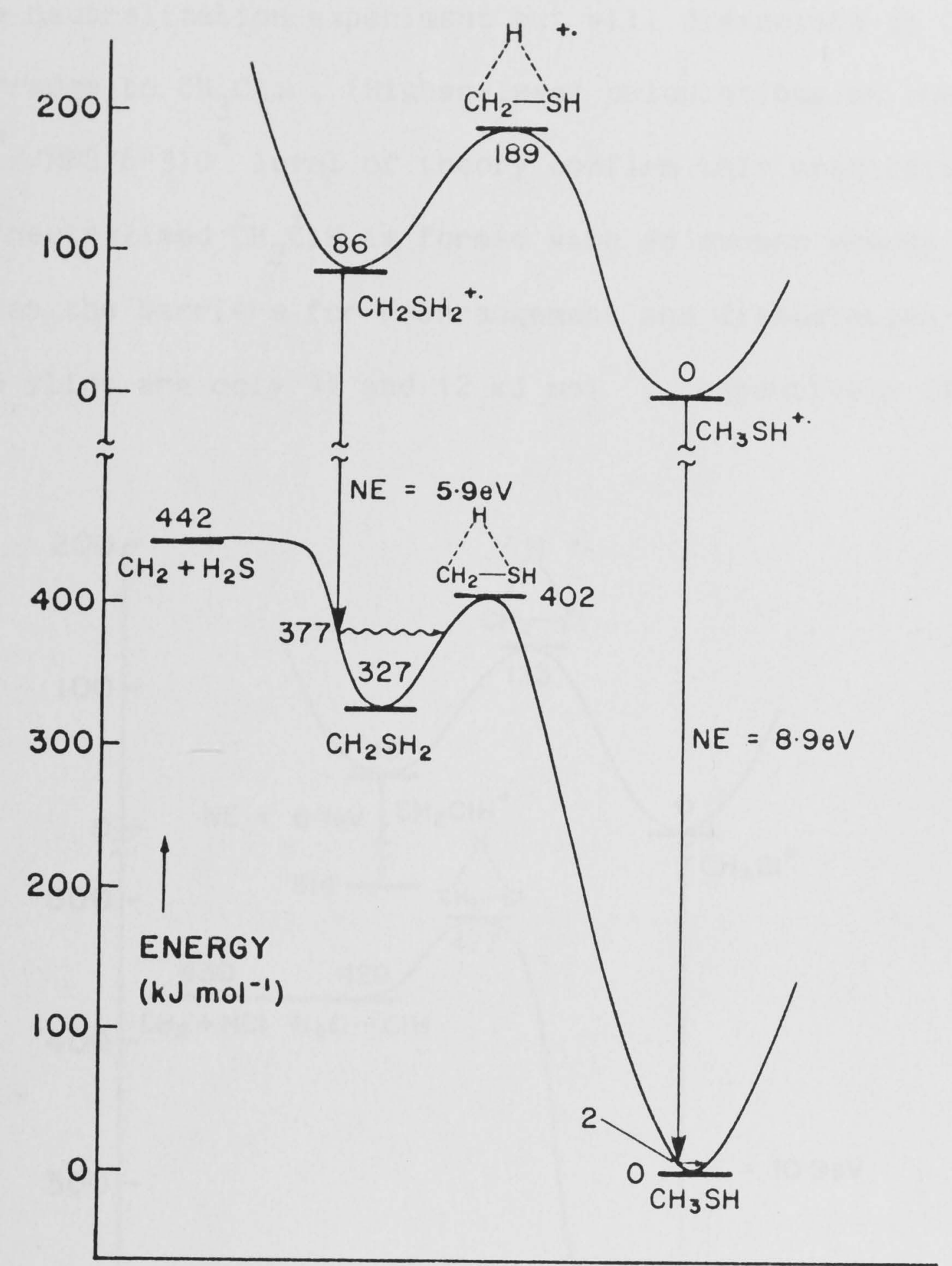

Figure 6.2 Schematic potential energy profile showing the production of $\mathrm{CH}_{2} \mathrm{SH}_{2}$ by vertical neutralization of $\stackrel{\mathrm{C}}{\mathrm{H}}{ }_{2} \stackrel{+}{\mathrm{S}} \mathrm{H}_{2}$, and possible rearrangement and fragmentation reactions.

It has already been shown in Chapter Three that $\mathrm{CH}_{2} \mathrm{ClH}$ is located in a very shallow potential well (Figure 6.3), with a barrier to dissociation to $\mathrm{CH}_{2}+\mathrm{HCl}$ of barely $1 \mathrm{~kJ} \mathrm{~mol}^{-1}$ at the level of theory used here. It is clear, therefore, that with an excess energy of $85 \mathrm{~kJ} \mathrm{~mol}^{-1}$ when formed vertically from $\stackrel{\mathrm{C}}{\mathrm{H}_{2}} \stackrel{+}{\mathrm{C}} \mathrm{H}, \mathrm{CH}_{2} \mathrm{ClH}$ will not 
153.

survive the neutralization experiment but will dissociate to $\mathrm{CH}_{2}+\mathrm{HCl}$ and/or rearrange to $\mathrm{CH}_{3} \mathrm{Cl}$. (Higher-level calculations at the MP4/6-31 ${ }^{* *} / / \mathrm{MP} 2 / 6-31 \mathrm{G}^{*}$ level of theory confirm this prediction: vertically neutralized $\dot{\mathrm{C}}_{2} \stackrel{+}{\mathrm{C}} \mathrm{H} \mathrm{H}$ is formed with an excess energy of $64 \mathrm{~kJ}$ $\mathrm{mol}^{-1}$ whereas the barriers for rearrangement and dissociation of the equilibrium ylide are only 44 and $12 \mathrm{~kJ} \mathrm{~mol}^{-1}$, respectively (Table 3.6).)

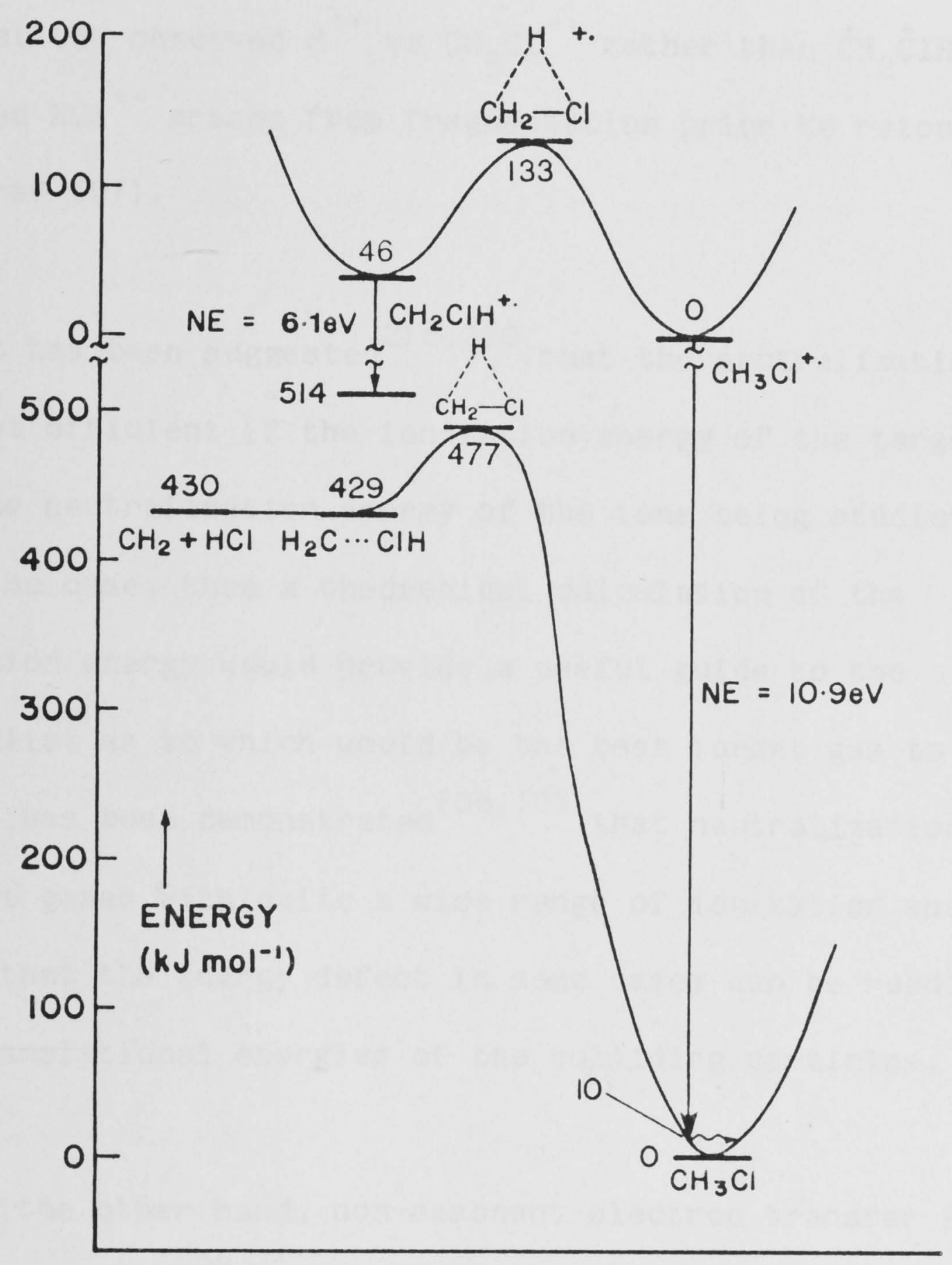

Figure 6.3 Schematic potential energy profile showing the production of $\mathrm{CH}_{2} \mathrm{ClH}$ by vertical neutralization of $\dot{\mathrm{C}}_{2} \stackrel{+}{\mathrm{C}} \mathrm{H}$, and possible rearrangement and fragmentation reactions. 
The NRMS experiments performed to date by McLafferty and coworkers ${ }^{106,219}$ on $\dot{\mathrm{CH}}_{2} \stackrel{+}{\mathrm{C}} 1 \mathrm{H}$ show both $\mathrm{M}^{+}\left(\underline{\mathrm{m}} / \underline{\mathrm{z}}\right.$ 52) and $\mathrm{HCl}^{+}$in the mass spectrum. However, a definitive interpretation of these results requires first, establishment of the identity of the observed $\mathrm{M}^{+\cdot}$ ion (i.e. $\dot{\mathrm{C}}_{2} \stackrel{+}{\mathrm{C}} \mathrm{H}$ or $\mathrm{CH}_{3} \mathrm{Cl}^{+\cdot}$ ) and secondly, determination of the origin of the $\mathrm{HCl}^{+}$(these ions could be formed from neutral fragments or from $\mathrm{CH}_{2} \mathrm{ClH}$ after reionization). The results presented here strongly suggest that the observed $\mathrm{M}^{+\cdot}$ is $\mathrm{CH}_{3} \mathrm{Cl}^{+\cdot}$ rather than $\dot{\mathrm{CH}}_{2} \stackrel{+}{\mathrm{C}} 1 \mathrm{H}$, and that the observed $\mathrm{HCl}^{+}$arises from fragmentation prior to reionization (see also ref 107 ).

It has been suggested 218,220 that the neutralization process will be most efficient if the ionization energy of the target gas is close to the neutralization energy of the ions being studied. If this were the case, then a theoretical calculation of the neutralization energy would provide a useful guide to the experimentalist as to which would be the best target gas to use. However, it has been demonstrated ${ }^{106,109}$ that neutralization can occur using target gases with quite a wide range of ionization energies, suggesting that the energy defect in some cases can be readily made up from the translational energies of the colliding particles.

On the other hand, non-resonant electron transfer is also a distinct possibility ${ }^{220}$ and this would lead to production of neutral species in vibrationally or electronically excited states. This phenomenon is more likely to occur when using target gases with low ionization energies (such as potassium ( IE $=4.34 \mathrm{eV}$ ) or sodium ( IE = $5.14 \mathrm{eV}$ ) vapour) than when using target gases with high ionization energies (such as xenon $(I E=12.1 \mathrm{eV})$ ). 


\subsection{Concluding Remarks}

The calculations discussed in this chapter predict that the prototype phosphonium $\left(\mathrm{CH}_{2} \mathrm{PH}_{3}\right)$ and sulfonium $\left(\mathrm{CH}_{2} \mathrm{SH}_{2}\right)$ ylides should be observable in NRMS experiments, whereas the chloronium ylide $\left(\mathrm{CH}_{2} \mathrm{ClH}\right)$ formed by vertical neutralization of $\dot{\mathrm{C}}_{2}{ }_{2} \stackrel{+}{\mathrm{C}} \mathrm{H}$ will not be stable with respect to dissociation or rearrangement processes.

Further predictions can also be made for the other prototype ylides discussed in Chapter Three. The results presented there showed that the prototype ammonium ylide $\left(\mathrm{CH}_{2} \mathrm{NH}_{3}\right)$ lies in a moderately deep well, suggesting that it too would have a sufficiently long lifetime to be observable via NRMS. (The well depth for the nitrogen and sulfur ylides is, however, sufficiently shallow that the neutralization-reionization mass spectrum of the corresponding ylidions is likely to be contaminated by fragments arising from rearrangement and dissociation products of the neutral ylides.)

On the other hand, the additional results presented in Chapter Three show that the remaining prototype ylide $\mathrm{CH}_{2} \mathrm{OH}_{2}$ and the hydrogen-bonded species $\mathrm{H}_{2} \mathrm{CHF}$ and $\mathrm{H}_{2} \mathrm{CHCl}$ have rather small binding energies and their barriers for rearrangement (which for these systems were recalculated at the highest level in Table 3.6) are only 4, 6 and $0 \mathrm{~kJ} \mathrm{~mol}{ }^{-1}$, respectively. In addition, for $\mathrm{CH}_{2} \mathrm{OH}_{2}, \mathrm{CH}_{2} \mathrm{ClH}, \mathrm{H}_{2} \mathrm{CHF}$ and $\mathrm{H}_{2} \mathrm{CHCl}$, the results presented in Chapters Three and Four show that there are large differences in equilibrium geometries of the charged and neutral species. In terms of the NRMS experiment, this means that the vertically neutralized ylides will be formed with considerable excess energy, thus facilitating their rearrangement or 
fragmentation. In principle, the amount of excess energy of the neutral could be reduced if neutralization occurred from thermally excited ylidions that were already distorted towards the equilibrium geometries of the ylides. However, in the four cases considered here, the differences in geometry are so large that the chances of this happening are likely to be small. Although still higher level calculations may shorten the long bonds in some of these structures, present experience with progressively more sophisticated calculations suggests that these species should, at best, lie in only shallow wells on their respective ground-state potential surfaces. On this basis, it seems likely that neutralization of $\dot{\mathrm{C}}_{2} \stackrel{+}{\mathrm{O}}_{2}, \quad \dot{\mathrm{C}}_{2} \stackrel{+}{\mathrm{F}} \mathrm{H}$ and $\dot{\mathrm{C}} \mathrm{H}_{2} \stackrel{+}{\mathrm{C}} 1 \mathrm{H}$ would yield products with fairly short lifetimes $\left(<10^{-6} \mathrm{~s}\right)$ and therefore their detection in NRMS experiments ${ }^{106,219}$ cannot be explained by the present results. 
CHAPTER SEVEN

\author{
DISTONIC RADICAL CATIONS: GUIDELINES \\ FOR THE ASSESSMENT OF THEIR STABILITY
}

\title{
7.1 Introduction
}

On the basis of extensive theoretical and experimental

work, ${ }^{221-257}$ it has recently been noted that gas-phase radical cations in which the charge and radical sites are formally separated often display a stability with respect to unimolecular decomposition which contrasts with that of the neutral molecules from which they are derived. For example, the methyleneoxonium radical cation $\left(\dot{\mathrm{C}}_{2}{\stackrel{+}{\mathrm{O}} \mathrm{H}_{2}}_{2}\right)$ discussed in Chapter Four is found both theoretically and experimentally to be more stable than its conventional isomer, the methanol radical cation $\left(\mathrm{CH}_{3} \mathrm{OH}^{+\cdot}\right)$. Again, the ethyleneoxonium radical cation $\left(\dot{\mathrm{C}}_{2} \mathrm{CH}_{2} \stackrel{+}{\mathrm{O}}_{2}\right)$ is more stable than the ethanol radical cation $\left(\mathrm{CH}_{3} \mathrm{CH}_{2} \mathrm{OH}^{+\cdot}\right) \cdot 227,228$ Recently, the trimethyleneoxoni um radical cation $\left(\dot{\mathrm{C}}_{2} \mathrm{CH}_{2} \mathrm{CH}_{2} \stackrel{+}{\mathrm{O}}_{2}\right)$ has also been observed. 231

The term distonic (derived from the Greek $\delta \imath \varepsilon \sigma \tau \omega s$ (diestos) and the Latin distans meaning separate) radical cation is introduced here to describe the general class of radical cations in which the charge and radical centres are separated. (The term ylidion describes the subclass of distonic radical cations in which the charge and radical sites are on adjacent centres (e.g. $\dot{\mathrm{C}}_{2}{\stackrel{+}{\mathrm{O}} \mathrm{H}_{2}}_{2}$.) 
158.

Many radical cations have several valence structures, one of which might have separated charge and radical sites. For example, formaldehyde radical cation can be written $\stackrel{+}{\mathrm{C}} \mathrm{H}_{2}-\dot{0}$. Should this ion be regarded as distonic? It is proposed as a general rule that the term distonic be reserved for those radical cations which arise formally from ionization of neutral systems which are best written as zwitterions (ylides in the case of adjacent charges) or biradicals. On this basis, $\mathrm{CH}_{2} \mathrm{O}^{+\cdot}$ (arising from $\mathrm{CH}_{2}=0$ ) and $\mathrm{CH}_{2} \mathrm{CH}_{2}^{+\cdot}$ (arising from $\mathrm{CH}_{2}=\mathrm{CH}_{2}$ ) are not distonic radical cations whereas $\dot{\mathrm{C}} \mathrm{H}_{2} \stackrel{+}{\mathrm{O}} \mathrm{H}_{2}$ (arising from $\overline{\mathrm{C}} \mathrm{H}_{2}-\stackrel{+}{\mathrm{O}_{2}}$ ) and $\dot{\mathrm{C}} \mathrm{H}_{2} \mathrm{O} \stackrel{+}{\mathrm{C}} \mathrm{H}_{2}$ (arising from $\dot{\mathrm{C}} \mathrm{H}_{2} \mathrm{O} \dot{\mathrm{C}}_{2}$ ) are.

It would be highly desirable to be able to predict a priori the circumstances under which distonic radical cations might be more stable than their conventional isomers. In the following discussion, guidelines to this effect are presented and preliminary testing of these guidelines is reported.

This chapter begins with an examination, using ab initio molecular orbital theory, of the effect of increasing the separation of the charge and radical sites in distonic radical cations. This is achieved through calculations on the distonic radical cations $\dot{\mathrm{C}} \mathrm{H}_{2}\left(\mathrm{CH}_{2}\right) \stackrel{+}{\mathrm{N}} \mathrm{H}_{3}$ and their conventional isomers $\mathrm{CH}_{3}\left(\mathrm{CH}_{2}\right) \underline{n}_{2} \mathrm{NH}_{2}^{+\cdot}$ for $\underline{\mathrm{n}}=0$, 1,2 and 3. A second series of calculations then examines whether the relative stabilities of distonic radical cations $\dot{Y}\left(\mathrm{CH}_{2}\right) \stackrel{+}{\mathrm{X}} \mathrm{H}$ and their isomers $\mathrm{HY}\left(\mathrm{CH}_{2}\right) \mathrm{n}^{+}\left(\mathrm{X}=\mathrm{NH}_{2}, \mathrm{OH}, \mathrm{F}, \mathrm{PH}_{2}, \mathrm{SH}, \mathrm{Cl} ; \mathrm{Y}=\mathrm{CH}_{2}, \mathrm{NH}, \mathrm{O}\right)$ can be predicted from the energies of the component systems $\mathrm{CH}_{3} \dot{\mathrm{Y}}$, $\mathrm{CH}_{3} \stackrel{+}{\mathrm{X}} \mathrm{H}, \mathrm{CH}_{3} \mathrm{YH}, \mathrm{CH}_{3} \mathrm{X}^{+\cdot}, \mathrm{CH}_{3} \mathrm{YH}^{+\cdot}$ and $\mathrm{CH}_{3} \mathrm{X}$. 


\subsection{Method}

Geometry optimizations were performed with the $3-21 \mathrm{G}^{(*)}$ basis set and improved relative energies obtained at the MP2/6-31G ${ }^{*}$ level, either directly or by assuming additivity of basis set enhancement and electron correlation effects (Section 1.4.3):

$\Delta E\left(M P 2 / 6-31 G^{*}\right)=\Delta E\left(H F / 6-31 G^{*}\right)+\Delta E(M P 2 / 6-31 G)-\Delta E(H F / 6-31 G)$.

All-trans arrangements of the heavy-atom skeletons were assumed for the purpose of the analysis presented here. Deviations from such conformations will need to be considered when making comparisons with experiment.

It should be stressed that calculations at higher levels of theory would be possible for most of the systems examined in this chapter. Indeed, some of the other chapters in this thesis include such higher-level calculations. However, the principal aim here is to examine the relationship between the directly calculated relative stabilities of distonic and conventional isomers of radical cations and the predictions which can be made from data on appropriate small molecules. This task has been tackled through calculations at modest levels of theory on a large set of radical cations. It is believed that the levels of theory employed in this paper are probably sufficient in most (but perhaps not all) cases for the testing of such a relationship and help to obtain a broad-brush picture. On the other hand, absolute results for individual molecules may indeed be modified at higher levels of theory. 


\subsection{Results and Discussion}

Calculated total energies for optimized structures (Figure 7.1) of the distonic radical cations $\dot{\mathrm{CH}}_{2}\left(\mathrm{CH}_{2}\right) \stackrel{+}{\mathrm{N}_{2}} \mathrm{H}_{3}$ and their conventional isomers $\mathrm{CH}_{3}\left(\mathrm{CH}_{2}\right) \mathrm{n}_{2}{ }^{+}$are presented in Table 7.1 and corresponding relative energies are shown in Table 7.2. It may be seen that the distonic radical cations are consistently lower in energy than their conventional isomers. The energy difference between the two forms appears to converge with increasing $\mathrm{n}$ towards a value of about $30 \mathrm{~kJ} \mathrm{~mol}^{-1}$.

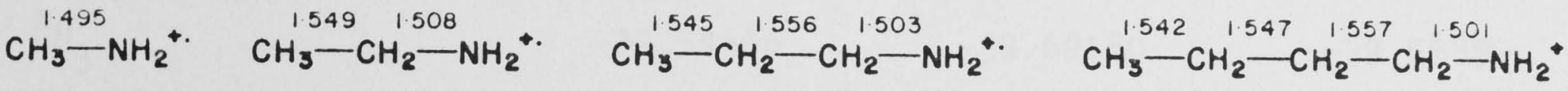

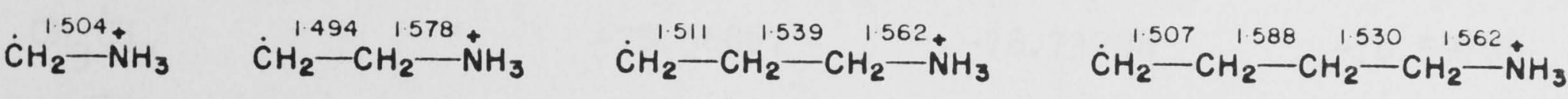

Figure 7.1 Schematic representation of bond lengths between heavy atoms within fully-optimized all-trans structures (3-21G) of distonic radical cations $\dot{\mathrm{CH}}_{2}\left(\mathrm{CH}_{2}\right) \underset{\mathrm{n}}{\stackrel{+}{\mathrm{N}} \mathrm{H}_{3}}$ and their conventional isomers $\mathrm{CH}_{3}\left(\mathrm{CH}_{2}\right)_{n^{n}} \mathrm{NH}_{2}^{+\cdot}$. 
Table 7.1 Calculated Total Energies (hartrees) for Distonic Radical Cations $\dot{\mathrm{CH}}_{2}\left(\mathrm{CH}_{2}\right){ }_{n} \stackrel{+}{\mathrm{N}}_{3}$ and their Conventional Isomers $\mathrm{CH}_{3}\left(\mathrm{CH}_{2}\right)_{\underline{n}} \mathrm{NH}_{2}^{+\cdot}$, and Appropriate Component Systems ${ }^{a}$

\section{Species}

HF / $6-31 \mathrm{G}$

$M P 2 / 6-31 G$

$\mathrm{HF} / 6-31 \mathrm{G}^{*}$

$\mathrm{CH}_{3} \mathrm{NH}_{2}^{+\cdot}$

$\dot{\mathrm{C}} \mathrm{H}_{2} \stackrel{+}{\mathrm{N}} \mathrm{H}_{3}$

$\mathrm{CH}_{3} \mathrm{CH}_{2} \mathrm{NH}_{2}^{+}$

$\dot{\mathrm{CH}}_{2} \mathrm{CH}_{2} \stackrel{\stackrel{+}{\mathrm{N}}}{\mathrm{H}_{3}}$

$\mathrm{CH}_{3} \mathrm{CH}_{2} \mathrm{CH}_{2} \mathrm{NH}_{2}{ }^{+} \cdot$

$\dot{\mathrm{C}} \mathrm{H}_{2} \mathrm{CH}_{2} \mathrm{CH}_{2} \stackrel{+}{\mathrm{N}} \mathrm{H}_{3}$

$\mathrm{CH}_{3} \mathrm{CH}_{2} \mathrm{CH}_{2} \mathrm{CH}_{2} \mathrm{NH}_{2}{ }^{+\bullet}$

$\dot{\mathrm{C}} \mathrm{H}_{2} \mathrm{CH}_{2} \mathrm{CH}_{2} \mathrm{CH}_{2} \stackrel{+}{\mathrm{N}} \mathrm{H}_{3}$

$\dot{\mathrm{C}} \mathrm{H}_{3}$

$\stackrel{+}{\mathrm{N}} \mathrm{H}_{4}$

$\mathrm{CH}_{4}$

$\mathrm{NH}_{3}{ }^{+\cdot}$

$\mathrm{CH}_{3} \dot{\mathrm{C}} \mathrm{H}_{2}$

$\mathrm{CH}_{3} \stackrel{+}{\mathrm{N}} \mathrm{H}_{3}$

$\mathrm{CH}_{3} \mathrm{CH}_{3}$

$\mathrm{CH}_{3} \mathrm{CH}_{2} \dot{\mathrm{C}} \mathrm{H}_{2}$

$\mathrm{CH}_{3} \mathrm{CH}_{2} \stackrel{+}{\mathrm{N}} \mathrm{H}_{3}$

$\mathrm{CH}_{3} \mathrm{CH}_{2} \mathrm{CH}_{3}$
$-94.89776$

$-94.89765$

$-133.92460$

$-133.93399$

$-172.94574$

$-172.95492$

$-211.96540$

$-211.97463$

$-39.54666$

$-56.51622$

$-40.18055$

$-55.85916$

$-78.56867$

$-95.53832$

$-79.19747$

$-117.58639$

$-134.56528$

$-118.21601$
$-95.07169$

$-95.07809$

$-134.18845$

$-134.20398$

$-173 \cdot 30088$

$-173.31495$

$-212.41187$

$-212.42564$

$-39.62180$

$-56.63348$

$-40.27872$

$-55.94555$

$-78.73208$

$-95.74244$

$-79.38477$

$-117.84025$

$-134.85913$

$-118.49403$
$-94.93148$

$-94.92994$

$-133.97438$

$-133.98190$

$-173.01180$

$-173.01903$

$-212.04775$

$-212.05488$

$-39.55899$

$-56.53056$

$-40.19517$

$-55.87311$

$-78.59706$

$-95.57260$

$-79.22861$

$-117.63117$

$-134.61556$

$-118.26339$

a 3-21 G optimized structures. 
Table 7.2 Calculated Relative Energies ( $\Delta E=E$ (Conventional) E(Distonic), $\mathrm{KJ} \mathrm{mol}^{-1}$ ) of Distonic Radical Cations $\dot{\mathrm{C}}_{2}\left(\mathrm{CH}_{2}\right) \underline{\mathrm{n}}_{3}^{\stackrel{+}{\mathrm{N}} \mathrm{H}_{3}}$ and their Conventional Isomers $\mathrm{CH}_{3}\left(\mathrm{CH}_{2}\right)_{\underline{n}} \mathrm{NH}_{2}^{+\cdot}$

Conventional Distonic $\Delta \mathrm{E}^{\mathrm{a}}$

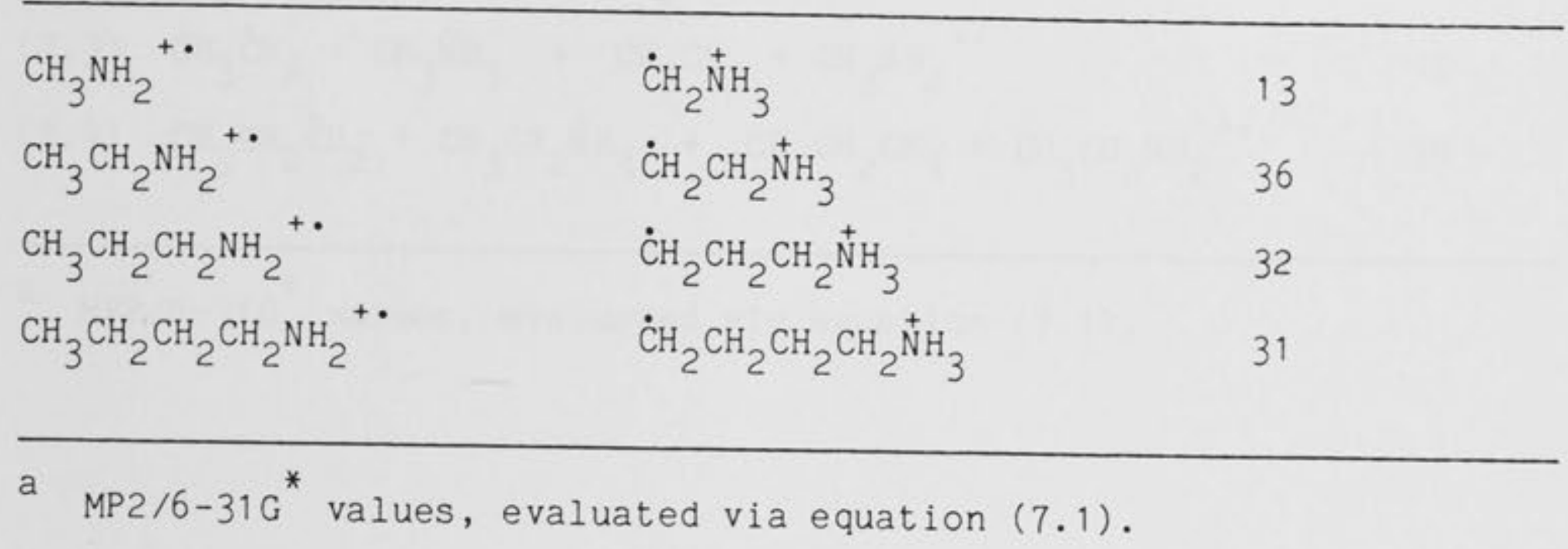

Is there a simple means of predetermining what this limiting energy difference between the distonic and conventional ions might be? The approach used here to answer this question has been to examine energy differences between pairs of component systems which might serve as models for the distonic and conventional isomers. The simplest such pairs, $\mathrm{CH}_{4}+\mathrm{NH}_{3}^{+}$(for the conventional isomer) and $\dot{\mathrm{CH}}_{3}$ $+\stackrel{+}{\mathrm{N}} \mathrm{H}_{4}$ (for the distonic isomer), provide only a very rough measure of the conventional-distonic energy difference, yielding $76 \mathrm{~kJ} \mathrm{~mol}^{-1}$ ( $\Delta \mathrm{E}$ for reaction (7.2), Table 7.3). 
Table 7.3 Calculated Relative Energies ( $\triangle E, \mathrm{~kJ} \mathrm{~mol}^{-1}$ ) for Model Components of Distonic Radical Cations and their Conventional Isomers

\section{Reaction}

(7.2) $\dot{\mathrm{CH}}_{3}+\stackrel{+}{\mathrm{N}} \mathrm{H}_{4} \rightarrow \mathrm{CH}_{4}+\mathrm{NH}_{3}^{+}$

$(7.3)$

$$
\mathrm{CH}_{3} \dot{\mathrm{C}} \mathrm{H}_{2}+\mathrm{CH}_{3} \stackrel{+}{\mathrm{N}} \mathrm{H}_{3} \rightarrow \mathrm{CH}_{3} \mathrm{CH}_{3}+\mathrm{CH}_{3} \mathrm{NH}_{2}^{+\cdot}
$$

$\mathrm{CH}_{3} \mathrm{CH}_{2} \dot{\mathrm{CH}}_{2}+\mathrm{CH}_{3} \mathrm{CH}_{2} \stackrel{+}{\mathrm{N}} \mathrm{H}_{3} \rightarrow$
$\Delta \mathrm{E}^{\mathrm{a}}$

a $M P 2 / 6-31 G^{*}$ values, evaluated via equation $(7.1)$.

Much better results are obtained for the larger model systems of reactions (7.3) and (7.4) of Table 7.3 for which the calculated energy changes are 42 and $39 \mathrm{~kJ} \mathrm{~mol}^{-1}$, respectively. These energies are quite close to the limiting value of Table 7.2 .

The correspondence between the limiting behaviour of Table 7.2 and results for the component systems of Table 7.3 suggests a possible means of assessment of the relative stabilities of distonic radical cations and their conventional isomers. These stabilities are related to the proton affinities (PAs) and ionization energies (IEs) of the appropriate model systems (e.g. $\mathrm{CH}_{3} \mathrm{NH}_{2}$ (cf reaction (7.3)) in the above case). The distonic isomer is favoured by a large proton affinity (which corresponds to a stabilization of the distonic form) or by a large ionization energy (which corresponds to a destabilization of the conventional isomer) of the relevant component molecules. More precisely, the energy change $\Delta E$ for reaction (7.3) 
is given in terms of PAs, IEs and $\mathrm{C}-\mathrm{H}$ bond dissociation energies (BDEs) of component systems as

$$
\Delta E=\operatorname{PA}\left(\mathrm{CH}_{3} \mathrm{NH}_{2}\right)+\operatorname{IE}\left(\mathrm{CH}_{3} \mathrm{NH}_{2}\right)-\mathrm{BDE}\left(\mathrm{CH}_{3} \mathrm{CH}_{3}\right)-\operatorname{IE}\left(\mathrm{H}^{\bullet}\right) .
$$

More generally, it might be expected that a distonic radical cation $\dot{\mathrm{Y}}\left(\mathrm{CH}_{2}\right) \underline{\mathrm{n}}{ }^{\mathrm{X}} \mathrm{H}$ will normally be more stable than its conventional isomer $\mathrm{HY}\left(\mathrm{CH}_{2}\right)_{\underline{n}} \mathrm{X}^{+\cdot}$ (e.g. $\mathrm{Y}=\mathrm{CH}_{2}, \mathrm{X}=\mathrm{NH}_{2}$ ) if the pair $\mathrm{CH}_{3} \dot{\mathrm{Y}}+\mathrm{CH}_{3} \stackrel{+}{\mathrm{H}} \mathrm{H}$ lies lower in energy than the more stable of the pairs $\mathrm{CH}_{3} \mathrm{YH}^{+} \mathrm{CH}_{3} \mathrm{X}^{+\cdot}$ or $\mathrm{CH}_{3} \mathrm{YH}^{+\cdot}+\mathrm{CH}_{3} \mathrm{X}$, corresponding respectively to

$$
\Delta \mathrm{E}=\mathrm{E}\left(\mathrm{CH}_{3} \mathrm{YH}\right)+\mathrm{E}\left(\mathrm{CH}_{3} \mathrm{X}^{+\cdot}\right)-\mathrm{E}\left(\mathrm{CH}_{3} \dot{\mathrm{Y}}\right)-\mathrm{E}\left(\mathrm{CH}_{3} \stackrel{+}{\mathrm{X}} \mathrm{H}\right)
$$

or

$$
\Delta \mathrm{E}=\mathrm{E}\left(\mathrm{CH}_{3} \mathrm{YH}^{+\cdot}\right)+\mathrm{E}\left(\mathrm{CH}_{3} \mathrm{X}\right)-\mathrm{E}\left(\mathrm{CH}_{3} \dot{\mathrm{Y}}\right)-\mathrm{E}\left(\mathrm{CH}_{3} \stackrel{+}{\mathrm{X}} \mathrm{H}\right)
$$

being positive. These conditions are equivalent respectively to the requirements that the energy change

$$
\Delta E=P A\left(\mathrm{CH}_{3} \mathrm{X}\right)+\mathrm{IE}\left(\mathrm{CH}_{3} \mathrm{X}\right)-\mathrm{BDE}\left(\mathrm{CH}_{3} \mathrm{YH}\right)-\mathrm{IE}\left(\mathrm{H}^{\bullet}\right)
$$

or

$$
\Delta E=P A\left(\mathrm{CH}_{3} \mathrm{X}\right)+\mathrm{IE}\left(\mathrm{CH}_{3} \mathrm{YH}\right)-\mathrm{BDE}\left(\mathrm{CH}_{3} \mathrm{YH}\right)-\mathrm{IE}\left(\mathrm{H}^{\bullet}\right)
$$

be positive. ${ }^{a}$ It might be expected that the rule will hold most faithfully when $\underline{n}$ is large. Exceptions for "real" (as opposed to

a. Similar relationships have been employed by other authors. See, for example, refs 108, 239 and 249. 
conformationally constrained) molecules may result from cyclic intramolecular interaction. There may also be exceptions for small $\underline{n}$ due to the superposition of specific short-range interactions.

The above guidelines potentially have powerful predictive value. Thus, on the basis of data, either experimental or theoretical, for a limited set of parent molecules $\left(\mathrm{CH}_{3} \dot{\mathrm{Y}}, \mathrm{CH}_{3} \stackrel{+}{\mathrm{X}}\right.$, $\mathrm{CH}_{3} \mathrm{YH}, \mathrm{CH}_{3} \mathrm{X}^{+\cdot}, \mathrm{CH}_{3} \mathrm{YH}^{+\cdot}$ and $\left.\mathrm{CH}_{3} \mathrm{X}\right)$, predictions which would otherwise not be straightforward may be made of the likely stability of a large set of distonic ions (e.g. $\mathrm{O}_{\mathrm{CH}_{2}} \stackrel{+}{\mathrm{P}}_{3} \mathrm{H}_{3}$ ) relative to their conventional isomers (e.g. $\mathrm{HOCH}_{2} \mathrm{PH}_{2}^{+\cdot}$ ). It is important to assess the generality and limitations of this and related predictive schemes and some initial steps in this direction are described below.

Calculated total energies for the set of component systems $\mathrm{CH}_{3} \dot{\mathrm{Y}}, \mathrm{CH}_{3} \stackrel{+}{\mathrm{X}} \mathrm{H}, \mathrm{CH}_{3} \mathrm{YH}, \mathrm{CH}_{3} \mathrm{X}^{+\cdot}, \mathrm{CH}_{3} \mathrm{YH}^{+\cdot}$ and $\mathrm{CH}_{3} \mathrm{X}$ with $\mathrm{Y}=\mathrm{CH}_{2}, \mathrm{NH}$ and $\mathrm{O}$, and $\mathrm{X}=\mathrm{NH}_{2}, \mathrm{OH}, \mathrm{F}, \mathrm{PH}_{2}, \mathrm{SH}$ and $\mathrm{Cl}$ are listed in Table 7.4. Theoretical relative energies, calculated according to equation (7.6a) or $(7.6 \mathrm{~b})$, and experimental relative energies, calculated according to equation $(7.7 a)$ or $(7.7 b), b$ are presented in Table 7.5 .

The theoretical and experimental values generally agree to within about $40-50 \mathrm{~kJ} \mathrm{~mol}^{-1}$. Further improvement is likely at higher levels of theory.

b. Using data from refs 56, 74, 258 and 259 . 
Table 7.4 Calculated Total Energies (hartrees) for Distonic Radical Cations $\dot{\mathrm{Y}}\left(\mathrm{CH}_{2}\right) \stackrel{+}{\mathrm{X}} \underline{H}^{\mathrm{H}}$ and their Conventional Isomers $\mathrm{HY}\left(\mathrm{CH}_{2}\right) \underline{n}^{+}$and Appropriate Component Systems ${ }^{a}$

\begin{tabular}{|c|c|c|c|}
\hline Species & $\mathrm{MP} 2 / 6-31 \mathrm{G}^{*}$ & Species & $\mathrm{MP} 2 / 6-31 \mathrm{G}^{*}$ \\
\hline $\mathrm{CH}_{3} \mathrm{NH}_{2}^{+\cdot}$ & -95.18927 & & -95.19670 \\
\hline $\mathrm{CH}_{3} \mathrm{OH}^{+\cdot}$ & -114.94531 & & -114.97057 \\
\hline $\mathrm{CH}_{3} \mathrm{~F}^{+\cdot}$ & $-138.88291^{b}$ & $\dot{\mathrm{C}} \mathrm{H}_{2} \stackrel{+}{\mathrm{F}} \mathrm{H}$ & -138.88992 \\
\hline $\mathrm{CH}_{3} \mathrm{PH}_{2}^{+\cdot}$ & -381.41070 & & $-381 \cdot 38992$ \\
\hline $\mathrm{CH}_{3} \mathrm{SH}^{+\cdot}$ & -437.62160 & & -437.58235 \\
\hline $\mathrm{CH}_{3} \mathrm{Cl}^{+\cdot}$ & -498.94253 & $\dot{\mathrm{C}} \mathrm{H}_{2} \stackrel{+}{\mathrm{C}} 1 \mathrm{H}$ & -498.92025 \\
\hline $\mathrm{NH}_{2} \mathrm{NH}_{2}^{+\cdot}$ & -111.22524 & $\dot{\mathrm{N}} \mathrm{HN}^{+} \mathrm{H}_{3}$ & -111.17598 \\
\hline $\mathrm{NH}_{2} \mathrm{OH}^{+\cdot}$ & -131.00046 & $\dot{\mathrm{N}} \mathrm{HO}^{+} \mathrm{H}_{2}$ & -130.93856 \\
\hline $\mathrm{NH}_{2} \mathrm{~F}^{+\cdot}$ & -154.92092 & $\dot{\mathrm{N}} \mathrm{HF}^{+} \mathrm{H}$ & -154.85257 \\
\hline $\mathrm{NH}_{2} \mathrm{PH}_{2}^{+\cdot}$ & -397.45318 & $\dot{\mathrm{N}} \mathrm{HP}^{+} \mathrm{H}_{3}$ & -397.39363 \\
\hline $\mathrm{NH}_{2} \mathrm{SH}^{+\bullet}$ & -453.66171 & $\dot{\mathrm{N}} \mathrm{HS}^{+} \mathrm{H}_{2}$ & -453.57881 \\
\hline $\mathrm{NH}_{2} \mathrm{Cl}^{+\cdot}$ & -514.99398 & $\dot{\mathrm{N}} \mathrm{H} \stackrel{+}{\mathrm{C}} \mathrm{l} \mathrm{H}$ & -514.89248 \\
\hline $\mathrm{HONH}_{2}{ }^{+\cdot}$ & -131.00046 & $\dot{\mathrm{O}}^{+} \mathrm{H}_{3}$ & -130.96583 \\
\hline $\mathrm{HOOH}^{+\cdot}$ & -150.76379 & $\dot{\mathrm{O}}^{+} \mathrm{H}_{2}$ & -150.70949 \\
\hline $\mathrm{HOF}^{+\cdot}$ & $-175.08480^{C}$ & $\dot{\mathrm{O}}_{\mathrm{F} \mathrm{H}}^{+}$ & $-174.97511^{c}$ \\
\hline $\mathrm{HOPH}_{2}{ }^{+\cdot}$ & -417.27086 & $\dot{\mathrm{O}}^{+} \mathrm{H}_{3}$ & -417.21910 \\
\hline $\mathrm{HOSH}^{+\cdot}$ & -473.46340 & $\stackrel{+}{\mathrm{O}} \mathrm{H}_{2}$ & $-473 \cdot 39239$ \\
\hline $\mathrm{HOCl}^{+\cdot}$ & $-534.76411^{c}$ & $\dot{\mathrm{O}}_{\mathrm{C}}^{+} \mathrm{H}$ & $-534.63336^{c}$ \\
\hline $\mathrm{CH}_{3} \mathrm{CH}_{2} \mathrm{NH}_{2}^{+\cdot}$ & $-134 \cdot 36224$ & $\dot{\mathrm{C}} \mathrm{H}_{2} \mathrm{CH}_{2} \stackrel{+}{\mathrm{N}} \mathrm{H}_{3}$ & $-134 \cdot 37855$ \\
\hline $\mathrm{CH}_{3} \mathrm{CH}_{2} \mathrm{OH}^{+\cdot}$ & $-154 \cdot 14534$ & $\dot{\mathrm{C}} \mathrm{H}_{2} \mathrm{CH}_{2} \stackrel{+}{\mathrm{O}} \mathrm{H}_{2}$ & $-154 \cdot 16019$ \\
\hline $\mathrm{CH}_{3} \mathrm{CH}_{2} \mathrm{~F}^{+\cdot}$ & -178.09144 & $\dot{\mathrm{C}} \mathrm{H}_{2} \mathrm{CH}_{2} \stackrel{+}{\mathrm{F}} \mathrm{H}$ & -178.11961 \\
\hline $\mathrm{CH}_{3} \mathrm{CH}_{2} \mathrm{PH}_{2}^{+\cdot}$ & -420.58002 & $\dot{\mathrm{C}} \mathrm{H}_{2} \mathrm{CH}_{2} \stackrel{+}{\mathrm{P}} \mathrm{H}_{3}$ & -420.56251 \\
\hline
\end{tabular}


167.

\begin{tabular}{|c|c|c|c|}
\hline $\mathrm{CH}_{3} \mathrm{CH}_{2} \mathrm{SH}^{+\cdot}$ & -476.79435 & $\dot{\mathrm{C}} \mathrm{H}_{2} \mathrm{CH}_{2} \stackrel{+}{\mathrm{S}} \mathrm{H}_{2}$ & -476.76285 \\
\hline $\mathrm{CH}_{3} \mathrm{CH}_{2} \mathrm{Cl}^{+\cdot}$ & -538.11741 & & -538.12306 \\
\hline $\mathrm{NH}_{2} \mathrm{CH}_{2} \mathrm{NH}_{2}^{+\cdot}$ & $-150 \cdot 38103$ & & $-150 \cdot 39802$ \\
\hline $\mathrm{NH}_{2} \mathrm{CH}_{2} \mathrm{OH}^{+\cdot}$ & -170.21064 & & $-170 \cdot 18050$ \\
\hline $\mathrm{NH}_{2} \mathrm{CH}_{2} \mathrm{~F}^{+\cdot}$ & $-194 \cdot 18628$ & $\dot{\mathrm{N}} \mathrm{HCH}_{2}{ }_{2}^{+}$ & -194.15771 \\
\hline $\mathrm{NH}_{2} \mathrm{CH}_{2} \mathrm{PH}_{2}^{+\cdot}$ & -436.59923 & & -436.57304 \\
\hline $\mathrm{NH}_{2} \mathrm{CH}_{2} \mathrm{SH}^{+\cdot}$ & -492.81540 & & -492.77661 \\
\hline $\mathrm{NH}_{2} \mathrm{CH}_{2} \mathrm{Cl}^{+\cdot}$ & -554.19770 & & -554.15747 \\
\hline $\mathrm{HOCH}_{2} \mathrm{NH}_{2}{ }^{+\cdot}$ & -170.21064 & & -170.22169 \\
\hline $\mathrm{HOCH}_{2} \mathrm{OH}^{+\cdot}$ & -190.00010 & & -190.00986 \\
\hline $\mathrm{HOCH}_{2} \mathrm{~F}^{+\cdot}$ & -213.95071 & & -213.97346 \\
\hline $\mathrm{HOCH}_{2} \mathrm{PH}_{2}^{+\cdot}$ & -456.42072 & & -456.38542 \\
\hline $\mathrm{HOCH}_{2} \mathrm{SH}^{+\cdot}$ & -512.63865 & & -512.58713 \\
\hline $\mathrm{HOCH}_{2} \mathrm{Cl}^{+\cdot}$ & -573.95839 & & -573.97385 \\
\hline $\mathrm{CH}_{3} \mathrm{CH}_{2} \mathrm{CH}_{2} \mathrm{NH}_{2}^{+\cdot}$ & -173.53087 & & -173.54575 \\
\hline $\mathrm{CH}_{3} \mathrm{CH}_{2} \mathrm{CH}_{2} \mathrm{OH}^{+\cdot}$ & $-193 \cdot 32557$ & & $-193 \cdot 32503$ \\
\hline $\mathrm{CH}_{3} \mathrm{CH}_{2} \mathrm{CH}_{2} \mathrm{~F}^{+\cdot}$ & -217.27789 & & -217.28893 \\
\hline $\mathrm{CH}_{3} \mathrm{CH}_{2} \mathrm{CH}_{2} \mathrm{PH}_{2}^{+\cdot}$ & -459.74515 & & -459.72886 \\
\hline $\mathrm{CH}_{3} \mathrm{CH}_{2} \mathrm{CH}_{2} \mathrm{SH}^{+\cdot}$ & -515.96206 & & -515.92641 \\
\hline $\mathrm{CH}_{3} \mathrm{CH}_{2} \mathrm{CH}_{2} \mathrm{Cl}^{+\cdot}$ & -577.29774 & & -577.29532 \\
\hline $\mathrm{NH}_{2} \mathrm{CH}_{2} \mathrm{CH}_{2} \mathrm{NH}_{2}^{+\cdot}$ & -189.57308 & $\dot{\mathrm{N}} \mathrm{HCH}_{2} \mathrm{CH}_{2} \stackrel{+}{\mathrm{N}} \mathrm{H}_{3}$ & -189.56109 \\
\hline $\mathrm{NH}_{2} \mathrm{CH}_{2} \mathrm{CH}_{2} \mathrm{~F}^{+\cdot}$ & -233.35926 & $\dot{\mathrm{N}} \mathrm{HCH}_{2} \mathrm{CH}_{2} \stackrel{+}{\mathrm{F}} \mathrm{H}$ & -233.27687 \\
\hline $\mathrm{HOCH}_{2} \mathrm{CH}_{2} \mathrm{OH}^{+\cdot}$ & -229.19659 & $\dot{\mathrm{O}} \mathrm{CH}_{2} \mathrm{CH}_{2} \stackrel{+}{\mathrm{O}} \mathrm{H}_{2}$ & -229.15374 \\
\hline $\mathrm{HOCH}_{2} \mathrm{CH}_{2} \mathrm{~F}^{+\cdot}$ & $-253 \cdot 15320$ & $\dot{\mathrm{O}} \mathrm{CH}_{2} \mathrm{CH}_{2} \stackrel{+}{\mathrm{F}} \mathrm{H}$ & -253.08425 \\
\hline $\mathrm{HOCH}_{2} \mathrm{CH}_{2} \mathrm{Cl}^{+\cdot}$ & -613.17001 & $\dot{\mathrm{O}} \mathrm{CH}_{2} \mathrm{CH}_{2} \stackrel{+}{\mathrm{C}} 1 \mathrm{H}$ & -613.10345 \\
\hline $\mathrm{CH}_{3} \mathrm{CH}_{3}$ & -79.49429 & $\mathrm{CH}_{3} \dot{\mathrm{C}} \mathrm{H}_{2}$ & -78.83518 \\
\hline $\mathrm{CH}_{3} \mathrm{NH}_{2}$ & -95.50459 & $\mathrm{CH}_{3} \dot{\mathrm{N} H}$ & -94.85172 \\
\hline $\mathrm{CH}_{3} \mathrm{OH}$ & $-115 \cdot 34538$ & $\mathrm{CH}_{3} \mathrm{O}$ & -114.68407 \\
\hline
\end{tabular}


168.

$\begin{array}{llll}\mathrm{CH}_{3} \mathrm{~F} & -139.33544 & \mathrm{CH}_{3} \mathrm{SH} & -437.95233 \\ \mathrm{CH}_{3} \mathrm{Cl} & -499.35399 & \mathrm{CH}_{3} \mathrm{CH}_{3}^{+\cdot} & -79.07455 \\ \mathrm{CH}_{3} \stackrel{+}{\mathrm{N}} \mathrm{H}_{3} & -95.86714 & \mathrm{CH}_{3} \stackrel{+}{\mathrm{PH}_{3}} & -382.05426 \\ \mathrm{CH}_{3} \stackrel{+}{\mathrm{O}}{ }_{2} & -115.64102 & \mathrm{CH}_{3} \stackrel{+}{\mathrm{S}} \mathrm{H}_{2} & -438.25010 \\ \mathrm{CH}_{3}^{+} \stackrel{+}{\mathrm{F}} & -139.56883 & \mathrm{CH}_{3} \stackrel{+}{\mathrm{C}} 1 \mathrm{H} & -499.59143\end{array}$

a $3-21 G^{(*)}$ optimized structures unless otherwise specified.

b MP2 $/ 6-31 \mathrm{G}^{*}$ optimized structure, from ref 146 .

c $6-31 G^{*}$ optimized structure. 
Table 7.5 Comparison of Theoretical and Experimental Estimates of $E($ Conventional) - $E(D$ istonic), as Calculated from Component Systems $\left(\mathrm{kJ} \mathrm{mol}{ }^{-1}\right)$

Component Systems

$\mathrm{CH}_{3} \dot{\mathrm{C}} \mathrm{H}_{2}+\mathrm{CH}_{3} \stackrel{+}{\mathrm{N}} \mathrm{H}_{3} \rightarrow \mathrm{CH}_{3} \mathrm{CH}_{3}+\mathrm{CH}_{3} \mathrm{NH}_{2}^{+\cdot}$

$\mathrm{CH}_{3} \dot{\mathrm{C}} \mathrm{H}_{2}+\mathrm{CH}_{3} \stackrel{+}{\mathrm{O}}_{2} \rightarrow \mathrm{CH}_{3} \mathrm{CH}_{3}+\mathrm{CH}_{3} \mathrm{OH}^{+} \cdot$

$\mathrm{CH}_{3} \dot{\mathrm{C}} \mathrm{H}_{2}+\mathrm{CH}_{3} \stackrel{+}{\mathrm{F}} \mathrm{H} \rightarrow \mathrm{CH}_{3} \mathrm{CH}_{3}^{+\cdot}+\mathrm{CH}_{3} \mathrm{~F}$

$\mathrm{CH}_{3} \dot{\mathrm{C}} \mathrm{H}_{2}+\mathrm{CH}_{3} \stackrel{+}{\mathrm{PH}_{3}} \rightarrow \mathrm{CH}_{3} \mathrm{CH}_{3}+\mathrm{CH}_{3} \mathrm{PH}_{2}^{+} \cdot$

$\mathrm{CH}_{3} \dot{\mathrm{CH}}_{2}+\mathrm{CH}_{3} \stackrel{+}{\mathrm{S}} \mathrm{H}_{2} \rightarrow \mathrm{CH}_{3} \mathrm{CH}_{3}+\mathrm{CH}_{3} \mathrm{SH}^{+\cdot}$

$\mathrm{CH}_{3} \dot{\mathrm{CH}}_{2}+\mathrm{CH}_{3} \stackrel{+}{\mathrm{C}} \mathrm{H} \mathrm{H} \rightarrow \mathrm{CH}_{3} \mathrm{CH}_{3}+\mathrm{CH}_{3} \mathrm{Cl}^{+\cdot}$

$\mathrm{CH}_{3} \dot{\mathrm{N}} \mathrm{H}+\mathrm{CH}_{3} \stackrel{+}{\mathrm{N}} \mathrm{H}_{3} \rightarrow \mathrm{CH}_{3} \mathrm{NH}_{2}+\mathrm{CH}_{3} \mathrm{NH}_{2}^{+\bullet}$

$\mathrm{CH}_{3} \dot{\mathrm{N}} \mathrm{H}+\mathrm{CH}_{3} \stackrel{+}{\mathrm{O}}_{2} \rightarrow \mathrm{CH}_{3} \mathrm{NH}_{2}^{+\cdot}+\mathrm{CH}_{3} \mathrm{OH}$

$\mathrm{CH}_{3} \dot{\mathrm{N}} \mathrm{H}+\mathrm{CH}_{3} \stackrel{+}{\mathrm{F}} \mathrm{H} \rightarrow \mathrm{CH}_{3} \mathrm{NH}_{2}^{+\cdot}+\mathrm{CH}_{3} \mathrm{~F}$

$\mathrm{CH}_{3} \dot{\mathrm{NH}}+\mathrm{CH}_{3} \stackrel{+}{\mathrm{PH}_{3}} \rightarrow \mathrm{CH}_{3} \mathrm{NH}_{2}+\mathrm{CH}_{3} \mathrm{PH}_{2}^{+}$

$\mathrm{CH}_{3} \dot{\mathrm{N}} \mathrm{H}+\mathrm{CH}_{3} \stackrel{+}{\mathrm{S}} \mathrm{H}_{2} \rightarrow \mathrm{CH}_{3} \mathrm{NH}_{2}^{+\cdot}+\mathrm{CH}_{3} \mathrm{SH}$

$\mathrm{CH}_{3} \dot{\mathrm{N}} \mathrm{H}+\mathrm{CH}_{3} \stackrel{+}{\mathrm{C}} 1 \mathrm{H} \rightarrow \mathrm{CH}_{3} \mathrm{NH}_{2}^{+\cdot}+\mathrm{CH}_{3} \mathrm{Cl}$

$\mathrm{CH}_{3} \dot{\mathrm{O}}+\mathrm{CH}_{3} \stackrel{+}{\mathrm{N}} \mathrm{H}_{3} \rightarrow \mathrm{CH}_{3} \mathrm{OH}+\mathrm{CH}_{3} \mathrm{NH}_{2}+$

$\mathrm{CH}_{3} \dot{\mathrm{O}}+\mathrm{CH}_{3} \stackrel{+}{\mathrm{O}}_{2} \rightarrow \mathrm{CH}_{3} \mathrm{OH}+\mathrm{CH}_{3} \mathrm{OH}^{+\cdot}$

$\mathrm{CH}_{3} \dot{\mathrm{O}}+\mathrm{CH}_{3} \stackrel{+}{\mathrm{F}} \mathrm{H} \rightarrow \mathrm{CH}_{3} \mathrm{OH}^{+\cdot}+\mathrm{CH}_{3} \mathrm{~F}$

$\mathrm{CH}_{3} \dot{\mathrm{O}}+\mathrm{CH}_{3} \stackrel{+}{\mathrm{PH}_{3}} \rightarrow \mathrm{CH}_{3} \mathrm{OH}+\mathrm{CH}_{3} \mathrm{PH}_{2}^{+}+$

$\mathrm{CH}_{3} \dot{\mathrm{O}}+\mathrm{CH}_{3} \stackrel{+}{\mathrm{S}} \mathrm{H}_{2} \rightarrow \mathrm{CH}_{3} \mathrm{OH}+\mathrm{CH}_{3} \mathrm{SH}^{+}$

$$
\mathrm{CH}_{3} \dot{\mathrm{O}}+\mathrm{CH}_{3} \stackrel{+}{\mathrm{C}} \mathrm{H} \mathrm{H} \rightarrow \mathrm{CH}_{3} \mathrm{OH}^{+\cdot}+\mathrm{CH}_{3} \mathrm{Cl}
$$


According to the guidelines provided above, the results from Table 7.5 predict that, in most cases within the range of groups $X$ and Y considered here, the conventional isomer should be the more stable form. The distonic isomer should be preferred when $X=\mathrm{NH}_{2}$ because of the high calculated proton affinity (952 $\mathrm{kJ} \mathrm{mol}^{-1}$ ) of $\mathrm{CH}_{3} \mathrm{NH}_{2}$ (stabilizing the distonic form). A preference for the distonic isomer is also predicted for several of the OH-containing systems (e.g. $Y=\mathrm{CH}_{3}, X=\mathrm{OH}$ and $\left.\mathrm{Y}=\mathrm{OH}, X=\mathrm{OH}\right)$, largely due to the high IE (1050 kJ $\mathrm{mol}^{-1}$ ) of $\mathrm{CH}_{3} \mathrm{OH}$ (leading to a destabilization of the conventional isomer). However, this result is reversed if there is a more readily ionizable group (than $\mathrm{OH}$ ) present in the molecule since under such circumstances equations (7.6b) and (7.7b) (rather than (7.6a) and (7.7a)) apply. Thus, for $\mathrm{Y}=\mathrm{NH}_{2}, \mathrm{X}=\mathrm{OH}$, the conventional isomer is predicted to be more stable due to the low IE ( $828 \mathrm{~kJ} \mathrm{~mol}^{-1}$ ) of $\mathrm{CH}_{3} \mathrm{NH}_{2} \cdot$

Likewise, there is a predicted strong preference for the conventional isomer in the case of the pairs with $\mathrm{X}=\mathrm{F}, \mathrm{Y}=\mathrm{NH}$ and $\mathrm{X}=\mathrm{Cl}$, $\mathrm{Y}=\mathrm{NH}$. This appears to be attributable to a combination of the relatively low proton affinities of $\mathrm{CH}_{3} \mathrm{~F}\left(613 \mathrm{~kJ} \mathrm{~mol}^{-1}\right)$ and $\mathrm{CH}_{3} \mathrm{Cl}(623$ $\mathrm{kJ} \mathrm{mol}^{-1}$ ) and the relatively low ionization energy of $\mathrm{CH}_{3} \mathrm{NH}_{2}$ already noted above.

Explicit calculations have been carried out for a selection of the distonic and conventional radical cations with $\underline{\mathrm{n}}=0,1$ and 2 in order to test the predictions of Table 7.5. Total energies are included in Table 7.4 , a selection of optimized structures is displayed in Figure 7.2, and relative energies are shown in Table 7.6. 
171.

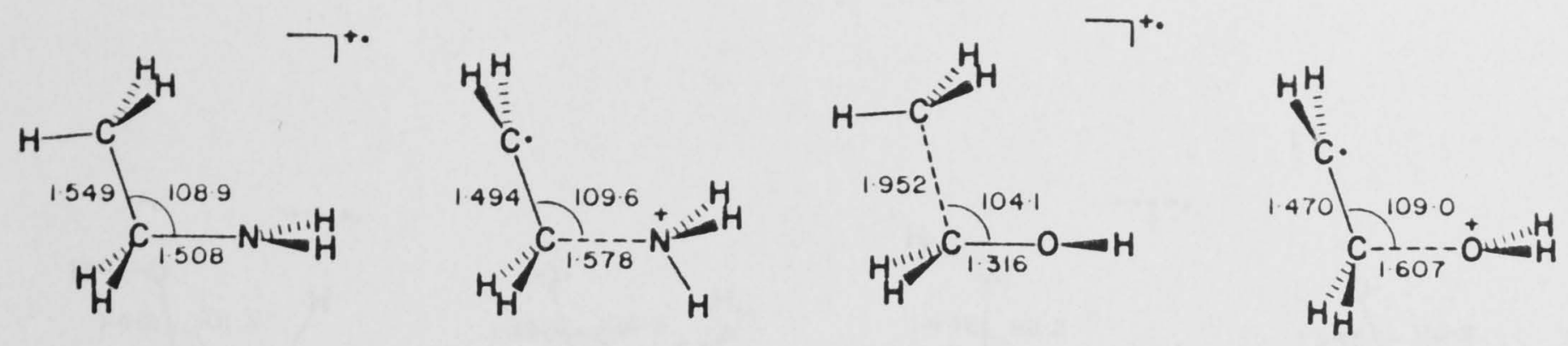

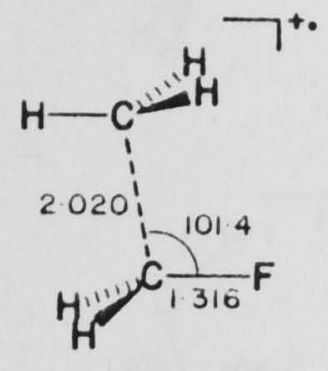

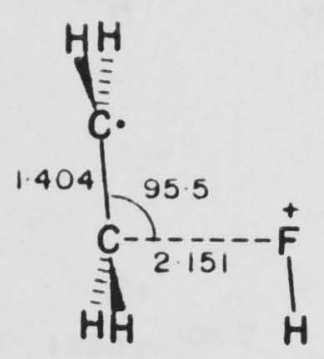<smiles>PPC1CCCC1</smiles>

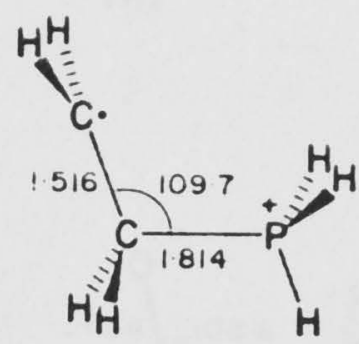<smiles>CC(CS)CS</smiles><smiles>C=CC1C[13CH2][C@@H]1C</smiles><smiles>CC(Cl)CC=O</smiles>

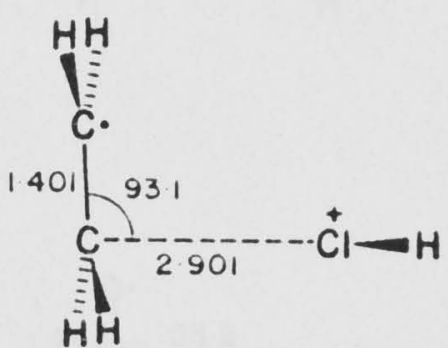<smiles>N[14CH2]N</smiles>

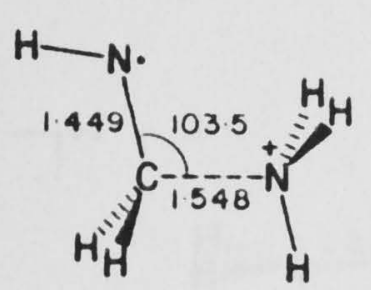<smiles>COOC</smiles><smiles>O[14CH2][14CH]1[14CH2][14CH2][14CH2][14CH2]1</smiles><smiles>CNCCF</smiles><smiles>P[I-][C@@H]1C[C@@H]2C[C@H]1N2</smiles><smiles>C[C@@H]1NC1P</smiles>

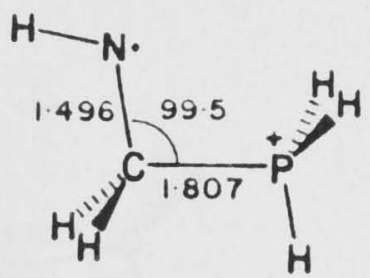<smiles>C[C@H]1NC1OS</smiles>

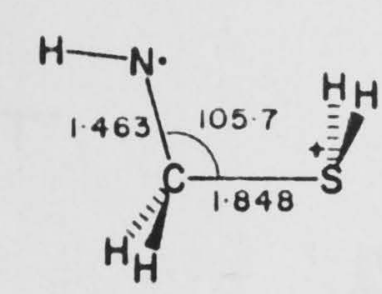<smiles>CNC(=O)CCl</smiles>

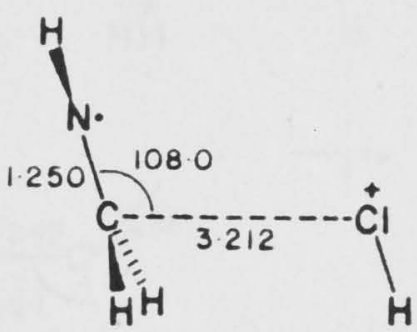

Figure 7.2 Bond lengths between heavy atoms and skeletal bond angles within fully optimized structures $\left(3-21 \mathrm{G}^{(*)}\right)$ of distonic radical cations $\dot{Y}\left(\mathrm{CH}_{2}\right) \stackrel{+}{\mathrm{X}} \mathrm{H}$ and their conventional isomers $\mathrm{HY}\left(\mathrm{CH}_{2}\right)_{\underline{n}} \mathrm{X}^{+\cdot}$. Formal location of charge and radical sites shown for distonic ions. 

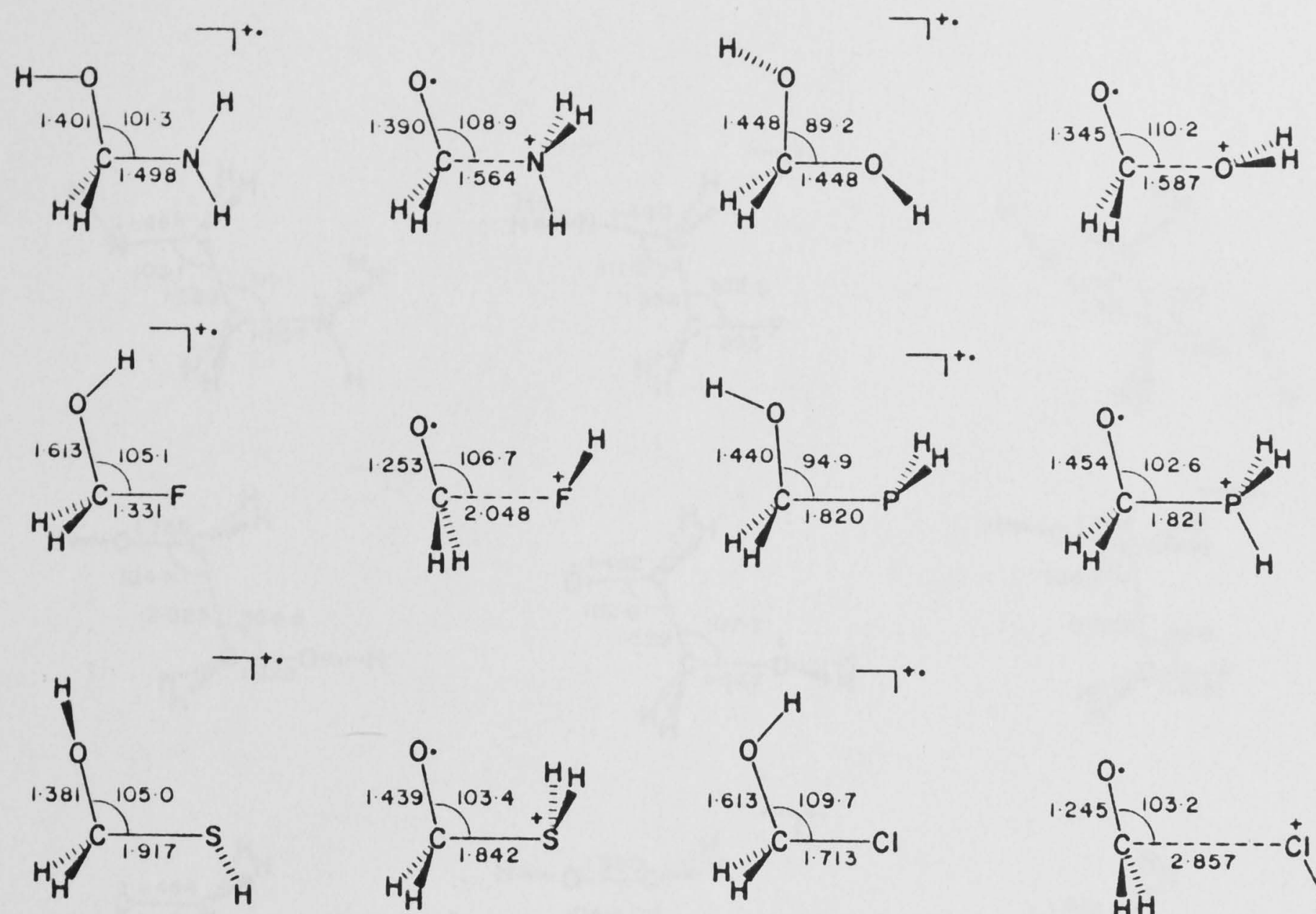<smiles>O[C@H]1[CH][C@@H](O)[C@@H]1[18OH]</smiles>

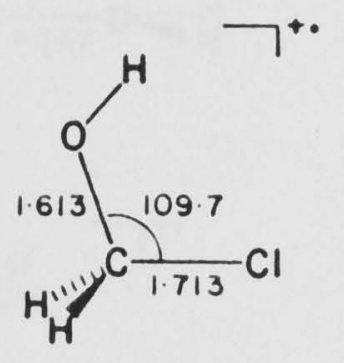

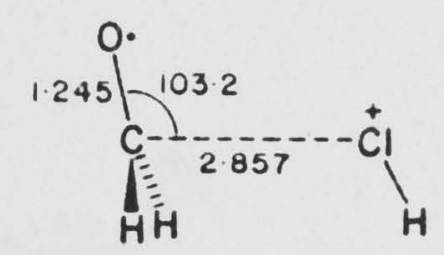<smiles>C[C@H]1[C@H](C)[C@@H](N)[C@@H]1C</smiles>

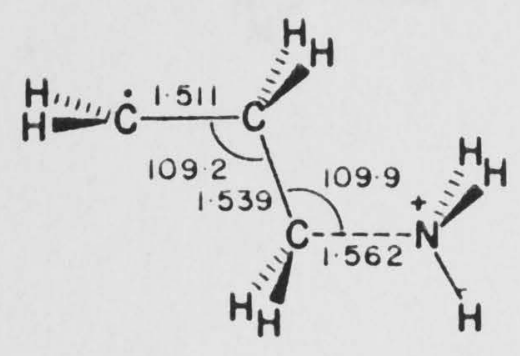<smiles>CC1CCCC1C=CO</smiles>

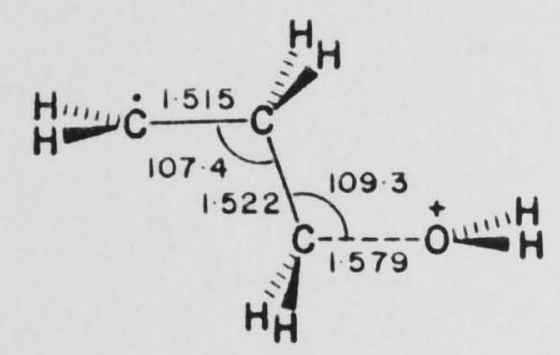<smiles>CCCCC(C)F</smiles>

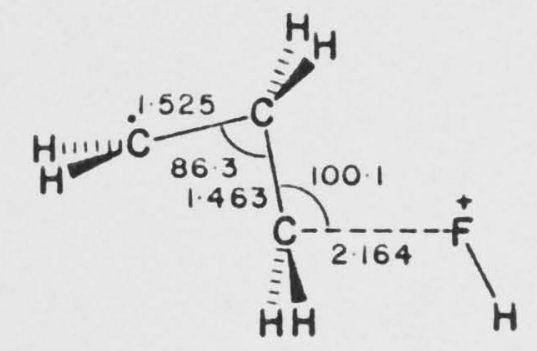<smiles>Cl[C@@H]1[C@H]2[C@@H](Cl)[C@@H]([C@H]2Cl)[C@H]1Cl</smiles><smiles>[CH][C@@H]1[C@H]([CH][CH2])[C@@H]2C[C@H]1[C@@H]2C</smiles><smiles>N[14CH2]N=[14CH]C1CCN1N</smiles>

Figure 7.2 (continued) 

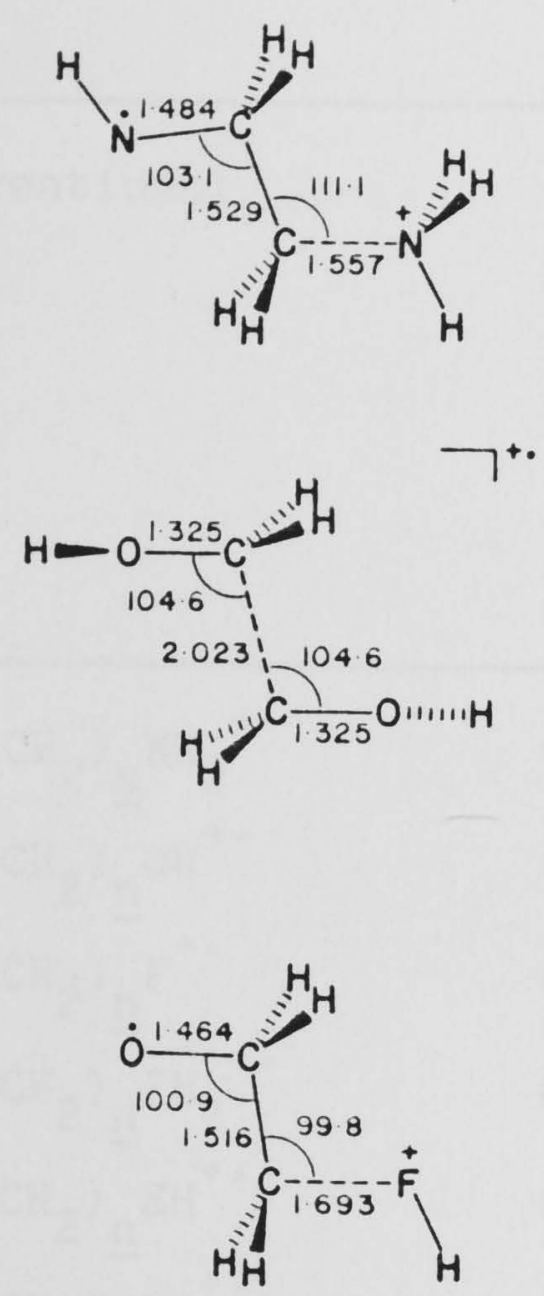
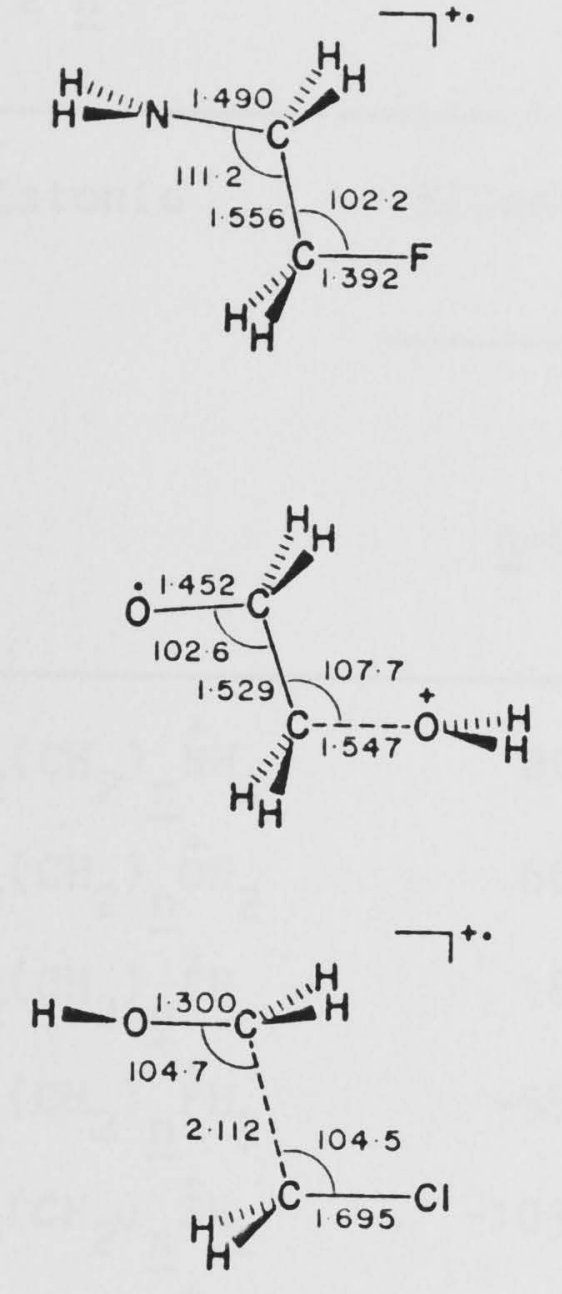
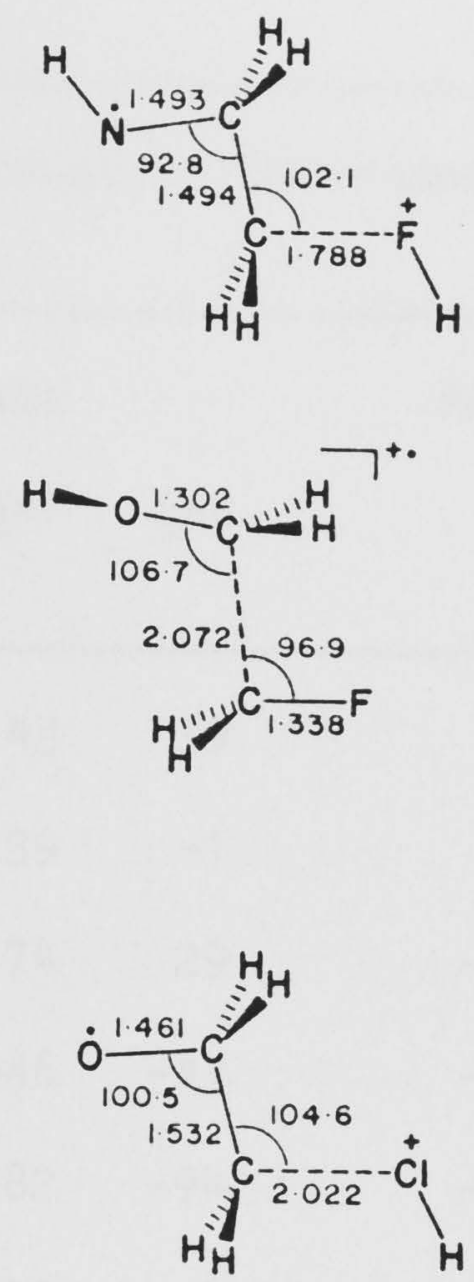
Table 7.6 Comparison of Calculated and Predicted Relative Energies $\left(\mathrm{kJ} \mathrm{mol}^{-1}\right)$ of Distonic Radical Cations $\dot{\mathrm{Y}}\left(\mathrm{CH}_{2}\right){ }_{\underline{n}}^{\stackrel{+}{\mathrm{X}} \mathrm{H}}$ and their

Conventional Isomers $\mathrm{HY}\left(\mathrm{CH}_{2}\right) \underline{n}^{+\cdot}$

\begin{tabular}{|c|c|c|c|c|c|}
\hline $\mathrm{CH}_{3}\left(\mathrm{CH}_{2}\right){ }_{n} \mathrm{NH}_{2}^{+\cdot}$ & $\dot{\mathrm{C}} \mathrm{H}_{2}\left(\mathrm{CH}_{2}\right)_{\underline{n}} \stackrel{+}{\mathrm{N}} \mathrm{H}_{3}$ & 20 & 43 & 39 & 49 \\
\hline $\mathrm{CH}_{3}\left(\mathrm{CH}_{2}\right)_{\underline{n}} \mathrm{OH}^{+\cdot}$ & $\dot{\mathrm{C}} \mathrm{H}_{2}\left(\mathrm{CH}_{2}\right)_{\underline{n}} \stackrel{+}{\mathrm{O}} \mathrm{H}_{2}$ & 66 & 39 & -1 & 96 \\
\hline $\mathrm{CH}_{3}\left(\mathrm{CH}_{2}\right){ }_{\underline{n}}^{-} \mathrm{F}^{+\cdot}$ & $\dot{\mathrm{C}}_{2}\left(\mathrm{CH}_{2}\right)_{\underline{n}}^{-}{ }^{+} \mathrm{H}$ & 18 & 74 & 29 & -15 \\
\hline $\mathrm{CH}_{3}\left(\mathrm{CH}_{2}\right){ }_{\underline{n}} \mathrm{PH}_{2}^{+\cdot}$ & $\dot{\mathrm{C}} \mathrm{H}_{2}\left(\mathrm{CH}_{2}\right)_{\underline{n}} \stackrel{+}{\mathrm{P}} \mathrm{H}_{3}$ & -55 & -46 & -43 & -41 \\
\hline $\mathrm{CH}_{3}\left(\mathrm{CH}_{2}\right) \underline{\mathrm{n}}^{+} \mathrm{SH}^{+\cdot}$ & $\dot{\mathrm{C}} \mathrm{H}_{2}\left(\mathrm{CH}_{2}\right)_{\underline{n}}^{-} \stackrel{+}{\mathrm{S}} \mathrm{H}_{2}$ & -103 & -82 & -94 & -80 \\
\hline $\mathrm{CH}_{3}\left(\mathrm{CH}_{2}\right) \underline{\mathrm{n}}^{+\cdot}$ & $\dot{\mathrm{C}} \mathrm{H}_{2}\left(\mathrm{CH}_{2}\right)_{\underline{n}} \stackrel{+}{\mathrm{C}} l \mathrm{H}$ & -58 & 13 & -6 & -27 \\
\hline $\mathrm{NH}_{2}\left(\mathrm{CH}_{2}\right) \underline{\mathrm{n}} \mathrm{NH}^{+\cdot}$ & $\dot{\mathrm{N}} \mathrm{H}\left(\mathrm{CH}_{2}\right){ }_{n}^{+}{ }^{+} \mathrm{H}_{3}$ & -129 & 45 & -31 & 66 \\
\hline $\mathrm{NH}_{2}\left(\mathrm{CH}_{2}\right)_{\underline{n}} \mathrm{OH}^{+\cdot}$ & $\dot{\mathrm{N}} \mathrm{H}\left(\mathrm{CH}_{2}\right)_{\underline{n}} \stackrel{+}{\mathrm{O}}_{2}$ & -163 & -79 & & -110 \\
\hline $\mathrm{NH}_{2}\left(\mathrm{CH}_{2}\right){ }^{n} \mathrm{~F}^{+\cdot}$ & $\dot{\mathrm{N}} \mathrm{H}\left(\mathrm{CH}_{2}\right) \underline{{ }_{\mathrm{n}}}{ }^{+} \mathrm{H}$ & -179 & -75 & -216 & -273 \\
\hline $\mathrm{NH}_{2}\left(\mathrm{CH}_{2}\right){ }_{n} \mathrm{PH}_{2}^{+\cdot}$ & $\dot{\mathrm{N}} \mathrm{H}\left(\mathrm{CH}_{2}\right){ }_{\underline{\mathrm{n}}} \stackrel{+}{\mathrm{P}} \mathrm{H}_{3}$ & -156 & -69 & & -24 \\
\hline $\mathrm{NH}_{2}\left(\mathrm{CH}_{2}\right)^{-} \underline{\mathrm{SH}}^{+\cdot}$ & $\dot{\mathrm{N}} \mathrm{H}\left(\mathrm{CH}_{2}\right){ }_{\underline{n}} \stackrel{+}{\mathrm{S}} \mathrm{H}_{2}$ & -218 & -102 & & -104 \\
\hline $\mathrm{NH}_{2}\left(\mathrm{CH}_{2}\right) \underline{\mathrm{n}}^{+\cdot}$ & $\dot{\mathrm{N}} \mathrm{H}\left(\mathrm{CH}_{2}\right){ }_{n}{ }_{-}^{+} \mathrm{C} l \mathrm{H}$ & -266 & -106 & & -263 \\
\hline $\mathrm{HO}\left(\mathrm{CH}_{2}\right) \underline{\mathrm{n}}_{2}{ }^{+\cdot}$ & $\dot{\mathrm{O}}\left(\mathrm{CH}_{2}\right) \underline{\mathrm{n}}^{\stackrel{\overline{\mathrm{N}}}{\mathrm{N}} \mathrm{H}_{3}}$ & -91 & 29 & & 43 \\
\hline $\mathrm{HO}\left(\mathrm{CH}_{2}\right){ }_{\underline{n}} \mathrm{OH}^{+\cdot}$ & $\dot{\mathrm{O}}\left(\mathrm{CH}_{2}\right){ }_{\underline{\mathrm{n}}} \stackrel{+}{\mathrm{O}}_{2}$ & -143 & 26 & -113 & 90 \\
\hline $\mathrm{HO}\left(\mathrm{CH}_{2}\right)_{\underline{n}}^{-} \mathrm{F}^{+\cdot}$ & $\dot{\mathrm{O}}\left(\mathrm{CH}_{2}\right)_{\underline{n}}^{\stackrel{+}{\mathrm{F}} \mathrm{H}}$ & -288 & 60 & -181 & -73 \\
\hline $\mathrm{HO}\left(\mathrm{CH}_{2}\right)^{-}{ }^{-}{ }^{\mathrm{PH}_{2}}{ }^{+\cdot}$ & $\dot{\mathrm{O}}\left(\mathrm{CH}_{2}\right) \stackrel{+}{\mathrm{P}} \mathrm{P}_{3}$ & -136 & -93 & & -47 \\
\hline $\mathrm{HO}\left(\mathrm{CH}_{2}\right)^{-} \mathrm{SH}^{+\cdot}$ & $\dot{\mathrm{O}}\left(\mathrm{CH}_{2}\right)^{-} \stackrel{+}{\mathrm{S}} \mathrm{H}_{2}$ & -186 & -135 & & -86 \\
\hline $\mathrm{HO}\left(\mathrm{CH}_{2}\right){ }^{-}{ }^{-}{ }^{+\cdot}$ & $\dot{\mathrm{O}}\left(\mathrm{CH}_{2}\right) \underline{\mathrm{n}}^{+} \mathrm{C} 1 \mathrm{H}$ & -343 & 41 & -175 & -62 \\
\hline
\end{tabular}

a MP2 $/ 6-31 \mathrm{G}^{*}$ values.

b

From Table 7.5. 
Some of the optimized structures show interesting features

including the long-bonded geometries noted previously for the radical cations of other saturated molecules.177,227,260-262 Details of the structural effects are tangential to the aim of this chapter.

However, it may be noted that deviations from idealized geometries for both the conventional and distonic radical cations are likely to contribute to differences between the directly calculated and predicted relative energies for some of the systems under consideration.

When $\underline{\mathrm{n}}=0$, i.e. for comparisons of $\mathrm{HYX}^{+\cdot}$ with $\dot{\mathrm{Y}}^{+} \mathrm{X}$, the directly calculated relative energies differ substantially in several instances from the values based on the consideration of component systems. Errors of more than $200 \mathrm{~kJ} \mathrm{~mol}^{-1}$ can be seen. This result is not surprising and reflects the dominance in some of the systems of specific short-range interactions between the directly-bonded $X$ and $Y$ groups. The direction of the error in these worst cases corresponds to the conventional isomer being more stable than expected. This may be attributed to stabilizing $\pi$-type overlap in species such as $\mathrm{NH}_{2} \mathrm{NH}_{2}^{+\cdot}$.

When $\underline{n}=1$, i.e. in comparisons of $\mathrm{HYCH}_{2} \mathrm{X}^{+\cdot}$ with $\stackrel{\dot{\mathrm{Y}} \mathrm{CH}}{2} \stackrel{+}{\mathrm{X}} \mathrm{H}$, there is a significant improvement and, in most cases, calculated and predicted relative energies lie within about $50 \mathrm{~kJ} \mathrm{~mol}^{-1}$ of one another. Direct $\pi$-type overlap is no longer possible and, for example, the error for $\mathrm{NH}_{2} \mathrm{CH}_{2} \mathrm{NH}_{2}^{+\cdot}$ vs $\dot{\mathrm{N} H C H}{ }_{2} \stackrel{+}{\mathrm{N}} \mathrm{H}_{3}$ is about $20 \mathrm{~kJ} \mathrm{~mol}^{-1}$ compared with a nearly $200 \mathrm{~kJ} \mathrm{~mol}^{-1}$ error noted above for the corresponding $\underline{n}=0$ systems. There are, however, a few cases where the agreement is very poor (e.g. $\mathrm{NH}_{2} \mathrm{CH}_{2} \mathrm{~F}^{+\cdot}$ vs $\dot{\mathrm{NHCH}}_{2} \stackrel{+}{\mathrm{F} H}$ ) suggesting that 
interaction between the $X$ and $Y$ groups is still significant. For example, the fluoro substituent in $\mathrm{NH}_{2} \mathrm{CH}_{2} \mathrm{~F}$ makes the ionization energy considerably greater than that of the component system $\mathrm{CH}_{3} \mathrm{NH}_{2} \cdot{ }^{\mathrm{C}}$ As a consequence, the conventional radical cation $\mathrm{NH}_{2} \mathrm{CH}_{2} \mathrm{~F}^{+\cdot}$ is less stable than expected. This additional relative destabilization of the conventional isomer is found for many of the systems with $X=F$ or Cl. As can be seen from Figure 7.2, some of the optimized geometries differ considerably from those of idealized models. The component molecules used in the prediction scheme are therefore less appropriate in some cases and this may also contribute to the deviations seen in Table 7.6 .

Only a limited number of calculations have been carried out at this stage for the $\underline{n}=2$ systems, i.e. comparisons of $\mathrm{HYCH}_{2} \mathrm{CH}_{2} \mathrm{X}^{+}$. with $\stackrel{\mathrm{Y}}{\mathrm{CH}_{2}} \mathrm{CH}_{2} \stackrel{+}{\mathrm{X}} \mathrm{H}$. It should be emphasized that these calculations have been performed with the heavy-atom skeleton in a constrained trans arrangement for the purpose of testing the predictive scheme. In practice, some of these species may well prefer alternative arrangements. The results indicate substantially reduced errors for some of the $\underline{\mathrm{n}}=1$ problem cases. For example, the error for $\mathrm{NH}_{2} \mathrm{CH}_{2} \mathrm{CH}_{2} \mathrm{~F}^{+\cdot}$ vs $\dot{\mathrm{N}} \mathrm{HCH}_{2} \mathrm{CH}_{2} \stackrel{+}{\mathrm{F}} \mathrm{H}$ is $57 \mathrm{~kJ} \mathrm{~mol}^{-1}$ compared with nearly $200 \mathrm{~kJ}$ $\mathrm{mol}^{-1}$ for the corresponding $\underline{\mathrm{n}}=1$ systems. However, new problems arise for comparisons such as $\mathrm{NH}_{2} \mathrm{CH}_{2} \mathrm{CH}_{2} \mathrm{NH}_{2}^{+}$vs $\dot{\mathrm{N}}_{\mathrm{HCH}} \mathrm{CH}_{2} \stackrel{+}{\mathrm{N}} \mathrm{H}_{3}$. It appears that the two $\mathrm{NH}_{2}$ substituents in $\mathrm{NH}_{2} \mathrm{CH}_{2} \mathrm{CH}_{2} \mathrm{NH}_{2}^{+}$stabilize the structure corresponding to ionization from the $\mathrm{C}_{\alpha}-\mathrm{C}_{\beta}$ bond to such an extent that it is more stable than the structure corresponding to ionization from the nitrogen lone pair. 260,261 The latter would have

\footnotetext{
c. Calculated values are $\mathrm{IE}_{2}\left(\mathrm{NH}_{2} \mathrm{CH}_{2} \mathrm{~F}\right)=913 \mathrm{~kJ} \mathrm{~mol}^{-1}$ compared with $\mathrm{IE}_{\mathrm{a}}\left(\mathrm{CH}_{3} \mathrm{NH}_{2}\right)=828 \mathrm{~kJ} \mathrm{~mol}^{-1}$.
} 
been expected to be more stable on the basis of ionization energy data for the component molecules $\left(\mathrm{CH}_{3} \mathrm{NH}_{2}\right.$ and $\left.\mathrm{CH}_{3} \mathrm{CH}_{3}\right)$. ${ }^{d}$ As a consequence, the conventional isomer (which displays a long $\mathrm{C}_{\alpha}---\mathrm{C}_{\beta}$ bond) is considerably more stable than predicted. Similar considerations apply to $\mathrm{CH}_{3} \mathrm{CH}_{2} \mathrm{CH}_{2} \mathrm{OH}^{+\cdot}$, $\mathrm{HOCH}_{2} \mathrm{CH}_{2} \mathrm{OH}^{+\cdot}$, $\mathrm{HOCH}_{2} \mathrm{CH}_{2} \mathrm{~F}^{+\cdot}$ and $\mathrm{HOCH}_{2} \mathrm{CH}_{2} \mathrm{Cl}^{+\cdot}$, the remaining poor cases in Table 7.6.

It is anticipated that problems attributable to ionization from $\mathrm{C}-\mathrm{C}$ bonds should be less severe in systems with $\underline{\mathrm{n}}=3$ since reinforcing effects of substituents on the $\mathrm{C}_{\alpha}-\mathrm{C}_{\beta}$ bond are no longer possible. Indeed, preliminary calculations for $\mathrm{NH}_{2} \mathrm{CH}_{2} \mathrm{CH}_{2} \mathrm{CH}_{2} \mathrm{NH}_{2}^{+}$and $\dot{\mathrm{N}} \mathrm{HCH}_{2} \mathrm{CH}_{2} \mathrm{CH}_{2} \stackrel{+}{\mathrm{N}} \mathrm{H}_{3}$ result in a calculated energy difference of $53 \mathrm{~kJ} \mathrm{~mol}^{-1}$ in favour of the distonic isomer which compares well with the $66 \mathrm{~kJ}$ $\mathrm{mol}^{-1}$ predicted on the basis of component systems.

\subsection{Concluding Remarks}

The calculations in this chapter indicate that the energy difference between the distonic radical cations $\dot{\mathrm{C}} \mathrm{H}_{2}\left(\mathrm{CH}_{2}\right) \stackrel{+}{\mathrm{N}} \mathrm{H}_{3}$ and their conventional isomers $\mathrm{CH}_{3}\left(\mathrm{CH}_{2}\right) \underline{\mathrm{n}}_{2}{ }^{+}$converges with increasing $\underline{n}$ towards a limit which may be approximated using energy data for appropriate small component systems. Generalization of this observation suggests that data for a limited number of small molecules $\left(\mathrm{CH}_{3} \dot{\mathrm{Y}}, \mathrm{CH}_{3} \stackrel{+}{\mathrm{X} H}, \mathrm{CH}_{3} \mathrm{YH}, \mathrm{CH}_{3} \mathrm{X}^{+\cdot}, \mathrm{CH}_{3} \mathrm{YH}^{+\cdot}\right.$ and $\left.\mathrm{CH}_{3} \mathrm{X}\right)$ should permit the prediction of relative energies of a much larger set of distonic and

d. Calculated values for the component molecules are $\mathrm{IE}_{\mathrm{a}}\left(\mathrm{CH}_{3} \mathrm{NH}_{2}\right)=$ $828 \mathrm{~kJ} \mathrm{~mol}^{-1}$ and $\mathrm{IE}_{\mathrm{a}}\left(\mathrm{CH}_{3} \mathrm{CH}_{3}\right)=1102 \mathrm{~kJ} \mathrm{~mol}^{-1}$ whereas in fact IE ${ }_{a}\left(\mathrm{NH}_{2} \mathrm{CH}_{2} \mathrm{CH}_{2} \mathrm{NH}_{2}\right)=732 \mathrm{~kJ} \mathrm{~mol}^{-1}$. 
conventional radical cations. However, explicit calculations on the larger systems reveal a sufficient number of exceptions that caution must be exercised in applying this and related predictive schemes.

The predictions based on the small components are least useful for the species with $\underline{n}=0$ (i.e. $\dot{\mathrm{Y} X} \mathrm{XH}_{\mathrm{H}}$ vs $\mathrm{HYX}^{+\cdot}$ ). For these systems, the conventional isomer is often more stable than expected due to favourable $\pi$-type interactions between the directly-bonded $x$ and $\mathrm{Y}$ groups (e.g. $\mathrm{NH}_{2} \mathrm{NH}_{2}^{+\cdot}$ ). Such interactions are not important

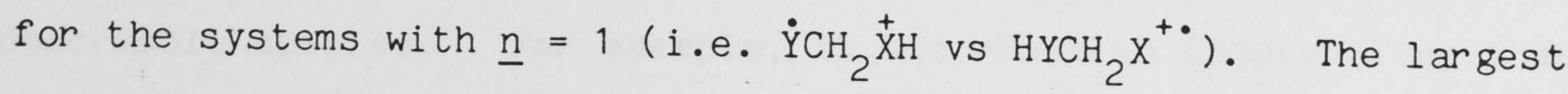
errors now occur for substituents (notably $X=F$ ) which have a large perturbing effect on the properties (notably the ionization energy) of the parent molecules. The conventional isomer is often less stable than expected in these cases. The preliminary calculations for systems with $\underline{n}=2$ (i.e. comparisons of $\dot{\mathrm{Y}} \mathrm{CH}_{2} \mathrm{CH}_{2} \stackrel{+}{\mathrm{X}} \mathrm{H}$ with $\mathrm{HYCH}_{2} \mathrm{CH}_{2} \mathrm{X}^{+\cdot}$ ) appear to indicate substantially reduced effects of this type. However, substantial deviations between predicted and calculated relative energies now occur for several systems (e.g. $\mathrm{NH}_{2} \mathrm{CH}_{2} \mathrm{CH}_{2} \mathrm{NH}_{2}{ }^{+\cdot}$ ) for which the lowest-energy conventional isomer corresponds to ionization from the $\mathrm{C}_{\alpha}-\mathrm{C}_{\beta}$ bond rather than from a heteroatom lone pair. The conventional isomer is considerably more stable than expected in these cases.

Finally, it is noted that the most favourable circumstances for a distonic radical cation to be preferred over its conventional isomer occur for systems which contain a group (X) with a high proton affinity but which do not contain a group ( $X, Y$ or perturbed $C-C$ ) with a low ionization energy. 


\subsection{Introduction}

It is well established $d^{221-257}$ that isomers of conventional radical cations can exist in the gas phase as stable, independently observable species. For example, it was shown in Chapter Four that the methyleneammonium radical cation $\left(\dot{\mathrm{C}}_{2} \stackrel{+}{\mathrm{N}} \mathrm{H}_{3}\right)$ is a stable isomer of the methylamine radical cation $\left(\mathrm{CH}_{3} \mathrm{NH}_{2}{ }^{+}\right)$and furthermore lies slightly lower in energy than the conventional structure. Recently, there has been considerable interest $108,179,239,240$ in the analogous $\left[\mathrm{C}_{2} \mathrm{H}_{7} \mathrm{~N}\right]^{+\cdot}$ system, for which five possible isomers are shown in Figure 8.1 (1-5). Two of these isomers are the radical cations ( 3 and 4, respectively) of ethylamine and dimethylamine, while the other three<smiles>[C+]C[NH3+]</smiles>

1<smiles>C[CH+][NH3+]</smiles>

2
$\left[\mathrm{CH}_{3}-\mathrm{CH}_{2}-\mathrm{NH}_{2}\right]^{+}$.<smiles>[CH2][NH2+]CC</smiles>

4

Figure 8.1 Possible isomeric $\left[\mathrm{C}_{2} \mathrm{H}_{7} \mathrm{~N}\right]^{+\cdot}$ structures. 
isomers (all of which may be written as distonic radical cations) appear to have no stable neutral counterparts. In cases such as this, theory can provide a useful guide in suggesting which of the isomers with unusual structures might be stable species in the gas phase. 156,263

The only calculations for the $\left[\mathrm{C}_{2} \mathrm{H}_{7} \mathrm{~N}\right]^{+\cdot}$ system published previously are some results from a low-level ab initio study of 1 and 3 reported over a decade ago 264 and a brief mention of structure 5 in another ab initio study. ${ }^{167}$ As well as the five $\left[\mathrm{C}_{2} \mathrm{H}_{7} \mathrm{~N}\right]^{+}$isomers, a number of transition structures for their interconversion are examined in the present work. Such rearrangements in low-energy ionized alkylamines have been the subject of much recent interest. 108,239,240,265

\subsection{Method and Results}

Optimized structures were obtained with the $3-21 \mathrm{G}$ and $6-31 \mathrm{G}^{*}$ basis sets using gradient procedures. The spin-unrestricted HartreeFock (UHF) formalism was used for all open-shell systems. Improved relative energies were obtained with the larger $6-31 G^{* *}$ basis set and with valence-electron correlation incorporated using Moller-Plesset perturbation theory terminated at second (MP2) and third (MP3) order. Vibrational frequencies were calculated at the 3-21G//3-21G level and scaled by 0.9 . The best relative energies correspond to MP3 $/ 6-31 \mathrm{G}^{* *} / / 6-31 \mathrm{G}^{*}$ values with zero-point correction, estimated by using the additivity approximation of equation (1.16). Unless otherwise noted, these are the values given in the text. 
No appreciable spin contamination was encountered for the open-shell systems, except for transition structure 11. In that case, the $\left\langle\hat{S}^{2}\right\rangle$ value of 0.984 (compared with the value of 0.75 for a pure doublet) suggests (Section 1.4.2) that the corresponding calculated barrier is probably too high.

Results are reported for the five $\left[\mathrm{C}_{2} \mathrm{H}_{7} \mathrm{~N}\right]^{+\cdot}$ isomers $(1-5)$, several pairs of possible fragmentation products, and the various transition structures (6-11) for rearrangement and dissociation processes. Optimized geometries $\left(6-31 \mathrm{G}^{*}\right.$ with $3-21 \mathrm{G}$ values in parentheses) are displayed within the course of the text ${ }^{a}$ and unless otherwise noted, the $\mathrm{HF} / 6-31 \mathrm{G}^{*}$ values are used in the discussion. Calculated total energies and experimental heats of formation ${ }^{56}$ corrected to $0 \mathrm{~K}^{53,54}$ are presented in Table 8.1 and the corresponding relative energies in Table 8.2. The calculated relative energies are in pleasing agreement with the available experimental values.

a. Optimized geometries of the fragmentation products are only displayed where hitherto unpublished. In most cases, these geometries are available from refs 6 or 144 . 
Table 8.1 Calculated Total Energies ${ }^{\mathrm{a}}$ (hartrees) and Zero-Point Vibrational Energies (ZPVE, kJ mol ${ }^{-1}$ ), and Experimental Heats of Formation $\left(\mathrm{KJ} \mathrm{mol}^{-1}\right.$ ) for $\left[\mathrm{C}_{2} \mathrm{H}_{7} \mathrm{~N}\right]^{+\cdot}$ Structures and Component Systems

$$
\mathrm{HF} / 3-21 \mathrm{G}^{\mathrm{b}} \quad \mathrm{HF} / 6-31 \mathrm{G}^{*} \quad \mathrm{HF} / 6-31 \mathrm{G}^{* *} \quad \mathrm{MP} 2 / 6-31 \mathrm{G}^{*} \quad \mathrm{MP} 3 / 6-31 \mathrm{G}^{*} \quad \mathrm{ZPVE}^{\mathrm{b}} \quad \Delta \mathrm{H}^{\circ} \mathrm{fO}^{\mathrm{C}}
$$

\begin{tabular}{|c|c|c|c|c|c|c|c|c|}
\hline$\dot{\mathrm{C}}_{2} \mathrm{CH}_{2} \stackrel{+}{\mathrm{N}} \mathrm{H}_{3}$ & 1 & -133.25393 & -133.98289 & -133.99988 & $-134 \cdot 37870$ & $-134 \cdot 41219$ & 259.2 & \\
\hline $\mathrm{CH}_{3} \dot{\mathrm{C}} \mathrm{HNH}_{3}^{+}$ & 2 & -133.24915 & -133.97950 & -133.99679 & $-134 \cdot 37621$ & -134.40973 & 258.4 & \\
\hline $\mathrm{CH}_{3} \mathrm{CH}_{2} \mathrm{NH}_{2}^{+\cdot}$ & 3 & -133.24354 & -133.97527 & -133.99072 & -134.36365 & $-134 \cdot 39944$ & 253.9 & $828^{d}$ \\
\hline $\mathrm{CH}_{3} \mathrm{NHCH}_{3}^{+\cdot}$ & 4 & -133.25141 & -133.98556 & -133.99912 & $-134 \cdot 37301$ & -134.40915 & 253.5 & $796^{d}$ \\
\hline $\mathrm{CH}_{3} \stackrel{+}{\mathrm{N}} \mathrm{H}_{2} \dot{\mathrm{C}} \mathrm{H}_{2}$ & 5 & -133.24290 & -133.97229 & -133.98768 & $-134 \cdot 36635$ & -134.39952 & 257.9 & \\
\hline $\operatorname{TS}\left(1 \rightarrow 1^{\prime}\right)$ & 6 & -133.19871 & -133.93200 & -133.94973 & $-134 \cdot 32796$ & $-134 \cdot 36152$ & 249.1 & \\
\hline $\operatorname{TS}(2 \rightarrow 1)$ & 7 & -133.14882 & -133.88538 & -133.90548 & -134.29687 & $-134 \cdot 32835$ & 244.4 & \\
\hline $\operatorname{TS}(3 \rightarrow 1)$ & 8 & -133.16981 & -133.89860 & -133.91734 & $-134 \cdot 30877$ & $-134 \cdot 34089$ & 245.0 & \\
\hline $\operatorname{TS}(3 \rightarrow 2)$ & 9 & -133.15615 & -133.89411 & -133.91458 & $-134 \cdot 30528$ & $-134 \cdot 33658$ & 242.3 & \\
\hline $\operatorname{TS}(5 \rightarrow 4)$ & 10 & -133.15091 & -133.88897 & -133.90687 & -134.29678 & $-134 \cdot 32805$ & 242.4 & \\
\hline $\mathrm{TS}\left(5+\dot{\mathrm{C}}_{3}+\mathrm{NH}_{2} \mathrm{CH}_{2}^{+}\right)$ & 11 & -133.19150 & -133.92246 & -133.93879 & $-134 \cdot 30876$ & $-134 \cdot 34370$ & 243.3 & \\
\hline $\mathrm{CH}_{2} \mathrm{CH}_{2}$ & & $-77.60099^{e}$ & $-78.03172^{e}$ & $-78.03884^{e}$ & $-78.28435^{e}$ & $-78.30536^{e}$ & 144.6 & 61 \\
\hline $\mathrm{CH}_{2} \mathrm{CH}_{2}^{+\cdot}$ & & $-77.27146^{e}$ & $-77.71233^{e}$ & $-77.71941^{e}$ & $-77.91717^{e}$ & $-77.94313^{\mathrm{e}}$ & 137.8 & 1075 \\
\hline
\end{tabular}


с $\mathrm{H} 3$

$\mathrm{CH} 2\left({ }^{3} \mathrm{~B}_{1}\right)$

$\mathrm{CH}_{2} \mathrm{CHNH}_{3}{ }^{+}$

$\mathrm{CH}_{3} \mathrm{CHNH}_{2}^{+}$

$\mathrm{CH}_{3} \mathrm{NHCH}_{2}^{+}$

$$
-39.34261^{e}
$$$$
-38.70907^{e}
$$

$-132.68465$

$-132.70564^{e}$

$-132.69019$ $-39.55899^{e}$

$-38.92150^{e}$

$-133.41213$

$-133.44291^{e}$

$-133.42727$
$-39.56446$

$-38.92548^{e}$

$-133.42808$

$-133.45781$

$-133.43958$
$-39.66867$

$-39.00330^{e}$

$-133.82349$

$-133.84769$

$-133.83272$
$-39.68451$

$-39.01721^{e}$

81.4

47.6

$-133.85172$

$-133.87531$

$-133.85971$

234.9

232.0

232.8

a Based on $6-31 \mathrm{G}^{*}$ optimized geometries unless otherwise noted.

b Based on 3-21G optimized geometries.

c From ref 56 .

d

$\Delta \mathrm{H}_{\mathrm{f} 298}^{\circ}$ value corrected to $0 \mathrm{~K}$ using standard formulae from refs 53 and 54 and calculated vibrational frequencies.

e From ref 144 . 
Table 8.2 Calculated ${ }^{a, b}$ and Experimental ${ }^{c}$ Relative Energies (kJ mol ${ }^{-1}$ ) for $\left[\mathrm{C}_{2} \mathrm{H}_{7} \mathrm{~N}^{+}{ }^{-}\right.$Structures and Component Systems $\mathrm{HF} / 3-21 \mathrm{G} \quad \mathrm{HF} / 6-31 \mathrm{G}^{*} \quad \mathrm{HF} / 6-31 \mathrm{G}^{* *} \mathrm{MP} 2 / 6-31 \mathrm{G}^{*} \mathrm{MP} 3 / 6-31 \mathrm{G}^{*} \mathrm{MP} 3 / 6-31 \mathrm{G}^{* *} \mathrm{MP} 3 / 6-31 \mathrm{G}^{* * \mathrm{~d}} \quad$ ExptI

\begin{tabular}{|c|c|c|c|c|c|c|c|c|c|}
\hline$\dot{\mathrm{CH}}_{2} \mathrm{CH}_{2} \stackrel{+}{\mathrm{N}} \mathrm{H}_{3}$ & 1 & -27 & -20 & -24 & -40 & -33 & -38 & -33 & \\
\hline $\mathrm{CH}_{3} \dot{\mathrm{C}} \stackrel{\stackrel{H}{N} \mathrm{H}_{3}}{3}$ & 2 & -15 & -11 & -16 & -33 & -27 & -32 & -28 & \\
\hline $\mathrm{CH}_{3} \mathrm{CH}_{2} \mathrm{NH}_{2}^{+\cdot}$ & 3 & 0 & 0 & 0 & 0 & 0 & 0 & 0 & 0 \\
\hline $\mathrm{CH}_{3} \mathrm{NHCH}_{3}^{+}$ & 4 & -21 & -27 & -22 & -25 & -25 & -21 & -21 & -32 \\
\hline $\mathrm{CH}_{3} \stackrel{+}{\mathrm{N}} \mathrm{H}_{2} \stackrel{\dot{\mathrm{C}}}{\mathrm{H}} 2$ & 5 & 2 & 8 & 8 & -7 & 0 & 0 & 4 & \\
\hline
\end{tabular}

\begin{tabular}{|c|c|c|c|c|c|c|c|c|}
\hline $\operatorname{TS}\left(1 \rightarrow 1^{\prime}\right)$ & 6 & 118 & 114 & 108 & 94 & 100 & 94 & 89 \\
\hline $\operatorname{TS}(2 \rightarrow 1)$ & 7 & 249 & 236 & 224 & 175 & 187 & 174 & 166 \\
\hline $\operatorname{TS}(3 \rightarrow 1)$ & 8 & 194 & 201 & 193 & 144 & 154 & 145 & 137 \\
\hline $\operatorname{TS}(3 \rightarrow 2)$ & 9 & 229 & 213 & 200 & 153 & 165 & 152 & 141 \\
\hline $\operatorname{TS}(5 \rightarrow 4)$ & 10 & 243 & 227 & 220 & 176 & 187 & 181 & 171 \\
\hline $\mathrm{TS}\left(5 \rightarrow \dot{\mathrm{C}} \mathrm{H}_{3}+\mathrm{NH}_{2} \mathrm{CH}_{2}^{+}\right)$ & 11 & 137 & 139 & 136 & 144 & 146 & 144 & 134 \\
\hline
\end{tabular}




\begin{tabular}{|c|c|c|c|c|c|c|c|c|}
\hline $\mathrm{CH}_{2} \mathrm{CH}_{2}+\mathrm{NH}_{3}^{+\cdot}$ & 174 & 185 & 176 & 199 & 197 & 188 & 170 & 174 \\
\hline $\mathrm{CH}_{2} \mathrm{CH}_{2}^{+\cdot}+\mathrm{NH}_{3}$ & 262 & 206 & 199 & 244 & 239 & 231 & 212 & 208 \\
\hline $\mathrm{CH}_{2} \mathrm{NH}_{2}{ }^{+}+\dot{\mathrm{C}} \mathrm{H}_{3}$ & 100 & 87 & 83 & 96 & 101 & 97 & 79 & 75 \\
\hline $\mathrm{CH}_{3} \mathrm{NH}_{2}+\mathrm{CH}_{2}^{+\cdot}$ & 563 & 523 & 521 & 584 & 584 & 582 & 555 & 562 \\
\hline $\mathrm{CH}_{3} \mathrm{NH}_{2}{ }^{+\cdot}+\mathrm{CH}_{2}\left({ }^{3} \mathrm{~B}_{1}\right)$ & 311 & 319 & 317 & 446 & 435 & 432 & 402 & 422 \\
\hline $\mathrm{CH}_{3} \mathrm{NH}_{2}{ }^{+\cdot}+\mathrm{CH}_{2}\left({ }^{1} \mathrm{~A}_{1}\right)$ & 461 & 448 & 446 & 534 & 512 & 510 & 478 & \\
\hline $\mathrm{CH}_{2} \mathrm{CHNH}_{3}^{+}+\mathrm{H}^{-}$ & 165 & 170 & 169 & 110 & 130 & 129 & 112 & \\
\hline $\mathrm{CH}_{3} \mathrm{CHNH}_{2}^{+}+\mathrm{H}^{\bullet}$ & 109 & 90 & 91 & 47 & 68 & 69 & 50 & \\
\hline $\mathrm{CH}_{3} \mathrm{NHCH}_{2}^{+}+\mathrm{H}^{\cdot}$ & 150 & 131 & 139 & 86 & 109 & 117 & 98 & \\
\hline
\end{tabular}

a Based on the total energies in Table 8.1 .

b Appropriate total energies and zero-point vibrational energies taken from $\mathrm{Table}_{3} 1 \mathrm{for}$ the fragments $\mathrm{CH}_{3} \mathrm{NH}_{2}$, $\mathrm{NH}_{3}$, $\mathrm{CH}_{2}\left({ }^{1} \mathrm{~A}_{1}\right)$ and $\mathrm{H}^{\cdot}$, from Table 4.1 for $\mathrm{CH}_{3} \mathrm{NH}_{2}{ }^{+\cdot}$ and $\mathrm{CH}_{2} \mathrm{NH}_{2}^{+}$, and from Table 5.1 for $\mathrm{NH}_{3}^{+\cdot}$.

c Based on the $\Delta \mathrm{H}_{\mathrm{fo}}^{0}$ values in Table 8.1 .

d Estimated using the additivity approximation of equation (1.16).

e MP $3 / 6-31 G^{* *}$ value with zero-point vibrational energy correction. 


\subsection{Discussion}

\subsection{1 $\dot{\mathrm{CH}}_{2} \mathrm{CH}_{2} \stackrel{+}{\mathrm{N}} \stackrel{\mathrm{H}}{3}_{3} \stackrel{(1)}{-}$}

The lowest-energy structure found on the $\left[\mathrm{C}_{2} \mathrm{H}_{7} \mathrm{~N}\right]^{+\cdot}$ surface is the ethyleneammonium radical cation (1). It is calculated to have $\underline{\underline{C}}$ symmetry with a $\mathrm{C}-\mathrm{N}$ bond which is slightly longer than that in $\mathrm{CH}_{3} \mathrm{NH}_{3}^{+}$ $\left(1.507 \AA\right.$ at the level of theory used here). ${ }^{266}$

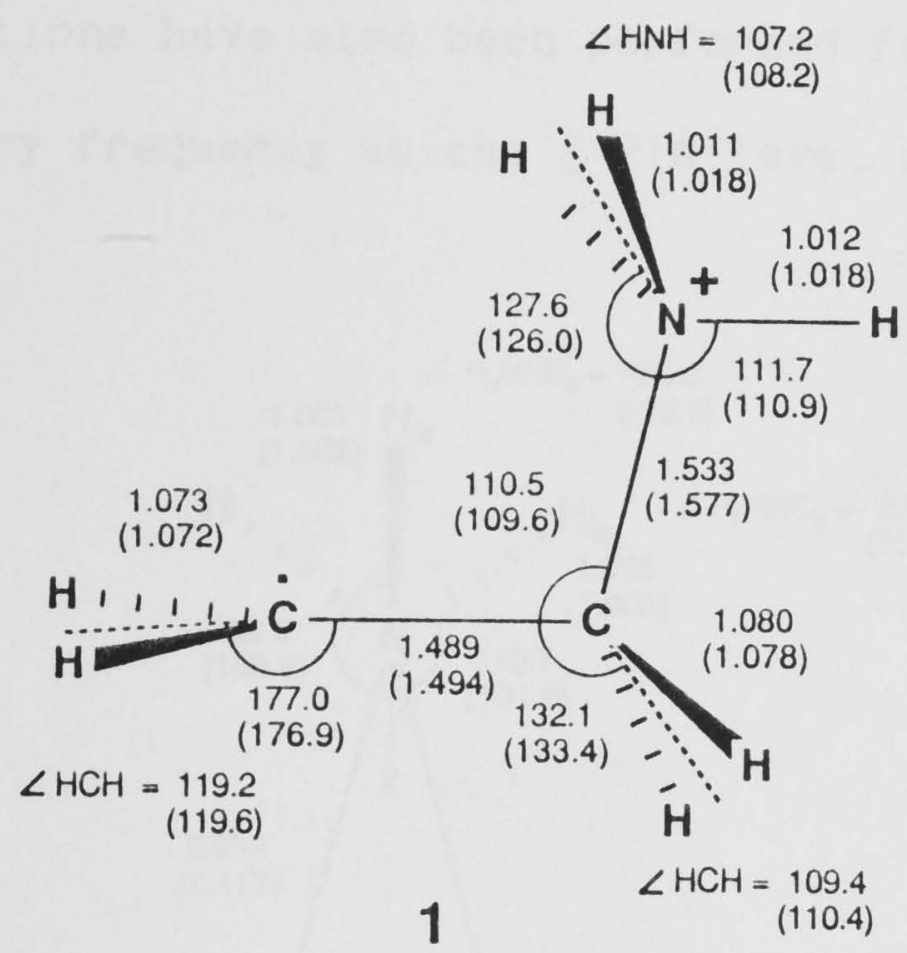

$\dot{\mathrm{C}} \mathrm{H}_{2} \mathrm{CH}_{2} \stackrel{+}{\mathrm{N}} \mathrm{H}_{3}$ (1) is bound with respect to the pairs of fragments $\mathrm{CH}_{2} \mathrm{CH}_{2}+$ $\mathrm{NH}_{3}{ }^{+\cdot}$ and $\mathrm{CH}_{2} \mathrm{CH}_{2}{ }^{+\cdot}+\mathrm{NH}_{3}$ by 203 and $245 \mathrm{~kJ} \mathrm{~mol}^{-1}$, respectively, and fragmentation to the lower-energy pair is calculated to occur without reverse activation energy. It is also calculated that 1 is bound with respect to $\mathrm{CH}_{2} \mathrm{CHNH}_{3}{ }^{+}+\mathrm{H}^{-}$by $145 \mathrm{~kJ} \mathrm{~mol}^{-1}$.

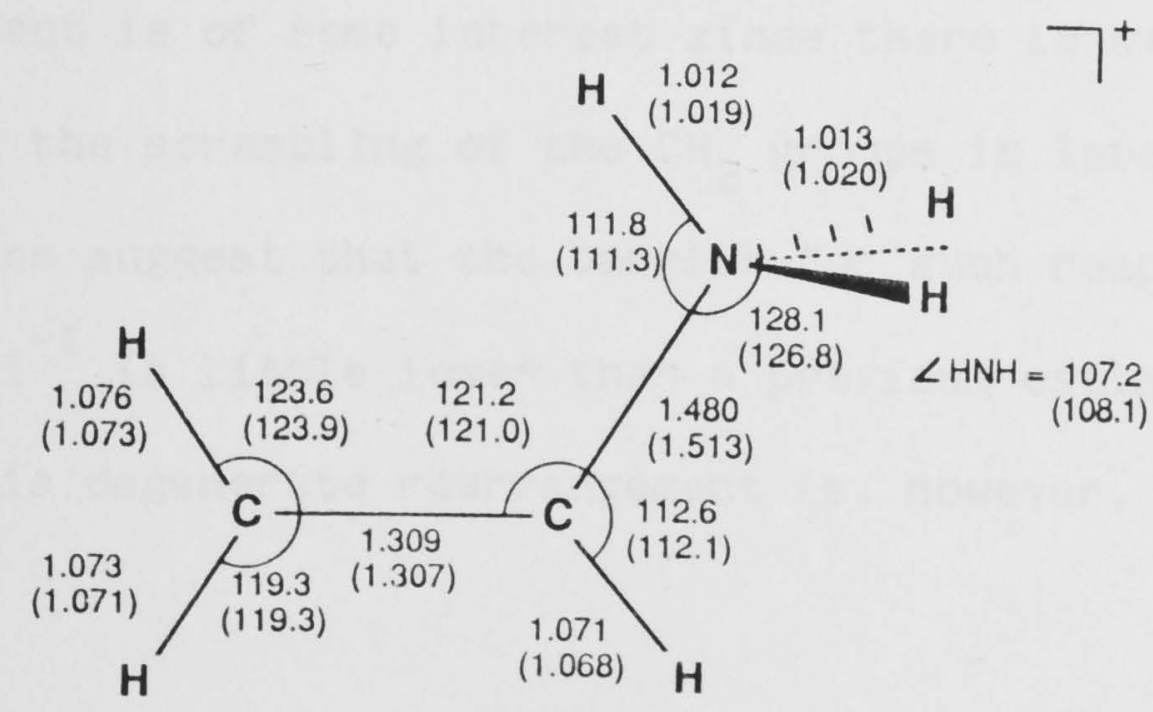


The radical cation 1 was suggested as a possible reaction product some years ago 254 and its structure subsequently characterized by Holmes et al. ${ }^{179}$ in a collisional-activation mass spectrometry labelling study. The ion has since been unambiguously identified after production from a variety of precursors ${ }^{240}$ and, more recently, further characterization of 1 was achieved using neutralizationreionization mass spectrometry. ${ }^{108}$

Calculations have also been performed for structure 6 which, with one imaginary frequency at the $3-21 \mathrm{G}$ level of theory, represents

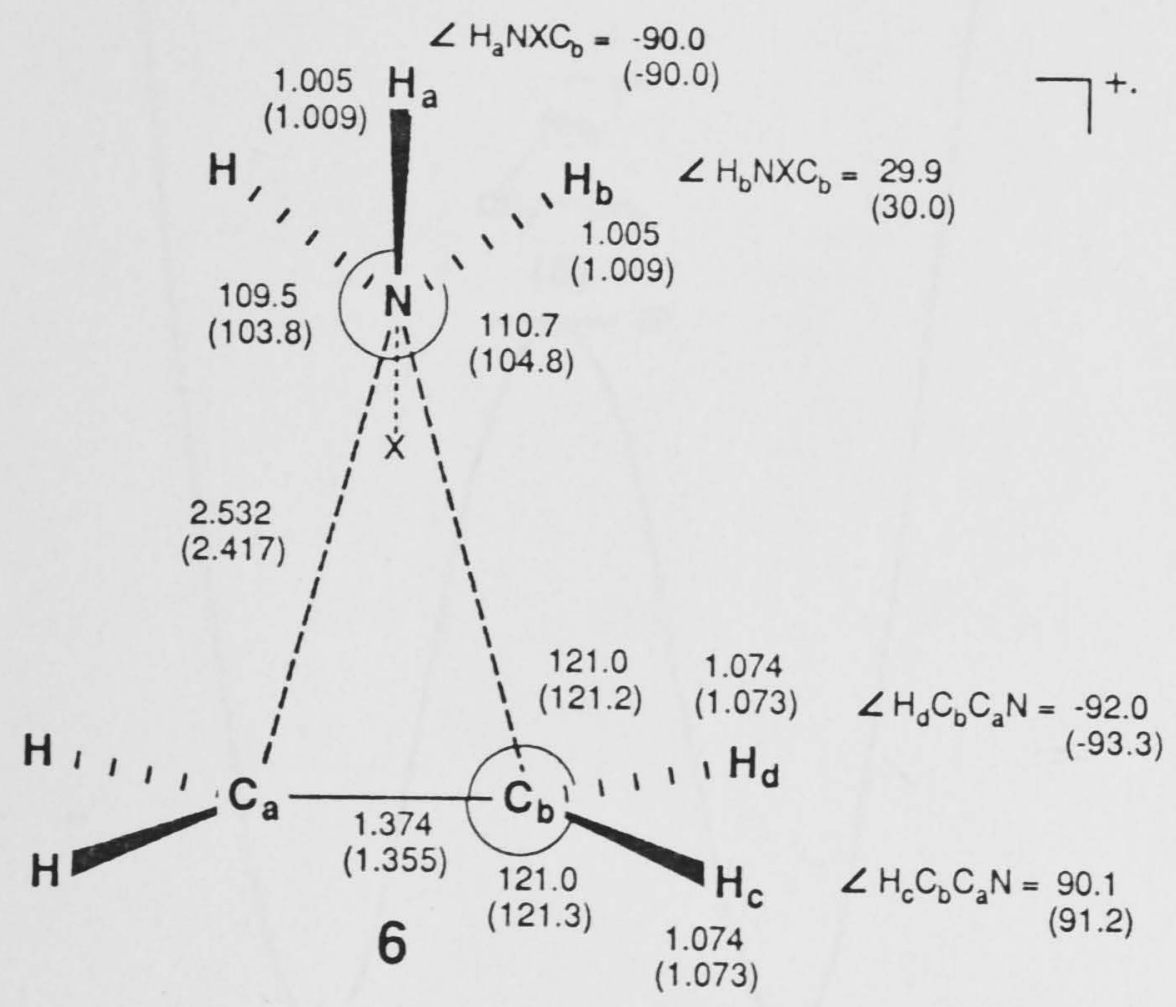

the transition structure for the degenerate $1,2-\mathrm{NH}_{3}$ shift $1 \rightarrow 1$ '. This rearrangement is of some interest since there is experimental evidence 240 for the scrambling of the $\mathrm{CH}_{2}$ groups in labelled 1 . The best calculations suggest that the barrier for such rearrangement (via 6) is $122 \mathrm{~kJ} \mathrm{~mol}^{-1}$ (a little lower than a previous estimate ${ }^{264}$ of 139 $\mathrm{kJ} \mathrm{mol}^{-1}$ ). This degenerate rearrangement is, however, less costly 
188.

than other possible rearrangement or fragmentation processes of 1 (Table 8.2 and Figure 8.2 ) and the present results are therefore consistent with the experimental observations. Despite its long $\mathrm{C}---\mathrm{N}$ bond lengths $(2.532 \mathrm{~A}), 6$ is bound with respect to $\mathrm{CH}_{2} \mathrm{CH}_{2}+$ $\mathrm{NH}_{3}^{+\cdot}$ by $81 \mathrm{~kJ} \mathrm{~mol}^{-1}$.

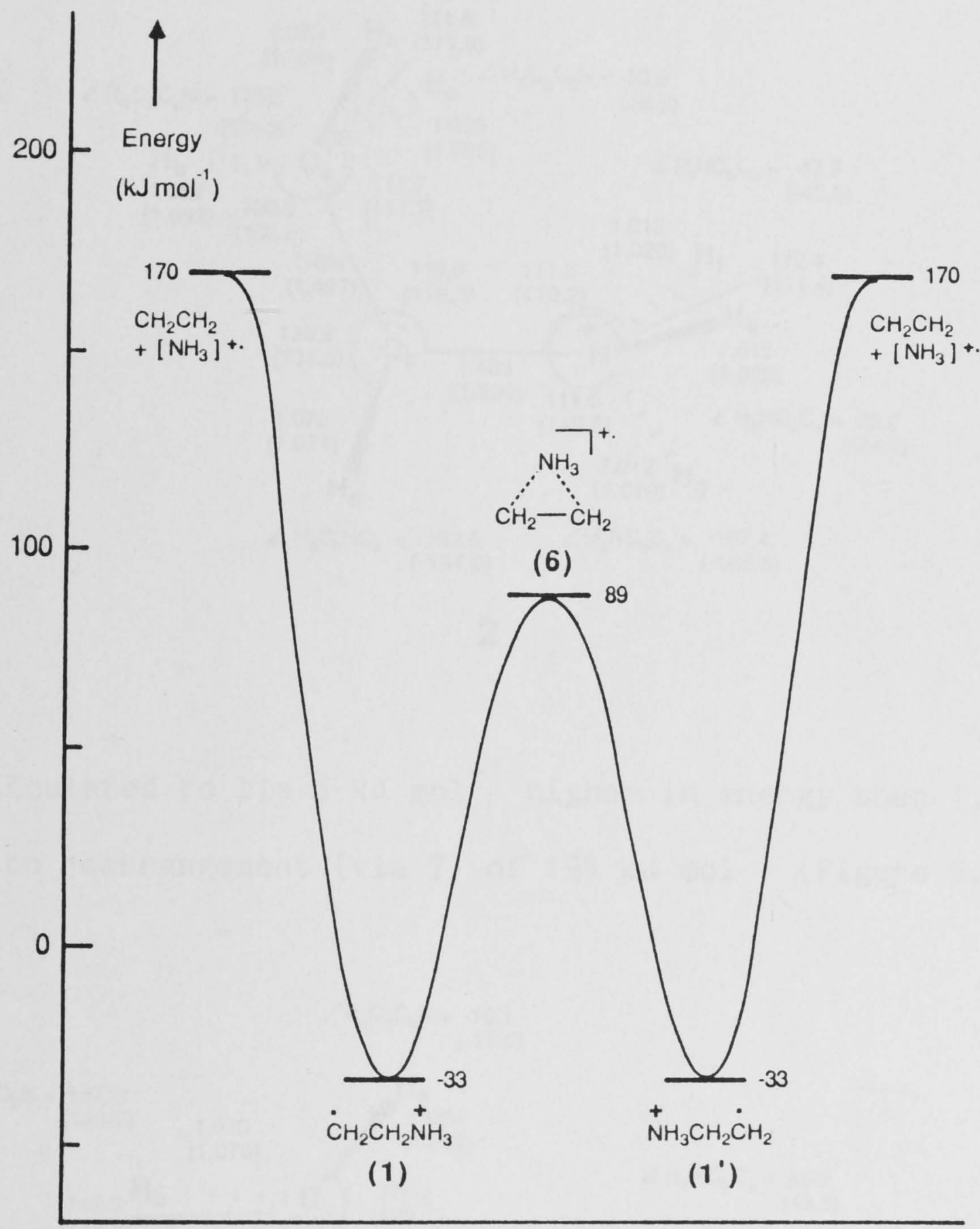

Figure 8.2 Schematic energy profile for the $\alpha$-cleavage and degenerate rearrangement processes in the ethyleneammonium radical cation ( 1 ). 


\section{$8.3 .2 \dot{\mathrm{CH}}_{3} \mathrm{CHNH}_{3}^{+}$(2)}

The next-lowest-energy structure on the $\left[\mathrm{C}_{2} \mathrm{H}_{7} \mathrm{~N}\right]^{+\cdot}$ surface is the distonic radical cation 2 with $\underline{\mathrm{C}}_{1}$ symmetry.

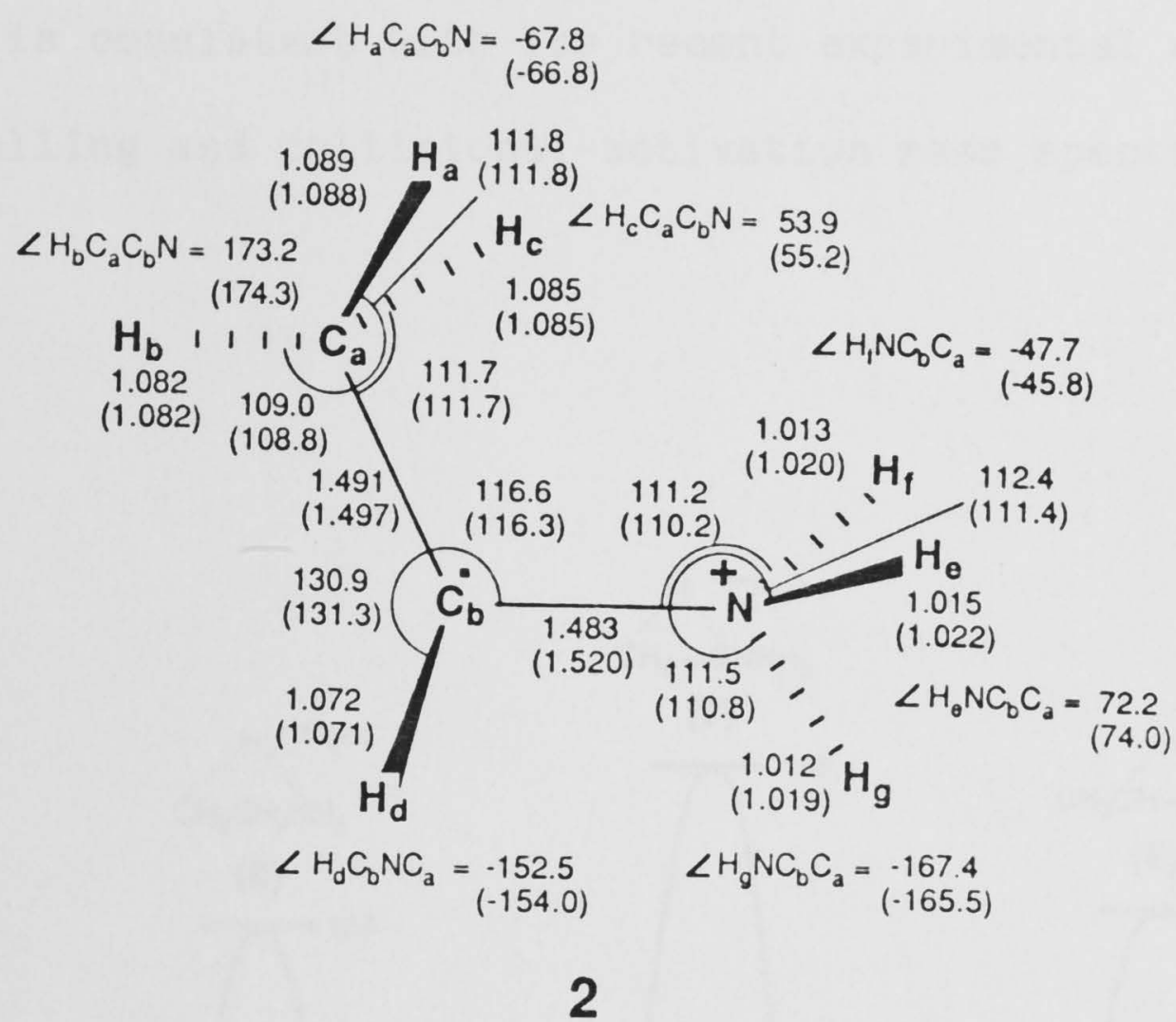

It is calculated to lie $5 \mathrm{~kJ} \mathrm{~mol}^{-1}$. higher in energy than 1 , with a barrier to rearrangement (via 7) of $194 \mathrm{~kJ} \mathrm{~mol}^{-1}$ (Figure 8.3).

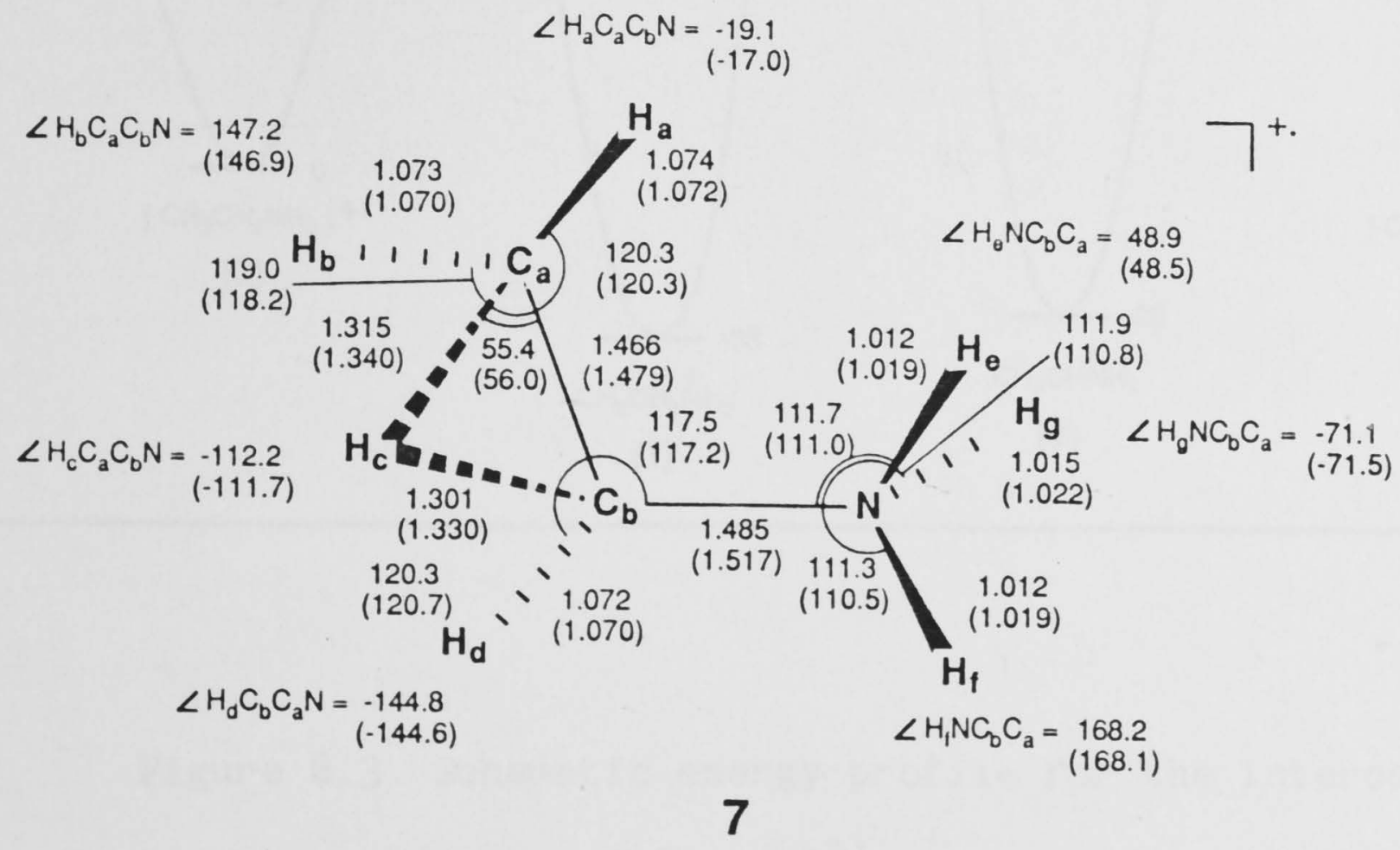


The binding energies of 2 with respect to $\mathrm{H}^{-}+\mathrm{CH}_{2} \mathrm{CHNH}_{3}^{+}$and $\mathrm{CH}_{3} \mathrm{CHNH}_{2}{ }^{+}$

$+\mathrm{H}^{\circ}$ are calculated to be 140 and $78 \mathrm{~kJ} \mathrm{~mol}^{-1}$, respectively. By analogy with the $\left[\mathrm{CH}_{5} \mathrm{~N}\right]^{+\cdot}$ system, ${ }^{145}$ it is expected that the latter fragmentation would have a reverse barrier in the vicinity of $80 \mathrm{~kJ}$ mol $^{-1}$. Thus 2 is predicted to lie in a moderately deep potential well, which is consistent with its recent experimental observation 240 through labelling and collisional-activation mass spectrometric studies.

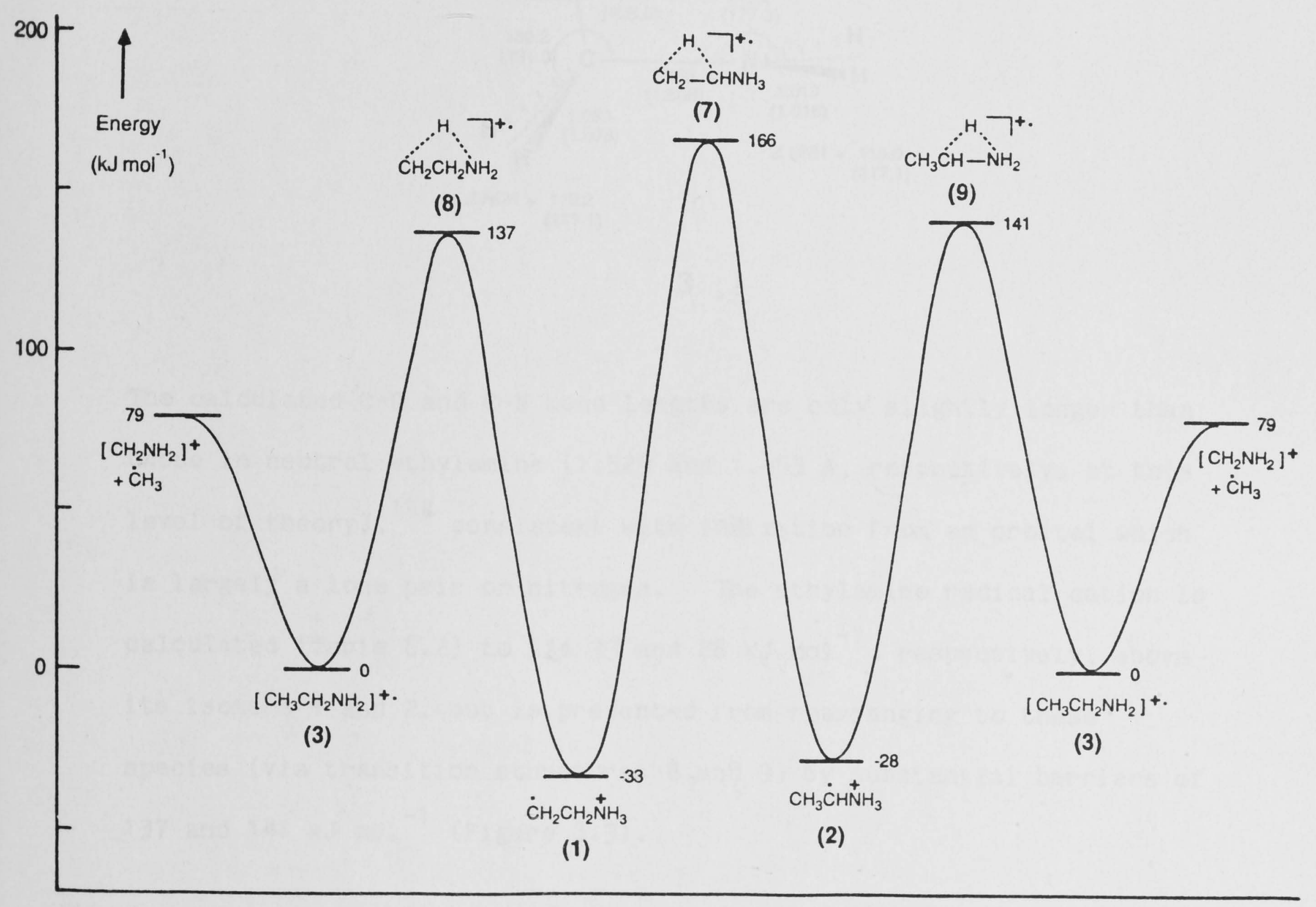

Figure 8.3 Schematic energy profile for the interconversion and fragmentation of $\left[\mathrm{C}_{2} \mathrm{H}_{7} \mathrm{~N}\right]^{+\cdot}$ isomers 1,2 and 3 . 


\subsection{3 $\mathrm{CH}_{3} \mathrm{CH}_{2} \mathrm{NH}_{2} \stackrel{+\cdot(3)}{-}$}

\section{The ethylamine radical cation (3) is found to have $\underline{C}_{\underline{S}}$} symmetry with the bonds at nitrogen nearly coplanar.

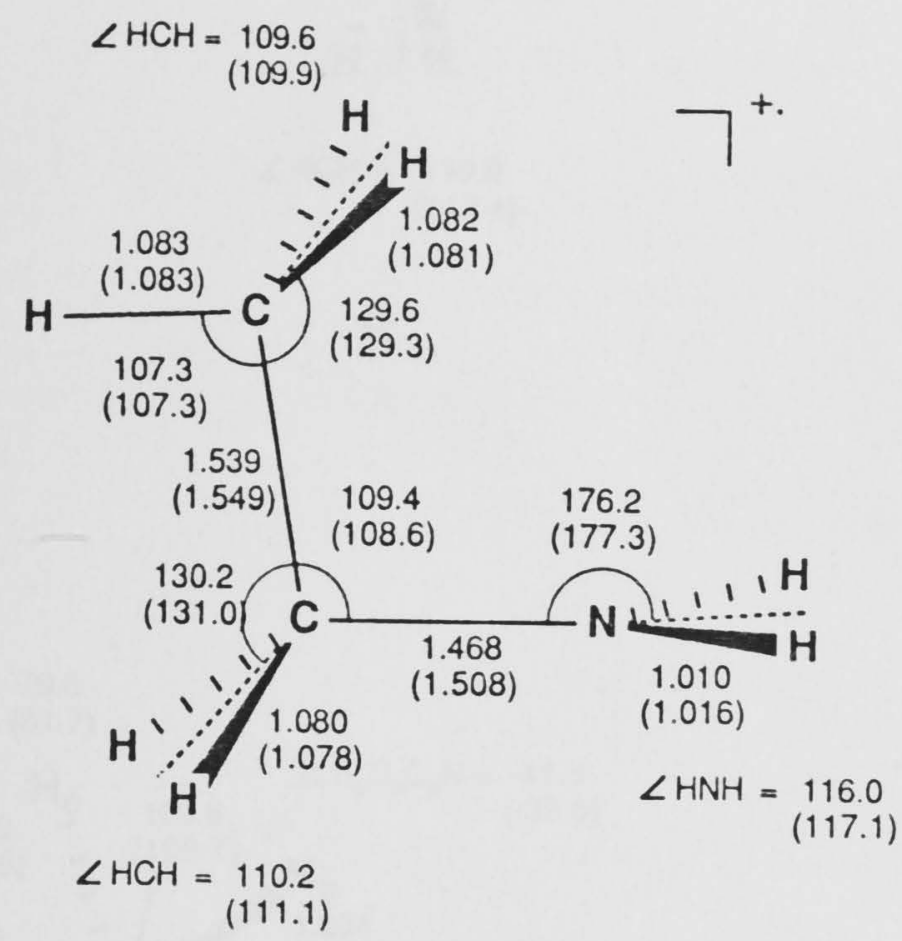

3

The calculated $\mathrm{C}-\mathrm{C}$ and $\mathrm{C}-\mathrm{N}$ bond lengths are only slightly longer than those in neutral ethylamine $(1.529$ and $1.455 \AA$, respectively, at this level of theory), ${ }^{144}$ consistent with ionization from an orbital which is largely a lone pair on nitrogen. The ethylamine radical cation is calculated (Table 8.2) to lie 33 and $28 \mathrm{~kJ} \mathrm{~mol}^{-1}$, respectively, above its isomers 1 and 2, but is prevented from rearranging to these species (via transition structures 8 and 9) by substantial barriers of 137 and $141 \mathrm{~kJ} \mathrm{~mol}^{-1}$ (Figure 8.3). 


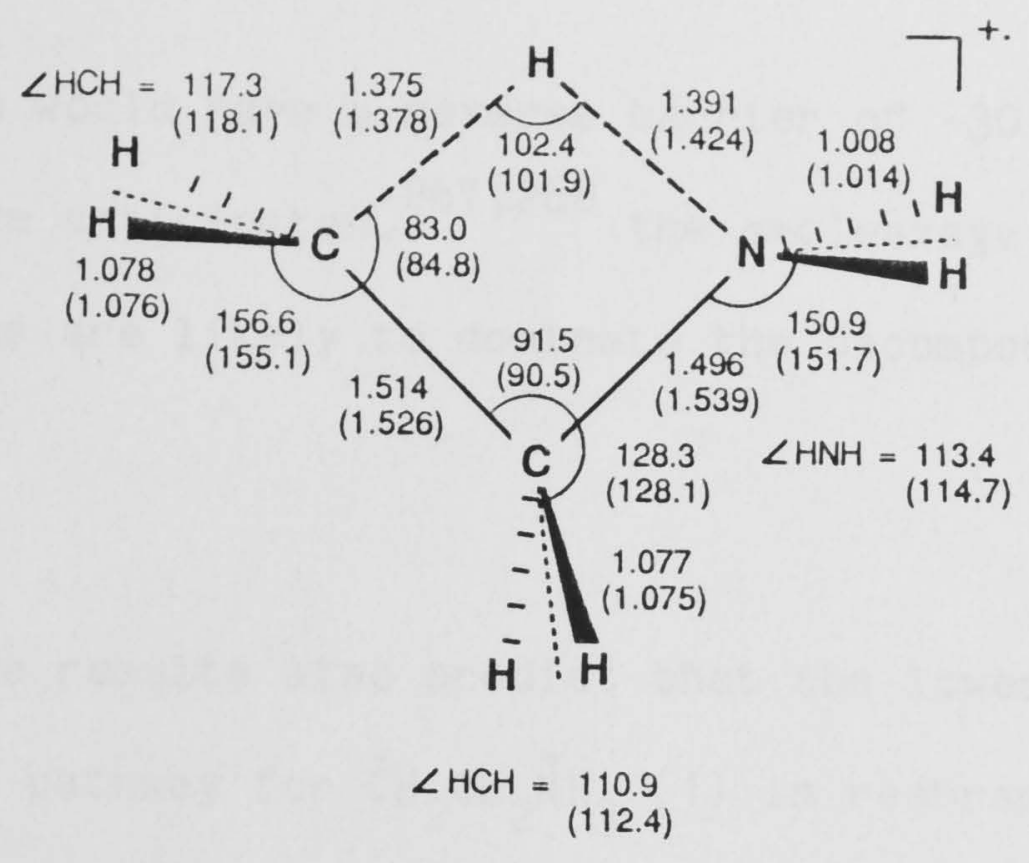

\section{8}

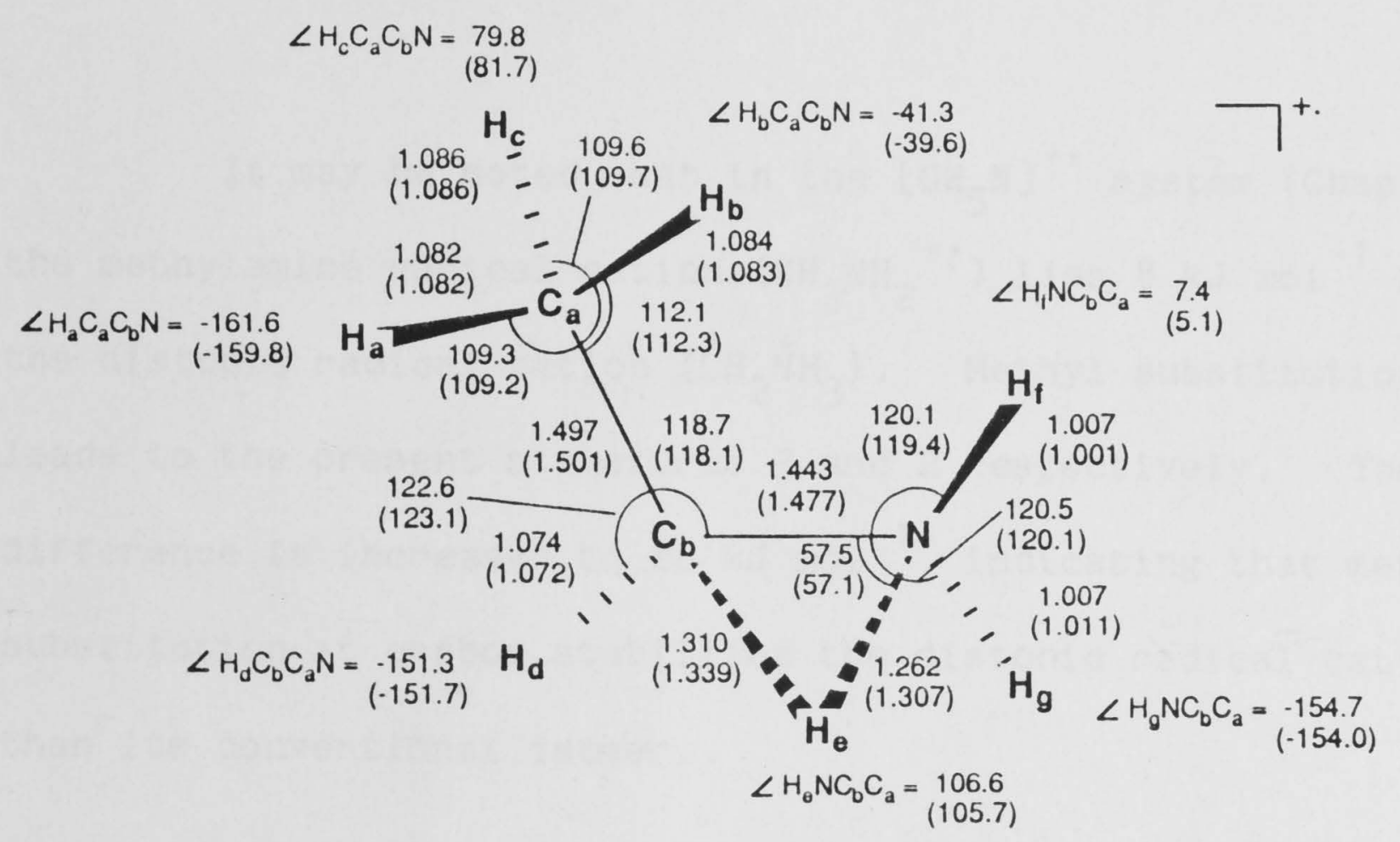

9

However, the calculations show that $\alpha$-cleavage of 3 can occur without a reverse barrier, leading to products $\left(\dot{\mathrm{CH}}_{3}+\mathrm{CH}_{2} \mathrm{NH}_{2}{ }^{+}\right)$which lie higher in energy by only $79 \mathrm{~kJ} \mathrm{~mol}^{-1}$ (in close agreement with the experimentally derived value of $75 \mathrm{~kJ} \mathrm{~mol}^{-1}$ ). Binding of 3 with respect to $\mathrm{CH}_{3} \mathrm{CHNH}_{2}{ }^{+}+\mathrm{H}^{-}$is also not very large $\left(50 \mathrm{~kJ} \mathrm{~mol}^{-1}\right)$. By analogy with the $\left[\mathrm{CH}_{5} \mathrm{~N}\right]^{+\cdot}$ system, ${ }^{145}$ however, it is expected that this 
fragmentation would have a reverse barrier of $-30 \mathrm{~kJ} \mathrm{~mol}^{-1}$. Thus, as one might have anticipated, ${ }^{267,268}$ the $\alpha$-cleavage and hydrogen-atomloss reactions are likely to dominate the decomposition of 3 in the gas phase.

These results also predict that the lowest-energy decomposition pathway for $\dot{\mathrm{C}}_{2} \mathrm{CH}_{2}{ }^{\mathrm{N}} \mathrm{H}_{3}$ (1) is rearrangement to 3 (via 8) followed by fragmentation to give the $\alpha$-cleavage products (Figure 8.3). This is consistent with the experimental observation of $\mathrm{CH}_{2} \mathrm{NH}_{2}^{+}$rather than $\mathrm{NH}_{3}^{+}$as the dominant fragmentation product of 1. 179,240

It may be noted that in the $\left[\mathrm{CH}_{5} \mathrm{~N}\right]^{+}$system (Chapter Four), the methylamine radical cation $\left(\mathrm{CH}_{3} \mathrm{NH}_{2}^{+\cdot}\right)$ lies $8 \mathrm{~kJ} \mathrm{~mol}{ }^{-1}$ higher than the distonic radical cation $\left(\dot{\mathrm{C}}_{2} \stackrel{+}{N}_{3}\right)$. Methyl substitution at carbon leads to the present structures 3 and 2 respectively. The energy difference is increased to $28 \mathrm{~kJ} \mathrm{~mol}^{-1}$, indicating that methyl substitution at carbon stabilizes the distonic radical cation more than its conventional isomer.

\section{$8.3 .4 \mathrm{CH}_{3} \mathrm{NHCH}_{3}^{+\cdot(4)}$}

The well-known dimethylamine radical cation (4) is calculated to have $\underline{C}_{2}$ symmetry with a $\mathrm{C}-\mathrm{N}$ bond length which is only marginally longer than that in neutral dimethylamine $(1.447 \AA) .^{144}$ The radical ion (4) is calculated to lie $21 \mathrm{~kJ} \mathrm{~mol}^{-1}$ lower in energy than 3 , which is in rough agreement with the value derived from the experimental 


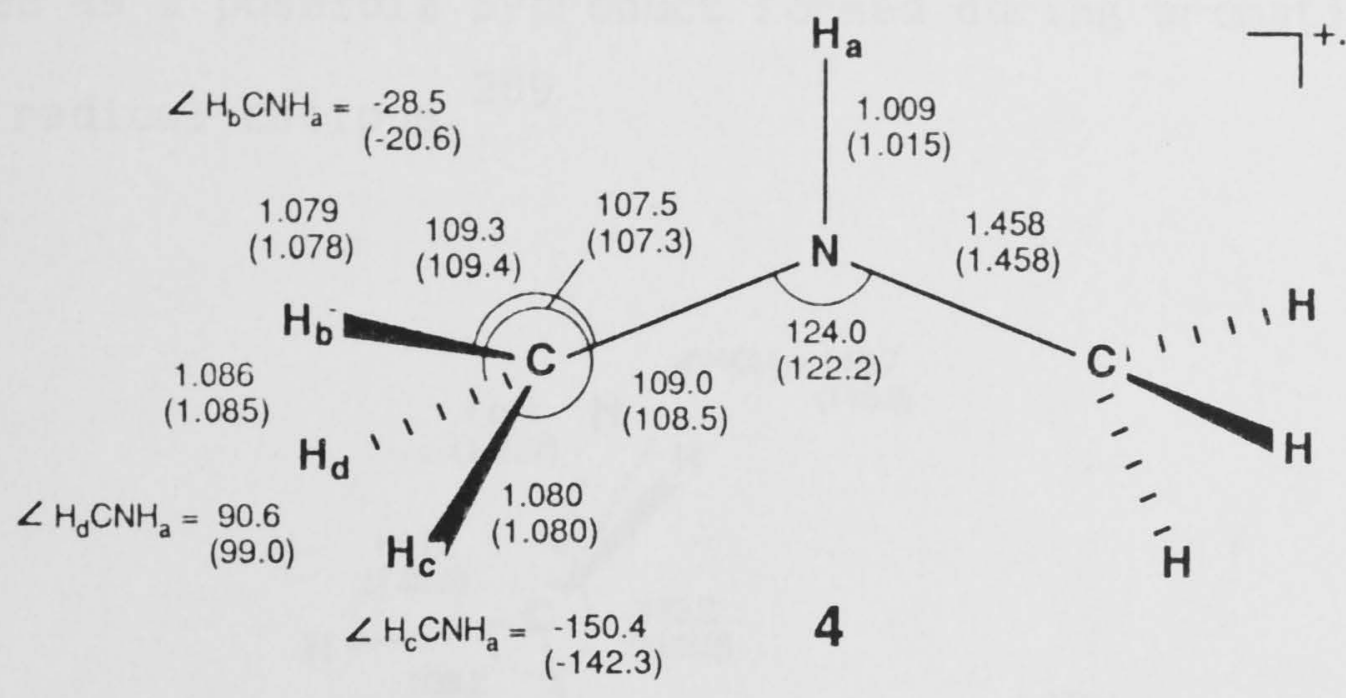

heats of formation (Table 8.2). The calculations also show that it is bound with respect to $\mathrm{CH}_{3} \mathrm{NHCH}_{2}^{+}+\mathrm{H}^{\cdot}$ by $119 \mathrm{~kJ} \mathrm{~mol}^{-1}$.

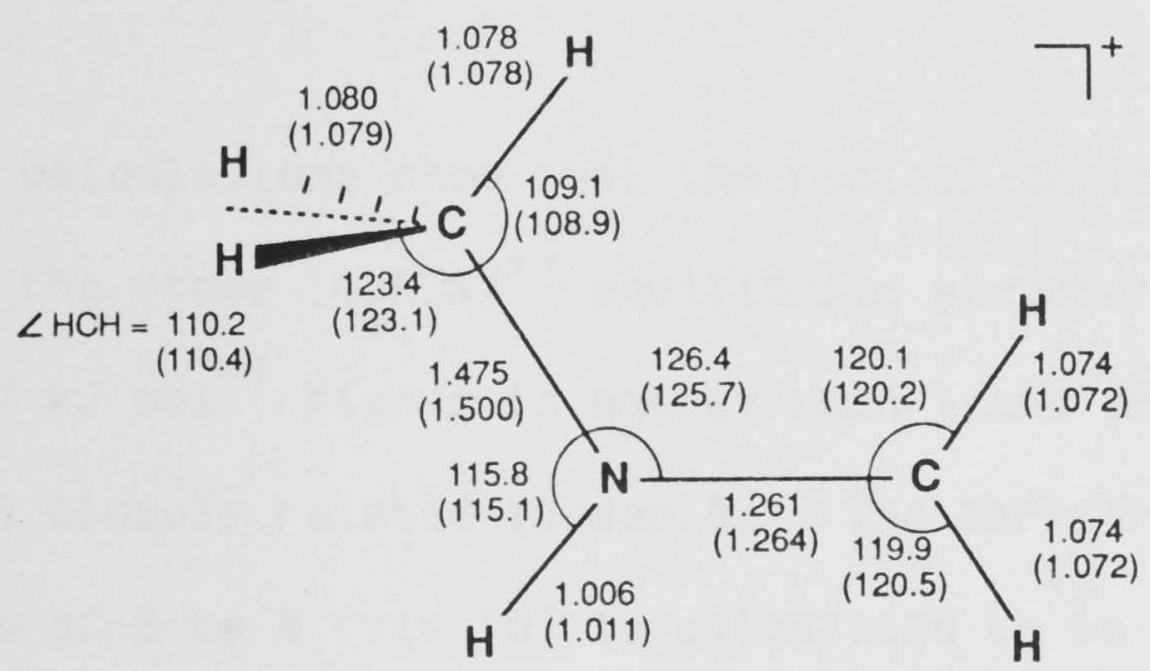

\subsection{5 $\mathrm{CH}_{3} \stackrel{+}{\stackrel{\mathrm{N}}{H}} 2 \stackrel{\mathrm{C}}{\mathrm{C}}_{2}-(5)$}

The distonic isomer (5) of the dimethylamine radical cation (4) is found to have $\underline{C}_{S}$ symmetry with $\mathrm{C}-\mathrm{N}$ bonds comparable to those in $\mathrm{CH}_{3} \mathrm{NH}_{3}^{+}(1.570 \AA)^{266}$ and $\dot{\mathrm{CH}}_{2} \stackrel{+}{\mathrm{N}}_{3}(1.470 \AA) .^{145}$ There do not appear to have been any experimental observations of 5 , al though attempts have been made to produce the radical cation from the ionization of 
195.

secondary alkylamines. 240 Recently, structure 5 has also been

invoked as a possible byproduct formed during aromatic amination by amino radical cations. 269

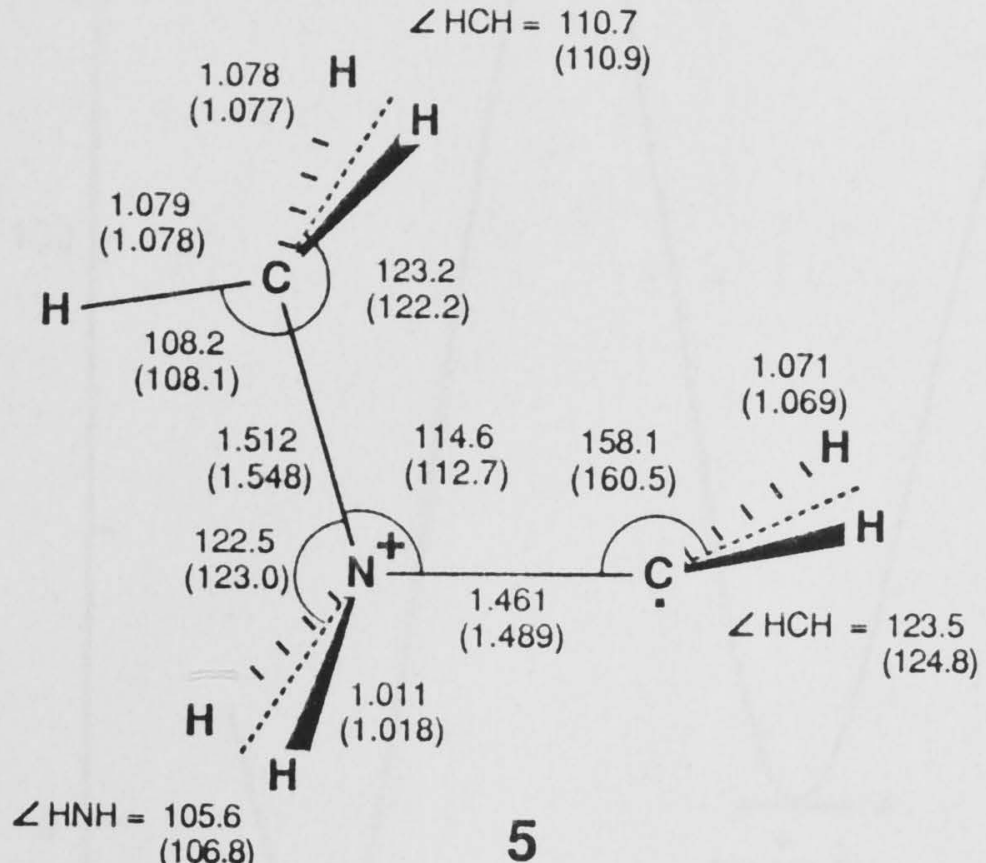

The calculations show that the radical cation 5 is comparable in energy to the other $\left[\mathrm{C}_{2} \mathrm{H}_{7} \mathrm{~N}\right]^{+\cdot}$ equilibrium structures discussed so far, lying $37 \mathrm{~kJ} \mathrm{~mol}^{-1}$ higher in energy than 1 and $25 \mathrm{~kJ} \mathrm{~mol}^{-1}$ higher than its more closely related isomer 4. The barrier for rearrangement of 5 to 4 (via 10) is calculated to be $167 \mathrm{~kJ} \mathrm{~mol}^{-1}$

(Figure 8.4).

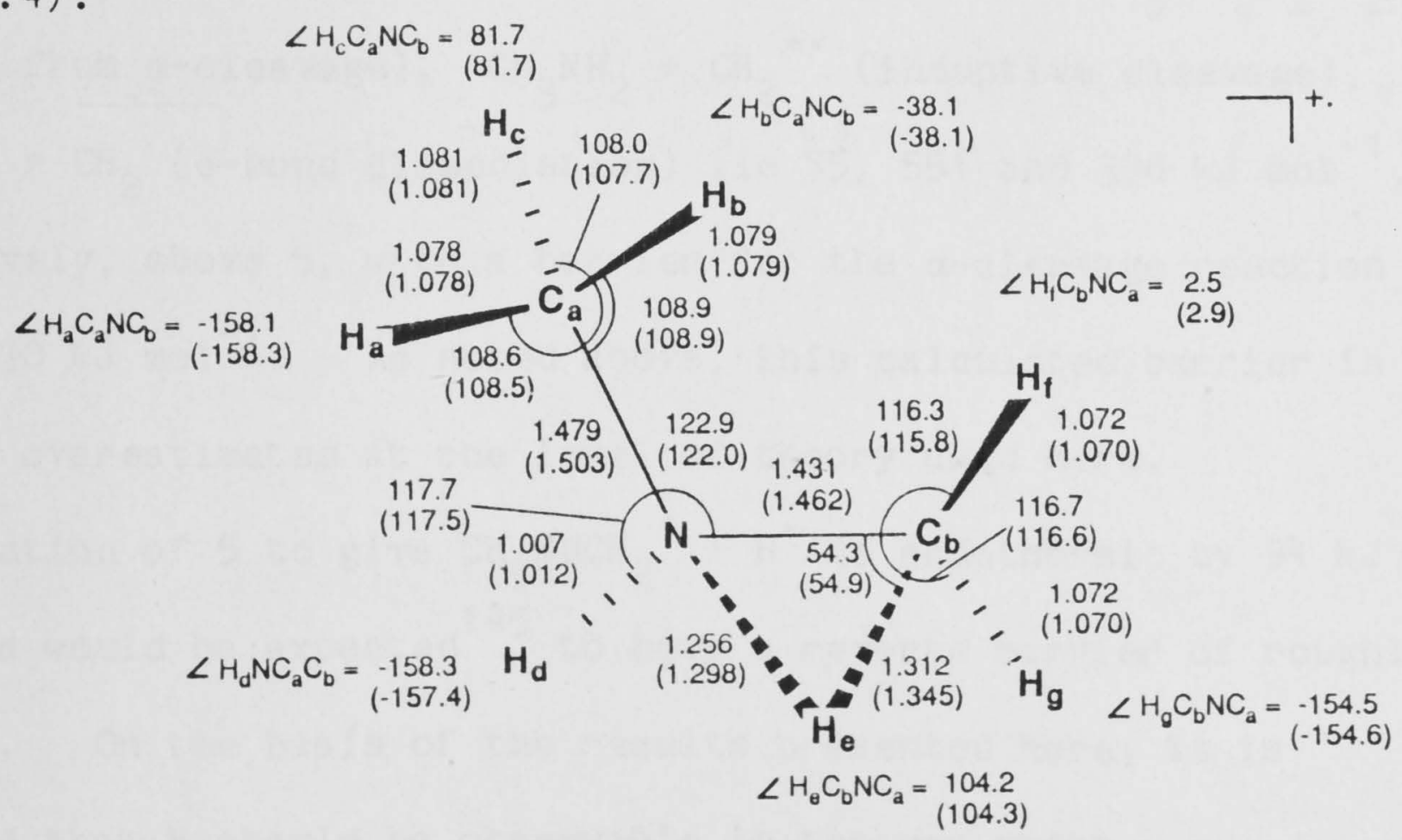




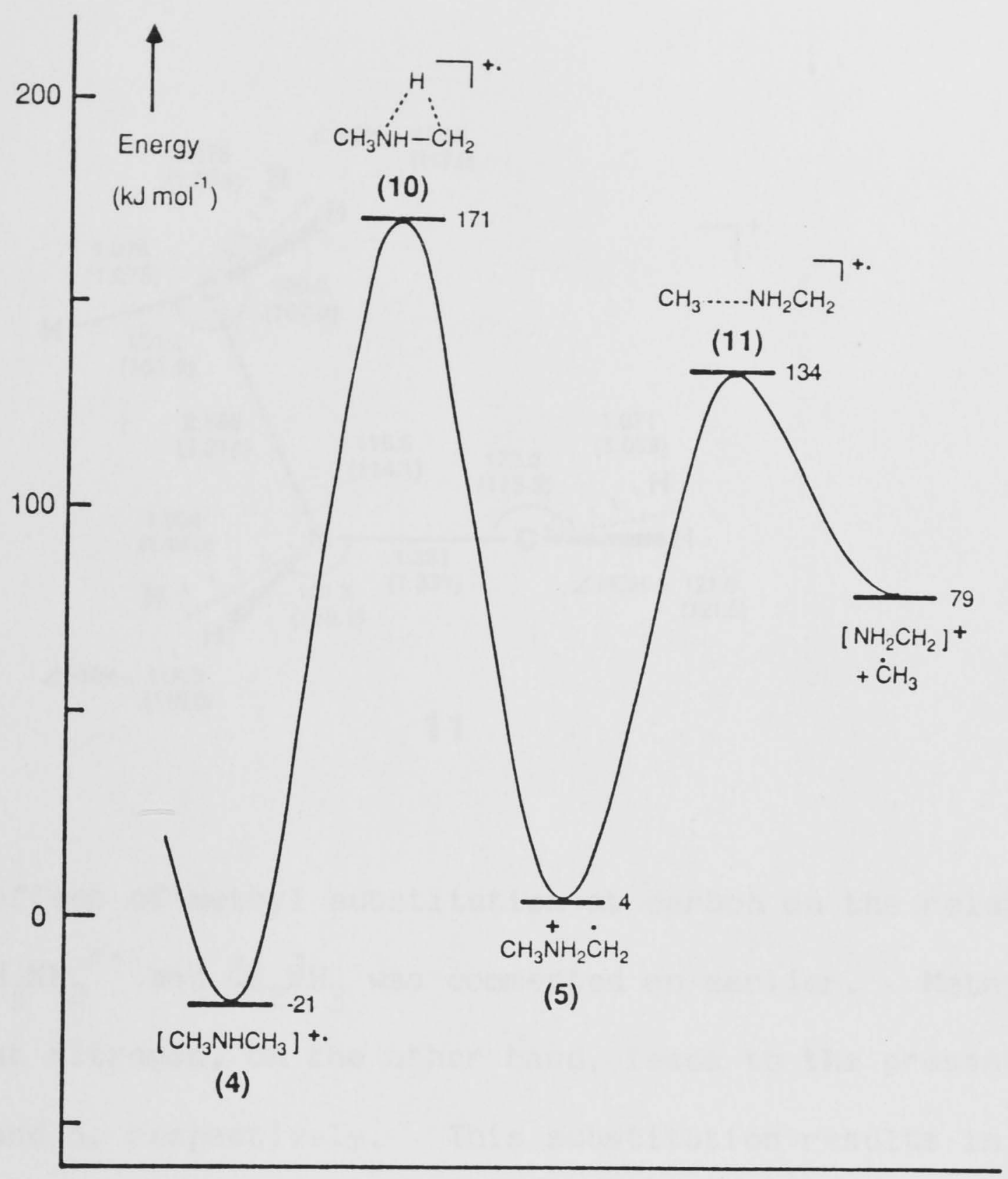

Figure 8.4 Schematic energy profile for the interconversion and fragmentation of $\left[\mathrm{C}_{2} \mathrm{H}_{7} \mathrm{~N}\right]^{+\cdot}$ isomers 4 and 5 .

It is found that the possible fragmentation products $\dot{\mathrm{CH}}_{3}+\mathrm{NH}_{2} \mathrm{CH}_{2}{ }^{+}$ (arising from $\alpha$-cleavage), $\mathrm{CH}_{3} \mathrm{NH}_{2}+\mathrm{CH}_{2}{ }^{+\cdot}$ (inductive cleavage), or $\mathrm{CH}_{3} \mathrm{NH}_{2}^{+\cdot}+\mathrm{CH}_{2}$ ( $\sigma$-bond dissociation) lie 75,551 and $398 \mathrm{~kJ} \mathrm{~mol}^{-1}$, respectively, above 5, with a barrier for the $\alpha$-cleavage reaction (via 11) of $130 \mathrm{~kJ} \mathrm{~mol}^{-1}$. As noted above, this calculated barrier is probably overestimated at the level of theory used here. Fragmentation of 5 to give $\mathrm{CH}_{3} \mathrm{NHCH}_{2}^{+}+\mathrm{H}^{-}$is endothermic by $94 \mathrm{~kJ}$ $\mathrm{mol}^{-1}$ and would be expected ${ }^{145}$ to have a reverse barrier of roughly 80 $\mathrm{kJ} \mathrm{mol}^{-1}$. On the basis of the results presented here, it is predicted that 5 should be observable in the gas phase. 


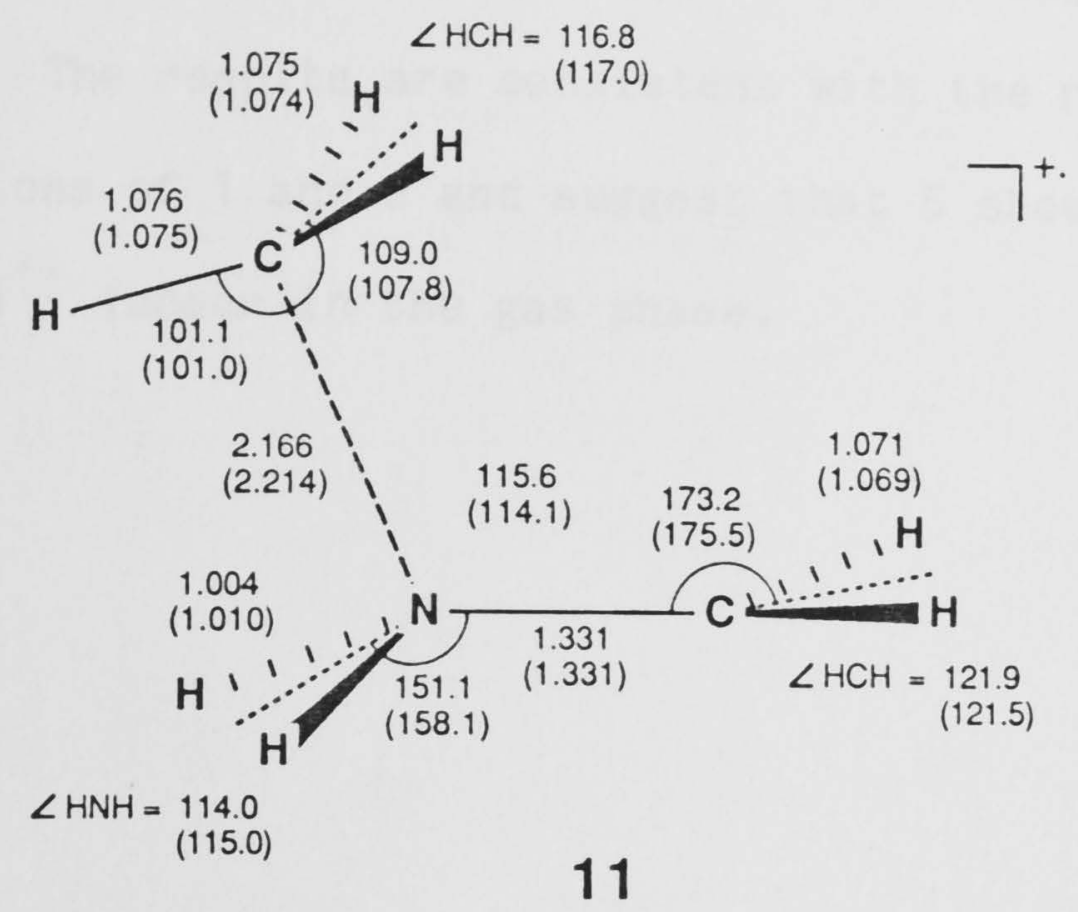

The effect of methyl substitution at carbon on the relative

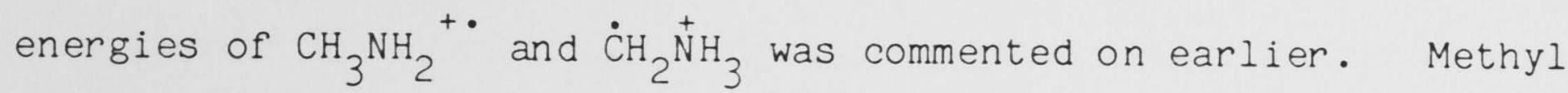
substitution at nitrogen, on the other hand, leads to the present structures 4 and 5 , respectively. This substitution results in a reversal of the energy ordering $\left(\mathrm{CH}_{3} \mathrm{NH}_{2}^{+}\right.$lies $8 \mathrm{~kJ}$ mol ${ }^{-1}$ higher than $\dot{\mathrm{CH}}_{2} \stackrel{+}{\mathrm{N}} \mathrm{H}_{3}$, whereas 4 lies $25 \mathrm{~kJ} \mathrm{~mol}^{-1}$ lower than 5) indicating that methyl substitution at nitrogen stabilizes the conventional isomer more than the distonic radical cation (see also ref 167 ).

\subsection{Conclusions}

The calculations reported in this chapter reveal five lowlying isomers on the $\left[\mathrm{C}_{2} \mathrm{H}_{7} \mathrm{~N}\right]^{+\cdot}$ surface. The lowest-energy structures are the distonic radical cations $\dot{\mathrm{CH}}_{2} \mathrm{CH}_{2} \stackrel{+}{\mathrm{N}} \mathrm{H}_{3}$ (1) and $\mathrm{CH}_{3} \dot{\mathrm{C}} \stackrel{\stackrel{+}{N} H_{3}}{\text { (2) }}$. These lie lower in energy (by 33 and $28 \mathrm{~kJ} \mathrm{~mol}^{-1}$, respectively) than the ethylamine radical cation (3), while $\mathrm{CH}_{3} \stackrel{+}{\mathrm{N}} \mathrm{H}_{2} \dot{\mathrm{C}} \mathrm{H}_{2}$ (5) lies $25 \mathrm{~kJ}$ $\mathrm{mol}^{-1}$ higher than the dimethylamine radical cation (4). The barriers 
198.

for various intramolecular rearrangements connecting 1-5 are all substantial. The results are consistent with the recent experimental characterizations of 1 and 2 and suggest that 5 should also exist as a stable $\left[\mathrm{C}_{2} \mathrm{H}_{7} \mathrm{~N}\right]^{+\cdot}$ isomer in the gas phase. 


\section{CHAPTER NINE}

\subsection{Introduction}

Many of the gas-phase ions with unusual structures discussed in this thesis might formally be derived from their more conventional isomers by simple hydrogen shifts. For example, the methyleneoxonium radical cation $\dot{\mathrm{C}}_{2} \stackrel{+}{\mathrm{O}}_{2}$ (Chapter Four) is conceptually related to the methanol radical cation $\mathrm{CH}_{3} \mathrm{OH}^{+}$by a 1,2 -hydrogen shift:

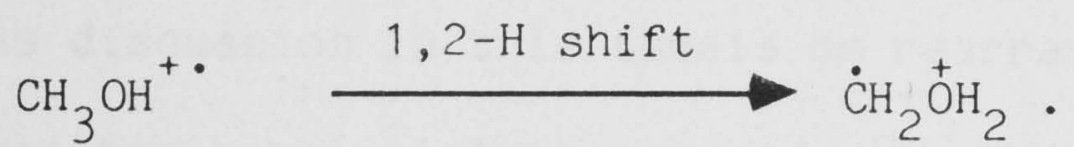

Similarly, the distonic radical cations $\dot{\mathrm{C}} \mathrm{H}_{2} \mathrm{CH}_{2} \stackrel{+}{\mathrm{O}} \mathrm{H}_{2}$ and $\dot{\mathrm{C}}_{2} \mathrm{CH}_{2} \mathrm{CH}_{2} \stackrel{+}{\mathrm{O}} \mathrm{H}_{2}$ are related to their isomers ethanol ${ }^{+\cdot}$ and propanol ${ }^{+}$by $1,3-$ and $1,4-$ hydrogen shifts, respectively. (For relevant theoretical studies, see refs $227,262,264$ and 270.$)$

The hydrogen shifts connecting conventional radical cations and their distonic isomers in some cases have important experimental consequences in mass spectrometric studies ${ }^{271}$ where they may lead to characteristic fragmentation patterns. 272,273 For example, it is well known 272,274 that aliphatic alcohols will readily 1 ose $\mathrm{H}_{2} \mathrm{O}$ in the mass spectrometer. The corresponding rearrangements in the amine radical cations are less important from an analytical point of 
view 267,268 since the high-energy ions are more likely to undergo facile $\alpha$-cleavage reactions (yielding $\mathrm{CH}_{2} \mathrm{NH}_{2}^{+}$) than to lose $\mathrm{NH}_{3}$. In a review of the literature up to the mid-1970s, ${ }^{274}$ only a few reports of $\mathrm{NH}_{3}$ loss from alkylamines were noted. However, in 1978 Lobanov et al. ${ }^{169}$ reported that intramolecular hydrogen migration does occur in the field-ionization mass spectrometry of aliphatic amines. More recently, Hammerum ${ }^{238}$ has shown through labelling studies that lowenergy amine radical cations produced in a similar manner in the mass spectrometer undergo extensive intramolecular hydrogen shifts prior to fragmentation. These observations have since been confirmed in a number of other gas-phase studies ${ }^{275}$ which have investigated in more detail the rearrangement reactions of low-energy amine radical cations.

Previous discussion in this thesis on rearrangement reactions in radical cations has been mainly concerned with the 1,2-hydrogen shifts in ylidions (Chapter Four). In this chapter, these studies are extended to larger systems by examining the rearrangement of primary alkylamine radical cations $\mathrm{CH}_{3}\left(\mathrm{CH}_{2}\right) \underline{\mathrm{NH}}_{2}{ }^{+\cdot}$ to their distonic isomers $\dot{\mathrm{CH}}_{2}\left(\mathrm{CH}_{2}\right){ }_{\underline{n}} \mathrm{NH}_{3}{ }^{+}$for $\underline{\mathrm{n}}=0,1,2$ and 3. The 1,5-hydrogen rearrangement $(\underline{n}=3)$ is analogous to the process which occurs in solution in the well-known Hofmann-Löffler reaction. 238,276-282

\subsection{Method and Results}

Optimized structures were obtained using gradient procedures and the 3-21G basis set. These structures were reoptimized with the $6-31 \mathrm{G}^{*}$ basis set, except for the $\mathrm{C}_{4} \mathrm{H}_{11} \mathrm{~N}^{+}$system where computational expense precluded the larger calculations. The spin-unrestricted 
Hartree-Fock (UHF) formalism was used for all systems and no appreciable spin contamination was encountered. Improved relative energies were obtained through single-point calculations at the MP2/6-31G ${ }^{*}$ level of theory. Vibrational frequencies, calculated at the 3-21G//3-21G level and then scaled by 0.9 , were used to characterize stationary points on the surface and to evaluate thermodynamic properties.

Relative energies at $0 \mathrm{~K}$ for equilibrium structures and transition structures were obtained from

$$
\Delta E_{0}=\Delta E\left(M P 2 / 6-31 G^{*}\right)+\Delta(Z P V E) .
$$

Unless stated otherwise, these are the values given in the text. Temperature corrections to the relative enthalpies $\left(\mathrm{H}_{298}-\mathrm{H}_{0}\right)$ and absolute entropies $\left(\mathrm{S}_{298}\right)$ were calculated using standard formulae, 6,52 leading to values of $\Delta H_{298}$ and $\Delta G_{298}$.

Classical transition state theory $(\mathrm{TST})^{283-285}$ was used to obtain approximate rate constants (k) for the hydrogen shifts from the relation

$$
k=\left(k_{B} T / h\right)\left(Q^{\neq} / Q\right) \exp \left(-\Delta E_{0}{ }^{\neq} / R T\right)
$$

where $k_{B}$ is the Boltzmann constant, $T$ is the temperature, $h$ is the Planck constant, $Q^{\neq}$and $Q$ are partition functions calculated for a transition structure and an equilibrium structure, respectively, $\Delta \mathrm{E}_{0}{ }^{\neq}$ is the barrier height calculated via (9.1), and $R$ is the gas constant. Within this framework, the activation energy that would be measured 
experimentally for a unimolecular reaction is given approximately by

$$
\mathrm{E}_{\mathrm{a}}=\Delta \mathrm{H}_{\mathrm{T}}{ }^{\neq}+\mathrm{RT} \text {. }
$$

Since tunnelling may be important for these hydrogen-shift reactions, a simple tunnelling correction due to Wigner ${ }^{286}$ was also evaluated. This may be written as

$$
k=1+u^{2} / 24 \text {, }
$$

where $u=h \nu_{i}^{*} / k_{B} T$ and $\nu_{i}^{*}$ is the (scaled) imaginary frequency at the saddle point. With the inclusion of the tunnelling correction, equations (9.2) and (9.3) become

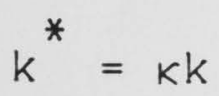

and

$$
E_{a}^{*}=E_{a}-R T \ln k \text {. }
$$

Although more sophisticated methods are available for treating the reaction rates of unimolecular processes, ${ }^{287-292}$ the crude picture presented here is probably adequate for allowing relative comparisons to be made.

Calculated total and relative energies are presented in Tables 9.1 and 9.2, respectively, for the alkylamine radical cations $(1 a-4 a)$, their distonic isomers $(1 b-4 b)$ and the transition structures $(1 \mathbf{c}-4 \mathbf{c})$ for the hydrogen shifts which connect them. Optimized structures $\left(6-31 G^{*}\right.$ with $3-21 G$ values in parentheses) for $3 a-c$ and $4 a-c$ 
are displayed within the course of the discussion. Schematic energy profiles for the hydrogen shifts (based on MP2/6-31G* relative energies) are shown in Figure 9.1. Rate constants and activation energies are presented in Table 9.3.

Experimental heats of formation for the conventional isomers $s^{56}$ and for the methyleneammonium radical cation (1b) ${ }^{179}$ are included in Table 9.1. Values for the heats of formation of $2 b-4 b$ were taken from the work of McLafferty and co-workers ${ }^{108}$ who obtained estimates using an approximate thermochemical scheme. Relative energies based on these values are compared with the present ab initio results in Table 9.2 . 
Table 9.1 Calculated Total Energies ${ }^{\mathrm{a}}$ (hartrees), Zero-Point Vibrational Energies (ZPVE, kJ mol ${ }^{-1}$ ), Thermal Corrections $\left(\mathrm{H}_{298^{-}} \mathrm{H}_{0}, \mathrm{~kJ} \mathrm{~mol}^{-1}\right)$ and Entropies $\left(\mathrm{S}_{298}, \mathrm{~J} \mathrm{~mol}^{-1} \mathrm{~K}^{-1}\right)$, and Experimental Heats of Formation ( $\Delta \mathrm{H}_{\mathrm{f} 298}^{0}$, $\mathrm{kJ} \mathrm{mol}^{-1}$ )

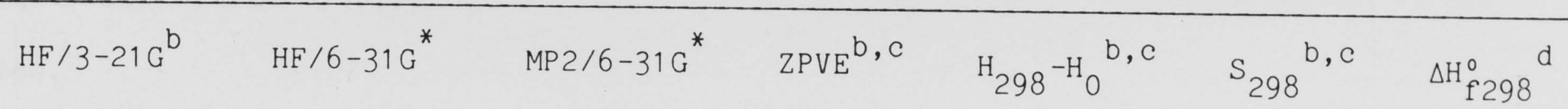

\begin{tabular}{|c|c|c|c|c|c|c|c|c|c|}
\hline $\mathrm{CH}_{3} \mathrm{NH}_{2}^{+\cdot}$ & $1 \mathrm{a}$ & $\underline{C}_{\underline{S}}$ & -94.41602 & -94.93223 & -95.19044 & 155.2 & 13.0 & 263.0 & 843 \\
\hline$\dot{\mathrm{C}} \mathrm{H}_{2} \stackrel{+}{\mathrm{N}} \mathrm{H}_{3}$ & $1 \mathrm{~b}$ & $\underline{C}_{\underline{s}}$ & -94.41730 & -94.93081 & -95.19674 & 158.8 & 12.9 & 255.9 & $958^{e}$ \\
\hline $\operatorname{TS}(1 \mathrm{a} \rightarrow 1 \mathrm{~b})$ & $1 \mathrm{c}$ & $\underline{\mathrm{C}}_{\underline{\mathrm{s}}}$ & $-94 \cdot 32253$ & -94.84401 & -95.12377 & 145.5 & 10.9 & 242.0 & - \\
\hline $\mathrm{CH}_{3} \mathrm{CH}_{2} \mathrm{NH}_{2}^{+\cdot}$ & $2 a$ & $\mathrm{C}_{\underline{s}}$ & -133.24354 & -133.97527 & $-134 \cdot 36365$ & 228.3 & 16.0 & 307.6 & 808 \\
\hline$\dot{\mathrm{C}} \mathrm{H}_{2} \mathrm{CH}_{2} \stackrel{+}{\mathrm{N}} \mathrm{H}_{3}$ & $2 b$ & $\underline{c} \underline{\underline{s}}$ & -133.25393 & -133.98289 & $-134 \cdot 37870$ & 233.3 & 15.5 & 288.3 & $770^{\mathrm{f}}$ \\
\hline $\operatorname{TS}(2 a \rightarrow 2 b)$ & $2 c$ & $\underline{C}_{\underline{s}}$ & -133.16981 & -133.89860 & $-134 \cdot 30877$ & 220.5 & 12.8 & 269.2 & - \\
\hline $\mathrm{CH}_{3} \mathrm{CH}_{2} \mathrm{CH}_{2} \mathrm{NH}_{2}^{+}$ & $3 a$ & $\underline{C}_{\underline{s}}$ & -172.06576 & -173.01284 & -173.53251 & 301.3 & 18.9 & 322.5 & 777 \\
\hline$\dot{\mathrm{C}} \mathrm{H}_{2} \mathrm{CH}_{2} \mathrm{CH}_{2} \stackrel{+}{\mathrm{N}} \mathrm{H}_{3}$ & $3 b$ & $\underline{C}_{1}$ & -172.07901 & -173.02283 & -173.55022 & 306.8 & 18.1 & 314.0 & $745^{f}$ \\
\hline $\operatorname{TS}(3 a \rightarrow 3 b)$ & $3 c$ & $\underline{C}_{1}$ & -172.02452 & -172.96628 & -173.50664 & 295.7 & 15.0 & 292.6 & - \\
\hline $\mathrm{CH}_{3} \mathrm{CH}_{2} \mathrm{CH}_{2} \mathrm{CH}_{2} \mathrm{NH}_{2}^{+}$ & $4 a$ & $\underline{\mathrm{C}}_{\underline{S}}$ & -210.88620 & $-212.04775^{b}$ & $-212.69797^{b}$ & - & - & - & 748 \\
\hline$\dot{\mathrm{CH}}_{2} \mathrm{CH}_{2} \mathrm{CH}_{2} \mathrm{CH}_{2} \stackrel{+}{\mathrm{N}} \mathrm{H}_{3}$ & $4 b$ & $\underline{C}_{1}$ & -210.90141 & $-212.05825^{b}$ & $-212.71972^{b}$ & - & - & - & $720^{f}$ \\
\hline $\mathrm{TS}(4 \mathrm{a} \rightarrow 4 \mathrm{~b})$ & $4 c$ & $\underline{C}_{1}$ & -210.86310 & $-212.01828^{b}$ & $-212.69093^{b}$ & 369.3 & 17.7 & 316.3 & - \\
\hline
\end{tabular}


a Based on $6-31 \mathrm{G}^{*}$ optimized geometries unless otherwise noted.

b Based on 3-21G optimized geometries.

c Using calculated vibrational frequencies scaled by 0.9 .

d From ref 56 unless otherwise noted.

e From ref 179.

f Estimated value from ref 108 . 
Table 9.2 Calculated and Experimental Relative Energies ( $\left.\mathrm{JJ} \mathrm{mol}^{-1}\right)^{a}$

\begin{tabular}{|c|c|c|c|c|c|c|c|c|}
\hline & & $\mathrm{HF} / 3-21 \mathrm{G}$ & $\mathrm{HF} / 6-31 \mathrm{G}^{*}$ & $\mathrm{MP} 2 / 6-31 \mathrm{G}^{*}$ & $\Delta E_{O}^{b}$ & $\Delta \mathrm{H}_{298}{ }^{\mathrm{c}}$ & $\Delta G_{298}^{d}$ & $\operatorname{Exptl}{ }^{e}$ \\
\hline $\mathrm{CH}_{3} \mathrm{NH}_{2}^{+\cdot}$ & $1 \mathrm{a}$ & 0 & 0 & 0 & 0 & 0 & 0 & 0 \\
\hline$\dot{\mathrm{C}} \mathrm{H}_{2} \stackrel{+}{\stackrel{N}{N}} \mathrm{H}_{3}$ & $1 \mathrm{~b}$ & -3 & 4 & -17 & -13 & -13 & -11 & 115 \\
\hline $\mathrm{TS}(1 \mathrm{a} \rightarrow 1 \mathrm{~b})$ & $1 \mathrm{c}$ & 246 & 232 & 175 & 165 & 163 & 170 & - \\
\hline $\mathrm{CH}_{3} \mathrm{CH}_{2} \mathrm{NH}_{2}^{+\cdot}$ & $2 a$ & 0 & 0 & 0 & 0 & 0 & 0 & 0 \\
\hline$\stackrel{\mathrm{C}}{\mathrm{C}} \mathrm{H}_{2} \mathrm{CH}_{2} \stackrel{+}{\mathrm{N}} \mathrm{H}_{3}$ & $2 b$ & -27 & -20 & -40 & -35 & -35 & -29 & $-38^{f}$ \\
\hline $\operatorname{TS}(2 a \rightarrow 2 b)$ & $2 c$ & 194 & 201 & 144 & 136 & 133 & 145 & - \\
\hline $\mathrm{CH}_{3} \mathrm{CH}_{2} \mathrm{CH}_{2} \mathrm{NH}_{2}^{+\cdot}$ & $3 a$ & 0 & 0 & 0 & 0 & 0 & 0 & 0 \\
\hline$\stackrel{\mathrm{C}_{2}}{\mathrm{CH}_{2}} \mathrm{CH}_{2} \stackrel{+}{\mathrm{N}} \mathrm{H}_{3}$ & $3 b$ & -35 & -26 & -47 & -41 & -42 & -39 & $-32^{f}$ \\
\hline $\mathrm{TS}(3 \mathrm{a} \rightarrow 3 \mathrm{~b})$ & $3 c$ & 108 & 122 & 68 & 62 & 58 & 67 & - \\
\hline $\mathrm{CH}_{3} \mathrm{CH}_{2} \mathrm{CH}_{2} \mathrm{CH}_{2} \mathrm{NH}_{2}^{+\cdot}$ & $4 a$ & 0 & 0 & 0 & - & - & - & 0 \\
\hline$\dot{\mathrm{C}} \mathrm{H}_{2} \mathrm{CH}_{2} \mathrm{CH}_{2} \mathrm{CH}_{2} \stackrel{+}{\mathrm{N}} \mathrm{H}_{3}$ & $4 b$ & -40 & -28 & -57 & - & - & - & $-28^{f}$ \\
\hline
\end{tabular}


a Based on the total energies in Table 9.1 .

b From equation (9.1).

c $\Delta E_{0}$ plus the difference in $\mathrm{H}_{298}-\mathrm{H}_{0}$ values.

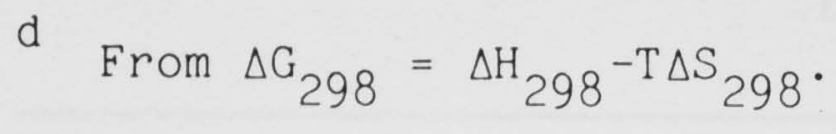

e Based on the $\Delta \mathrm{H}_{\mathrm{f} 298}^{0}$ values in Table 9.1 .

f Includes estimated heat of formation from Table 9.1 . 
Table 9.3 Barriers and Rates for Hydrogen Shifts in Ionized Alkylamines

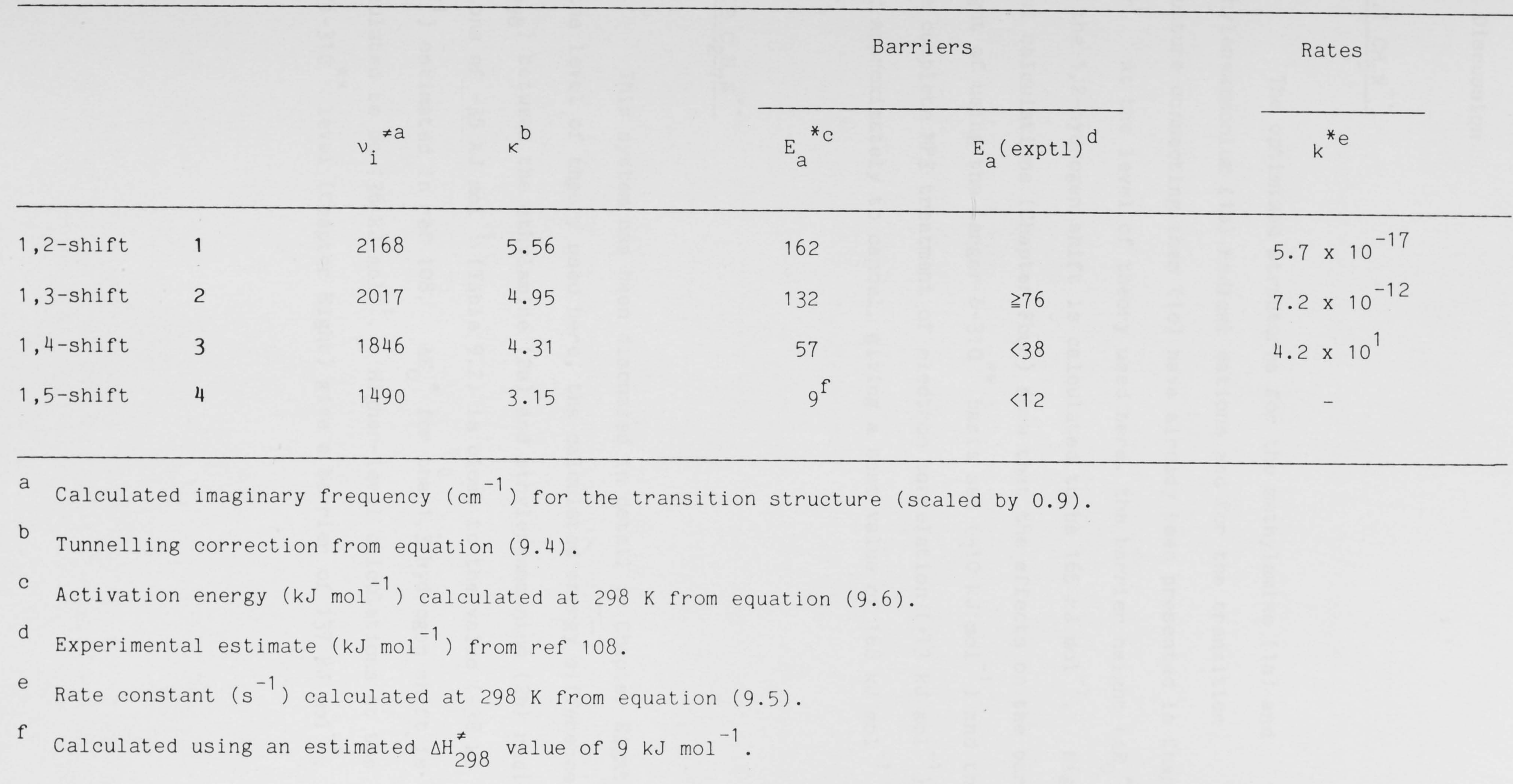




\subsection{Discussion}

\section{$9.3 .1 \mathrm{CH}_{5} \mathrm{~N}^{+\cdot}$}

The optimized structures for the methylamine (1a) and methyleneammonium (1b) radical cations and for the transition structure connecting them (1c) have already been presented in Chapter Four. At the level of theory used here, the barrier height $\left(\Delta \mathrm{E}_{0}{ }^{\neq}\right)$ for the 1,2-hydrogen shift is calculated to be $165 \mathrm{~kJ} \mathrm{~mol}^{-1}$. Higherlevel calculations (Chapter Four) show that the effects on the barrier height of using the larger $6-31 \mathrm{G}^{* *}$ basis set $\left(-10 \mathrm{~kJ} \mathrm{~mol}{ }^{-1}\right)$ and the more complete MP3 treatment of electron correlation ( $+13 \mathrm{~kJ} \mathrm{~mol}^{-1}$ ) tend approximately to cancel, giving a best value of $168 \mathrm{~kJ} \mathrm{~mol}^{-1}$ for $\Delta \mathrm{E}_{0}{ }^{\neq}$.

$\underline{9.3 .2 \mathrm{C}} 2 \mathrm{H}_{7} \mathrm{~N}^{+\cdot}$

This system has been discussed in detail in Chapter Eight. At the level of theory used here, the calculated energy difference $\left(\Delta \mathrm{H}_{298}\right)$ between the ethylamine (2a) and ethyleneammonium (2b) radical cations of $-35 \mathrm{~kJ} \mathrm{~mol}^{-1}$ (Table 9.2) is close to the value $(-38 \mathrm{~kJ}$ $\mathrm{mol}^{-1}$ ) estimated in ref 108. $\Delta \mathrm{E}_{0}{ }^{\neq}$for the 1,3-hydrogen shift is calculated to be $136 \mathrm{~kJ} \mathrm{~mol}^{-1}$. Higher-level calculations at the MP3/6-31G ${ }^{* *}$ level (Chapter Eight) give a barrier of $137 \mathrm{~kJ} \mathrm{~mol}^{-1}$. 


\section{$\underline{9.3 \cdot 3 \mathrm{C}_{3}} 3 \mathrm{H}_{9} \mathrm{~N}^{+\cdot}$}

The optimized structures for the $\mathrm{C}_{3} \mathrm{H}_{9} \mathrm{~N}^{+\cdot}$ system (3a-c) are shown on the next page. Evidence for the existence of the trimethyleneammonium radical cation (3b) has come recently from two separate mass-spectrometric experiments. ${ }^{108,182}$ The calculations show that $3 \mathrm{~b}$ lies $42 \mathrm{~kJ} \mathrm{~mol}^{-1}$ below the propylamine radical cation (3a) $\left(\Delta_{298}\right.$, Table 9.2), which is again close to the estimate (32 kJ $\mathrm{mol}^{-1}$ ) from ref 108 . It should be noted that only the results for the lowest-energy conformations that have been found for the two isomers are reported here. For the level of theory used, these correspond to an all-trans arrangement of the heavy atoms for $3 a$ and a gauche arrangement for $3 \mathrm{~b}$. The alternative gauche and all-trans conformations lie $3 \mathrm{~kJ} \mathrm{~mol}^{-1}$ and $9 \mathrm{~kJ} \mathrm{~mol}^{-1}$ higher in energy than $3 \mathrm{a}$ and $3 \mathrm{~b}$, respectively. $\Delta \mathrm{E}_{0}^{\neq}$for the 1,4-hydrogen shift connecting $3 \mathrm{a}$ with $3 \mathrm{~b}$ is calculated to be $62 \mathrm{~kJ} \mathrm{~mol}^{-1}$. a It is expected that this value is unlikely to change significantly with higher-level calculations, based on the observations for the $\mathrm{CH}_{5} \mathrm{~N}^{+\cdot}$ and $\mathrm{C}_{2} \mathrm{H}_{7} \mathrm{~N}^{+\cdot}$ systems.

a. On the basis of a calculated charge distribution in propylamine radical cation, Yamamoto et al. (ref 293) have suggested that the 1,4-hydrogen shift process might be unfavourable, but no value for the barrier was given. 

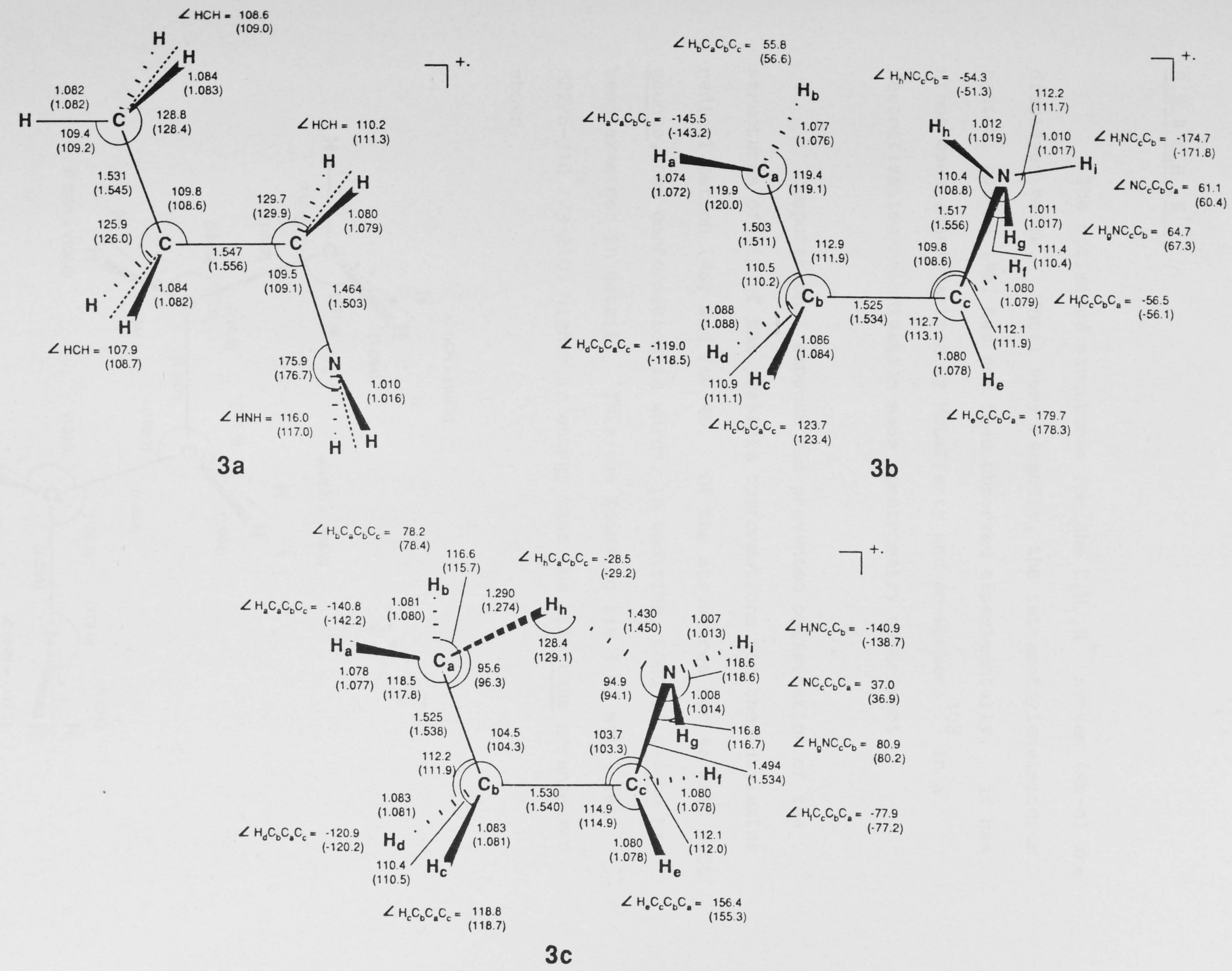
$\underline{9.3 .4 \mathrm{C}_{4}} \mathrm{H}_{-11} \mathrm{~N}^{+\cdot}$

The optimized structures for the $\mathrm{C}_{4} \mathrm{H}_{11} \mathrm{~N}^{+\cdot}$ system $(4 \mathrm{a}-\mathrm{c}$ ) are displayed below. Until very recently, the tetramethyleneammonium radical cation ( $4 b$ ) had not been observed experimentally. It has since been characterized by McLafferty and co-workers ${ }^{108}$ in a neutralization-reionization mass spectrometry experiment.

\section{Computational expense has prevented optimization of the} structures of all of the possible conformations for the butylamine radical cation ( $4 a$ ) and for $4 b$. Of the structures for $4 a$ with NCCC gauche, the conformation in which, in addition, CCCC is gauche has been examined in detail. This was found to lie $4 \mathrm{~kJ} \mathrm{~mol}^{-1}$ (at MP2 $/ 6-31 G^{*} / / 3-21 G$ ) higher in energy than the all-trans arrangement shown.

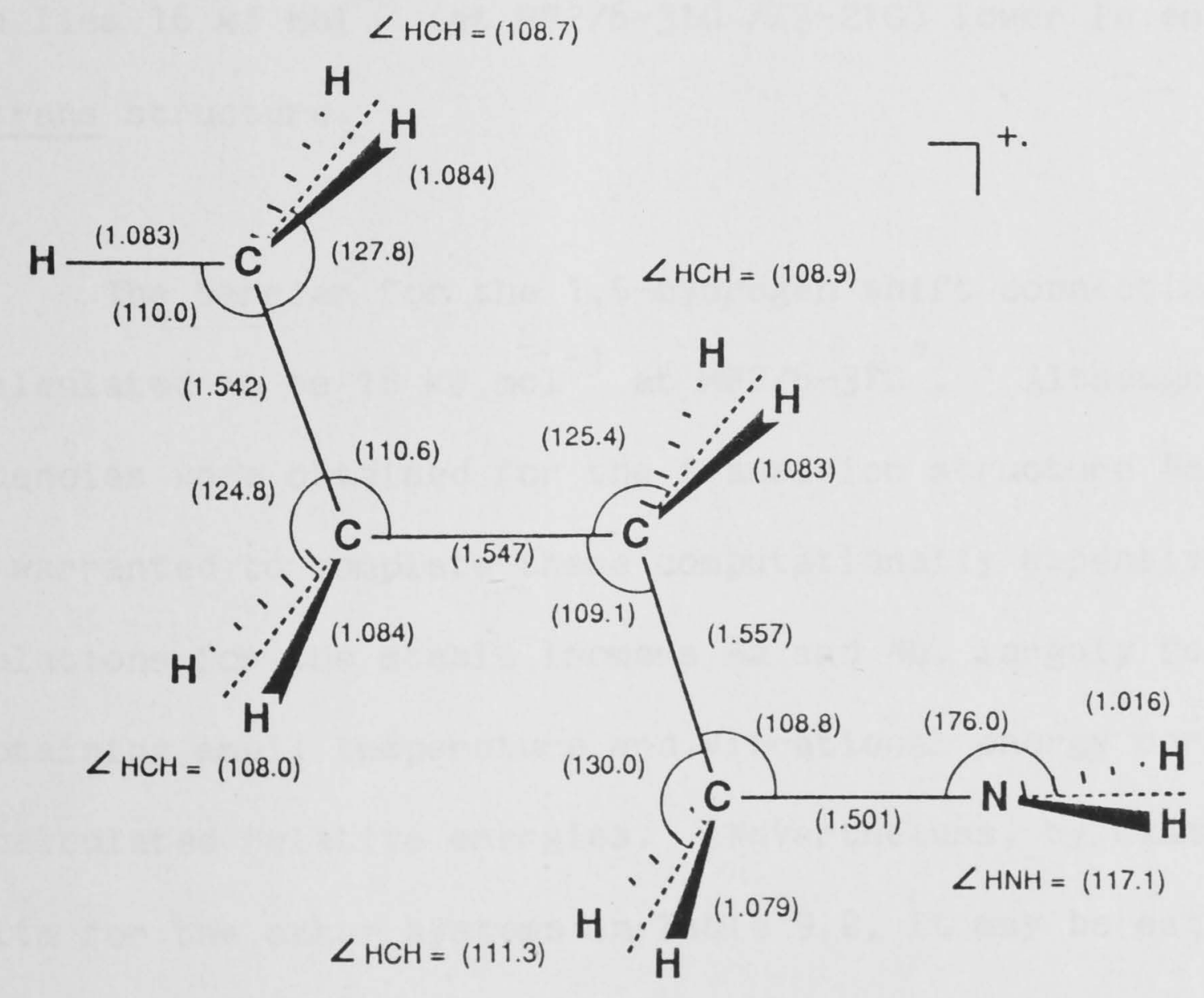


213.

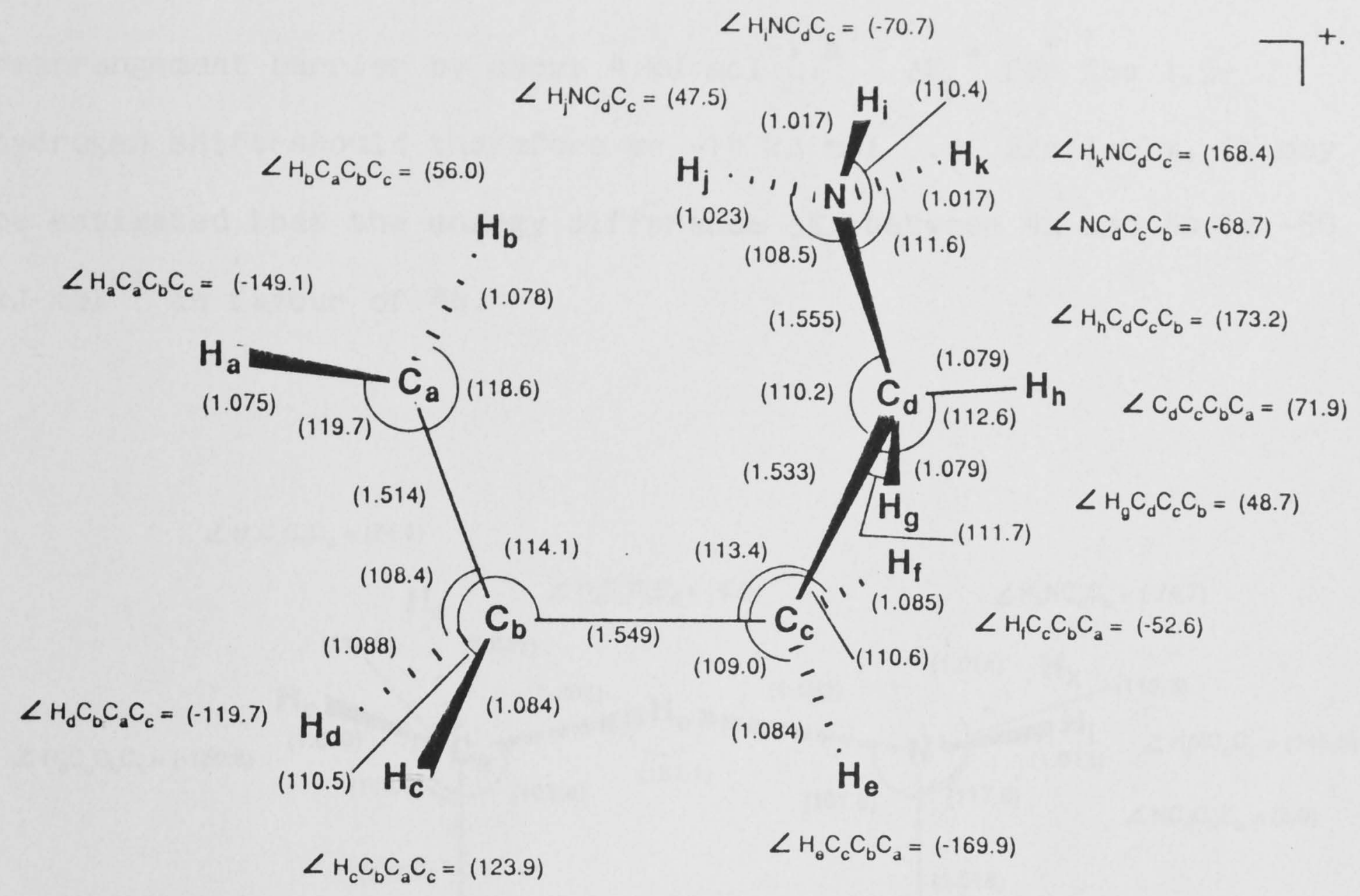

$4 b$

For the distonic isomer (4b), three different gauche conformations were optimized in addition to the all-trans structure. The lowestenergy conformation found for $4 \mathrm{~b}$ is the gauche arrangement shown, which lies $16 \mathrm{~kJ} \mathrm{~mol}^{-1}$ (at $\mathrm{MP} 2 / 6-31 \mathrm{G}^{*} / / 3-21 \mathrm{G}$ ) lower in energy than the all-trans structure.

The barrier for the 1,5-hydrogen shift connecting $4 a$ with $4 b$ is calculated to be $18 \mathrm{~kJ} \mathrm{~mol}^{-1}$ at $\mathrm{MP} 2 / 6-31 \mathrm{G}^{*}$. Although vibrational frequencies were obtained for the transition structure $4 \mathrm{c}$, it did not seem warranted to complete these computationally expensive calculations for the stable isomers $4 \mathrm{a}$ and $4 \mathrm{~b}$, largely for the purpose of obtaining small temperature and vibrational energy corrections to the calculated relative energies. Nevertheless, by examining the results for the other systems in Table 9.2, it may be estimated that the inclusion of zero-point vibrational contributions would lower the 
rearrangement barrier by about $4 \mathrm{~kJ} \mathrm{~mol}^{-1} \cdot \mathrm{b} \quad \Delta \mathrm{E}_{0}{ }^{\neq}$for the $1,5-$ hydrogen shift should therefore be $-14 \mathrm{~kJ} \mathrm{~mol}^{-1}$. Similarly, it may be estimated that the energy difference $\Delta \mathrm{E}_{0}$ between $4 \mathrm{a}$ and $4 \mathrm{~b}$ is -50 $\mathrm{kJ} \mathrm{mol}{ }^{-1}$ in favour of $4 \mathrm{~b}$.

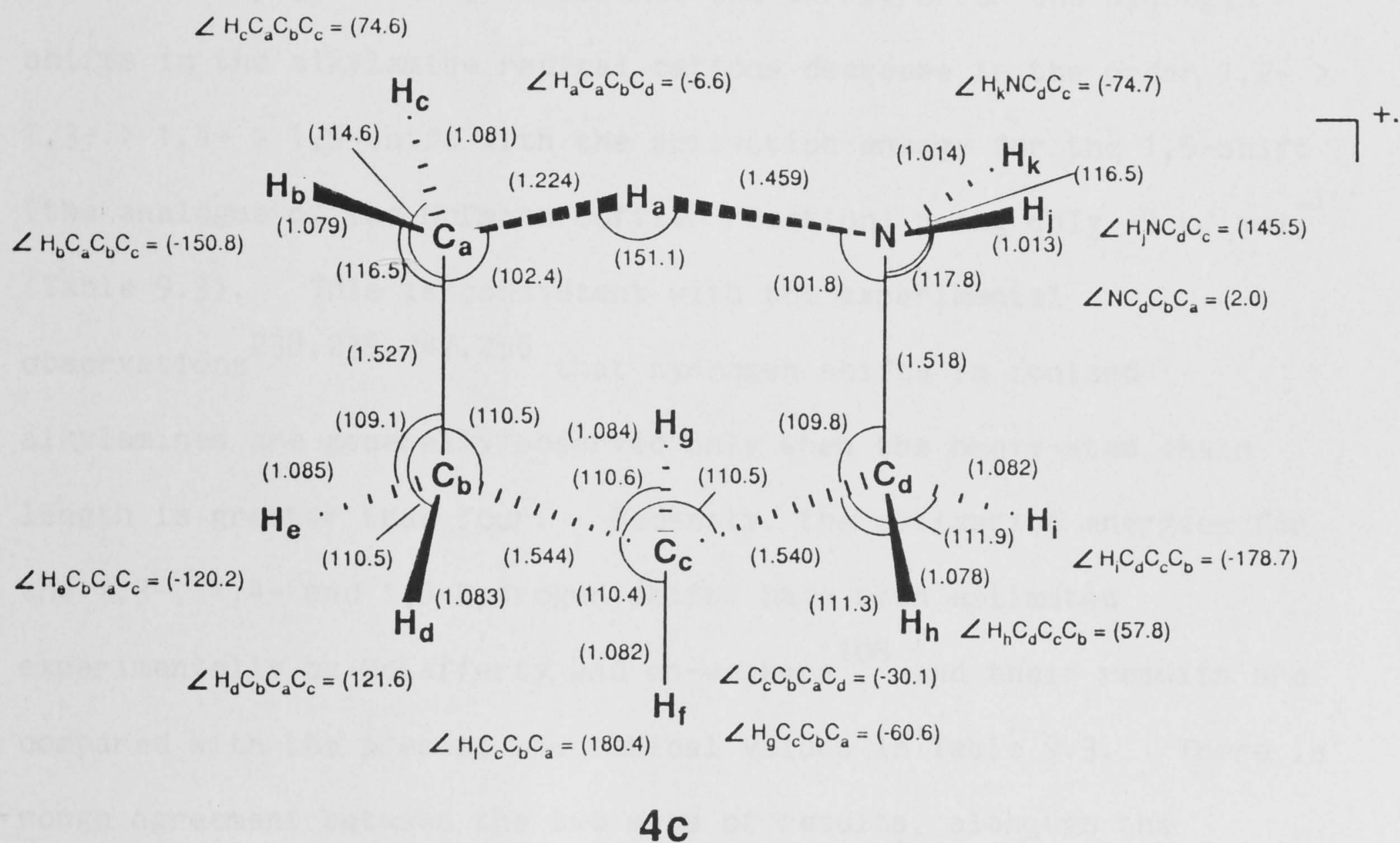

The 1,4-hydrogen shift from 4a (yielding the distonic $\mathrm{CH}_{3} \dot{\mathrm{C}} \mathrm{HCH}_{2} \mathrm{CH}_{2} \stackrel{+}{\mathrm{N}} \mathrm{H}_{3}$ ) might in principle be expected to compete with the 1,5-process. 108 However, it is anticipated (on the basis of the results for the 1,4-hydrogen shift in the propylamine radical cation (3a)) that this will require greater energy than the 1,5-shift.

b. Zero-point vibrational contributions lower the energies of the hydrogen-shift barriers by 10,8 and $6 \mathrm{~kJ} \mathrm{~mol}^{-1}$ in the $\mathrm{CH}_{5} \mathrm{~N}^{+\cdot}$, $\mathrm{C}_{2} \mathrm{H}_{7} \mathrm{~N}^{+\cdot}$ and $\mathrm{C}_{3} \mathrm{H}_{9} \mathrm{~N}^{+\cdot}$ systems, respectively. 


\subsubsection{Barriers and Rates for Hydrogen Migration}

It may be noted initially that the results in Tables 9.2 and

9.3 show that there is very little difference between the calculated barrier heights for hydrogen migration at $\mathrm{O} K$ (where $\Delta \mathrm{E}^{*}=\Delta \mathrm{H}^{*}=\Delta \mathrm{G}^{*}$ ) and the temperature-corrected estimates $\Delta \mathrm{H}_{298}^{\neq}$and $\mathrm{E}_{a} \cdot{ }^{C} \quad$ Figure 9.1 on the next page clearly shows that the barriers for the hydrogen shifts in the alkylamine radical cations decrease in the order 1,2-> $1,3->1,4->1,5$-shift with the activation energy for the 1,5-shift (the analogue of the Hofmann-Löffler reaction) being only $-9 \mathrm{~kJ} \mathrm{~mol}^{-1}$ (Table 9.3). This is consistent with the experimental observations $238,239,247,256$ that hydrogen shifts in ionized alkylamines are generally observed only when the heavy-atom chain length is greater than four. Recently, the activation energies for the 1,3-, 1,4- and 1,5-hydrogen shifts have been estimated experimentally by McLafferty and co-workers ${ }^{108}$ and their results are compared with the present theoretical values in Table 9.3. There is rough agreement between the two sets of results, although the theoretical values tend to be somewhat greater than those from experiment. This may be due in part to the (small) amount of excess internal energy that would be possessed by the metastable ionized species.

A number of observations may be made concerning the ease of hydrogen transfer in the systems studied here. First, significant ring strain would be expected in the three- and four-membered-ring

c. Strictly speaking, the transition structure for the hydrogen shift process at $298 \mathrm{~K}$ should really correspond to the saddle point on the $\Delta H$ or $\Delta G$ surface at this temperature. For a recent discussion of the temperature dependence of the transition structure, see ref 294. 


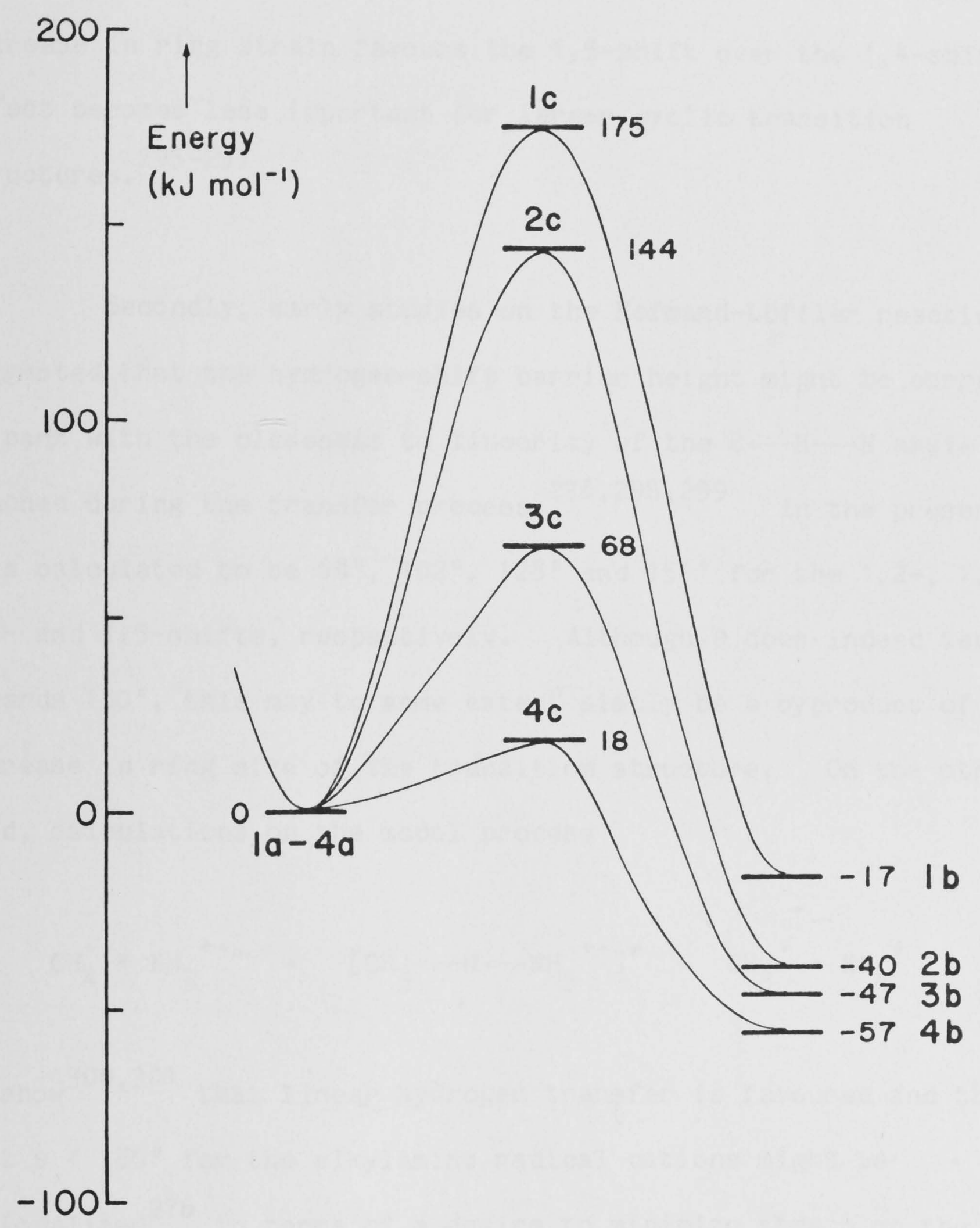

Figure 9.1 Schematic energy profiles for the hydrogen shifts in the alkylamine radical cations (1: 1,2-shift; $2: 1,3$-shift; $3: 1,4-$ shift; 4: 1,5-shift). 
217.

transition structures involved in the 1,2- and 1,3-shifts. The effect of this ring strain would account to a large extent for the change in the $\Delta \mathrm{H}_{298}^{\neq}$values (Table 9.3), which show a dramatic decrease as the ring size of the transition structure increases. Although the decrease in ring strain favours the 1,5-shift over the 1,4-shift, this effect becomes less important for larger cyclic transition structures. $295-297$

Secondly, early studies on the Hofmann-Löffler reaction suggested that the hydrogen-shift barrier height might be correlated in part with the closeness to linearity of the C---H---N angle $(\theta)$ reached during the transfer process. $276,298,299$ In the present work, $\theta$ is calculated to be $68^{\circ}, 102^{\circ}, 128^{\circ}$ and $151^{\circ}$ for the $1,2-, 1,3-$, 1,4- and 1,5-shifts, respectively. Although $\theta$ does indeed tend towards $180^{\circ}$, this may to some extent simply be a byproduct of the increase in ring size of the transition structure. On the other hand, calculations on the model process

$$
\mathrm{CH}_{4}+\mathrm{NH}_{3}^{+\cdot} \rightarrow\left[\mathrm{CH}_{3}---\mathrm{H}^{---\mathrm{NH}_{3}}{ }^{+\cdot}\right]^{\neq} \rightarrow \mathrm{CH}_{3}^{\cdot}+\mathrm{NH}_{4}^{+}
$$

do show 300,301 that 1 inear hydrogen transfer is favoured and the fact that $\theta<180^{\circ}$ for the alkylamine radical cations might be rationalized ${ }^{276}$ in terms of a desire to minimize strain on the other angles in the transition structure. The calculated transfer angle for the prototype Hofmann-Löffler reaction (the 1,5-shift) is $151^{\circ}$. In a recent molecular mechanics study of the related Barton reaction,

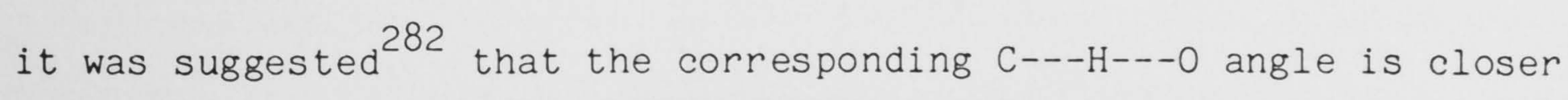
to $180^{\circ}$. 
Thirdly, as the ring size of the transition structure increases, entropy loss due to cyclic interaction should become increasingly unfavourable. 295,302 This loss of entropy is expected to be least important in the formation of the three-membered-ring transition structure and to be only modest for the other small rings. $295,296,302$ This is borne out by the calculated $\Delta S_{298}^{\neq}$values, which are $-21,-38$ and $-30 \mathrm{~kJ} \mathrm{~mol}^{-1}$ for the 1,2-, 1,3- and 1,4-shifts, respectively. For longer-range shifts, the entropy factor is expected to become more significant.

While a consideration of these three factors suggests that 1,5-shifts will dominate hydrogen migrations in alkylamine radical cations, $^{d}$ evidence has nevertheless been presented for the more distant 1,6-, 1,7- and 1,8-shifts, both in solution 276,279 and in the gas phase. 243 It may be noted in passing that it does not appear as though orbital symmetry considerations play a major role in the rearrangements of alkylamine radical cations. ${ }^{305}$

Not surprisingly, the calculated rate constants for the hydrogen migrations increase dramatically in the order $1,2-<1,3-<$ 1,4-shift (Table 9.3), with the value for the 1,4-shift being $-40 \mathrm{~s}^{-1}$. The tunnelling effects (as measured by $k$, Table 9.3) are quite substantial and the simple Wigner correction may be inappropriate for these reactions. Although no corresponding experimental rate constants for the ionized alkylamines are available, values for the gas-phase 1,4- and 1,5-hydrogen shifts in hexanol radical cation have

d. This is certainly the case for free-radical rearrangement reactions in solution. See refs 303 and 304 . 
been roughly estimated (for low-energy $\mathrm{M}^{+}$) to be $<10^{3}$ and $-10^{5} \mathrm{~s}^{-1}$, respectively. 306 These results are consistent with the accepted view 267,268 that gas-phase hydrogen shifts are more facile in ionized alcohols than in amines. ${ }^{e}$

\subsection{Conclusions}

The calculations presented in this chapter show that barrier heights for hydrogen shifts in unbranched primary alkylamine radical cations decrease in the order 1,2->1,3->1,4->1,5-hydrogen shift. The increasing ease of hydrogen migration in these systems parallels the decreasing ring strain and increasing linearity of the $\mathrm{C}--_{-\mathrm{H}---\mathrm{N}}$ angle in the corresponding transition structures. For the gas-phase prototype of the Hofmann-Löffler reaction (the 1,5-shift), hydrogen transfer is predicted to occur at an angle of $151^{\circ}$. Finally, the calculated barriers and rate constants for the hydrogen rearrangements are consistent with experimental evidence for the occurrence of facile 1,5-hydrogen shifts in ionized amines and for the absence, generally, of $1,2-, 1,3-$ and 1,4 -shifts.

e. However, the rate constant for the 1,5-hydrogen shift in dibutylamine radical cation in solution has been estimated to be $>10^{6} \mathrm{~s}^{-1}$. See ref 307 . 


\section{APPENDIX CONVERSION FACTORS}

Energy conversion factors are summarized in the Table below.

Table Conversion Factors for Energy Units ${ }^{a}$

\begin{tabular}{lccccc}
\hline & hartree & $\mathrm{kJ} \mathrm{mol}^{-1}$ & $\mathrm{kcal} \mathrm{mol}$ & $\mathrm{eV}$ & $\mathrm{cm}^{-1}$ \\
\hline hartree & 1 & 2625.46 & 627.51 & 27.212 & $2.1947 \times 10^{5}$ \\
$\mathrm{~kJ} \mathrm{~mol}^{-1}$ & $3.8088 \times 10^{-4}$ & 1 & 0.23901 & $1.0364 \times 10^{-2}$ & 83.593 \\
$\mathrm{kcal} \mathrm{mol}^{-1}$ & $1.5936 \times 10^{-3}$ & 4.1840 & 1 & $4.3363 \times 10^{-2}$ & 349.75 \\
$\mathrm{eV}$ & $3.6749 \times 10^{-2}$ & 96.485 & 23.061 & 1 & 8065.5 \\
$\mathrm{~cm}^{-1}$ & $4.5563 \times 10^{-6}$ & $1.1963 \times 10^{-2}$ & $2.8592 \times 10^{-3}$ & $1.1963 \times 10^{-2}$ & 1 \\
\hline
\end{tabular}

a From ref 308 .

Conversion factors used for geometrical parameters are:

$$
\begin{aligned}
1 \text { bohr } & =0.529177 \AA \\
& =5.29177 \times 10^{-11} \mathrm{~m}
\end{aligned}
$$

and

$$
1 \text { radian }=57.296^{\circ}
$$




\section{REFERENCES}

(1) Baldwin, M.A. Mass Spectrom. 1985, 8, 34 .

(2) Hückel, E. Z. Phys. 1931, 70, 204.

(3) Hoffmann, R. J. Chem. Phys. 1963, 39, 1397.

(4) Pople, J.A.; Beveridge, D.L. Approximate Molecular Orbital Theory; McGraw-Hill: New York, 1970.

(5) Dewar, M.J.S. ; Zoebisch, E.G.; Healy, E.F.; Stewart, J.J.P. J. Am. Chem. Soc. 1985, 107, 3902.

(6) Hehre, W.J.; Radom, L.; Schleyer, P.v.R. ; Pople, J.A. Ab Initio Molecular Orbital Theory; Wiley: New York, 1986.

(7) McQuarrie, D.A. Quantum Chemistry; Oxford University Press: Oxford, 1983.

(8) Schrödinger, E. Ann. Phys. (Leipzig) 1926, 79, 361.

(9) Born, M.; Oppenheimer, J.R. Ann. Phys. (Leipzig) 1927, 84, 457.

(10) (a) Hartree, D.R. Proc. Cam. Phil. Soc. 1928, 24, 89.

(b) Hartree, D.R. ibid. 1928, 24, 111.

(c) Hartree, D.R. ibid. 1928, 24, 426.

(11) (a) Slater, J.C. Phys. Rev. 1929, 34, 1293.

(b) Slater, J.C. ibid. 1930, 35, 509.

(12) Slater, J.C. Phys. Rev. 1930, 36, 57.

(13) Boys, S.F. Proc. Roy. Soc. (London) 1950, A200, 542.

(14) Roothaan, C.C.J. Rev. Mod. Phys. 1951, 23, 69.

(15) Hall, G.G. Proc. Roy. Soc. (London) 1951, A205, 541.

(16) Fock, V. Z. Phys. 1930, 61, 126.

(17) Roothaan, C.C.J. Rev. Mod. Phys. 1960, 32, 179.

(18) Binkley, J.S. ; Pople, J.A.; Dobosh, P.A. Mol. Phys. 1974, 28, 1423.

(19) Pople, J.A.; Nesbet, R.K. J. Chem. Phys. 1954, 22, 571.

(20) Wilson, S. Electron Correlation in Molecules; Clarendon Press: Oxford, $198 \overline{4}$. 
(21) Shavitt, I. In Advanced Theories and Computational Approaches to the Electronic Structure of Molecules; Dykstra, C.E., Ed.; D. Reidel: Dordrecht, $1984 ;$ p 185.

(22) Shavitt, I. In Methods of Electronic Structure Theory;

Schaefer III, H.F., Ed.; Plenum Press: New York, 1977; Chapter 6.

(23) Kutzelnigg, W. In Methods of Electronic Structure Theory;

Schaefer III, H.F., Ed.; Plenum Press: New York, 1977; Chapter 5 .

(24) Čížek, J. J. Chem. Phys. 1966, 45, 4256.

(25) Paldus, J. ; Č́ižek, J. ; Shavitt, I. Phys. Rev. 1972, A5, 50.

(26) Pople, J.A.; Krishnan, R. ; Schlegel, H.B.; Binkley, J.S. Int. J. Quantum Chem. 1978, 14, 545.

(27) Bartlett, R. J.; Dykstra, C.E. ; Paldus, J. In Advanced Theories and Computational Approaches to the Electronic Structure of Molecules; Dykstra, C.E., Ed.; D. Reidel: Dordrecht, 1984; p 127.

(28) Wahl, A.C.; Das, G. In Methods of Electronic Structure Theory; Schaefer III, H.F., Ed.; Plenum Press: New York, 1977; Chapter 3.

(29) Dunning Jr., T.H. In Advanced Theories and Computational Approaches to the Electronic Structure of Molecules; Dykstra, C.E., Ed.; D. Reidel: Dordrecht, 1984; p 67.

(30) Moller, C.; Plesset, M.S. Phys. Rev. 1934, 46, 618.

(31) Pople, J.A.; Binkley, J.S. ; Seeger, R. Int. J. Quantum Chem., Quantum Chem. Symp. 1976, 10, 1.

(32) Krishnan, R.; Pople, J.A. Int. J. Quantum Chem. 1978, 14, 91.

(33) Krishnan, R. ; Frisch, M.J. ; Pople, J.A. J. Chem. Phys. 1980, $\underline{72}, 4244$.

(34) Farnell, L.; Nobes, R.H. ; Poppinger, D.; Yates, B.F., unpublished.

(35) Baker, J.; Nobes, R.H.; Poppinger, D., unpublished.

(36) Binkley, J.S.; Whiteside, R.A. ; Krishnan, R. ; Seeger, R.; DeFrees, D.J.; Schlegel, H.B.; Topiol, S. ; Kahn, L.R. ; Pople, J.A. QCPE $1981,13,406$.

(37) Binkley, J.S.; Frisch, M.J. ; DeFrees, D.J.; Raghavachari, K. ; Whiteside, R.A.; Schlegel, H.B.; Fluder, E.M.; Pople, J.A. Carnegie-Mellon University, Pittsburgh, PA 15213, U.S.A.

(38) Binkley, J.S.; Pople, J.A.; Hehre, W.J. J. Am. Chem. Soc. 1980, $102,939$. 
(39) Gordon, M.S.; Binkley, J.S.; Pople, J.A.; Pietro, W.J.; Hehre, W.J. J. Am. Chem. Soc. 1982, $104,2797$.

(40) Hehre, W.J.; Ditchfield, R.; Pople, J.A. J. Chem. Phys. 1972, $\underline{56}, 2257$.

(41) Francl, M.M.; Pietro, W.J.; Hehre, W.J.; Binkley, J.S. ; Gordon, M.S.; DeFrees, D.J.; Pople, J.A. J. Chem. Phys. 1982, 77, 3654.

(42) Pietro, W.J.; Francl, M.M.; Hehre, W.J.; DeFrees, D.J.; Pople, J.A.; Binkley, J.S. J. Am. Chem. Soc. 1982, 104, 5039.

(43) Hariharan, P.C.; Pople, J.A. Theor. Chim. Acta 1973, 28, 213.

(44) Frisch, M.J.; Pople, J.A.; Binkley, J.S. J. Chem. Phys. 1984, 80,3265 .

(45) Baker, J. J. Comput. Chem., in press.

(46) Poppinger, D. Chem. Phys. Lett. 1975, 35, 550.

(47) Pople, J.A.; Krishnan, R.; Schlegel, H.B.; Binkley, J.S. Int. J. Quantum Chem., Quantum Chem. Symp. 1979, 13, 225.

(48) Gaw, J.F.; Handy, N.C. Annu. Rep. Prog. Chem., Sect.C 1984, 81, 291.

(49) Geometrical Derivatives of Energy Surfaces and Molecular Properties; Jorgensen, P., Simons, J., Eds.; D. Reidel: Dordrecht, 1986.

(50) Baker, J. J. Comput. Chem., in press.

(51) Wilson, E.B.; Decius, J.C.; Cross, P.C. Molecular Vibrations; McGraw-Hill: London, 1955.

(52) McQuarrie, D.A. Statistical Mechanics; Harper and Row: New York, 1976.

(53) Stull, D.R.; Westrum, E.F.; Sinke, J.C. The Chemical Thermodynamics of Organic Compounds; Wiley: New York, 1969.

(54) Hehre, W.J.; Ditchfield, R.; Radom, L.; Pople, J.A. J. Am. Chem. Soc. 1970, 92, 4796.

(55) Traeger, J.C.; McLoughl in, R.G. J. Am. Chem. Soc. 1981, 103, 3647 .

(56) Rosenstock, H.M.; Draxl, K.; Steiner, B.W.; Herron, J.T. J. Phys. Chem. Ref. Data Suppl. 1 1977, 6.

(57) Yates, B.F.; Nobes, R.H.; Radom, L. Chem. Phys. Lett. 1985, 116,474 .

(58) Yates, B.F.; Radom, L., to be published.

(59) Gill, P.M.W.; Radom, L., submitted for publication. 
(60) Hout Jr., R.F.; Levi, B.A.; Hehre, W.J. J. Comput. Chem. 1982, $\underline{3}, 234$.

(61) Defrees, D.J. ; McLean, A.D. J. Chem. Phys. 1985, 82, 333.

(62) Handy, N.C.; Knowles, P.J.; Somasundram, K. Theor. Chim. Acta $1985,68,87$.

(63) Nobes, R.H. ; Bouma, W.J. ; Radom, L. Chem. Phys. Lett. 1982, 89, 497.

(64) McKee, M.L.; Lipscomb, W.N. J. Am. Chem. Soc. 1981, 103, 4673.

(65) Morgan, R.P.; Beynon, J.H. ; Bateman, R.H. ; Green, B.N. Int. J. Mass Spectrom. Ion Phys. 1978, 28, 171.

(66) Howe, I.; Williams, D.H.; Bowen, R.D. Mass Spectrometry: Principles and Applications, 2nd ed; McGraw-Hill: New York, 1981.

(67) Watson, J.T. Introduction to Mass Spectrometry; Raven Press: New York, 1985.

(68) Budzikiewicz, H.; Djerassi, C.; Williams, D.H. Mass Spectrometry of Organic Compounds; Holden-Day: San Francisco, CA, 1967.

(69) McLafferty, F.W. Interpretation of Mass Spectra, 3rd ed; University Science Books: Mill Valley, CA, 1980.

(70) Levsen, K. Fundamental Aspects of Organic Mass Spectrometry; Verlag Chemie: New York, 1978.

(71) Maccol1, A. Org. Mass Spectrom. 1982, 17, 1.

(72) Holmes, J.L. Org. Mass Spectrom. 1985, 20, 169.

(73) Vogel, P. Carbocation Chemistry; Elsevier: Amsterdam, 1985.

(74) Levin, R.D.; Lias, S. Ionization Potential and Appearance Potential Measurements 1971-1981; NSRDS-NBS 71; U.S. Govt. Printing Office: Washington, DC, 1982.

(75) Lossing, F.P.; Traeger, J.C. Int. J. Mass Spectrom. Ion Phys. $1976,19,9$.

(76) Traeger, J.C.; McLoughlin, R.G. Int. J. Mass Spectrom. Ion Phys. 1978, 27, 319.

(77) Levsen, K.; Schwarz, H. Mass Spectrom. Rev. 1983, 2, 77.

(78) Tandem Mass Spectrometry; McLafferty, F.W., Ed.; Wiley: New York, 1983.

(79) Howe, I. Mass Spectrom. 1984, 7, 119. 
(80) Molecular Ions: Spectroscopy, Structure and Chemistry; Miller,
T.A., Bondybey, V.E., Eds.; North-Holland: Amsterdam, 1983.

(81) Leach, S. J. Mol. Struct. 1986, 141, 43.

(82) Cooks, R.G.; Beynon, J.H.; Caprioli, R.M.; Lester, G.R. Metastable Ions; Elsevier: Amsterdam, 1973.

(83) Holmes, J.L. ; Terlouw, J.K. Can. J. Chem. 1975, 53, 2076.

(84) Terlouw, J.K.; Wezenberg, J.; Burgers, P.C.; Holmes, J.L. J. Chem. Soc., Chem. Commun. 1983, 1121.

(85) Jennings, K.R. Int. J. Mass Spectrom. Ion Phys. 1968, 1, 227.

(86) Haddon, W.F.; McLafferty, F.W. J. Am. Chem. Soc. 1968, 90, 4745 .

(87) McLafferty, F.W.; Bente III, P.F.; Kornfeld, R.; Tsai, S.C.; Howe, I. J. Am. Chem. Soc. 1973, 95, 2120.

(88) Baykut, G.; Watson, C.H. ; Weller, R.R. ; Eyler, J.R. J. Am. Chem. Soc. 1985, 107, 8036.

(89) Cooks, R.G.; Beynon, J.H.; Ast, T. J. Am. Chem. Soc. 1972, 94 , 1004 .

(90) Ast, T. Adv. Mass Spectrom. 1980, 8, 555.

(91) Kingston, E.E.; Beynon, J.H. ; Ast, T. ; Flammang, R. ; Maquestiau, A. Org. Mass Spectrom. 1985, 20, 546.

(92) Koch, W.; Maquin, F.; Stahl, D. ; Schwarz, H. Chimia 1985, 39, 376 .

(93) Seibl, J. Org. Mass Spectrom. 1969, 2, 1033.

(94) Guilhaus, M.; Kingston, R.G.; Brenton, A.G.; Beynon, J.H. Org. Mass Spectrom. 1985, 20, 424.

(95) Proctor, C.J.; Porter, C.J.; Ast, T.; Bolton, P.D. ; Beynon, J.H. Org. Mass Spectrom. 1981, 16, 454.

(96) Koch, W.; Schwarz, H. Int. J. Mass Spectrom. Ion Processes $1986,68,49$.

(97) Kingston, E.E. ; Brenton, A.G.; Beynon, J.H. ; Flammang, R. ; Maquestiau, A. Int. J. Mass Spectrom. Ion Processes 1984, 62, 317 .

(98) Guilhaus, M.; Boyd, R.K.; Brenton, A.G.; Beynon, J.H. Int. J. Mass Spectrom. Ion Processes 1985, 67, 209.

(99) Pachuta, S.J. ; Isern-Flecha, I. ; Cooks, R.G. Org. Mass Spectrom. 1986, 21, 1 . 
(100) McLafferty, F.W.; Todd, P.J.; McGilvery, D.C.; Baldwin, M.A. J. Am. Chem. Soc. 1980, 102, 3360.

(101) Burgers, P.C.; Holmes, J.L.; Mommers, A.A.; Terlouw, J.K. Chem. Phys. Lett. 1983, 102, 1.

(102) Holmes, J.L.; Mommers, A.A. Org. Mass Spectrom. 1984, 19, 460.

(103) Burgers, P.C.; Holmes, J.L.; Mommers, A.A.; Szulejko, J.E.; Terlouw, J.K. Org. Mass Spectrom. 1984, 19, 442.

(104) Clair, R.; Holmes, J.L.; Mommers, A.A.; Burgers, P.C. Org. Mass Spectrom. 1985, 20, 207.

(105) Terlouw, J.K.; Holmes, J.L.; Burgers, P.C. Int. J. Mass Spectrom Ion Processes 1985, 66, 239.

(106) Danis, P.0.; Wesdemiotis, C.; McLafferty, F.W. J. Am. Chem. Soc. $1983, \underline{105}, 7454$.

(107) Terlouw, J.K.; Kieskamp, W.M.; Holmes, J.L.; Mommers, A.A.; Burgers, P.C. Int. J. Mass Spectrom. Ion Processes 1985, 64, 245.

(108) Wesdemiotis, C.; Danis, P.0.; Feng, R.; Tso, J.; McLafferty, F.W. J. Am. Chem. Soc. 1985, 107, 8059.

(109) Holmes, J.L.; Mommers, A.A.; Terlouw, J.K.; Hop, C.E.C.A. Int. J. Mass Spectrom. Ion Processes 1986, 68, 249.

(110) Wittig, G.; Geissler, G. Justus Liebigs Ann. Chem. 1953, 580, 44.

(111) Gosney, I.; Rowley, A.G. In Organophosphorus Reagents in Organic Synthesis; Cadogan, J.I.G., Ed.; Academic Press: New York, 1979; p 17.

(112) Stevens, T.S.; Creighton, E.M.; Gordon, A.B.; MacNicol, M. J. Chem. Soc. 1928, 3193.

(113) Block, E. Reactions of Organosulfur Compounds; Academic Press: New York, 1978; p 198.

(114) Morris, D.G. Surv. Prog. Chem. 1983, 10, 189.

(115) Bernardi, F.; Schlegel, H.B.; Whangbo, M.; Wolfe, S. J. Am. Chem. Soc. 1977, 99, 5633.

(116) Král, V.; Arnold, Z. Collect. Czech. Chem. Commun. 1980, 45, 92.

(117) Jardine, W.K.; Langler, R.F.; MacGregor, J.A. Can. J. Chem. $1982,60,2069$.

(118) Hoffmann, R.; Boyd, D.B.; Goldberg, S.Z. J. Am. Chem. Soc. $1970,92,3929$. 
(119) Boyd, D.B.; Hoffmann, R. J. Am. Chem. Soc. 1971, 93, 1064.

(120) Absar, I.; Wazer, J.R.v. J. Am. Chem. Soc. 1972, $94,2382$.

(121) Whangbo, M.; Wolfe, S.; Bernardi, F. Can. J. Chem. 1975, 53, 3040 .

(122) Albright, T. Org. Magn. Reson. 1976, 8, 489.

(123) Whangbo, M.; Wolfe, S. Can. J. Chem. 1976, 54, 949.

(124) Lischka, H. J. Am. Chem. Soc. 1977, 99, 353.

(125) Strich, A. Nouveau J. Chim. 1979, 3, 105.

(126) Trinquier, G.; Malrieu, J.-P. J. Am. Chem. Soc. 1979, 101, 7169.

(127) Zyubin, A.S.; Charkin, O.P. Zh. Neorg. Khim. 1982, 27, 565.

(128) Bews, J.R.; Glidewell, C. J. Mol. Struct. 1983, 104, 105.

(129) Schoeller, W.W.; Niemann, J. J. Am. Chem. Soc. 1986, 108, 22.

(130) Tatsumi, K.; Yoshioka, Y.; Yamaguchi, A.; Fueno, T. Tetrahedron $1976, \underline{32}, 1705$.

(131) Minyaev, R.M.; Minkin, V.I.; Sadekov, I.D.; Naddaka, V.I. Zh. Obshch. Khim. 1977, 47, 1294.

(132) Kral, V.; Arnold, Z.; Jehlicka, V.; Exner, O. Collect. Czech. Chem. Commun. 1980, 45, 1236.

(133) Kral, V.; Arnold, Z.; Havlas, Z. Collect. Czech. Chem. Commun. $1981, \underline{46}, 883$.

(134) Hoffman, R.V.; Belfoure, E. L. J. Am. Chem. Soc. 1982, 104, 2183.

(135) Harding, L.B. ; Schlegel, H.B. ; Krishnan, R. ; Pople, J.A. J. Phys. Chem. 1980, 84, 3394.

(136) Höller, R.; Lischka, H. J. Am. Chem. Soc. 1980, 102, 4632.

(137) Mitchell, D.J. ; Wolfe, S.; Schlegel, H.B. Can. J. Chem. 1981, $\underline{59}, 3280$.

(138) Wolfe, S.; Stolow, A.; LaJohn, L.A. Tetrahedron Lett. 1983, 24, 4071 .

(139) Volatron, F.; Eisenstein, O. J. Am. Chem. Soc. 1984, 106, 6117.

(140) Eades, R.A.; Gassman, P.G.; Dixon, D.A. J. Am. Chem. Soc. 1981, 103,1066 .

(141) Dixon, D.A.; Dunning Jr., T.H.; Eades, R.A.; Gassman, P.G. J. Am. Chem. Soc. 1983, 105, 7011. 
(142) Pople, J.A.; Raghavachari, K.; Frisch, M.J.; Binkley, J.S.; Schleyer, P.v.R. J. Am. Chem. Soc. 1983, 105, 6389.

(143) The $6-311 \mathrm{G}^{* *}$ basis set is described in: Krishnan, R.; Binkley, J.S.; Seeger, R.; Pople, J.A. J. Chem. Phys. 1980, 72, 650.

(144) Whiteside, R.A.; Frisch, M.J.; Binkley, J.S.; Krishnan, R.; DeFrees, D.J.; Schlegel, H.B.; Pople, J.A. Carnegie-Mellon Quantum Chemistry Archive; Department of Chemistry, CarnegieMellon University: Pittsburgh, PA 15213, 1983.

(145) Bouma, W.J.; Dawes, J.M. ; Radom, L. Org. Mass Spectrom. 1983, $18,12$.

(146) Bouma, W.J.; Yates, B.F.; Radom, L. Chem. Phys. Lett. 1982, 92 , 620.

(147) Bart, J.C.J. J. Chem. Soc. B 1969, 350.

(148) Raghavachari, K.; Chandrasekhar, J. ; Gordon, M.S. ; Dykema, K.J. J. Am. Chem. Soc. 1984, 106, 5853.

(149) Woodward, R.B.; Hoffmann, R. The Conservation of Orbital Symmetry; Academic Press: New York, 1971; p 131.

(150) Johnson, A.W. Ylid Chemistry; Academic Press: New York, 1966.

(151) Kutzelnigg, W. Angew. Chem., Int. Ed. Engl. 1984, 23, 272.

(152) Bouma, W.J.; Nobes, R.H.; Radom, L. J. Am. Chem. Soc. 1982, $104,2929$.

(153) Frisch, M.J.; Raghavachari, K.; Pople, J.A.; Bouma, W.J. ; Radom, L. Chem. Phys. 1983, 75, 323.

(154) Bouma, W.J.; MacLeod, J.K.; Radom, L. J. Am. Chem. Soc. 1982, $104,2930$.

(155) Holmes, J.L.; Lossing, F.P.; Terlouw, J.K.; Burgers, P.C. J. Am. Chem. Soc. 1982, 104, 2931.

(156) Radom, L. ; Bouma, W.J. ; Nobes, R.H. ; Yates, B.F. Pure Appl. Chem. 1984, 56, 1831.

(157) Schwarz, H. Shitsuryo Bunseki 1984, 32, 3.

(158) Yates, B.F.; Bouma, W.J.; Radom, L. J. Am. Chem. Soc. 1984, 106,5805 .

(159) Chase Jr., M.W.; Curnutt, J.L. ; Downey Jr., J.R. ; McDonald, R.A.; Syverud, A.N.; Valenzuela, E.A. J. Phys. Chem. Ref. Data $1982,11,695$.

(160) Martin, R.H.; Lampe, F.W.; Taft, R.W. J. Am. Chem. Soc. 1966, 88, 1353.

(161) Nobes, R.H.; Radom, L. Org. Mass Spectrom. 1982, 17, 340. 
(162) Bouma, W.J. ; MacLeod, J.K. ; Nobes, R.H. ; Radom, L. Int. J. Mass Spectrom. Ion Phys. 1983, 46, 235.

(163) Lathan, W.A.; Curtiss, L.A. ; Hehre, W.J. ; Lisle, J.B. ; Pople, J.A. Prog. Phys. Org. Chem. 1974, 11, 175.

(164) Bonazzola, L. ; Iacona, C.; Michaut, J.P.; Roncin, J. J. Chem. Phys. 1980, 73, 4175.

(165) Bonazzola, L. ; Lerary, N. ; Ellinger, Y. Chem. Phys. 1982, 73, 145.

(166) Halim, H. ; Ciommer, B. ; Schwarz, H. Angew. Chem., Int. Ed. Engl. 1982, 21, 528.

(167) Frenking, G.; Koch, W. J. Mol. Struct., Theochem 1984, 110, 49.

(168) Dewar, M.J.S. ; Rzepa, H.S. J. Am. Chem. Soc. 1977, 99, 7432.

(169) Lobanov, V.V.; Aleksankin, M.M.; Kruglyak, Y.A. Theor. Exp. Chem. (Engl. Transl.) 1978, 14, 263.

(170) Nguyen, M.T.; Hegarty, A.F.; Brint, P. J. Chem. Soc., Dalton Trans. 1985, 1915.

(171) Nobes, R.H. ; Bouma, W.J.; Radom, L. J. Am. Chem. Soc. 1984, 106,2774 .

(172) van Dijk, J.M.F.; Pennings, J.F.M.; Buck, H.M. J. Am. Chem. Soc. $1975, \underline{97}, 4836$.

(173) Colwell, S.M.; Amos, R.D.; Handy, N.C. Chem. Phys. Lett. 1984, $\underline{109}, 525$.

(174) Jahn, H.A.; Teller, E. Proc. Roy. Soc. A 1937, 161, 220.

(175) Moffitt, W.; Liehr, A.D. Phys. Rev. 1957, 106, 1195.

(176) Glidewell, C. Inorg. Chim. Acta 1982, 64, L59.

(177) Bouma, W.J.; Poppinger, D. ; Radom, L. Isr. J. Chem. 1983, 23, 21 and references therein.

(178) Terlouw, J.K.; Heerma, W.; Dijkstra, G.; Holmes, J.L.; Burgers, P.C. Int. J. Mass Spectrom. Ion Phys. 1983, 47, 147.

(179) Holmes, J.L.; Lossing, F.P.; Terlouw, J.K.; Burgers, P.C. Can. J. Chem. 1983, 61, 2305.

(180) Weger, E. ; Levsen, K.; Ruppert, I.; Burgers, P.C.; Terlouw, J.K. Org. Mass Spectrom. 1983, 18, 327.

(181) Maquin, F.; Stahl, D.; Sawaryn, A. ; Schleyer, P.v.R.; Koch, W.; Frenking, G.; Schwarz, H. J. Chem. Soc., Chem. Commun. 1984, 504 . 
(182) Sack, T.M.; Cerny, R.L.; Gross, M.L. J. Am. Chem. Soc. 1985, 107,4562 .

(183) Gross, M.L.; McLafferty, F.W. J. Am. Chem. Soc. 1971, 93, 1267.

(184) Gross, M.L. J. Am. Chem. Soc. 1972, 94, 3744.

(185) Sieck, L.W.; Gordon, R.; Ausloos, R. J. Am. Chem. Soc. 1972, 94, 3744 .

(186) Staley, R.; Corderman, R.C.; Foster, M.S.; Beauchamp, J.L. J. Am. Chem. Soc. 1974, 96, 1260.

(187) Lias, S.G.; Buckley, T.J. Int. J. Mass Spectrom. Ion Processes $1984,56,123$.

(188) Butler, J. J. ; Baer, T.; Evans, S. A. J. Am. Chem. Soc. 1983, $105,3451$.

(189) Kohin, R.P.; Nadeau, P.G. J. Chem. Phys. 1966, 44, 691.

(190) Khusidman, M.B.; Vyatkin, V.P.; Grigor'eva, N.V.; Dobychin, S.L. Zh. Prikl. Khim. (Leningrad) 1983, 56, 222.

(191) Brimage, D.R.G.; Cassell, J.D.P. ; Sharp, J.H. ; Symons, M.C.R. J. Chem. Soc. A 1969, 2619.

(192) Bouma, W.J. ; Radom, L. J. Am. Chem. Soc. 1983, 105, 5484.

(193) Schleyer, P.v.R.; Kos, A. J.; Pople, J.A. ; Balaban, A.T. J. Am. Chem. Soc. 1982, 104, 3771.

(194) Lammertsma, K.; Olah, G.A.; Barzaghi, M.; Simonetta, M. J. Am. Chem. Soc. 1982, 104, 6851 .

(195) For leading recent references to experimental studies, see ref 92 and:

(a) Hanner, A.W.; Abbey, L.E.; Bostwick, D.E. ; Burgess, E.M.; Moran, T.F. Org. Mass Spectrom. 1982, 17, 19.

(b) Rabrenovic, M.; Proctor, C.J.; Ast, T.; Herbert, C.G.; Brenton, A.G.; Beynon, J.H. J. Phys. Chem. 1983, 87, 3305.

(c) Rye, R.R.; Houston, J.E. J. Chem. Phys. 1983, 78, 4321.

(d) Brehm, B.; Fröbe, U.; Neitzke, H.-P. Int. J. Mass Spectrom. Ion Processes 1984, 57, 91.

(e) Kingston, R.G.; Guilhaus, M.; Brenton, A.G.; Beynon, J.H. Org. Mass Spectrom. 1985, 20, 406.

(f) Fournier, P.G.; Fournier, J.; Salama, F.; Richardson, P. J.; Eland, J.H.D. J. Chem. Phys. 1985, 83, 241.

(g) Koch, W.; Schwarz, H. ; Maquin, F.; Stahl, D. Int. J. Mass Spectrom. Ion Processes 1985, 67, 305. 
(h) Lablanquie, P.; Nenner, I.; Millie, P.; Morin, P.; Eland, J.H.D. ; Hubin-Franskin, M.J. ; Delwiche, J. J. Chem. Phys. 1985, $82,2951$.

(i) Samson, J.A.R.; Masuoka, T. ; Pareek, P.N. J. Chem. Phys. $1985,83,5531$.

(j) Dujardin, G.; Winkoun, D. J. Chem. Phys. 1985, 83, 6222.

(k) Mathur, D.; Badrinathan, C.; Rajgara, F.A.; Raheja, U.T. Chem. Phys. 1986, 103, 447.

(1) Burdick, G.W.; Appling, J.R. ; Moran, T.F. J. Phys. B 1986 , 19,629 .

(196) For leading references to theoretical studies, see refs 92, 192 and:

(a) Koch, W.; Maquin, F.; Schwarz, H. ; Stahl, D. J. Am. Chem. Soc. $1985, \underline{107}, 2256$.

(b) Lammertsma, K.; Pople, J.A. ; Schleyer, P.v.R. J. Am. Chem. Soc. $1986,108,7$.

(197) (a) Appell, J.; Durup, J.; Fehsenfeld, F.C.; Fournier, P. J. Phys. B 1973, 6, 197.

(b) Cooks, R.G.; Ast, T.; Beynon, J.H. Int. J. Mass Spectrom. Ion Phys. 1973, 11, 490.

(198) (a) Tsai, B.P.; Eland, J.H.D. Int. J. Mass Spectrom. Ion Phys. $1980,36,143$.

(b) Cosby, P.C.; Moller, R.; Helm, H. Phys. Rev. A 1983, 28, 766 .

(c) Curtis, D.M.; Eland, J.H.D. Int. J. Mass Spectrom. Ion Phys. 1985, 63, 241.

(d) Dujardin, G.; Winkoun, D.; Leach, S. Phys. Rev. A 1985, 31 , 3027 .

(199) (a) Stalherm, D. ; Cliff, B. ; Hillig, H. ; Mehlhorn, W. Z. Naturforsch., A: Astrophys. Phys. Chem. 1969, 24, 1728.

(b) Spohr, R. ; Bergmark, T. ; Magnusson, N. ; Werme, L. O. ; Nordling, C.; Siegbahn, K. Phys. Scr. 1970, 2, 31.

(c) Moddeman, W.E. ; Carlson, T.A. ; Krause, O. ; Pullen, B.P. J. Chem. Phys. 1971, 55, 2317.

(d) Netzer, F.P.; Mathew, J.A.D. J. Electron Spectrosc. Relat. Phenom. 1979, 16, 359.

(e) Jennison, D.R. Phys. Rev. A 1981, 23, 1215.

(f) Agren, A. J. Chem. Phys. 1981, 75, 1267. 
(g) Thompson, M.; Baker, M.D.; Christie, A.; Tyson, J.F. Auger Electron Spectroscopy; Wiley: New York, 1985.

(200) For leading references, see: Correia, N. ; Baker, J. J. Phys. Chem. 1985, 89, 3861 .

(201) Baker, J. Chem. Phys. 1983, 79, 117.

(202) Almlöf, J. Report 74-29, Institute of Physics, University of Stockholm, Sweden.

(203) Beebe, N.H.; Purvis, G.D.; Kurtz, H.A., Quantum Theory Project, University of Florida, Gainesville, FL 32611, USA.

(204) Baker, J., EOM, Department of Quantum Chemistry, University of Uppsala, Sweden.

(205) See, for example: Baker, J.; Pickup, B.T. Mol. Phys. 1983, 49, 651 .

(206) Paddon-Row, M.N.; Santiago, C.; Houk, K.N. J. Am. Chem. Soc. $1980,102,6561$.

(207) Lammertsma, K. J. Am. Chem. Soc. 1984, 106, 4619.

(208) Strausz, O.P.; Kozmutza, C.; Kapuy, E.; Robb, M.A.;

Theodorakopoulos, G.; Csizmadia, I.G. Theor. Chim. Acta 1978, $48,215$.

(209) Strausz, O.P.; Kapuy, E. ; Kozmutza, C.; Robb, M.A.; Csizmadia, I.G. J. Mol. Struct. 1982, 89, 235.

(210) Novoa, J. J. J. Mol. Struct., Theochem 1985, 121, 29.

(211) Koch, W.; Frenking, G. Chem. Phys. Lett. 1985, 114, 178.

(212) Collins, J.B.; Schleyer, P.v.R. ; Binkley, J.S. ; Pople, J.A. J. Am. Chem. Soc. 1976, 98, 3436.

(213) Pople, J.A.; Tidor, B. ; Schleyer, P.v.R. Chem. Phys. Lett. $1982,88,533$.

(214) Siegbahn, P.E.M. Chem. Phys. 1982, 66, 443.

(215) Wong, M.W.; Yates, B.F.; Nobes, R.H.; Radom, L., submitted for publication.

(216) Pople, J.A. ; Frisch, M.J. ; Luke, B.T.; Binkley, J.S. Int. J. Quantum Chem., Quantum Chem. Symp. 1983, 17, 307.

(217) Appell, J.; Durup, J.; Fehsenfeld, F.C.; Fournier, P. J. Phys. B $1974, \underline{7}, 406$.

(218) Gellene, G.I.; Kleinrock, N.S.; Porter, R.F. J. Chem. Phys. 1983, 78, 1795 . 
(219) Wesdemiotis, C.; Feng, R.; Danis, P.O.; Williams, E.R.; McLafferty, F.W. J. Am. Chem. Soc., submitted for publication. Sincere thanks are due to Professor McLafferty for providing a preprint of this paper.

(220) Gellene, G.I.; Porter, R.F. Acc. Chem. Res. 1983, 16, 200.

(221) Bouma, W.J. ; MacLeod, J.K. ; Radom, L. Nouveau J. Chim. 1978, 2, 439.

(222) Bouma, W.J. ; MacLeod, J.K.; Radom, L. J. Chem. Soc., Chem. Commun. 1978, 724 .

(223) Bouma, W.J.; MacLeod, J.K.; Radom, L. J. Am. Chem. Soc. 1979, 101,5540 .

(224) Bouma, W.J. ; MacLeod, J.K.; Radom, L. Int. J. Mass Spectrom. Ion Phys. 1980, 33, 87.

(225) Bouma, W.J.; MacLeod, J.K. ; Radom, L. J. Am. Chem. Soc. 1980, $102,2246$.

(226) Bouma, W.J.; Nobes, R.H. ; Radom, L. Org. Mass Spectrom. 1982, 17, 315.

(227) Bouma, W.J. ; Nobes, R.H. ; Radom, L. J. Am. Chem. Soc. 1983, $105,1743$.

(228) Terlouw, J.K.; Heerma, W.; Dijkstra, G. Org. Mass Spectrom. $1981, \underline{16}, 326$.

(229) Holmes, J.L.; Burgers, P.C.; Terlouw, J.K.; Schwarz, H. ; Ciommer, B.; Halim, H. Org. Mass Spectrom. 1983, 18, 208.

(230) Terlouw, J.K.; de Koster, C.G.; Heerma, W.; Holmes, J.L. ; Burgers, P.C. Org. Mass Spectrom. 1983, 18, 222.

(231) Holmes, J.L.; Mommers, A.A.; Szulejko, J.E.; Terlouw, J.K. J. Chem. Soc., Chem. Commun. 1984, 165.

(232) Burgers, P.C.; Holmes, J.L.; Terlouw, J.K.; van Baar, B. Org. Mass Spectrom. 1985, 20, 202.

(233) Apeloig, Y.; Ciommer, B.; Frenking, G.; Karni, M.; Mandelbaum, A.; Schwarz, H. ; Weisz, A. J. Am. Chem. Soc. 1983, 105, 2186.

(234) Apeloig, Y.; Karni, M.; Ciommer, B.; Frenking, G.; Schwarz, H. Int. J. Mass Spectrom. Ion Processes 1983, 55, 319.

(235) Ciommer, B. ; Frenking, G. ; Schwarz, H. Int. J. Mass Spectrom. Ion Processes 1984, 57, 135.

(236) Weiske, T.; van der Wel, H. ; Nibbering, N.M.M.; Schwarz, H. Angew. Chem., Int. Ed. Engl. 1984, 23, 733.

(237) Wesdemiotis, C.; Feng, R.; McLafferty, F.W. J. Am. Chem. Soc. $1985,107,715$. 
(238) Hammerum, S. Tetrahedron Lett. 1981, 22, 157.

(239) Hammerum, S. ; Christensen, J.B. ; Egsgaard, H. ; Larsen, E. ; Derrick, P.J.; Donchi, K. Int. J. Mass Spectrom. Ion Phys. 1983, 47, 351 .

(240) Hammerum, S.; Kuck, D.; Derrick, P. J. Tetrahedron Lett. 1984, $\underline{25}, 893$.

(241) Hammerum, S.; Derrick, P.J. J. Chem. Soc., Chem. Commun. 1985, 996.

(242) Hammerum, S. ; Ingemann, S. ; Nibbering, N. Org. Mass Spectrom. $1985,20,314$.

(243) Sozzi, G.; Denhez, J.P.; Audier, H.E. ; Vulpius, T. ; Hammerum, S. Tetrahedron Lett. 1985, 26, 3407.

(244) Crow, F.W.; Gross, M.L.; Bursey, M.M. Org. Mass Spectrom. 1981, $16,309$.

(245) Morton, T.H. ; Beauchamp, J. L. J. Am. Chem. Soc. 1975, 97, 2355.

(246) Corderman, R.R.; Le Breton, P.R.; Buttrill, S.E.; Williamson, A.D. ; Beauchamp, J.L. J. Chem. Phys. 1976, 65, 4929.

(247) Audier, H.E.; Milliet, A.; Denhez, J.P. Org. Mass Spectrom. $1983,18,131$.

(248) Audier, H.E.; Milliet, A. Int. J. Mass Spectrom. Ion Phys. $1983, \underline{47}, 475$.

(249) Audier, H.E.; Denhez, J.P.; Milliet, A.; Sozzi, G. Can. J. Chem. 1984, 62, 931.

(250) Audier, H.E.; Milliet, A.; Sozzi, G.; Denhez, J.P. Org. Mass Spectrom. 1984, 19, 79 .

(251) Audier, H.E.; Tabet, J.C. Org. Mass Spectrom. 1985, 20, 313.

(252) Bouchoux, G.; Hoppilliard, Y. Int. J. Mass Spectrom. Ion Processes 1983, 55, 47.

(253) Bouchoux, G.; Flammang, R.; Maquestiau, A. Org. Mass Spectrom. $1985,20,154$.

(254) Eckhardt, G. Org. Mass Spectrom. 1979, 14, 31.

(255) van Velzen, P.N.T.; van der Hart, W.J. Chem. Phys. Lett. 1981, $\underline{83}, 55$.

(256) Bowen, R.D.; Maccoll, A. Org. Mass Spectrom. 1985, 20, 331.

(257) See, in addition, refs $57,84,106,108,128,145,146,152-$ $158,161-172$ and $178-188$. 
(258) Lias, S.G.; Liebman, J.F.; Levin, R.D. J. Phys. Chem. Ref. Data $1984, \underline{13}, 695$.

(259) McMillen, D.F.; Golden, D.M. Ann. Rev. Phys. Chem. 1982, 33 , 493.

(260) Bellville, D. J. ; Bauld, N. L. J. Am. Chem. Soc. 1982, 104, 294 and references therein.

(261) Bellville, D. J.; Pabon, R.A.; Bauld, N. L. J. Am. Chem. Soc. $1985,107,4978$.

(262) Takeuchi, T.; Ueno, S. ; Yamamoto, M.; Matsushita, T.; Nishimoto, K. Int. J. Mass Spectrom. Ion Processes 1985, 64 , 33 .

(263) See, for example, ref 227 and:

(a) Nobes, R.H.; Radom, L. Org. Mass Spectrom. 1984, 19, 385.

(b) Bouma, W.J.; Gill, P.M.W.; Radom, L. Org. Mass Spectrom. $1984,19,610$.

(264) Golding, B. T.; Radom, L. J. Am. Chem. Soc. 1976, 98, 6331.

(265) Audier, H.E.; Sozzi, G.; Denhez, J.P. Tetrahedron 1986, 42, 1179.

(266) Nobes, R.H.; Radom, L. Chem. Phys. 1983, 74, 163.

(267) Ref 68; p 297.

(268) Ref 69; pp 51,54.

(269) Citterio, A.; Gentile, A.; Minisci, F.; Navarrini, V.; Serravalle, V.; Ventura, S. J. Org. Chem. 1984, 49, 4479.

(270) Postma, R., Ruttink, P.J.A.; van Baar, B. ; Terlouw, J.K.; Holmes, J. L. ; Burgers, P.C. Chem. Phys. Lett. 1986, 123, 409.

(271) For a general introduction to the importance of hydrogen rearrangements in mass spectrometry, see: Bursey, M.M. Mass Spectrom. Rev. 1982, 1, 1.

(272) Ref 69; pp 68-9.

(273) Schwarz, H. Top. Curr. Chem. 1981, 97, 1.

(274) Kingston, D.G.I.; Hobrock, B.W.; Bursey, M.M. ; Bursey, J.T. Chem. Rev. 1975, 75, 693.

(275) See refs $108,239-243,247,249-251,256,265$ and:

Sozzi, G.; Audier, H.E.; Denhez, J.P.; Milliet, A. Nouveau J. Chim. 1983, ㄱ, 735.

(276) Corey, E.J.; Hertler, W.R. J. Am. Chem. Soc. 1960, 82, 1657. 
(277) Wolff, M.E. Chem. Rev. 1963, 63, 55.

(278) Carruthers, W. Some Modern Methods of Organic Synthesis; Cambridge University Press: Cambridge, 1971; pp 173-8.

(279) Chow, Y.L.; Danen, W.C.; Nelsen, S.F.; Rosenblatt, D.H. Chem. Rev. 1978, $\underline{78}, 243$.

(280) Green, M.M.; Moldowan, J.M.; Armstrong, M.W.; Thompson, T.L. ; Sprague, K.J. ; Hass, A.J. ; Artus, J. J. J. Am. Chem. Soc. 1976, 98, 849.

(281) Green, M.M. Tetrahedron 1980, 36, 2687.

(282) Green, M.M.; Boyle, B.A.; Vairamani, M.; Mukhopadhyay, T.; Saunders Jr., W.H.; Bowen, P., Allinger, N. L. J. Am. Chem. Soc. $1986,108,2381$.

(283) Glasstone, S. ; Laidler, K.J.; Eyring, H. The Theory of Rate Processes; McGraw-Hill: New York, 1941.

(284) Evans, M.G.; Polanyi, M. Trans. Faraday Soc. 1935, 31, 875.

(285) Laidler, K.J. Reaction Kinetics; Pergamon Press, Oxford, 1963; Vol. 1 .

(286) Ref 283; p 191.

(287) Robinson, P.J.; Holbrook, K.A. Unimolecular Reactions; Wiley: New York, 1972.

(288) Forst, W. Theory of Unimolecular Reactions; Academic Press: New York, 1973.

(289) Truhlar, D. ; Garrett, B. Acc. Chem. Res. 1980, 13, 440.

(290) Hase, W. L. Acc. Chem. Res. 1983, 16, 258.

(291) Miller, W.H. ; Handy, N.C.; Adams, J.E. J. Chem. Phys. 1980, $\underline{72,}$ 99.

(292) Pritchard, H. O. The Quantum Theory of Unimolecular Processes; Cambridge University Press: Cambridge, 1984.

(293) Yamamoto, M.; Takeuchi, T. ; Nishimoto, K. Int. J. Mass Spectrom. Ion Phys. 1983, 46, 239.

(294) Doubleday, C.; McIver, J.; Page, M.; Zielinski, T. J. Am. Chem. Soc. $1985, \underline{107}, 5800$.

(295) Geissman, T.A. Principles of Organic Chemistry; Freeman: San Francisco, 1977 ; Chapter 27.

(296) Stirling, C.J.M. Tetrahedron 1985, 41, 1613.

(297) Wiberg, K.B. Angew. Chem., Int. Ed. Engl. 1986, 25, 312. 
(298) Wawzonek, S.; Culbertson, T.P. J. Am. Chem. Soc. 1960, 82, 441.

(299) Wilt, J.W. In Free Radicals; Kochi, J.K., Ed.; Wiley: New York, 1973; Vol. 1, pp 378,393.

(300) Baker, J.; Nguyen, M.T.; Radom, L., to be published.

(301) Yates, B.F.; Radom, L., to be published.

(302) See, for example: March, J. Advanced Organic Chemistry; McGraw-Hill: New York, 1977; pp 192-193.

(303) Ref 299, p 380.

(304) Beckwith, A.L.J.; Ingold, K.U. In Rearrangements in Ground and Excited States; de Mayo, P., Ed.; Academic Press: New York, 1980 ; Vol. 1, p 251 ff.

(305) For a recent discussion on orbital symmetry conservation and frontier orbital control in the reactions of organic radical cations, see: Dunkin, I.R.; Andrews, L. Tetrahedron 1985, 41, 145.

(306) Derrick, P.J.; Falick, A.M.; Burlingame, A.L. J. Am. Chem. Soc. $1973, \underline{95}, 437$.

(307) Ingold, K.U. In Free Radicals; Kochi, J.K., Ed.; Wiley: New York, 1973; Vol. 1, p 95.

(308) Cohen, E.R.; Taylor, B.N. J. Phys. Chem. Ref. Data 1973, 2, 663.

"Whoever thinks a faultless piece to see,

Thinks what ne'er was, nor is, nor e'er shall be." 